\title{
Report of the DOE Review Committee \\ on the Baseline Validation of the Superconducting Super Collider
}

August 1993

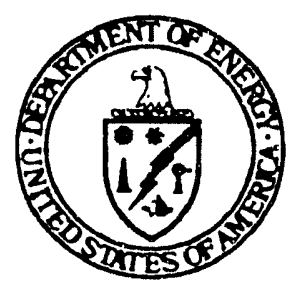

U.S. Department of Energy

Office of Field Management

(for the Office of Energy Research)

Washington, D.C. 20585

Pnnied with soy ink on recycled paper 


\section{EXECUTIVE SUMMARY}

A baseline validation review of the Superconducting Super Collider (SSC) project was conducted at the Superconducting Super Collider Laboratory (SSCL) from July 13 through July 31, 1993. This review was conducted in response to a request from the Acting Director of the Office of Energy Research to the Office of the Associate Deputy Secretary for Field Management.

To complete this review by the prescribed August 9 deadline, a Committee was assembled comprising knowledgeable, expert personnel from inside and outside the Department of Energy (DOE). The Committee responded to three charges:

1. Validate the project progress and status as identified in the May 1993 Monthly Progress Report.

2. Project an Estimate-at-Completion (EAC) range based on current trends and projected changes.

3. Based on information gathered from the review, provide an assessment of the usefulness of the current business management systems.

\section{Charge 1}

The Committee determined that the project's progress is reasonably reported in the May 1993 Monthly Progress Report at approximately 20 percent, but is very difficult to track using the current project and business management systems. This report tracks the project progress against the $\$ 8.24 y$ billion cost baseline as established in the January 1991 "Report on the Superconducting Super Collider Cost and Schedule Baseline" (Green Book), and the 1999 completion date. Progress was assessed through field visits, review of documentation of the actual percentage of work completed as compared to the planned percentage, comparison of progress with lower level schedules, and interviews with SSCL staff. The Committee determined that the methodology for assessment of earned value, leading to the report of progress in the May 1993 Monthly Progress Report, varies throughout the SSCL, requires explanation in many cases, and does not track through a 
top-level resource-loaded, Integrated Project Schedule (IPS) that reflects a well developed critical path. 


\section{Charge 2}

The Committee determined that there were several factors that have a significant influence on the EAC which could not be assessed during the 3-week review because of inadequate time for consideration. These factors include the following:

1. The Committee did not assess possible changes in management approach and contractual relationships.

2. The designs in several technical areas can be reviewed, optimized, and integrated by the SSCL. Trade-off studies are needed, including a careful examination of requirements (for example, correction magnet strengths and spool specifications) that can be relaxed without jeopardizing the higher level specifications of the project. The SSCL was in the process of accomplishing this as part of their rebaselining effort.

3. The SSCL does not have an integrated approach to significant issues that could impact the overall cost (e.g., resource-loaded, integrated schedule, acquisition planning).

4. The SSCL has not assessed staff efficiencies which could occur to minimize the effect of additional staff requirements (e.g., environmental, safety and health (ES\&H), and management).

5. The Committee did not incorporate the effect of potential savings through major scope changes because it was not a part of the Committee charge and because it would involve additional extensive analysis.

6. The analysis of foreign and other non-Federal contributions that will impact the cost to the Government was also not in the clarge to the Committee.

The Committee found that the cost at completion as shown in the May 1993 Monthly Progress Report has significant cost risk. The Committee reached this conclusion by estimating potential costs to complete the project ("estimate-to-complete" or "to-go" costs) based on data provided by the SSCL. It must be understood that the Committee's estimate does not establish a new baseline for the project. To develop a complete EAC 


\section{Committee's Assessment of Potential Cost Risks Associated with the Superconducting. Super Collider}

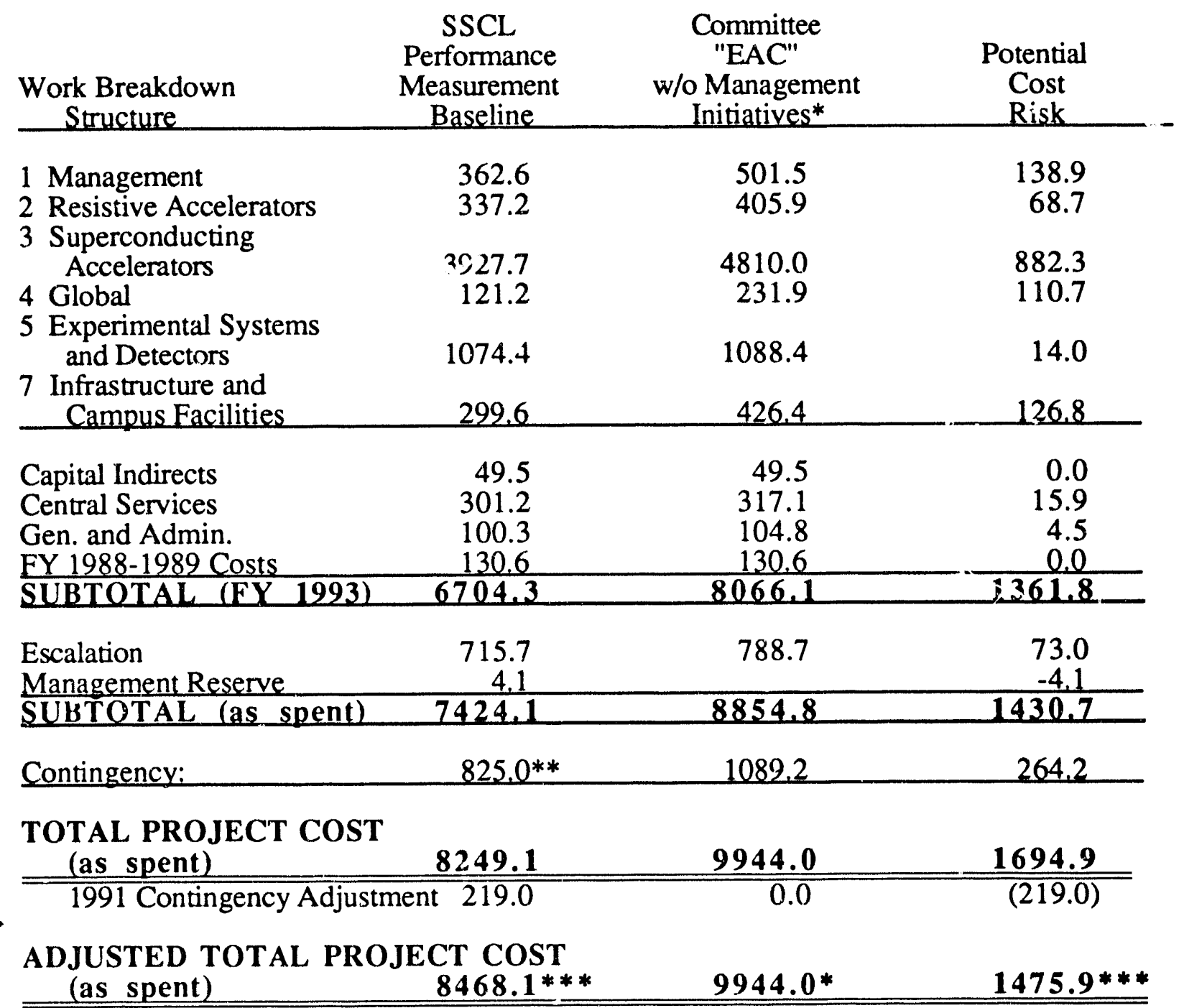

* This development of the "estimate-at-completion" assumes no change in project management. It was beyond the committee's charge to assess the impact of management improvements such as those proposed by the Secretary in her testimony before the Subcommittee on Oversight and Investigation on June 30, 1993. Program elements such as technical specifications (e.g., magnets and spools), production efficiencies, integration, staffing, and scheduling all present opportunities for mitigating the potential cost risk.

** Contingency based on page 41 of the January 1991 Report on SSC Cost and Schedule Baseline (Green Book). This does not include $\$ 219$ million for assumed non-Federal Contributions.

***Adding $\$ 219$ million to the $\$ 8249.1$ million from the Green Book yields a Total Project Cost of $\$ 8468.1$ million which can be cempared to the Committee's $\$ 9944.0$ million. Making this correction yields a final potential cost risk of $\$ 1475.9$ million. 
as defined by DOE Order 4700.1 (Project Management System), an estimate of all future conditions must be considered. Although the Committee developed an "estimate-atcompletion" in accordance with its charge, it is expected that normal project actions and workarounds would mitigate some of the identified risks. The Committee's assessment of cost risk is shown in the preceding table. As shown in the table, the Committee's estimate for the project would be higher for the total project cost (TPC) than the baseline unless significant management initiatives are undertaken to mitigate this increase. In addition, related costs beyond the TPC, which were previously identified but not included, are now to be addressed as part of present Department of Energy (DOE) policy. This policy is now to address all associated costs prior to operation. These costs total $\$ 1.2$ billion:

Costs in Green Book Outside TPC* (\$M As Spent)

Spares

Laboratory Operations

$\$ 110$

$\$ 494$ Committee's

Detectors (non-Federal Contributions)

\section{Estimate**}

(\$M As Spent)

$\$ 70$

$\$ 560$

$\$ 580$ (\$FY93)

* $\quad$ Cost shown on page 28 of the Green Book.

** Committee's estimate of rosts without significant management initiatives.

Details of the cost risk are discussed in section 4 of this report. A summary of the major differences between the Committee findings and the May 1993 Monthly Progress Report is as follows:

Management: The Committee found that the management of the SSCL will require additional funding to cover a projected shortfall between the baseline and the EAC and to fund an ES\&H function not covered in the Baseline Cost Estimate (BCE). A 25 percent reduction in indirect costs is also required to meet the present projected EAC.

Resistive Accelerators: The Committee found that the schedule for completing the warm accelerators appears optimistic. The most significant cost risk is associated with instrumentation and controls, which are still being defined and which are projected to increase in cost. 
Superconducting Accelerators: This work breakdown structure account, especially that part associated with the superconducting magnets, dominates the project costs. The Committee found that, although it has been demonstrated that accelerator quality superconducting magnets can be built in quantity, the present program is in the beginning of the industrial prototyping stage and has not yet demonsirated that the industrial SSC magnet designs meet requirements. The model and prototyle magnet programs must be pursued until successful magnets are demonstrate ${ }^{2}$. Until then, considerable cost and schedule uncertainty will remain. The estimate developed by the Committee represents its estimate of changes needed unless significant management initiatives are undertaken. Although firm magnet production costs will not be available for about 2 years, the Committee's estimate has been increased to project present risks. Other ancillary components, such as spools, require design optimization and finalization. Costs were also added to cover projected shortfalls in spools and other components. Severe cost consciousness in this area is required to meet production unit cost targets.

Global: This work breakdown structure is a collection of project activities which cut across various systems. The major increases are due to projected increases in the new installation contract and central control systems.

Experimental Systems and Detectors: The Committee found that the cost of the detectors, associated computers, and management costs has been reasonably well defined through previous extensive reviews and negotiations. A small shortfall in conventional construction and detector coordination costs has been identified. The baseline TPC included only the Federal portion of detector costs. Substantial contributions are expected from abroad, but are not yet fully determined and may not be sufficient to complete the detectors.

Infrastructure and Campus Facilities: The Committee has found that additional costs are required to cover several activities which were omitted from the initial estimate or which have increased in cost. They include communications systems, spoils handling, and electrical power systems. The increase also includes cost associated with the Architect Engineer/Construction Management (AE/CM) contract revision, which includes revised target costs for the latest $\mathrm{AE} / \mathrm{CM}$ scope. 
Escalation: Escalation was added to cover the increased costs through the outyears.

Contingency: The Committee developed a new contingency based on risk it perceived to be associated with the remaining work.

Qther Costs: The 1991 Report on SSC Cost and Schedule Baseline also discussed other related costs which were not included in the TPC. In addition to the \$219 million of contingency for assumed non-Federal contributions, the 1991 TPC did not include funds for special process spares; Laboratory operating costs for operating facilities after their successful commissioning and for physics research during construction; and for the non-Federal contributions to the detectors. The 1991 Baseline Report (page 28) suggests, $\$ 110$ million, \$494 million, and \$1180 million, respectively, for these items. The Committee estimates that approximately $\$ 70$ million will be required for spares, $\$ 560$ million for operations and research, and $\$ 580$ million for detectors beyond the TPC amount.

\section{Charge 3}

The Committee assessed the project and business management systems being utilized to manage the project and to track project progress. These systems were assessed to be of marginal usefulness. It was difficult to track costs relative to design and construction progress. Coordination of various pieces of data was required for the Committee to validate project progress.

\section{Conclusions}

It must be understood that the Committee used a different approach to address Charge 1 and 2. Charge 1 was to validate the project progress and status as identified in the May 1993 Project Progress Report. This assessment utilized the $\$ 8.249$ billion cost baseline and the 1999 completion date. In executing Charge 2, the Committee assessed the work "to go" from the project status in May 1993, and focused on trends and projected changes. This effort identified potential risks of $\$ 1.5$ billion and approximately a 1-year slip. 
In summary the Committee concluded that:

1. The project progress is reasonable, as indicated in the May 1993 Monthly Progress Report.

2. The EAC could increase by $\$ 1.6$ billion if all potential increases were to occur. Prompt and significant management actions are required to minimize cost growth. This requirement is especially true for the superconducting magnets and related accelerator comperants. A 1-year delay in project completion would be projected under the baseline assumptions. The May 1993 Monthly Progress Report begins to reflect guidance from DOE concerning out-year reduced funding scenarios identified by the Office of Management and Budget (OMB). This is severely restricting efforts to resolve existing schedule variances and will contribute to future milestone slippage.

3. The project and business management systems reporting project progress were of marginal usefulness in the evaluation of the current status and in developing the estimate.

\section{Recommendations}

The Committee recommends that:

1. The project be rebaselined and a new integrated, resource-loaded project schedule and bottoms-up estimate be completed.

2. As part of the rebaselining, the management structure and approach must be modified with the goals of reducing project costs, placing an emphasis on cost containment, and identifying cost responsibility. As part of this, the SSCL staffing levels and mix must be critically examined.

3. Substantial improvements to the project and business management systems be implemented immediately to bring these systems up to the standaràs normally required for complex, multi-billion dollar construction projects. 


\section{CONTENTS}

Executive Summary

1. Table of Contents

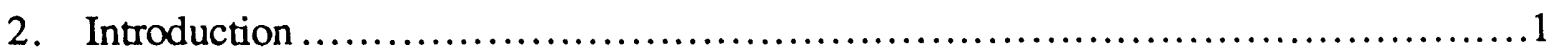

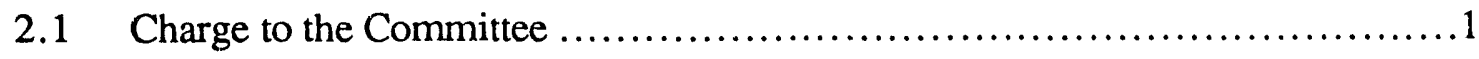

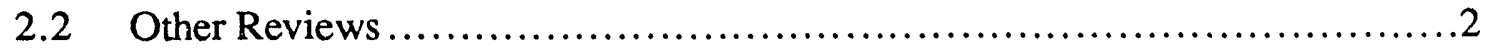

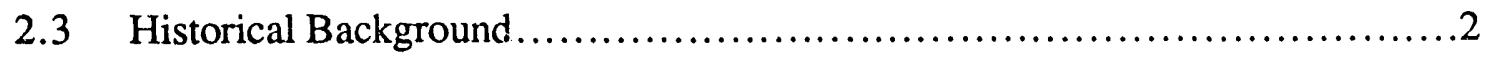

2.4 Committee Membership ............................................. 3

2.5 Review Process......................................................

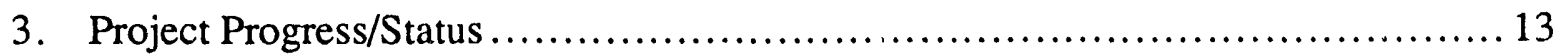

3.1 Conventional Facilities.............................................. 15

3.2 Management......................................................... 16

3.3 Resistive Accelerators................................................. 16

3.4 Superconducting Accelerators ........................................ 19

3.5 Experimental Systems and Detectors.................................. 21

3.6 Conventional Facilities: Infrastructure and Campus Facilities................... 22

3.7 Start-Up/Commissioning......................................... 23

3.8 Conclusions ....................................................... 23

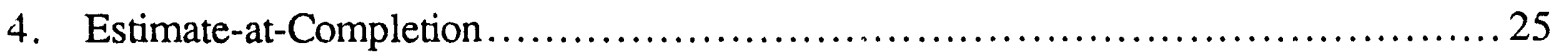

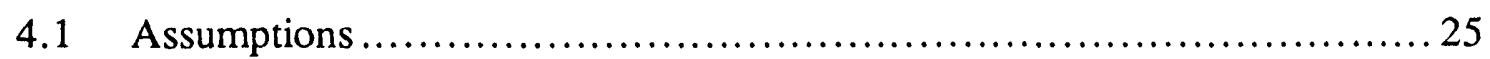

4.2 Cost Risk Areas ................................................... 26

4.3 Contingency.................................................... 31

4.4 Schedule........................................................ 33

4.5 Subcontract Analysis............................................. 34

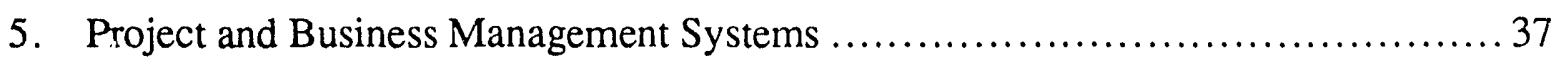

5.1 Financial and Progress Reporting Systems ............................. 37

5.2 Procurement......................................................... 38

5.3 Human Resources................................................. 39

5.4 Overall Assessments ............................................ 40 
6. Conclusions/Recommendations ......................................... 41

6.1 Conclusions.................................................... 41

6.2 Recommendations............................................. 42

7. Subcommittee Reports............................................... 45

7.1 Management................................................. 45

7.2 Superconducting Accelerators ...................................... 59

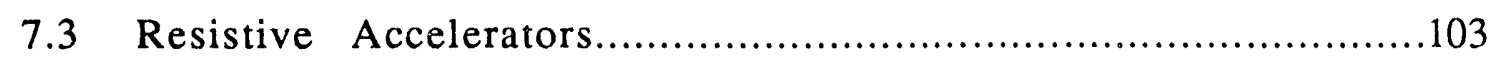

7.4 Detectors........................................................117

7.5 Startup and Commissioning........................................... 140

7.6 Conventional Facilities..................................................147

7.7 Environmental, Safety and Health.......................................189

7.8 Schedule...................................................... 194

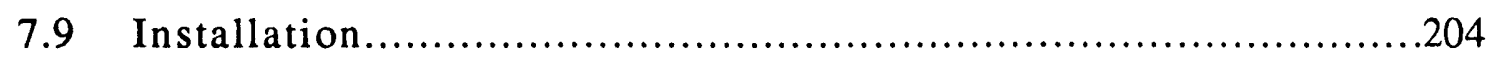

7.10 Laboratory Operations .............................................217

Appendices

A. Memorandum dated July 19, 1993, from Decker to Peters

B. Review Committee Membership

C. Review Committee Resumes

D. Memorandum dated July 14, 1993, from Cipriano to Scango

E. Review Committee Confidentiality Agreement

F. Information from SSC Laboratory to Review Committee

G. SSC Laboratory Organization Charts (including manpower) dated July 12,1993

H. Memorandum dated July 21, 1993, from Howe to Scango 


\section{INTRODUCTION}

The Secretary of Energy directed that an independent review of the current cost and schedule baseline for the SSC be conducted. The purpose of this independent review was to validate the current cost and schedule baseline and to ensure that the project status is accurate as currently reported. Through May 1993, approximately $\$ 1.5$ billion of the baseline cost of $\$ 8.249$ billion had been expended, with project completion forecasted on the baseline schedule as of September 1999.

This report documents the findings of the SSC Baseline Validation Review Committee (the Committee). The report is organized into five parts. The first section is the Executive Summary. This introduction is followed by a discussion of the project progress/status as determined by the Committee. The next section describes the Committee's estimate of thi cost at completion for the SSC project, followed by an assessment of the adequacy of the business management systems currently being used to manage the project. The final section presents the Committee's conclusions and recommendations. The main body of the report is followed by the subcommittee reports and appendices.

\subsection{Charge to the Committee}

The Director, Office of Energy Research, initiated the SSC Baseline Validation Review on July 19, 1993, in a memorandum to the Office of the Associate Deputy Secretary for Field Management (see Appendix A). This memorandum directed that the review be conducted and a written report be developed with the following three-part charge:

1. Validate the SSC project progress and status as identified in the May 1993 Monthly Progress Report (also known as the Cost Performance Report [CPR]).

2. Based on current trends and projected changes, forecast a range of total costs at completion of the project; that is, an EAC.

3. Based on information gathered from the review, provide an assessment of the usefulness of the business management systems currently being used to manage the project.

It was later directed that the written report be completed by August 13, 1993. 


\subsection{Other Reviews}

Three other reviews of the SSC project were conducted, essentially concurrently, with this review. The first review was a formal compliance review of the Project Management Control System (PMCS) that is being used as a tool to control the project's cost and schedule on a day-to-day basis. The second was a review of the project's cost growth by the General Accounting Office. The third was a review of the contractual relationship between the Universities Research Association (URA) and the Department of Energy (DOE) which was being performed at the direction of the Secretary of Energy.

The SSC project cost and schedule has been subjected to numerous independent reviews in the past. Most notable of these are the three independent reviews that were conducted by three separate teams in FY 1990 at the direction of the Secretary of Energy. The results of these reviews were ducumented in the "Report on the Superconducting Super Collider Cost and Schedule Baseline" (Green Book) that was pubiished by the Office of Energy Research in January 1991, and which established the project baseline.

\subsection{Historical Background}

The SSC is one of the largest, most complex scientific projects ever undertaken. This multi-billion dollar project requires the integration of design and construction activities to result in the largest (by an order of magnitude) high energy physics accelerator ever built. As an example of the st ale of the project, the tunnel in which the proton beams will be accelerated is on the average 150 feet underground and is about 54 miles in circumference. In addition, the project requires that a new high energy physics laboratory of considerable size and complexity be established on a "green-field" site.

The genesis of the project was a 1982 summer study of elementary particle physics in Snowmass, Colorado. The Conceptual Design Report (CDR) for a generic site was completed in 1986, and the CDR was updated to a Site-Specific CDR (SCDR) in 1990 to reflect the selection of Ellis County, Texas as the SSC site. Preliminary cost estimates were developed for both the CDR and the SCDR. The project scopes and technical baselines for the two estimates differed to a large extent, and are discussed in detail in the January 1991 Green Book. The project's cost baseline as documented in the Green Book is $\$ 8.249$ billion (asspent). Other costs outside this baseline are also discussed (spares, laboratory operations, and non-Federal contributions for detectors). 


\subsection{Committee Membership}

The SSC Baseline Validation Review Committee was chaired by Mr. John Scango from the Office of the Associate Deputy Secretary for Field Management. Although organized on very short notice, the Committee comprised 75 individuals with extensive accelerator and construction experience. Of these, 19 came from the DOE Superconducting Super Collider Project Office (SSCPO) and 56 came from DOE Headquarters, Operations Offices, the DOE National Laboratories, the Department of Defense, and private industry (consultants) with specialized experience. The SSCPO provided support to each of the subcommittees in identifying current issues. The Committee was divided into five subcommittees and additional crosscutting subgroups. The subcommittee assignments were made based on technical expertise and experience.

The review process made use of the experience of technical and project management personnel with past experience on projects and programs with similarities to the SSC. These projects include the Energy Saver (Tevatron) at the Fermi National Accelerator Lahoratory' (Fermilab), the Stanford Linear Collider at the Stanford Linear Accelerator Center (SLAC), the Relativistic Heavy Ion Collider (RHIC) at the Brookhaven National Laboratory, the Advanced Photon Source (APS) at the Argonne National Laboratory, the Advanced Light Source (ALS) at the Lawrence Berkeley Laboratory, and the Continuous Electron Beam Accelerator Facility (CEBAF).

Appendix $B$ lists the members of the Committee and their affiliations. It also indicates the subcommittee assignments. The membership of the Committee was scrutinized for organizational conflicts of interest $(\mathrm{OCI})$ and individuals with potential $\mathrm{OCI}$ were requested to excuse themselves from the review. In addition, members of the Committee were required to sign non-disclosure (confidentiality) agreements concerning the release of proprietary or business sensitive information. A sample is provided in Appendix E.

\section{$2.5 \quad$ Review Process}

\subsubsection{Schedule and Limitations}

The review was conducted at the SSCL in Waxahachie, Texas, over a 3-week period that began on July 13,1993, and ended on July 31, 1993. Tivo additional weeks were allocated for final review and completion of the draft report. 
The Committee comprised some of the foremost physicists and engineers with accelerator design and construction experience and large-scale construction project personnel. The group also had extensive experience with numerous recent and past DOE construction projects, including essentially all large DOE high energy physics projects. However, while the review was intensive, the 3 -week duration necessarily limited the scope of the revie'v. Though the Committee's efforts were extensive, an exhaustive investigation of low level costs was not conducted. The Committee did not have sufficient time to develop "bottoms-up" cost estimates. The project management systems and business management systems were not subjected to a traditional DOE compliance review/audit.

The Committee conducted the most extensive review possible in the time available. The Committee's efforts focused on the major cost drivers, such as superconducting magnets which alone account for approximately 25 percent of the total project cost. While, in some cases, minor cost items were not reviewed in detail, the Committee's review included virtually all of the projected costs for the SSC project.

The Committee was asked to review the project as designed to the present high-level specifications (20 TeV energy, high event rates with a luminosity of $10^{33} \mathrm{~cm}^{-2} \mathrm{sec}^{-1}$, two large detectors, etc.). The Committee did not consider potential changes to the scope, possible staging scenarios, etc. Both the poteritial savings and loss of physics would have to be carefully studied before adopting any changes, however, and the Committee has not reviewed or evaluated any of these.

The Cormmittee was asked to look at the project cost, estimated by standard U.S. practices, independent of the possibility that some of the components might be supplied by others. In addition to contributions from the State of Texas, potential saving of Federal funds may be realized from in-kind contributions from abroad (for example, components of the LEB and MEB are being supplied at low cost from Russia). Such possibilities were not considered in this review. 


\subsubsection{Review Committee Structure and Organization}

The Committee was divided into five subcommittees to parallel the major project areas as follows:

- Management

- Superconducting Accelerators

- Resistive Accelerators

- Experimental Systems and Detectors

- Startup/Commissioning

A number of issues were common to the various subcommittees. The following crosscutting subgroups were formed to address these issues separately and coordinate their results with the subcommittees:

- Conventional Facilities

- ES\&H

- Schedule

- Accelerator Systems

- Installation Contract

- Laboratory Operations

Evaluating the SSC project progress and status was accomplished through the assignment of third-level project Work Breakdown Structure (WBS) elements to the subcommittees. Many WBS elements were evaluated at a lower level by the subcommittees.

A number of assumptions were identified in establishing the Committee, as well as after the review was initiated. The most significant ones were:

1. Assumes no change in management approach.

2. The May 1993 CPR is the baseline status document for this review.

3. The January 1991 Report on the SSC Cost and Schedule Baseline is the baseline document for the SSC project, as modified by approved change control actions. 
4. The project would have been fully funded as shown in the 1991 Report on the SSC Cost and Schedule Baseline. The Committee noted that actual FY 1992 and FY 1993 funding was $\$ 310$ million less than the baseline assumptions.

5. All costs prior to start of operation (Key Decision \#4) are now to be included.

6. Sources of funding (Federal, state, international) are not to be considerea in this review.

7. All changes officially incorporated-by the Baseline Change Control Board (BCCB), management directives, etc.-are to be accepted. This includes new WBS elements, etc. All other changes are subject to validation by the Committee. An official list of potential changes was coordinated with the SSCL.

8. All cost assessments are made in FY 1993 dollars and then escalated as appropriate.

9. Actual cost of work performed (ACWP) to date was verified by a separate review and is accepted as correct in the May 1993 CPR.

10. The schedule baseline is the SSCL's IPS.

\subsubsection{Validation of Progress-to-Date (Charge 1)}

The charge to validate the SSC project progress and status as identified in the May 1993 CPR was carried out under the following guidelines:

1. A detailed audit could not be performed in the time allotted.

2. An assessment of the degree to which the project is complete and satisfactory (percent complete) must be made by a reasonable evaluation of the project progress and status. This assessment was expected to be judgmental but the basis for the judgment was required to be justified. 
3. The subcommittees were requested to develop a written assessment of the SSCL percent complete based on the original baseline. This was done by identifying the current phase of each machine or subsystem from planning through design and construction to commissioning, and then determining the level of completion of the phase to the extent possible.

4. The SSCL was requested to identify the percent complete for each machine or isystem and to present data that will justify that percent complete. It should be recognized that Cost Account Managers (CAM) in different technical areas measure percent complete in different ways. (For example, conventional systems may use linear feet of tunnel as a key element of determining percent complete.) Such differences were deemed acceptable for purposes of this review.

5. Data and information that were examined to assess the percent complete include:

- Budgeted Cost of Work Performed (BCWP) from the May 1993 CPR

- Variances from the May 1993 CPR

- Schedule status

- Other specific data, and deliverables: specifications, drawings, Requests for Proposals (RFPs) issued, plans developed, etc.

- Observations of existing hardware and on-going field construction activities

- Extensive interviews with SSCL personnel

- Subcontractor site visits (such as the visit to the General Dynamics [GD] facility in Hammond, Louisiana).

6. The PMCS Review, that occurred concurrently with the Committee's effort, reviewed the system for calculating earned value BCWP. Their results were communicated to the subcommittees as they became available.

7. The percent complete should be based on the $\$ 8.249$ billion baseline. 


\subsubsection{Forecast of Estimate-at-Completion (Charge 2)}

The charge to the Committee was to forecast an EAC range for the SSC project cost and schedule. The Committee's result was determined based on the summation of work accomplished to date (as indicated in the May 1993 CPR, plus the ETC ["to-go"] costs). The effort was integrated with the validation of progress to date. Many of the same data sources, such as drawings, specifications, contracts, CPRs, plans, and detailed and summary level schedules, were utilized. For example, where available, actual cost experience to date was utilized to judiciously project trends for the "to-go" portion of the work. The technical, schedule, and cost assumptions used to develop the original baseline were reviewed and revised when necessary. Major components, such as superconducting magnets and the collider tunnel, were forecasted at a detailed level based on cost experience to date, actual and projected changes to the technical specifications, experience on other projects, and historical cost estimating relationships. In the case of the collider dipole magnets, a visit was made to the magnet subcontractor by some of the Committee members to hold technical, cost, and manufacturing discussions, as well as to ascertain the current progress in building the magnet production facilities.

The Committee made extensive use of the SSCL's May 1993 CPR, as well as the more detailed CPRs from the major subcontractors such as General Dynamics (GD), Westinghouse (WEC), Babcock \& Wilcox (B\&W), and Parsons Brinckerhoff/Morrison Knudsen (PB/MK).

Committee members utilized interviews with the SSCL and SSCPO staffs extensively. The objectives of these interviews were to determine the technical status of the current activities, approved changes to the baseline, potential future changes to the baseline, current technical/cost/schedule risks, SSCL estimates of proposed changes, and known cost/schedule trends. The available data were evaluated at WBS Level 3 or lower (below Level 7 for the superconducting dipole magnets).

The Committee based its results on:

- The assessment of the cost and progress to date.

- The estimate of the "to-go" portion of the work which result from a continuation of historical trends, approved or potential technical changes, or an assessment by the Committee of the BCE for detailed WBS elements. 
The Committee review did not address other factors that could lead to significant reductions in an EAC. These factors include the following:

- The preliminary designs in several technical areas have not been be reviewed, optimized, and integrated by SSCL management. Trade-off studies are needed, including a careful examination of requirements (for example, correction magnet strengths and spool specifications) that may be relaxed without jeopardizing the higher level specifications of the project.

- The SSCL lacks an integrated approach to significant issues that could impact the overall cost (schedule, installation contract, acquisition planning).

- The potential for revisions to the contractual relationship between the DOE and URA.

- Possible staff efficiencies that could minimize new staff requirements (e.g., ES\&H and management).

- The Committee did not incorporate the effect of possible savings through largescale scope changes because it was not a part of the Committee charge and because it would involve extensive additional analysis.

- Analysis of foreign and other non-Ferleral contributions that will directly reduce the cost to the Government were not considered.

\subsubsection{Evaluation of Business Management Systems (Charge 3)}

The charge to the Committee was to provide an assessment of the usefulness of the business management systems as a tool for determining project status. The Committee included project management systems as part of this charge. The subcommittees concentrated on the data which provided input to the SSCL project and business management systems. Three additional inputs were also used by the Committee as discussed below. 
1. The subcommittees reviewed the functioning SSCL project and business management systems that address basic project management. Such systems include those that address:

- Earned value (reasonableness and acceptability of methodology)

- Development of cost estimates

- Change control actions

- Status reporting

2. The parallel but separate reviews by the PMCS Compliance Review Team resulted in findings concerning the development and implementation of project management systems, such as the following:

- Baseline change control system

- Overall scheduling system

- Financial and accounting system

3. The superconducting accelerators subcommittee conducted a limited review of some of the cost accounts and work packages for which the SSCL's Magnet Systems Division (MSD) has responsibility. Detailed work package documentation and earned value calculation methodologies were reviewed for reasonableness.

The evaluation of the business management systems made use of a combination of this qualitative information to determine the overall effectiveness of the management system.

\subsubsection{Schedule Assessment}

The schedule subgroup assessed the adequacy of the project schedule. This assessment was accomplished in two steps:

1. The schedule subgroup (with subcommittee input) assessed the adequacy of the present IPS in managing to the Beam-to-Experiment milestone (Start-ofOperations). The critical path through the entire project was assessed. 
2. The subcommittees (with schedule subgroup input) assessed the time required to complete (activity durations) of major individual machines and systems to determine the lower level schedule accuracy. This assessment was based on comparison of the work completed to date with the present baseline. In some cases, estimated durations were revised in the Committee's assessments.

\subsubsection{Contingency Assessment}

The Committee assessed project risk and reflected that risk in a revised estimate for project contingency. Management reserve was not addressed, since it represents a tool for management usage of, or additions to, contingency.

The following contingency guidelines were used:

1. The subcommittee assessments should determine the appropriate percentage contingency to cover "to-go" cost risks.

2. Contingency to cover the cost of proposed changes was not used in subcommittee evaluations. Proposed changes were estimated and contingency was applied as appropriate.

3. Contingency is considered as a single cost pool to be allocated as necessary. 


\section{PROJECT PROGRESS/STATUS}

The first charge assigned to the Committee was to validate the project progress and status as identified in the May 1993 Monthly Progress Report. The Report states that the SSC project is 20 percent complete based on the original baseline, while cumulative cost and schedule variances are 5 percent and 6 percent respectively. The Report indicates that all Level 1 milestones have been completed as scheduled. The Committee agrees that the value of the work performed is consistent with the expenditures to date, all Level 1 milestones have been met, and progress to date is satisfactory. However, the Committee believes that there are significant cost and schedule risks in the project work remaining "to-go".

All schedule analyses were performed at the subsystem level by the various subcommittees. Two basic parameter were examined and reported: percent complete and schedule status (months ahead/behind, etc.). In some cases, the analyses were rolled upward into a higher-level report. These assessments were made through discussions with the SSCL staff and by examination of existing documentation in order to verify the data contained in the May 1993 Monthly Progress Report.

The subcommittees used a variety of methodologies in performing the analyses. Budgeted Cost of Work Scheduled (BCWS)/Budgeted Cost of Work Performed (BCWP)/Actual Cost of Work Performed (ACWP) deliverables were examined when available; however, only 30 percent of the activities in the IPS are interfaced with the cost systems, thereby limiting this method of review.

To overcome this problem, physical observations were made, such as tunnel markings denoting progress to date. Moreover, supporting data were examined. For example, in the conventional area, current tunneling advance rate experience is as much as 400 feet per day, versus a planned rate of 150 feet. In all conventional construction areas, the subcommittees went through the WBS accounts with the SSCL CAM and PB/MK managers, visited the construction sites, and determined whether the calculation of percent complete was reasonably derived.

Subcommittees assessing the technical components met with SSCPO and SSCL personnel, reviewed schedules for the various machines, and then either determined independently or agreed with site personnel on the actual percent complete. In the case of magnets, personnel visited the GD plant in Louisiana to determine progress to date. 
The SSCL accounting system has been audited and found to comply with generally accepted accounting principles. Therefore, actual cost data for SSCL activities to date were accepted.

A detailed review of the IPS was performed utilizing the most current schedule issuance date of July 20,1993, with a schedule data date of May 23, 1993. The following are the findings of that review:

1. There appears to be a noticeable lack of interface relationships between machines (Linac, Low Energy Booster [LEB], Medium Energy Booster [MEB], and High Energy Booster [HEB], etc.). It is unclear if a negative impact and/or schedule slippage in one machine would logically impact other areas of the project. The lack of credible logic ties in these areas make the IPS suspect and any critical path analysis drawn from it questionable.

2. The activity durations incorporated in the IPS are too large to ascertain the specific steps necessary to complete a given task by the required timeframe. The given pieces are too large to monitor accurately on a monthly basis and can give rise to subjective assessments of physical percentage complete. It has been noted that 47 percent of the activities in the IPS have durations greater than 60 working days. In addition, 28 percent of the tasks in the IPS have durations greater than 120 working days. It is felt that if the IPS is to become useful to the project, the larger, more summary type activities must be broken down into more measurable parts.

The subcommittees experienced some difficulty interpreting SSCL's schedule status as described in the May 1993 Monthly Progress Report. There appeared to be some differences between the Project Summary Schedules and the information in the variance analysis sections and the Level 1 milestone list.

Due to the unavailability of an accurate earned value calculation on 70 percent of the WBS accounts, it was very difficult to track or verify the SSCL's percent-complete number. Also it was very difficult for the subcommittees to assess the overall project status, since the current system does not sufficiently integrate the relationships among the machines. Therefore, although a critical path is shown for the project the Committee questions its reliability. 
However, by using supplemental methods of observation and calculations, the subcommittees were able to provide an assessment of all critical areas. Given the above constraints, and the limited time available, the subcommittees conclude that the progress reflected in the individual WBS accounts in the May 1993 CPR is reasonable.

Following are the individual assessments by subcommittee/subgroup. Since the conventional facilities cut across much of the entire project (several WBS elements), the conventional facilities subgroup's approach in conducting its assessments applies to all the project areas.

\subsection{Conventional Facilities}

The overall methodology is provided here and more specific results are provided with each machine where appropriate. This subgroup was charged with assessing the schedule progress as reported in the May 1993 Monthly Progress Report. The current schedule reflected in the May 1993 Monthly Progress Report is based on the $\$ 8.249$ billion baseline. The subgroup developed a detailed plan which provided an assessment of the scheduled versus actual progress. The detailed plan included: the charge to the subgroup; assignments (based on the WBS elements which contain conventional construction activities); a listing of questions which the subgroup members would use when meeting with the WBS CAMs; and assessment forms. The subgroup then held interviews with the Conventional Construction Division (CCD) CAM, performed sampling of the physical progress of design and construction, and reviewed the status of contracts.

It appears, based on the Laboratory's current best projections, once $\mathrm{CCB}$ change E12.000254 is incorporated into the PMB, approximately $\$ 22.7$ million will be available for Laboratory Management Reserve which could offset part of the cost growth found during this review. However, the $\$ 22.7$ million is not reflected in the Committee's cost table, or in the May 1993 Monthly Progress Report.

Even with the lack of maturity of the PMCS, the construction progress to date appears to be very close to the reported values in the May 1993 Monthly Progress Report, based on physical observation of a sampling of specific construction sites. Therefore, based on this sampling, it was the consensus of the subgroup members that the project's conventional construction status is being accurately portrayed in the May 1993 Monthly Progress Report. 


\subsection{Managemint}

The subcommittee team members interviewed key management, supervisory, and program staff responsible for the project. The team also surveyed a large number of business reports and records used as direct and indirect background information to the reviewers. Time and other constraints required team members to take a deliberate, yet summary approach to complete the assessment of progress. The subcommittee acknowledged that a more detailed examination of staff and information would have provided a somewhat better understandin $\approx$ of the status of management costs.

The analysis of management functions dealt primarily with level-of-effort (LOE) activities. Because the management functions are LOE by nature, an assessment of earned value or percentage complete cannot be done with precision. Although the project is only 20 percent complete, approximately 48 percent of the baseline budget for management activities has been expended. Most indirect accounts have expended over 40 percent (with some nearly 50 percent) of the baseline budget.

A simple correlation of schedule to expenditures to date indicates a trend toward a significant cost overrun for management and indirect functions. The May 1993 CPR indicates that an additional $\$ 47$ million is needed. However, a multi-year resource-loaded schedule was not available to show that $\$ 47$ million is sufficient. Further discussion of additional requirements beycnd the May 1993 baseline can be found in section 4 .

\subsection{Resistive Accelerators}

The Resistive (warm) Accelerators subcommittee began its investigation by identifying the pertinent issues associated with its charge. Two sets of interview questions were developed - one to provide an overview of each major system (i.e., L inac, LEB, MEB, and Global Systems), and one to provide detailed status information of certain subsystems which have impacts across multiple machines (i.e., Power Systems, Radio Frequency (RF) Systems, Warm Magnets, Controls, Instrumentation, Safety and Vacuum). Interviews were first conducted with the respective machine leaders, as identified by the SSCL point of contact, who provided a machine-by-machine status overview. Further interviews were conducted by the subcommittee members with the CAMs for each of the selected subsystems to validate the information obtained from the interviews with the machine leaders. Additional interviews were 
conducted with the HEB and Collider machine leaders to discuss the status of the selected subsystems.

\subsubsection{Linac System and Facilities}

The Linac is in the design and construction phase. The Level 1 milestone shown in the May 1993 Monthly Progress Report for the start of Linac commissioning depicts this item as approximately 7 months behind schedule and 54 percent complete, while the subcommittee found the Linac 12 months behind the schedule to complete the facility and 35 percent complete.

Contracts have been let for the major components. An ion source, low-energy beam transport section, and the RF quadrupole have been fabricated and accepted. More than 30 percent of the klystrons for the Coupled Cavity Linac (CCL) have been completed and subassemblies are in hand for most of the remainder. Orders have been placed for the Drift Tube Linac (DTL) cavities and the CCL modules. Linac conventional construction is 75 percent complete, slightly under budget, and is on schedule. However, there are two CCB actions pending, one of which is approved (low conductivity water [LCW]), but not incorporated into the $\mathrm{PMB}$, and the other which is pending for design errors and omissions.

\subsubsection{Low Energy Booster}

The Level 1 milestones shown in the May 1993 Monthly Progress Report depicts this item as 4 months behind schedule and 29 percent complete. The subcommittee found the LEB 6-12 months behind the schedule to complete the facility and 25 percent complete. In general, LEB technical progress is good. The RF cavity, dipole magnet, and quadrupole magnet are all in the prototype testing phase. Some of the power system components are in the design phase while others are being delivered. The power systems and the magnets (dipoles and quadrupoles) do not exhibit any significant technical problems at this time. However, it appears that the expected performance of the RF cavity will not be met. The LEN conventional construction design is complete, and conventional construction is underway and approximately 29 percent complete. 


\subsubsection{Medium Energy Booster}

The Level 1 milestone shown in the May 1993 CPR report shows the MEB to be 3 months behind schedule and approximately 5 percent complete, while the subcommittee found the MEB 6-12 months behind schedule to complete the machine and approximately 5 percent complete. The dipole magnets are in prototype test at Fermilab. The dipole, quadrupole, and corrector magnets have successfully completed a Preliminary Design Review (PDR), and the prototype RF cavity is to be delivered in August.

MEB conventional construction design is complete and construction is approximately 6 percent complete.

\subsubsection{Global Systems}

This activity includes general support systems such as controls and safety systems. Information was gathered for the Global Systems WBS elements for both the Resistive and Superconducting Accelerators. Interviews were conducted with che designated machine leaders and the identified CAMs for controls.

The System Summary Schedule of the May 1993 Monthly Progress Report shows the controls/communications component of Global Systems to be 6 months behind schedule and 15 percent complete. The Committee assesses this to be correct, but it may understate the problems involved, especially in controls. The subcommittee found that this item has no integrated schedule, and status information is insufficient to determine completion percentage. However, controls and safety comprise the only significant areas of activity in this WBS. The subcommittee found that the safety systems appear to be on track. The Linac safety system is about 40 percent complete while the others are at lower levels of completion. However, the subcommittee uncovered significant concerns with the controls effort. The subcommittee could not determine a tie between system design and SSC operational requirements. The Accelerator Systems String Test (ASST) control system is operational, but uses a different system than that proposed for the SSC. Work on the Linac control system is about 50 percent complete. There have been no significant accomplishments on the remaining machines' control systems or the overall global control system. 


\subsection{Superconducting Accelerators}

The various system leaders made presentations to the subcommittee and were interviewed about the status and issues in their respective areas. Follow-up interviews with CAMs were conducted for clarification and confirmation of input. Several site inspections were also conducted including a view of the tunnel, a tour of the Magnet Development Laboratory (MDL) and the Magnet Test Laboratory (MTL), and a trip to the GD magnet facility in Louisiana by two of the subcommittee members.

\subsubsection{High Energy Booster}

The Project Summary Schedule on page 4, and the impact variance on page 88 of the May 1993 Monthly Progress Report show the HEB to be approximately 4-6 months behind schedule and approximately 7 percent complete. The subcommittee finds that this is representative of the current status. Development of contracts have been let with WEC for the dipoles and Saclay for the quadrupole cold mass. The quadrupoles will be produced by a small disadvantaged business using a technology transfer from Saclay. Key issues affecting progress to date are the resolution of the dipole magnet ramp rate sensitivity issue and issuance of the quadrupole cryostat contract. The solution to the dipole ramp rate issue appears to be a modification of the superconducting wire. In conventional construction, Title I has been initiated. However, there are several potential CCB actions involving the tunnel cooling system, industrial cooling water system, and tunnel shafts.

\subsubsection{Collider}

The Project Summary Schedule on page 4, and the impact variance on page 95 of the May 1993 Monthly Progress Report show the collider to be approximately 4-6 months behind schedule and approximately 15 percent complete. The SSCL evaluation of the overall schedule shows that, as of the end of May, the first dipole prototype schedule is delayed by 5 months. The subcommittee believes that this is an optimistic projection. Additional delays of 2-4 months appear likely (for a total of 7-9 months). GD has made significant progress, but it is still in the process of magnet design and equipment development. The first prototype assembly is in process. 
GD has identified potential cost increases in the fabrication of the 12 prototype, 35 preproduction, and 251 low rate initial production (LRIP) units. SSCL is working closely with GD to mitigate this issue. WEC is the follower on this contract and plans to build 35 preproduction and 251 LRIP units. WEC is presently relegated to an observer role and this could hamper the competitive bidding process at the conclusion of the LRIP.

Full-length model magnets (some of which were used in the ASST) were assembled by both GD and WEC and had generally acceptable performance. Recent short model magnets fabricated by GD showed quench performance problems and ramp rate dependence of multipoles. These issues are now being addressed.

The program of developing and acquiring superconducting cable appears to have been very successful. Favorable pricing was received in the manufacturing qualification program.

Cryogenic systems include the helium liquification, refrigeration at the surface and at the tunnel level, and associated connecting lines. Technical status is excellent and cost performance has been good. Firm fixed-price bids have been received for the helium plants, accounting for more than half the BCE for this WBS element, and are within budget. The SSCL cryogenics group has discovered some key omissions (such as liquid nitrogen recoolers and cold compressors) and is taking appropriate action.

The spool piece program at the present time involves design work at the SSCL in support of two competing industrial design and preproduction prototype programs, one at Martin Marietta and the other at WEC. This program was put on hold in June 1993 due to budget constraints. It is extremely important to press hard with this program since the spool pieces are a complex design problein and because the estimated cost has shown very large growth.

The impact on collider vacuum of photodesorption of gas molecules by synchrotron radiation was reviewed by the subcommittee. If too many of these desorbed molecules are present in the beam tube, the resulting beam-gas interactions will reduce the beam intensity (and thus the rate of collisions at the detectors), or in extreme cases result in the heating and quenching of magnets. This is perhaps the single most important technical issue remaining to be solved for the SSC design. The solution may introduce added complexity to the design with attendant reliability issues. It is imperative that this issue is resolved quickly since it impacts the design and cost of the collider components. 
In conventional construction, six of the ten tunnel contracts have been awarded (10 miles of tunnel constructed), and 29 of 36 shafts are under contract (15 completed). Progress is generally $\_n$ schedule.

Several CCB actions have been approved but not incorporated into the baseline. There are also several significant pending/projected $\mathrm{CCB}$ actions, including additional shafts, modifications to the collider cooling system, additional concrete for tunnel finishing, electrical distribution, etc. Most of these CCB actions, if approved, would adversely impact the currently reported latest revised estimate (LRE). Other CCB actions are anticipated for the magnets and other technical systems.

\subsection{Experimental Systems and Detectors}

This WBS element comprises seven subelements (Experimental Systems Research and Development [R\&D], Detectors, Experimental Systems Computing, Conventional Construction, Experimental Systems Support, Test Beams, and Physics Research Division Coordination).

The generic detector R\&D has been completed and the detector subsystems R\&D is essentially complete.

The May 1993 Monthly Progress Report indicates detectors to be on schedule and about 10 percent complete. Although both detectors have progressed well technically and managerially, there has been a recent slowdown for funding reasons, and their construction would benefit from a 1- to 2-year stretch out beyond the 1999 completion date.

The May 1993 Monthly Progress Report and the subcommittee both find computing to be on schedule and 15 percent complete.

The Level 1 milestone shown in the May 1993 Monthly Progress Report shows conventional construction associated with experimental systems to be 3 months behind schedule and approximately 4 percent complete. The subcommittee determined this area to be accurately reported. Portions of this item are in predesign and the remainder are in construction. Conventional construction for experimental facilities and support facilities for IR-5 and IR-8 is under contract but on-hold. 
The May 1993 Monthly Progress Report shows Experimental Systems Support to be 5 months behind schedule and 20 percent complete, while the subcommittee found this item to be on schedule and 20 percent complete. This item is in the design phase. These are utilities supporting the detectors such as cryogenics, electrical power, low conductivity piping, etc.

The Physics Research Division (PRD) Coordination effort consisis of the manpower for the PRD Electronics Group, the Gammas, Electrons, and Muons (GEM) Physics Group (Group B), and the Solenoidal Detector Collaboration (SDC) Physics Group (Group A) of the SSCL. The SSCL plans to support these activities in future years out of the Laboratory operations budget. The April 1992 "Proposal from the SSC Laboratory Physics Research Division to the DOE Division of High Energy Physics (DHEP)" contains estimates of these costs for the entire project period. The EAC shown in the May 1993 CPR for this element covers only costs to date and does not include any future costs. The Laboratory plans to support these coordination activities in future-years out of the Laboratory operations budget.

\subsection{Conventional Facilities: Infrastructure and Campus Facilities}

The May 1993 Monthly Progress Report shows the West Campus to be 2 months ahead of schedule and approximate 5 percent complete. The subcommittee concurs with these numbers. A West Campus conceptual design plan has been prepared by the SSCL. No decision has been made on the exact location of the campus. This effort has been removed from $\mathrm{PB} / \mathrm{MK}$ scope, but no acquisition strategy has been provided.

The May 1993 Monthly Progress Report and the subcommittee both find the E1 (N15) Campus to be on schedule and approximately 80 percent complete. This item is under construction. However, a warehouse has been added to N15 which will be constructed by Laboratory Technical Services in lieu of the Conventional Construction Division.

The Project Summary Schedule on page 5 of the May 1993 Monthly Progress Report shows the East Campus to be 1 month behind schedule and approximately 10) percent complete. The subcommittee concurs. This item is under construction. 
The Project Summary Schedule on page 5 of the May 1993 Monthly Progress Report and the subcommittee report show collider infrastructure to be 1 month behind schedule and approximately 20 percent complete. The subcommittee concurs. This item is under construction.

The May 1993 Monthly Progress Report and the subcommittee both find the Off-site Facilities (roads, utilities, etc.) to be on schedule and approximately 90 percent complete. This item is under construction.

\subsection{Start-Up/Commissioning}

This is a future activity, and only minimal planning efforts have been completed to date.

\subsection{Conclusions}

The May 1993 Monthly Progress Report shows the overall project to have a 6 percent schedule variance or about 2 months out of the 30 months of construction effort to date. This is well within the satisfactory range as defined by DOE Order 4700.1 . While this appears to be essentially correct from the view point of the overall project critical path, the subcommittee could not determine this from the lower level schedules. The Committee had difficulty assessing the overall project completion date with the machine ties provided. A resourceloaded critical path schedule for the entire project is needed, showing each schedule item and how it affects the final project completion date in order that detailed progress can be determined. It is recommended that no activity on the schedule have a duration longer than 60 days, otherwise, the activity becomes a level-of-effort item and there is no way to track progress.

The May 1993 CPR begins to reflect guidance from DOE concerning out-year reduced funding scenarios identified by the Office of Management and Budget (OMB). This is severely restricting efforts to resolve existing schedule variances and predicts future milestone slippage. 


\section{ESTIMATE-AT-COMPLETION}

The second charge assigned to the Committee was to project an EAC range based on current trends and projected changes.

The EAC of a project is the sum of the actual costs incurred to date plus the estimated costs of all remaining work. The interpretations of this definition, in this review, are addressed in the Executive Summary. The May 1993 Monthly Progress Report included an SSCL working estimate of the costs required to complete the project. This cost estimate is called the latest revised estimate (LRE). The LRE includes the estimated cost of approved change control actions. The LRE does not include baseline changes that are likely to be approved but have not yet been processed or those under development. While this is an orderly approach from the standpoint of process, these potential changes represent a significant cost to the project. Further, the LRE contained in the May 1993 Monthly Project Report does not appear to be consistently or rigorously developed. The change control system, which is used to formally approve changes to the baseline, does not appear to capture cost increases in a timely manner. Many of the baseline changes are approved pending the availability of funds from management reserve. The net effect is that the present SSCL LRE does not reflect a realistic EAC.

The Committee reviewed a number of potential cost changes that will, in the opinion of the Committee, be necessary to complete the project consistent with the project scope and these are included in the Committee's EAC. The changes and associated costs have not yet been subjected to the scrutiny of the SSCL change control process. Typically, this process will require trade-off studies, value engineering, etc., to minimize the costs.

\subsection{Assumptions}

The Committee assumed that the project would receive the funding profile shown in the January 1991 Green Book. The Committee charge did not include an examination of schedule and cost impacts associated with reduced or alternate budget profiles.

The SSCL PMB was developed in 1992 and includes the expenditures (costs) associated with the baseline 10 -year funding profile. The PMB serves as a working baseline for the project. The Committee could, however, find no evidence that the PMB was supported by an approved Acquisition Plan or a resource-loaded schedule. 


\subsection{Cost Risk Areas}

The Committee has determined that unless significant management actions are taken there is significant cost risk associated with the SSC project. If unattended, this cost risk could result in a cost of $\$ 9.95$ billion, (see table in Executive Summary) which is about $\$ 1.5$ billion above the previous baseline as shown in the January 1991 Green Book, adjusted to include all contingency. This cost does not include certain costs which are outside the TPC and which will be discussed below. The committee's estimate includes the full amount of the project contingency whereas the Green Book included only a portion. The development of the estimate by the Committee is discussed in the sections that follow and Table 4-1.

\subsubsection{WBS 1-Management (Plus Indirect Costs, Central Services and General and Administrative)}

WBS 1 covers project management for the overall project, SSCL management, as well as the management of the major SSCL Divisions. Many of these functions are level of effort. Expenditures to date led the Committee to conclude that an increase of approximately $\$ 63$ million will be required to fund this function for the remainder of the project.

In addition, the Committee determined that the ES\&H oversight function identified in the baseline was not specifically funded in the associated estimate. The estimate for these costs is $\$ 75.7$ million.

The SSCL predicts a need for \$20.4 million above current budget for the three indirect accounts (indirect, central services, and general and administrative) for the remainder of the project. The subcommittee concurs this amount is appropriate for these functions if SSCL management takes some positive action to reduce the indirect functions through reorganization, centralization, and increased utilization of the support and administrative staffs. To keep the costs within the SSCL estimate, a reduction on the order of 25 percent in the indirect level of effort is necessary.

It should be noted the committee did not include an allowance for indirect costs that could be associated with potential cost increases being recommended by other subcommittees for direct cost accounts. 


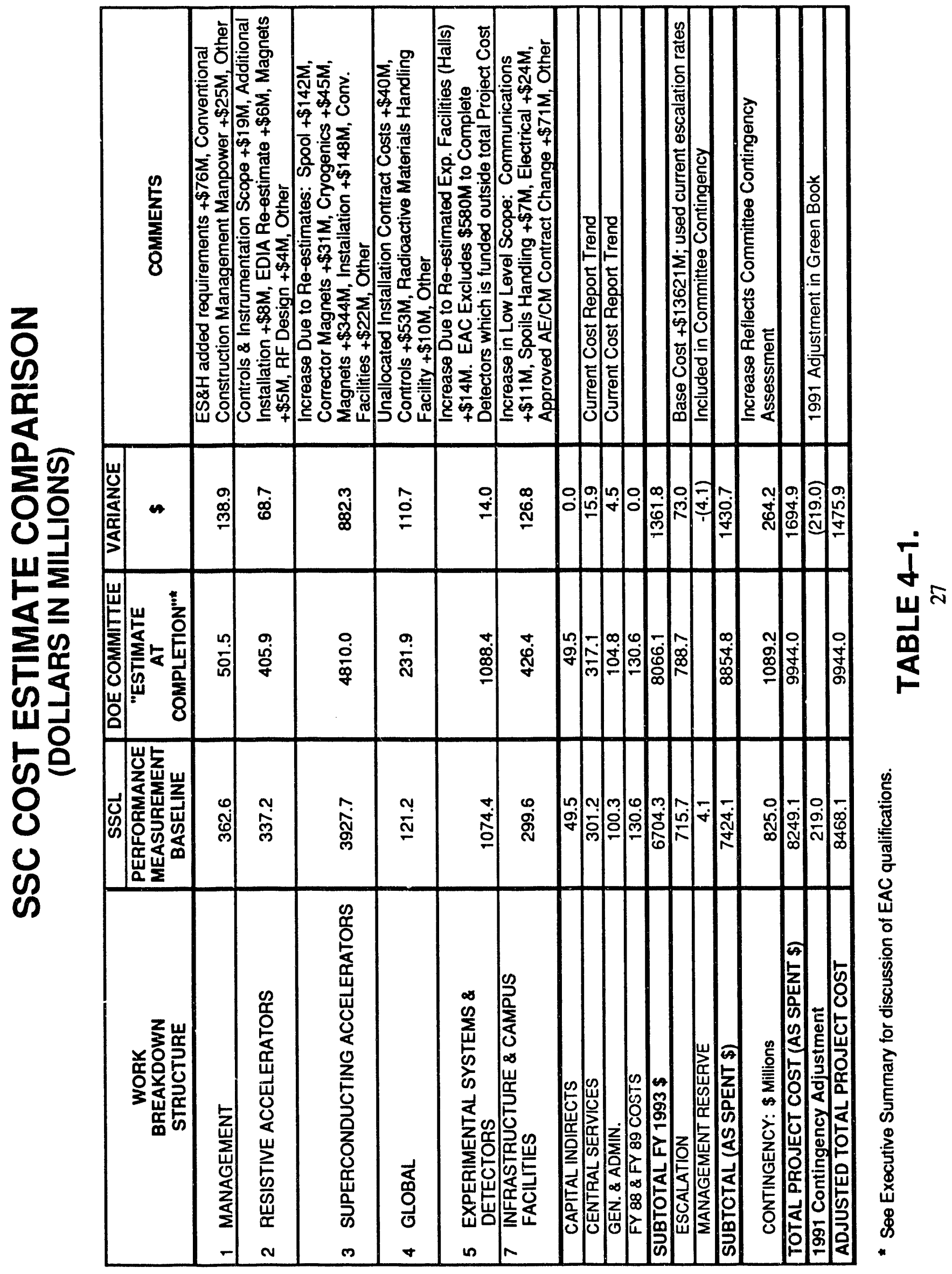




\subsubsection{WBS $2-$ Resistive Accelerators}

The cost risk associated with the Resistive Accelerators is about $\$ 68$ million. A number of changes in the design and design detail have been identified and a number of these technical changes are expected to be needed to complete the project. These were included in the Committee estimate. The RF system, power supplies, instrumentation, and controls were identified in the subcommittee reports as areas where cost increases were likely to occur. In some cases the initial cost estimates were not adequate, in other areas the cost increases came from additional information or a more advanced design.

The most significant cost risk (about $\$ 19$ million) is associated with the instrumentation and controls. The project PMB assumed that the Resistive Accelerator controls would be similar to systems at other facilities, such as Fermilab. This did not account for the integration of such systems into the overall control system for the entire SSC. The subcommittee report discusses each of the cost risk areas.

The Committee belicves that a 1-year schedule delay in the commissioning of the Resistive Accelerators is likely. Commissioning of the Linac, which is the first of the Resistive Accelerators, is projected to be about 1 year later than the Level 1 milestone indicates.

\subsubsection{WBS 3 - Superconducting Accelerators}

The most significant projected cost difference is an additional $\$ 882$ million for the superconducting accelerators. The superconducting magnets for the HEB and the Collider are a significant portion of the TPC, about 30 percent. These magnets have always been one of the most technically challenging parts of the project. The cost risks relate to uncertainties in the estimated cost of the individual magnet components, some changes in magnet specifications, and the cost of magnet production. Based on current trends, the Committee believes that the magnet costs will likely be higher than the baseline estimate. While the technical risks now appear to be well defined, production uncertainties are still a concern. It must be recognized that more definitive magnet cost estimates are not due until next year at the earliest. Under the assumptions used, without rigorous management attention, other technical components within this WBS are also projected to have significant increases, as shown in Table 4-2. 
TABLE 4-2 Summary of Potential Cost Risks for Cold Accelerators

(FY 1993 Million Dollars)

Superconducting Magnets

Spools

Installation

Conventional Construction

Cryogenics

Instrumentation/Controls/RF

Interconnects

Correction Magnets

Miscellaneous

TOTAL
$\$ 344$

142

148

22

45

36

35

31

79

$\$ 882$

\subsubsection{WBS 4 - Global}

This WBS element covers a collection of project activities which cut across various systems. The major increases are due to projected increases in the new installation contract, instrumentation and control systems, and a mixed-waste handling activity.

The Committee determined that the instrumentation and control system still requires additional definition and presents significant cost risk. Subsystem Laboratory-wide controls philosophy and a systems assessment need to be completed.

The installation contract will extend across various WBS elements. This work was originally not planned to be completed under a major integration contract, and thus costs are distributed throughout all WBSs. The plan has shifted to a program which now includes design and fabrication as well as installation. The scope has still not been approved by SSCL management. There are interfaces with virtually all SSC systems. The Committee added cost to cover higher expected contractor costs and labor rates.

\subsubsection{WBS 5 - Experimental Systems and Detectors}

The Committee only recommended a few changes in this area, in particular $\$ 14$ million for conventional facilities (experimental halls, etc.). Physics Research Project Coordination is being supported out of funds originally earmarked for detectors and eventually will become part of the Laboratory Operations. The January 1991 Green Book contained only the U.S. portion of the detectors. This is shown in the present PMB as $\$ 676$ million under 
WBS 52, and has not been adjusted by the Conmitter. i'he rest of the detector costs are discussed below in section 4.2.9.

\subsubsection{WBS 7 - Infrastructure and Campus Facilities:}

The cust risk associated with this WBS is $\$ 128.6$ million. Major cost elements of conventional con'uruction are now included in other functional areas (collider tunnel, detector halls, injector tunneis, etc.). Many of these facilities are under construction. Included in WBS 7 is infrastructure (roads and utilities) and the East and West Campuses. The estimated cost increase for this WBS element covers several activities which were omitted from the initial estimate or have increased cost. They include communications systems, spoils handling, and electrical power systems. It also includes increased cost associated with the $\mathrm{AE} / \mathrm{CM}$ contract revision which made the $\mathrm{AE} / \mathrm{CM}$ contract "whole" by including all required work not associated with the SSCL CCD (approximately $\$ 71$ million).

\subsubsection{Escalation}

The Committee translated potential increases in project costs from FY 1993 dollars into as-spent (then-year; dollars. Because it was not possible to time-phase the Committee's proposed cost increases within the time available, a simple calculation had to be used. With completion of the project 6 years from now under the assumptions made, the center of the funding profile is about 3 years from now and an escalation of 12 percent was taken for the Committee's "to go" costs. This escalation is consistent with the latest DOE issued escalation rate projections. Any inaccuracy in this method is considered minimal, and could change upward or downward from this figure depending on the method used. For example, lower annuai escalation rates would decrease the figure while utilizing a more realistic funding profile could increase the figure.

\subsubsection{Contingency}

The Committee developed a contingency estimate at low levels of the WBS to produce a total contingency budger ( $\$ 1.1$ billion as-spent) to cover the current projected cost risk. Contingency was added for only the "to-go" portion of the EAC. The total is 15 percent of the "to-go" costs. This important issue is discussed more fully in section 4.3. 


\subsubsection{Other Costs Outside the TPC}

These cost elements were identified in the original $\mathrm{BCE}$, and are included here to comply with the requirement to include all costs prior to start of operations.

Spares:

Laboratory

Operating Costs:

Detectors:

Contingency:
Approximately $\$ 70$ million (as spent) is required for special process spares to support the commissioning and preoperations program and prepare for the start of operations.

Approximately $\$ 560$ million (as sperit) is required for operating costs which occur for operating facilities such as the Linac, LEB, and MEB, after the successful commissioning of each of these machines. These costs also cover physics research during construction.

The baseline TPC included only the Federal portion of detector costs. The costs of the planned two large detectors (plus an allowance for smaller experiments) is now estimated at approximately $\$ 1,239$ million (FY 1993 dollars), about $\$ 580$ million more than in the TPC. Substantial contributions are expected from abroad but are not yet fully determined and may not be sufficient to make up this difference.

The BCE did not include $\$ 219$ million of contingency which was to be absorbed as part of foreign contributions.

\subsection{Contingency Analysis}

The current SSC project baseline includes contingency in the amount of $\$ 825$ million. Based on its estimate of the remairing risks and uncertainties under the assumptions used, the Committee recommended a total contingency of $\$ 1,089$ million as spent. This total includes all contingency regardless of funding source.

The Committee's estimate of contingency, developed at a detailed WBS level, is summarized in Table 4-3 and reflects its assessment of the current level of uncertainty in being 





able to complete the project within the Committee's estimated cost. The contingency recommended by the Committee was assessed only against the "to-go" portion of the EAC and equates to 15 percent of those costs.

Over 80 percent of the Committee's contingency is associated with the superconducting accelerators WBS, which is 64 percent of the Committee's "to-go" estimate. The Committee applied a contingency of 20 percent to the superconducting magnets. The Committee believes that considerable uncertainty in the production costs still exists for the superconducting magnets, and included this uncertainty in its recommendation of 20 percent.

The Committee devoted significant effort in attempting to ensure that the Committee estimate did not inadvertently double count by including additional costs within the base cost estimate, as well as additional contingency, to account for the uncertainty in completing the tasks within the estimated cost. However, current detailed cost estimates were generally not available from the SSCL. This issue must be addressed by the project management as they rebaseline the project and develop a new bottoms-up estimate.

The Committee recommends that an overall contingency level of 15 percent of the project remaining is the appropriate level for a project of the SSC's complexity, at its current stage of completion. The SSCL's original bottoms-up contingency analysis dates from 1990-1991 and the Committee believes that these early estimates no longer portray an accurate assessment of the uncertainties. The Committee recommends that a complete contingency analysis be prepared as part of the bottoms-up cost estimate for the project.

\subsection{Schedule}

The existing project baseline assumes the project had a 1999 completion date schedule with the baseline funding profile. The Committee found that an acceptable integrated, resource-loaded schedule was not yet available and this severely impacted the Committee's ability to complete all of its charges. While a critical path schedule is available, it has not been rigorously developed. There appear to be multiple paths near the machine-generated critical path which must have their logic verified. The detail and quality of available information makes it difficult to extrapolate possible schedule impacts. The Committee did not assign a cost for potential schedule delays because a detailed schedule was not available to accomplish this, and such an estimate could not be accomplished within the limited time. 
Given the assumptions, the Committee evaluated the remaining work to complete the project. The completion date would have been delayed approximately 12 months when compared to the baseline schedule. The May 1993 Monthly Progress Report indicates that Linac commissioning is likely to slip, which is expected to impact the remaining resistive accelerators. Further, the detectors and the installation contract are also likely to delay the project. In addition, the delay in the production of superconducting magnets could introduce some schedule difficulty.

\subsection{Subcontract Analysis}

A rudimentary analysis of 73 major subcontracts was performed to analyze cost over/underruns.

This subcontract trend analysis (Table 4-4) was conducted using the subcontract crosswalk summary from the May 1993 PMB/Subcontract Reconciliation. These numbers were corrected using data provided by the Conventional Construction and the Magnet Systems Divisions, which included modifications to original subcontract awards.

Out of the 73 major subcontracts awarded, 13 are over budget, 40 at budget, and 20 under budget. The total dollar amount of variances for the over budget subcontracts is $\$ 17.6$ million. These subcontracts are 12.5 percent over budget. The total dollar amount of variances for the under budget subcontracts is $\$ 93.7$ million and these subcontracts are 12.4 percent under budget.

TABLE 4-4 Subcontract Trend Analysis

(FY 1993 Thousand Dollars)

\begin{tabular}{|c|c|c|c|}
\hline \multicolumn{2}{|c|}{ Number of Subcontracts Awarded } & $\begin{array}{c}\text { Total } \\
\text { Over/Under } \\
\text { Budget } \\
\end{array}$ & $\begin{array}{c}\text { Percent of Subcontract } \\
\text { Dollars Over/Under } \\
\text { Budget }\end{array}$ \\
\hline $\begin{array}{l}\text { Over Budget } \\
\text { At Budget } \\
\text { Under Budget }\end{array}$ & $\begin{array}{l}=13(17.9 \text { percent }) \\
=40(54.8 \text { percent }) \\
=20(27.4 \text { percent })\end{array}$ & $\begin{array}{l}\$ 17,579 \\
(\$ 93,727)\end{array}$ & $\begin{array}{l}12.5 \text { percent } \\
12.4 \text { percent }\end{array}$ \\
\hline \multicolumn{4}{|c|}{$\begin{array}{l}\text { Of Those Sub- } \\
\text { projects Over or } \\
\text { Under Budget } \\
\begin{array}{ll}\text { Conventional } & =15(45.5 \text { percent }) \\
\text { Technical } & =18(54.5 \text { percent })\end{array}\end{array}$} \\
\hline TOTAL & $=73$ & $(\$ 76,148)$ & $6.8 \mathrm{p} \&$ rcent \\
\hline
\end{tabular}


The total dollars under budget for the 73 subcontracts is $\$ 76.1$ million, which translates to 6.8 percent of the subcontract dollars being under budget. It should be noted that a detailed comparison of the technical scopes of work contained in the budget estimates (PMB) as compared to the contractual scopes of work was not performed by the Committee due to limited time. The Committee believes that in some cases the contractual scopes of work may be significantly less than that of the original budget estimates, thereby, leading to an overstatement of the subcontract budget performance to date.

The Committee requested that the SSCL provide the Government estimates for these contracts. The Committee had intended to perform a detailed scope comparison between the Government estimates and the subcontract values for selected major subcontracts. Because of the limited time available, the SSCL was unable to provide the required information to the Committee.

The Committee concluded that initial contracting experience is encouraging, but without an in-depth analysis of the Government estimates, planned scopes of work, contract changes, etc., caution must be used in drawing conclusions. 


\section{PROJECT AND BUSINESS MANAGEMENT SYSTEMS}

Charge 3 to the Committee was to provide an assessment of the current business systems based on information gathered from the review. This was interpreted by the Committee to include Project Management Systems. The Committee's findings in the area of project and business management systems are classified in three areas: financial and progress reporting systems, procurement, and human resources. Each of these is discussed in the sections which follow.

\subsection{Financial and Progress Reporting Systems}

The overall utility of the project and business management system is currently constrained by two major problems. These two problems are: 1) inability to do adequate progress tracking, and 2) limited ability to provide consistent and accurate financial data. In addition, the lack of systems integration further renders most of the tracked data to be of limited value.

The Committee's findings with respect to project management and business management systems are consistent with those contained in the PMCS Compliance Review and form the basis for conclusions reached in other parts of this report concerning progress and status. Notable among these findings are:

- The data in the PMCS required extensive explanation to understand the actual progress it was presenting. Incorporation of change control actions, interpretation of actual progress, contracts, allocation of WBS costs, and integration of data from several divisions all influenced the final numbers.

- Project status and forecast information, including earned value and EAC, was difficult to track and lacked quantification.

- Time-phased resource plans for authorized tasks were unavailable.

- Implementation of the PMCS between divisions was inconsistent and lacked integration. 
- Resource-loaded schedules have not been uniformly developed. Schedule logic ties between machines for all the affected systems was insufficient.

- The supporting documentation for the BCE is not being maintained in an auditable and traceable manner. It was extremely difficult to track approved scope changes to the BCE at the detailed WBS level.

- Cost estimating responsibility was spread throughout the SSCL.

\section{$5.2 \quad$ Procurement}

The management subcommittee was able to assess certain procurement issues as part of its review. The following issues were identified as part of the management subcommittee review:

1. SSCL procurement management does not appear to be an integral member of the SSC Project Management Team.

The procurement organization includes eight procurement cells allocated (matrixed) throughout the project organization. While there are certain advantages to such an approach, there also are clear disadvantages, such as 1) decentralization may result in fragmentation, whereby control by the central procurement organization can be diminished; 2) more manpower is required under the decentralized approach and manpower flexibility to meet peak or emergency needs can be severely lessened; 3) standardization and adherence to SSCL procurement policies and procedures can be greatly compromised; and 4) procurement cell representatives may be more likely to be co-opted/ influenced by project management personnel. This organization should be reviewed to ensure that the SSCL procurement system is effective.

2. While SSCL procurement policies and procedures have been approved by DOE, there is no DOE-approved procurement system. The problem appears to be with the lack of effective implementation of the policies and procedures, including subcontract negotiation and administration. 
There is no listing or schedule for all project procurements. More important, there is no listing or schedule for those procurement actions on the critical path. The absence of such data provides an insufficient basis for procurement manpower planning and may preclude sufficient time for preparation of individual advance acquisition plans and appropriate implementing actions. It may also lead to the elimination of certain desirable business strategy options that will drive project cost.

DOE is reviewing essentially all procurement actions over $\$ 250$ thousand and all noncompetitive actions over $\$ 25$ thousand. The subcommittee review concluded that the resources of SSCL and DOE expended on minor actions are inefficient. This leaves few resources available for application on the more significant actions.

In summary, the preliminary assessment is that the ability of the SSCL procurement function to effectively support the SSC project is marginal.

\subsection{Human Resources}

The subcommittee was hampered in its efforts to do a comprehensive assessment of direct and indirect manpower because of the lack of defined manpower tables and positions in current year and future projected annualized form. The LRE has not been supplemented with a defined, planned allocation of annualized employment tabulations in a form that will permit management to perform multi-year planning and control of internal and external labor costs.

Resource projections were in more of a high-level, gross financial form for future years rather than a bottoms-up detailed form. Bottoms-up analysis is lacking and is important to manage and control costs. Assessments on current staffing and the transition from construction to operations is apparently unavailable. In particular, the necessary change in the skills mix as the SSCL moves towards the mixed construction/operations phase, and ultimately toward the actual operations phase, is evidently not well defined and no central control for managing this important interface was identified.

It was noted that there are several sources of manpower other than URA and EG\&G direct hires. Such manpower is acquired through such mechanisms as consulting agreements, support services subcontracts, and from other Management and Operating (M\&O) contractors via Memorandum Purchase Orders. The time and costs associated with such supplemental 
manpower must to be examined and evaluated, especially since some of the mechanisms are multi-year arrangements.

These human resources problems are further compounded by a fragmented multiemployer structure within the SSCL. The development and implementation of a positioncontrol system to guide SSCL and the other employers in overall manpower transition from construction to operation is essential if direct and indirect costs are to be balanced. For example, a detailed plan for SSCL or external project staffing was not provided to explain how magnet installation and maintenance activities would be completed. The information available tended to be historical rather than a forward look through each year to the year 2000 . The manpower staffing level of the project and the SSCL is a major cost driver and is a critical area of concern.

\subsection{Overall Assessments}

The Committee concludes that:

1. Integration and proper utilization of project management and business systems is required in order to provide effective management of the project. In particular, the indirect cost categories in the May 1991 Monthly Progress Report should be changed to a meaningful form that will capture and report costs in the manner that they are managed. This action will give the data the integrity and validity necessary for it to be meaningful.

2. Development of annualized manpower/position tables is needed to provide the proper visibility and control of labor costs.

3. Indirect costs should be the subject of further review to examine the organizational structure and the utilization of the manpower assigned to all support functions.

4. The procurement function requires improvement to effectively support the SSC project.

5. The project schedule is inadequate. A new schedule must be developed which is integrated, resource-loaded, and has critical paths verified.

6. Central estimating and budgeting functions are necessary to ensure integration and tracking to existing baselines. 


\section{CONCLUSIONS/RECOMMENDATIONS}

The review, although conducted in a relatively short time, has resulted in definitive findings. The Committee came into the project on short notice and, although the SSCL was most responsive to the Committee, it was very difficult to track data and answers had to be pieced together from multiple sources. Continual interfacing between the subcommittees was necessary to confirm conclusions and recommendations. It must be understood that the Committee used a different approach to address Charge 1 and Charge 2. Charge 1 was to assess project progress and status as identified in the May 1993 Project Progress Report. This assessment utilized the $\$ 8.249$ billion cost and a 1999 completion date. In executing Charge 2 the Committee assessed the significant work "to-go" from the project status in May 1993. The Committee focused on current trends and projected changes. Without significant management initiatives this assessment would lead to a TPC of $\$ 9.944$ billion and a projected schedule extension of 1 year. The Committee's conclusions and recommendations are summarized in Sections 6.1 and 6.2 .

\subsection{Conclusions}

1. Progress to date is generally accurately reported in the May 1993 Monthly Progress Report, but it is very difficult to track with the limited capabilities of the management systems of the SSCL.

2. The Committee identified cost risks of $\$ 1.5$ billion, unless significant management changes are undertaken. Additional costs prior to start of operations (spares, laboratory operations, non-Federal detector contributions) are $\$ 1.21$ billion. These costs are not in the $\$ 8.249$ billion SSCL baseline, or the Committee's estimate.

3. The magnet program still has considerable production cost risk. The technical risk has been significantly reduced from that present at the time of the 1991 baseline review. Assuming the Committee's estimate, no substantive cost risk beyond that covered by the contingency is apparent for other parts of the project.

4. The Committee has determined the $1991 \mathrm{BCE}$ has not been updated at the detailed level to reflect cost experience to date. 
5. The integrated project schedule is not adequate and in all probability understates the completion date. The magnet program status, the new installation contract, the detectors, and the critical paths of various machines all suggest a 1-year extension.

6. Non-Federal contributions or scope reductions could reduce some costs.

7. The application of current project and business management systems is marginally adequate to track design and construction earned value data, even with considerable, additional explanation.

8. The SSCL staffing levels and skills mix must be carefully re-examined and compared to those required to successfully complete the Project within budget and on schedule.

\subsection{Recommendations}

1. The project should be rebaselined. This assessment has shown that the basis for cost assumptions and schedule durations developed in 1990 have changed considerably. Moreover, the 1991 baseline is constraining realistic planning and decision making.

2. A new integrated, resource-loaded project schedule must be formulated. Integration between critical activities is presently lacking and the critical path is not clear.

3. The designs in several technical areas should be reviewed, optimized, and integrated by the Laboratory. Trade-off studies must be made, including a careful examination of requirements that can be relaxed without jeopardizing the higher level specifications of the project.

4. A new bottoms-up estimate is required, particularly for the superconducting magnets. Further, the function of Chief Estimator must be established. The Committee found no central estimating responsibility within the SSCL and found the connection to the old WBS, as well as actual contract progress, difficult to track. The contingency must be re-assessed. 
5. An ongoing, outside assessment program is recommended to provide the SSCPO Director with unbiased analysis of progress. This is especially recommended for the superconducting accelerators because of the cost and schedule risk associated with this area.

6. The SSC program must move into a final design and construction mode. Data collection and tracking must be directed at assessing cost and schedule progress. The staffing level and skill mix necessary to accomplish this should be re-evaluated. The new integration contract should be implemented as soon as possible and that contractor should participate in the rebaselining effort. 


\subsection{SUBCOMMITTEE REPORTS}

\subsection{Management}

\subsubsection{Executive Summary}

The subcommittee reviewed WBS 11 (program management) and indirect costs as identified in the May 1993 Cost Performance, Report (CPR) and recommends addition of $\$ 83.6$ million to the project budget for these elements. It should be noted that the SSC Cost Estimate Comparison Charts reflect an additional \$75.7 million in Environment, Safety and Health (ES\&H) requirements (see Section 7.7) for a total variance of $\$ 159.3$ million. In addition, this subcommittee is providing overall comments on the adequacy of the business management systems.

The subcommittee found that WBS 11 (program management) was generally coherent and there was little basis for disagreement with the Laboratory's "latest revised estimate" (LRE), with three exceptions. Those exceptions prompted the subcommittee to estimate a cost for Accelerator Systems Division Management (WBS 111) that was $\$ 6$ million higher than the budgat; to estimate a cost for Conventional Construction Division Management (WBS 114) that was $\$ 25$ million higher than the budget; and to estimate a cost for PB/MK Project Management and Administration (WBS 117) that was the same as the budget (these differences are discussed in Section 7.1.4).

The subcommittee's assessment of the indirect cost elements was much more difficult than it should have been, due in part to the inability to verify and validate the requested data caused by the lack of effective business systems for tracking the data. Although a multitude of datit is tracked, most of it is of no use in the verification of cost. The indirect costs are aggregated in the CPR in three cost elements that are ineffective from a standpoint of management and control-Capital Indirects, Central Services, and General and Administrative (G\&A) costs-that is, they comprise some 50 sub-elements, each of which is assigned to one, two, or all three of the indirect elements, in varying percentages.

Based on trend analysis of indirect cost, the subcommittee concluded that this area of the project seems headed for a serious overrun unless Laboratory management takes positive action to reduce indirect costs through reorganization, centralization, and increased utilization of the support and administrative staffs. A reduction on the order of 25 percent 
in the indirect costs appears to be in order. This action should control cost growth and possibly reduce the need for additional funding.

The present LRE predicts $\$ 20.4$ million above current budget for the three indirect accounts will be needed for the remainder of the project. The subcommittee concurs that this amount is an appropriate prediction for the total cost of the indirect functions, if the reductions discussed above are made.

It should be noted that this subcommittee did not include an allowance for indirect costs related to any cost increases being recommended by the other subcommittees.

As to the adequacy of business management systems in support of the project, the consensus of the subcommittee is that currently available information derived from that system is not yet integrated. In the subcommittee's opinion, there is widespread lack of discipline and standardization among procedures utilized by Cost Account Managers (CAMs) and Allocable Activity Managers (AAMs). There is a strong need for the project to institute integrated business management systems and introduce more standardization among organizations and cost accounts.

Our subcommittee could not accurately assess direct and indirect manpower because of the lack of information, as well as defined manpower tables and positions in annualized form. The LRE has not been supplemented with a defined, planned allocation of annualized manpower in a form that wi!! nermit management control of labor costs.

\subsubsection{Scope of Work Associated with WBS 11 and Indirects}

The subcommittee assessed WBS 11 (SSC management) and indirect costs.

WBS 11 comprises seven major sub-elements as listed below with their associated budgets:

Budget

WBS 111--Accelerator Systems Division Management

WBS 112--Magnet Systems Division Management

WBS 113--Physics Research Division Management

WBS 114--Conventional Construction Division Management

WBS 115--Project Management Office

WBS 116--Project Management Accelerators

WBS 117--PB/MK Project Management and Administration
$\$ 31.7$ million

32.0 million

4.2 million

101.8 million

36.6 million

2.0 million

154.3 million

$\$ 362.6$ million 
The indirect costs with corresponding budgets are as follows:

Budget

Capital Indirects

Central Services

$\$ 49.5$ million

G\&A

301.2 million

100.3 million

$\$ 451.0$ million

In the above tables, the budget figures are from the May 1993 CPR. That document shows the total project budget as $\$ 7,424$.1 million. Thus the WBS 11 element comprises 4.9 percent of the entire project budget and the indirects 6.1 percent; the indirects and WBS 11 combined total 11 percent.

All WBS 11 sub-elements are generically defined as containing technical support, administrative support, business management, and Other Direct Costs for the technical area managed. The three indirect cost centers represent a conglomeration of poorly-defined, difficult to understand, allocable-type costs. The subcommittee notes the indirect costs are not covered by WBS numbers and are not defined in the WBS dictionary.

\subsubsection{Assessment of Project Status}

Because the functions reviewed by this subcommittee are level-of-effort by nature, an assessment of earned value or percentage complete cannot be done in any meaningful way. Instead, the subcommittee considered that 3.5 years of a 10 -year project have now elapsed, leaving 6.5 years to go. Most of the indirect functions have expended over 40 percent-and some nearly 50 percent-of the baseline budget. A quick correlation of schedule to expenditures to date thus indicates a trend toward overrun of the LRE for indirect functions.

The subcommittee had a great deal of difficulty in understanding the composition of the indirect functions of Capital Indirects, Central Services, and G\&A. (The composition of WBS 11 was much more straight-forward.) It was very difficult to track approved changes from the 1991 Cost and Schedule Baseline (Green Book) to the May 1993 CPR. No one individual who could responsibly address costs in any of the major CPR indirect divisions was identified by the SSCL. Allocation policies have changed three times in 4 years, and organizational changes have occurred, compounding the task of tracking the indirect costs portrayed in the CPR. In short, the indirect cost area of the project is 
confusing and somewhat in disarray. The continued lack of data management and data integration have made it very difficult to cross track the data collected. This area of management does not provide evidence of satisfactory management in the 3-1/2-years of efforts being tracked by the SSCL.

\subsubsection{Plan to Complete}

Following is an account-by-account subcommittee analysis of each cost center reviewed:

1. WBS 111. The Director of the Accelerator Systems Division projects costs for this element on the basis of a slightly-downsized level-of-effort. He projects a total cost for WBS 111 of $\$ 35$ million to accomplish his cost objectives.

However, he assumes "reimbursement" of \$6 million will be made to WBS 111 for UNIX computer support costs and Applied Geodesy support costs by other Divisions. The SSC General Manager stated there would be no reimbursement. Therefore, a total of $\$ 41$ million will be required for WBS 111 . This equates to $\$ 9.3$ million more than the budget.

2. WBS 112. The subcommittee has found no basis to challenge the May CPR projection based on data examined. This CPR shows $\$ .2$ million less than the budget is needed. Managers charge a portion of their time to direct accounts, as appropriate.

3. WBS 113. This is a relatively small cost and was not reviewed by the subcommittee. The May CPR shows that $\$ .2$ million more than the budget is needed. It is recommended this WBS, in combination with WBS 571, be investigated at a later date should additional reviews be commissioned.

4. WBS 114. The Conventional Construction subcommittee assisted in the review of this WBS. Based on its review of two major approved Change Control Board (CCB) actions, an additional $\$ 25$ million is needed above the budget. This amount is driven by additional manpower requirements identified as required after FY 1994. 
5. WBS 115. The subcommittee has found no basis to challenge the May CPR projection based on data examined. The CPR shows $\$ 15.1$ million more than the budget is needed.

6. WBS 116. The subcommittee has found no basis to challenge the May CPR projection based on data examined. The CPR shows $\$ 13.8$ million more than the budget is needed. It should be noted that this group was formed as a result of reorganization. A CCB action is needed to better align the budget to the present organizational configuration.

7. WBS 117. The Conventional Construction subcommittee assisted in the review of this WBS. Based on their review of two major approved CCBs, the budgeted amount should be sufficient. It should be noted that WBS 114 is interactive with the WBS 117.

8. Capital Indirects. Central Services, G\&A. The Laboratory predicts a need for $\$ 20.4$ million above current budget for the three indirect accounts for the remainder of the project. The subcommittee concurs this amount is appropriate for management of these functions if Laboratory management takes some positive action to reduce the indirect functions through reorganization, centralization, and increased utilization of the support and administrative staffs. $A$ reduction on the order of 25 percent in the indirect costs is recommended and will ultimately control cost growth and possibly reduce the need for additional funding.

To summarize the above analysis, $\$ 83.6$ million more in management and indirect funding is needed for the remainder of the project.

\subsubsection{Interfaces}

The following cost elements have been addressed by other subcommittees. However, because they are related to WBS 11 and indirect costs covered by this subcommittee, they are discussed below: 
1. ES\&H. A separate subcommittee evaluated ES\&H cost impacts. A report of their findings is presented elsewhere in this report. Currently, it is not clear where ES\&H costs are being charged and in what amounts. The 25 percent reduction in indirect costs proposed by that subcommittee may be difficult to achieve should expansion in ES\&H cost exceed that already identified in the ES\&H subcommittee report.

2. WBS 571. This account is defined as containing the technical and administrative management required to manage the construction of those detector facilities that cannot be identified with a particular detector. Although this definition is similar to the functions contained in WBS 113, this subcommittee did not review this account. Rather, WBS 571 was analyzed by the detector subcommittee.

3. Bottom Line Cost Impacts on Indirects. It should be noted this subcommittee did not include an allowance for indirect costs related to the increases in direct cost reported by other subcommittees.

4. Operating Cost. The costs addressed by all the subcommittees assume that functions will be appropriately ramped down as the construction phase nears completion. This is an assumption typically found in any major construction project where there is an overlap between the initial operation and the final completion of all construction. All subcommittees are concerned that if operating funds are not made available as planned to overlap with construction ramp down, then construction funding may be forced to carry manpower longer than currently assumed, thereby increasing costs substantially above the current LRE.

\subsubsection{Documentation Reviewed, Contacts Interviewed}

\subsubsection{Documentation Reviewed}

A wide range of documentation was available to the subcommittee to support its analysis. The documentation consisted of data, organization charts, and reports provided by the SSCL at the beginning of the review as well as data requested by the subcommittee during interviews with SSCL employees. It should again be noted that the subcommittee 
was significantly hindered in the effort to obtain consistent information necessary to validate the data provided because of the lack of effective data integration. A complete list of all reference documentation follows:

1. Specification Tree

2. Level 1, 2 and 3 Specification (Numbers E10-000008 and E10-000001)

3. WBS Dictionary

4. Site Specific Conceptual Design Report

5. Updated Memorandum from J. Decker to F. Peters - "Status Validation of Current Baseline for the SSC"

6. Point of Contact (POC) listing for each team

7. ASD Organization Chart

8. Last six lab CPRs 8a, 8b, 8c, 8d, 8e, (December 1992 to May 1993) copies (6)

9. CCB Log Report as of: July 8, 1993

10. Last semi-annual report and its supporting viewgraphs

11. All major contract information, including: type, to whom, amount, schedule, percentage completion, actual costs, and pending changes to scope/schedule

12. Conventional Facilities Master Plan

13. SSCL Organizational Charts

a. SSCL Organization (Includes Directorate and General Manager's Office)

b. Laboratory Technical Services Division

c. Physics Research Division Organization

d. Administration

e. Project Management Office

f. Accelerator Systems Division

g. Magnet Division

h. Conventional Construction Division (Includes PB/MK)

14. SSCL Telephone Directory

15. Relevant Portions of Crosswalk from Original Baseline to Revised Baseline

16. Report on the Superconducting Super Collider Cost and Schedule Baseline, January 1991 (Green Book)

17. Project Management Plan for Superconducting Super Collider, January 1993 P40-000021 Rev. A

18. SSCL Responsibility Assignment Matrix (Includes All Responsibilities by WBS)

19. October 9, 1989 Letter from E. Whiting to J. Zimmer, EG\&G Staffir: ihrough December 31, 1997 (SSCL will present necessary data to justify procurement, design, construction, planning, etc.)

20. Projected EAC: SSCL will present data in following format:

- Baseline

- Projected Scope Changes Cost

- Baseline Estimate Revisions (Estimate "Busts")

- Funding Profile Revisions Based on Schedule Changes

21. Allocable Activities binder, July 1993

22. Public Relations Releases and SSC Promotional/General Information Red Packet

23. Review of SSCL FTEs (1992 SSCPO Review)

24. WBS EC RAM - May $3.0 \mathrm{~A}$

25. SSCL Population Report for Period Ending 6/11/93

26. EG\&G/URA Employees Roster by Division, Department, Job and Grade

27. PMB WBS X-WALK ( $\$$ in 000$) 4$ pages

28. PMB WBS RAM - May CPR (13 pages) 
29. Committee Contact Information (Name, telephone \#'s)

30. Master change list Dugan to Haas Memo dated $7 / 19 / 93$

31. Memo from Cindy Lowe to Goetz/Myers dated 7/21/93

32. Bob Sheldon June 26, 1990 Briefing Chart - Baseline Green Book Summary

33 Alan Stokes Computation of Indirect Cost Projection

34. July 20, 1993 Morning Review of Day/Week Plan

35. March 25, 1992 Letter from T. Cone to G. Provencher, Draft Request for Proposal for Temporary Employment Services

36. July 20, 1993 Facsimile to Alan Goetz and Steve Flannery from Jack Story

35. April 15, 1993 Memo from E. Sisken to J. Cipriano, Management Budgets and Projected Effort through FY 1993

38. Worksheet "WBS II" (through May 1993)

39. "Draft for Discussion Purposes - SSC Line of Inquiry/General Questionnaire"

\subsubsection{Contacts}

The following individuals on the SSCL staff were interviewed:

Susan Archer, Project Manger's Office

Karen Boudreau, Personnel Manager

Tom Bush, Associate Director, Magnet Systems Division

Charlie Dan, Director, Procurement

Bob Higbee, Finance Division

Cindy Howe, Project Manager's Office

John Ives, Associate Director, Conventional Construction Division

Ted Kozman, Associate Director, Accelerator Systems Division

Cindy Lowe, Finance Division

Wanda Mizutowicz, Chief Financial Officer

John Rees, Project Manager

Ed Sisken, General Manager

Jack Story, Laboratory Technical Services

Gary Tuttle, Project Manager's Office

\subsubsection{Assessment of Plan to Complete}

As stated in Section 7.1.4, the subcommittee feels an additional $\$ 83.6$ million should be added to the project budget for WBS 11 and the three indirect accounts. When the $\$ 75.7$ million identified by the ES\&H group report is added to this, the $\$ 159.3$ million variance shown in the SSC Cost Estimate Comparison Charts is obtained. 
Significant increases in scope/cost of the direct accounts may be expected to result in increases in indirect costs. However, it should be noted the subcommittee analysis did not include an allowance for indirect cost increases related to the increases in direct cost reported by other subcommittees.

The subcommittee concurs this additional $\$ 83.6$ million amount is appropriate for management of these functions. However, this increase will not be sufficient for the outyears unless Laboratory management takes some positive action to reduce the indirect functions through reorganization, centralization, and increased utilization of the support and personnel. A reduction on the order of 25 percent in the indirect costs is recommended and will ultimately control cost growth and possibly reduce the need for additional funding.

The recommendations proposed by the subcommittee were discussed with the SSCL General Manager, who stated that plans were being formulated to effect significant reduction.

The subcommittee feels that the indirect cost area should be the subject of further review to examine the appropriate organizational structure and improved utilization of the manpower assigned to all support functions. This same approach should be utilized in reviewing the EG\&G contract and centralizing of duplicated functions and activities.

\subsubsection{Assessment of Business Management Systems}

Because business systems evaluation cuts across all the subcommittees' work, the overall assessment of business systems is provided in this subcommittee report. The charter for this task included assessing procurement, financial reporting and progress reporting systems, and manpower.

It should be noted that while this subcommittee did not conduct a detailed review of the Project Management Control System (PMCS) - this was performed by a separate review team—our subcommittee did evaluate how effectively business management systems were utilizing output from the PMCS. Our subcommittee's findings are consistent, though, with the separate PMCS compliance review report.

Notwithstanding the above, the following observations relating to business systems were considered noteworthy and are offered as areas for further consideration. 


\subsubsection{Procurement}

The following procurement issues were identified:

1. SSCL procurement management does not appear to be an integral member of the SSC Project Management Team.

The procurement organization includes eight procurement cells collocated throughout the project organization. While there are certain advantages to such an approach, there also are clear disadvantages, such as (1) decentralization may result in fragmentation, whereby control by the central procurement organization is diminished; (2) more manpower is required under the decentralized approach and manpower flexibility to meet peak or emergency needs is severely lessened; (3) standardization and adherence to Laboratory procurement policies and procedures are greatly reduced; and (4) procurement cell representatives are more likely to be co-opted/influenced by project management personnel.

While SSCL procurement policies and procedures have been approved by DOE, there is no DOE-approved procurement system. The problem appears to be with the lack of effective implementation of the policies and procedures, including subcontract negotiation and administration.

There is no listing or schedule yet for all project procurements. More important, there is no listing or schedule for those actions on the critical path. The absence of such data provides an insufficient basis for procurement manpower planning and may preclude sufficient time for preparation of individual advance acquisition plans and appropriate implementing actions. It may also lead to the elimination of certain desirable business strategy options that will drive project cost.

DOE is reviewing essentially all procurement actions over $\$ 250$ thousand and all noncompetitive actions over $\$ 25$ thousand. The resources of SSCL and DOE expended on minor actions are not well managed. This leaves few 
resources available for application on the more significant actions. Unless URA can quickly improve its procurement system, this subcommittee would not recommend raising the procurement thresholds.

In summary, the preliminary assessment is that the ability of the SSCL procurement function to effectively support the SSC project is marginal.

\section{EG\&G Science Support Corporation}

EG\&G Science Support Corporation personnel are an integral part of the procurement system. EG\&G was a designated subcontractor under the original URA proposal and is provided for under the URA contract. The EG\&G contract provides approximately 31 percent of the SSCL permanent staff who perform an array of services spread throughout the organization. Their support to date has been valuable and the subcommittee found no problems with this contract.

However, this contract is currently managed and negotiated by the legal department. The people provided by EG\&G are scattered throughout the SSCL staff with the majority providing technical services support, including working in the procurement department.

The EG\&G contract also has a very high potential for being utilized to a greater extent than was originally anticipated. It was stated by the EG\&G manager that EG\&G personnel are being asked to do more and more work and that, if this trend continues, costs will go up. It is recommended that the control and management of this contract be reviewed.

\subsubsection{Financial and Progress Reporting Systems}

The overall utility of the business-management system is currently constrained by two major problems. These two problems are: (1) inability to do progress tracking, and (2) inability to provide consistent, accurate, and timely financial data. In addition, the lack of systems integration further renders most of the tracked data to be of no direct use in verifying costs to the funding profile. 
Our subcommittee's finding with respect to business systems are consistent with those contained in the SSC Project Management Control System Compliance Review, dated July 1993. Notable among these findings are:

- Project status and forecast information was found to require major improvement.

- Time-phased staffing plans against authorized tasks were unavailable.

- Implementation of the PMCS between divisions is inconsistent and lacked integration.

- Cost and scheduling monitoring functions are also not integrated, resulting in an inability to accurately measure project status and develop meaningful reports.

\subsubsection{Human Resources}

The subcommittee was hampered in its efforts to do a comprehensive assessment of direct and indirect manpower because of the lack of defined manpower tables and positions in current year and future projected annualized form. The LRE has not been supplemented with a defined, planned allocation of annualized employment tabulations in a form that will permit management to perform multi-year planning and control of internal or external labor costs.

Resource projections were in more of a high-level, gross financial form for future years rather than a bottoms-up detailed form. Bottoms-up analysis is lacking and is important to manage and control costs. Assessments on current staffing and the transition from construction to operations is apparently unavailable. In particular, the necessary change in the skills mix as the SSCL moves towards the mixed construction/operations phase towards an actual operations phase is evidently not well defined and no central control for managing this important interface was identified. 
It was noted that there are several sources of manpower other than URA and EG\&G direct hires. Such manpower is acquired through such mechanisms as consulting agreements, support services subcontracts and from other M\&O contractors via MPOs. The time and costs associated with such supplemental manpower needs to be examined and evaluated, especially since some of the mechanisms are multi-year arrangements.

These human resources problems are further compounded by a fragmented multiemployer structure within the Laboratory. The development and implementation of a position-control system to guide SSCL and the many other employers in overall manpower transition from construction to operation is essential if direct and indirect costs are to be balanced. For example, no definitive plan for inside or outside manpower were provided to explain how magnet installation and maintenance activities would be completed. The information available tended to be historical rather than a forward look through each year to the year 2000. The unmanaged manpower staffing level of the Laboratory is a major cost driver and is a critical area of concern.

\subsubsection{Conclusions/Recommendations}

The subcommittee concluded that:

1. An additional $\$ 83.6$ million will need to be added to the budget. These funds should be adequate provided that there are no major increases in direct-account scope/cost and a 25 percent reduction in indirect costs is accomplished in the near future. In order to reconcile this amount to the $\$ 159.3$ million variance to the budget that is reflected in the SSC Cost Estimate Comparison Charts, add $\$ 75.7$ million in ES\&H requirements (see Section 7.7).

2. Integration and management of business systems is required in order to provide effective management of the project. In particular, the indirect cost categories in the CPR should be changed to a meaningful form that will capture and report costs in the manner that they are managed. This action will make the data more timely and useful for management purposes. The subcommittee has noted that the finding that is common to all the subcommittees is a lack of integration in project schedule, and that the scheduie, in all probability, incorrectly states the project completion date. 
3. Development of annualized manpower/position tables is needed to provide proper control and visibility of labor costs.

4. Indirect costs should be the subject of further review and analysis to examine the optimum organizational structure for utilization of the manpower assigned to all common support functions.

5. The procurement function requires significant improvement. A detailed review of the role and utilization of the EG\&G subcontract should be conducted to determine the role of this contract, management of this contract, and the future utilization of the employees of FG\&G.

6. This subcommittee has noted that the Business Management System findings are common to all the subcommittees and that this project must be rebaselined. A new integrated project schedule will need to be formulated which clearly identifies all staffing and other resources. Integration between' critical activities is currently lacking and the currently defined critical path is meaningless without the necessary integrated links to all project initiatives. 


\subsection{Superconducting Accelerators}

\subsubsection{Executive Summary}

The superconducting accelerators comprise the high energy booster (HEB) and the collider, including the superconducting magnets, their associated cryogenics, other technical systems, and conventional construction. These accelerators physically dominate the SSC project and together account for over 60 percent of its budget. The collider alone, with its 54-mile tunnel containing two rings of powerful superconducting magnets, is estimated in the present Performance Measurement Baseline (PMB) budget at $\$ 3,469$ million (FY 1993 \$, without contingency).

This section primarily discusses the cold technical components of these accelerators. Warm components (power supplies, vacuum, etc.), conventional construction, installation, preoperations, and operations for these accelerators are discussed in other subcommittee reports.

Table 7.2.1-1 lists the major technical subsystems of the collider (WBS 321) and summarizes the changes recommended by the Superconducting Accelerators Subcommittee (first six items), as well as recommended changes from other subcommittees. Because of time constraints, the subcommittee concentrated on significant cost drivers and items with completion risk. Because of the technical, cost, and schedule implications of the collider dipole magnets (budgeted at $\$ 1539$ million), two members of the subcommittee made a visit to the General Dynamics (GD) magnet factory at Hammond, Louisiana.

As summarized in Table 7.2.1-1, unless substantial changes are made, we believe that the cost estimate for WBS 321 may have to be increased by a number ranging from about $\$ 668$ million to $\$ 861$ million (FY $1993 \$$ ), an overall increase of about 25 to 35 percent above the PMB of $\$ 2.63$ billion for these systems, (including installation). These recommendations are in general agreement with recent informal Laboratory estimates. Prompt and significant management actions are needed to minimize this cost growth. Trade-off studies should be made including a careful examination of requirements (for example, magnet field quality, correction magnet strengths, and spool specifications) that might be relaxed without jeopardizing the high-level specifications of the project. 


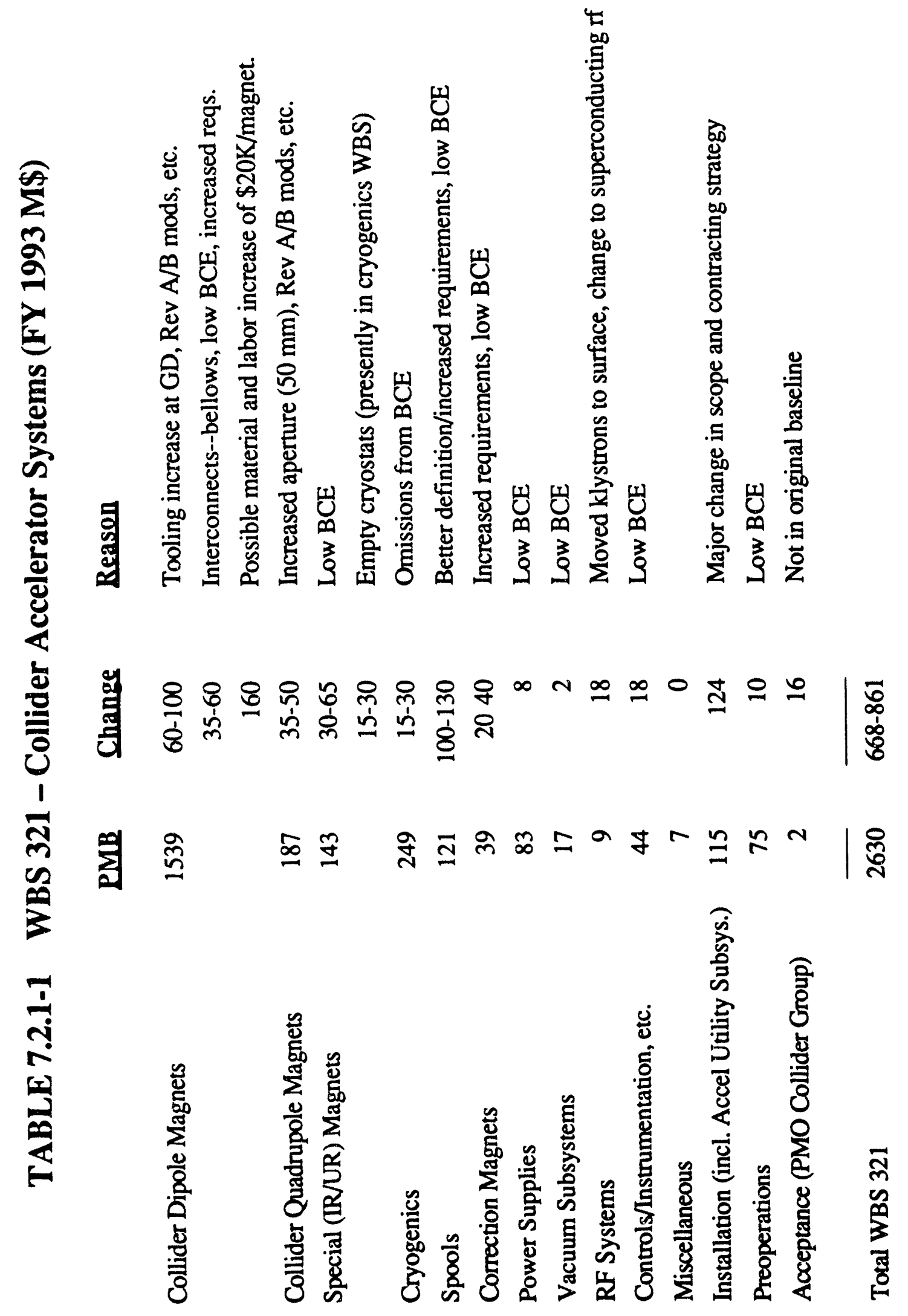


The increases shown in Table 7.2.1-1 are largely required to account for increased requirements resulting from better design definition and, in some cases, from omission, or anomalously low estimates in the 1991 baseline. The largest recommended changes to the estimated costs are shown for the collider dipole magnets (as might be expected since they have by far the largest cost of any system). While the design and industrialization of these magnets are progressing, they are somewhat behind schedule and it is still at least a year too early to give a definitive cost estimate. Experience must be gained with the magnet costs-materials, labor, and overheads-in a production setting. And competition at all levels must be encouraged to drive these costs down. For these reasons (further discussed below), we believe it would be premature to reduce the contingency corresponding to the uncertainties in these magnets to less than 20 percent.

While areas of potential cost growth have been identified, in many cases the situation is still in flux and thus a range of possible increases is shown in the table. The upper-end corresponds to what can happen unless firm and timely management action is taken. In general, it is an estimate based on laboratory designs that must now be integrated and optimized. This optimization process must be pursued vigorously and should include trade-off studies and a careful examination to determine those requirements that can be relaxed without jeopardizing the high-level project specifications. After the optimization, we believe there is a reasonable opportunity for the new estimates to be held to the low end of the ranges with close technical, cost and schedule controls. The entries in the Estimate at Completion (EAC) tables elsewhere in this report are close to the midpoint of the range shown in Table 7.2.1-1, except for interconnects, where the low end is believed to be achievable.

The procurement plan for the main bending and focusing magnets is summarized in the table below. The magnet procurement contracts are for design and build. The collider dipole magnet (CDM) contracts for the leader and follower each contain options for highrate production of 8,150 magnets. They are scheduled to be awarded to the lowest bidder on a firm fixed-price basis in January 1995. 
Magnet

Collider Dipole (15m \& 13m) $\quad \$ 1539$ million

PMB
Collider Quadrupole

HEB Dipole

HEB Quadrupole
Total Cost

\$187 million

\$156 million

$\$ 37$ million
Development Program Leader

Eollower

General Dynamics

(GD)

Westinghouse

Electric

Corporation

(WEC)

4 short models

12 prototypes

35 preproduction 35 preproduction

First unit due 4/94 First unit due 4/94

251 low rate initial 251 low rate initial production. First production. First unit due 11/94 unit due $11 / 94$

Babcock \& Wilcox GD $(\mathrm{B} \& \mathrm{~W}) /$ Siemens

WEC

CEN/Saclay

(design and tooling

only)

While progress has been shown at the GD factory, GD is still in the process of proofing and tooling, with the first prototype magnet now being assembled. Work stations are being brought into action in sequence upon the arrival of the first prototype. As for previous efforts with superconducting magnets for accelerators, this process is taking longer than originally planned and is presently more than 5 months behind schedule.

The new GD tooling is very automated and assumptions regarding its use in a production mode are very ambitious. The tooling was made more sophisticated than originally planned. While this is expected to save money in the long run, it has resulted in an overrun of some $\$ 20$ million in the present development contract. Not all of the baseline funds allocated for dipole development were committed in the present contracts, however, and the program manager anticipates being able to bring the effort to a successful conclusion within the baseline budget.

The new tooling, together with design modifications for manufacturability and reliability, will likely require more iterations to settle the design and manufacturing 
processes than were initially planned. It is critical that this manufacturing development work proceed expeditiously, with high priority at GD, WEC, and the SSCL. The use of short model magnets to test design changes will likely continue to be crucial in carrying out the necessary iterative process in a timely and cost effective manner. The short model magnet program has not yet demonstrated a successful design and only a limited number of interactions is possible in the long magnet program. The subcommittee recommends that the model magnet program continue to be used to test design changes.

The CDM Preproduction Design Review was originally scheduled to be held in June 1993, after test results from the first three GD prototypes were available. It appears that this review will be delayed at least 6 months. Because of this delay, the GD and WEC contracts need to be modified as both firms are now scheduled to place orders for material for 35 preproduction magnets each beginning in August 1993. Several million dollars ( 20 percent) of this material may be at risk because of design changes; much larger sums could be at risk 5 months later when long-lead material orders for 251 low-rate, initial-production (LRIP) magnets are to be issued per the current schedule. It is therefore recommended that the schedules in the GD and WEC contracts be reviewed and modified as required to reflect the delays that have occurred.

The other major magnet contractors, WEC and B\&W, appear to be proceeding well, but again it is too early to give a definitive new cost estimate. The committee believes that it is highly important that the CDM follower (WEC) remain viable in order that the project reap the planned benefits of competition. This must be given high priority. Unfortunately, WEC's effort as the follower was recently slowed by the SSCL, and this action should be reevaluated.

Other open issues include wire coatings to reduce ramp-rate effects, the possible need for a beam-tube liner in the collider, possible cold testing of additional magnets, and the extrapolation from the $\mathrm{CDM}$ cost projected by $\mathrm{GD}$ for low rate initial production to the PMB cost expected for production magnets.

A technical problem in the HEB dipole magnet program is the dependence of both the field at quench and the field quality on the ramp rate at which the magnet is energized. The subcommittee believes that a coating of some of the wire strands in the cable (as was done at the Tevatron more than a decade ago) will solve this problem at a cost of roughly $\$ 3$ million. Unfortunately, work by WEC on this important topic was recently stopped by 
the SSCL. While the energization rate in the collider is much lower than that of the HEB, there could still be some problem with field quality as a result of the same phenomenon. Presumably it can be controlled without increased costs, but this remains to be shown. If coating of inner coil cable is required for the collider, the cost would be about $\$ 35$ million.

The impact on the collider vacuum of photodesorption of gas molecules by synchrotron radiation is perhaps the most important technical issue remaining to be solved for the SSC design. While recent experiments done for the SSCL at Novosibirsk and Brookhaven have given considerable data, much remains to be done. At worst, we believe the solution would have a net up-front cost of about $\$ 70$ million for a cooled liner at 20 or $80 \mathrm{~K}$. This might be partially offset by operational (power) savings. It v'ould also provide additional flexibility in the event of more beam current being required to achieve the specified luminosity. Such a solution does introduce added complexity to the design, however, and complexity always has reliability implications. In any case, this decision should already have been made as it affects all of the collider magnets and many of the other components as well. This problem must be given considerably higher priority, resources, and vigor by the SSCL so that a decision can be made as soon as possible.

Another issue is the amount of cold testing needed for magnets. Existing experience with superconducting magnets shows good predictions of the magnetic field can be obtained with warm measurements. A total of about 20 percent of the magnets are already planned to be tested cold to check the reliability of such predictions and to gain experience with quench level performance and possible cold vacuum leaks. In any case, the possible need for additional cold testing will be reexamined once initial test data are available and a cost-trade study can be made between individual magnet tests and sector tests made in the tunnel following installation. We believe that the present plan is reasonable and no allowarce was therefore provided for additional cold testing in the EAC.

Finally, there is the question of CDM production costs. The baseline cost estimate contains a production cost per CDM of $\$ 146,400$ (FY $1990 \$$ ). This figure was arrived at by carefully looking at the costs of parts procured by FNAL and BNL, making adjustments for probable changes in design to improve manufacturability and tooling, and then estimating learning curves for each procured component and each assembly operation.

GD presented its current estimates for production costs averaged over the LRIP run to SSCL staff and a member of the review panel on July 21,1993 . Industrial experience in 
a production setting is needed and it is at least a year too early to get a reliable number, but the present estimate is $\$ 270,000$ per LRIP magnet (FY $1993 \$$ ), or $\$ 99,000$ above the baseline cost for volume production (adjusted for expected changes of scope). This estimate has dropped significantly since a joint SSCL/GD task force began working on it a month ago, reviewing methods of procurement, design and specification, and it is expected to be pushed down further. The committee still believes, after reviewing all the material submitted, that it is likely GD will not be able to meet the average baseline volume production cost. Accordingly, we have recommended that $\$ 20,000$ per magnet be added to the estimate at completion. (Following discussions with the subcommittee and using somewhat different methods, the Laboratory's Magnet Systems Division arrived at a similar potential cost increase per magnet.) With this additional $\$ 20,000$ per magnet, the average cost per magnet in volume production would be a factor of 1.4 below that now estimated for the LRIP magnets.

Potential savings should also be discussed. The SSCL proposes to provide all superconducting cable to the magnet vendors as Laboratory Furnished Equipment. This would save about $\$ 50$ million if approved, but dilutes liability for performance deficiencies somewhat. Other sources of significant savings may exist, including possible changes in magnet acquisition strategy.

Finally, a comment must be made on the impact of project organization on cost. While many successful projects deliberately separate those people defining specifications from those executing the project, care must be taken to ensure the necessary integration to allow technical and cost optimization as the engineering designs evolve and are finalized. This requires strong and knowledgeable management to strike the proper balance between the flexibility needed to solve problems as they arise and the discipline to implement a design that is "good enough," rather than make continual improvements. The present organization of SSCL accelerator design and engineering removes the cost responsibility for components from the people who set the requirements. In some cases, this has resulted in difficult-to-attain specifications. Furthermore, the people responsible for the component design and production do not answer directly to the people responsible for the success of the accelerators. This organization, which is neither true matrix, project oriented, nor product oriented is extremely difficult to manage. It also makes design-to-cost methodologies difficult to apply. 


\subsubsection{Scope of Work Associated with WBS 31 and 32}

The cold accelerators subcommittee was charged with examining two WBS 3 Level 2 elements: WBS 31 (High Energy Booster System and Facilities) and WBS 32 (collider). Each of these Level 2 elements has four or five Level 3 sub-elements. The subcommittee examined two of these nine sub-elements.

WBS 311 High Energy Booster (HEB)

WBS 321 Collider

The subcommittee confined itself to the cold components and their cryogenic support systems. The warm accelerators subcommittee analyzed the warm components of the cold machines (see Section 7.3). The conventional construction subcommittee was responsible for conventional construction areas for all machines (see Section 7.6).

The subcommittee's approach was to analyze selected Level 7 sub-elements; namely, those that had the highest cost, those that were thought to present the highest risk, and those that showed the largest increases in the SSCL's recent rebaselining exercise.

\subsubsection{Assessment of Project Status}

Very substantial progress has been made in the SSC superconducting accelerator magnets since the last DOE project baseline review in 1990. The R\&D program in the national laboratories solved the major technical problems recognized at that review. A technology transfer program was initiated to provide the industrial magnet manufacturers with the results of this program. GD and WEC technicians were then used to assemble laboratory-designed magnets for use in the successful Accelerator System String Test (ASST).

There are no fundamental technical issues relating to the cold accelerator systems that have not already been solved in the SSCL R\&D program, at DESY (HERA), or Fermilab (the Tevatron). GD is experiencing technical problems typical of those encountered by newcomers to the field of superconducting accelerator magnets as it moves from laboratory design to manufacturing design. GD has made considerable change to the earlier design and remaining technical issues must be pursued aggressively. 
Costs expended and committed to date were reviewed for six work packages as a sample. Reporting proved reasonably accurate. Because of time constraints, no assessment was made of the value of the cost performed (i.e., whether the percent complete was appropriate). Expenditures to date are small compared to those scheduled for the remainder of the project, so the subcommittee concentrated on the future. It also recognized that a separate evaluation of the Project Management Control System was being performed by the DOE and deferred to that review.

It was difficult to get all the information necessary to make assessments of cost and schedule progress from the management-information systems at the SSCL. The May 1993 SSCL CPR does not accurately reflect the schedule delays shown in the GD CPR provided to the Magnet Systems Division (MSD). The GD report shows a 5-month delay, and the subcommittee estimates that the actual delay to the next significant milestone, delivery of the first preproduction magnet by GD, will be 7 to 9 months. The Committee suggests that SSCL do its best to ensure that GD and WEC not prematurely order material for the preproduction units.

The MSD provided a list of changes in various categories: $\$ 3$ million in approved anc funded orders; $\$ 18$ million in approved but not funded changes; $\$ 15$ million in changes being prepared; and $\$ 157$ million in pending changes. Of these, $\$ 33$ million relate to the imposition of the ASME pressure vessel code. The subcommittee has received only a brief description of each change. A range of $\$ 50$ million to $\$ 150$ million is expected; the most probable value is about $\$ 100$ million. Changes should not be approved without identification of funding. It is suggested that a design-to-cost program be implemented for the CDM program that includes appropriate contractual incentives for GD.

The two types of dipole magnets will be now discussed in great detail because of their cost and impact on the project critical path. Other systems are discussed in less detail.

\subsubsection{Collider Dipole Magnets (CDM) - WBS 321.211X}

The CDMs are 6.76- $\mathrm{T}$ superconducting magnets with 50-mm aperture and nominal lengths of 15 and $13 \mathrm{~m}$. There are $8,428 \mathrm{CDMs}$ in the collider, all but 420 of them are $15 \mathrm{~m}$ long. All of the 50-mm CDMs will be constructed with the same cold-mass cross section. 
These magnets provide a uniform magnetic field within specified limits at a reference radius of $1-\mathrm{cm}$ throughout the magnetic cycle. The magnets will nominally operate at $4.25 \mathrm{~K}$ with a temperature margin of $0.6 \mathrm{~K}$ (equivalent to a field margin of 10 percent). Magnets are being designed to maintain the lattice alignment and quench performance criteria over the 25-year life of the collider, with failures of less than 80 of the installed CDM, including the associated interconnect regions (K.T. Dixon and J. Franciscovich, Supercollider 3 (1991), page 1122). The entire magnet system, including interconnects, has an allocated availability of 0.916 . Interconnects are currently a responsibility of the Accelerator Systems Division (ASD) but are being moved to the MSD; they will be discussed separately.

\section{CDM Status}

The MSD prepared a magnet-acquisition plan by which industry will design and produce all of the 15-m, 13-m, VDO, and VDI dipole magnets. The plan further encompasses a leader/follower concept. Cost plus fixed fee contracts were awarded to GD/WEC on July 12,1991, for the development phase. These contracts include the following elements:

1. Leader (GD) furnishes the design, production tooling processes, and a manufacturing plan for a rate of 10 magnets per day.

2. Follower (WEC) participates with leader and delivers a manufacturing plan for a rate of 10 magnets per day.

To accomplish the above tasks, the following are planned:

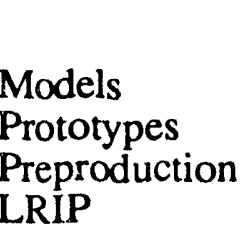

\begin{tabular}{ccc}
\multicolumn{3}{c}{ Leader } \\
\hline Short & $15-\mathrm{m}$ & $13-\mathrm{m}$ \\
4 & 7 at FNAL & -- \\
& 12 & 2 \\
& 35 & 2 \\
& 251 & 8
\end{tabular}

Eollower

15-m

5 at BNL

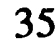

251

The leader will also provide test equipment, tooling, and long-lead material to the follower to accomplish the statement of work as directed by the SSCL, as specified by a contract option. WEC has proposed to design its own tooling, with potential significant savings, but has not received contractual approval. 
Full-length model magnets assembled by both GD and WEC at the national laboratories had generally acceptable performance. Five of the full-length model magnets assembled at Fermilab were used in the successful ASST milestone test. However, the design has been changed somewhat for manufacturability. Of four short models made to the new design, GD completed three assemblies using its labor at SSCL facilities with SSCL tooling. These magnets were tested with poor results on quench performance and multipoles, especially time-dependent multipoles. Analysis of the data indicated that the splice ramp needs redesign and that $\mathrm{AC}$ losses were excessive. These problems must be actively pursued until they are resolved.

The GD facility in Hammond, LA, is being brought on line and tooling is being proofed while processes are developed as the first prototype proceeds along the floor. Two cryogenic test units are ready, but much of the automated equipment is not yet fully functional. The first four prototypes are in the process of being fabricated by GD, with material purchased for seven units. The contract does not provide a delivery date for these units, but vendor reports indicate they are 6 months behind.

The design and analysis effort does not seem to be fully integrated with fabrication of prototypes. This may be due to the physical separation between technical resources in San Diego and the manufacturing facility in Hammond. Many uncertainties exist in design details and fabrication of the prototype units and additional time may be needed to introduce into the prototype test program modifications resulting from experience, test results, and design/analysis effort. Ordering materials for all seven units indicates high confidence level that only minor modifications are expected (and/or is motivated by schedule considerations). LRIP tooling is in the process of being ordered and may also need modifications depending on design evolution.

A Preliminary Design Review (PDR) was held March 1992, at which time authority was granted to proceed with detailed design of the prototypes and to build these units subject to satisfactory resolution of questions raised during this review. Authority also was granted to proceed with preproduction detailed design. It appears that considerably more time and effort was required than expected to resolve the PDR (and other) issues. The detailed prototype design proceeded more rapidly than information from analysis and engineering became available and was driven by the pressure to maintain fabrication schedule. 
The scope of the tooling program has increased significantly. The original tooling family consisted of 26 stations and 40 support tools, while current planning indicates 31 stations ard the support tool count now approaches 200 . It is expected that the majority of this increase in tool number and complexity will benefit overall production efficiency. However, it appears that the production tooling designs are still changing and that tooling costs are significantly understated in the PMB. A cost overrun, over and beyond the $\$ 17$ million scope increase, of approximately $\$ 21$ million has been recognized on the preproduction tooling.

WEC tooling procurements are ready to be placed and facility modifications have been started. Interior and exterior renovation is at a rate to support a February 1994 preproduction start.

The MSD indicated that availability/reliability and field-quality requirements were changed from requirement to goals. This may impact the Level 0 SSC specification of 80 percent availability. While the specified reliability is certainly difficult to meet, and it is prohibitive from the standpoint of cost and time to satisfy the requirement on a classical statistical basis, it does not follow that the methodology should not be followed in all design and analysis activities. No sub-allocation of reliability to components was evident. In reducing magnet costs, care must be taken to ensure that the resulting specifications for materials and components do not violate the reliability requirements.

\section{CDM Cost}

The PMB for the CDMs is $\$ 1,539$ million. SSCL has not performed a bottoms-up estimate on the remainder of activities, particularly the cost of the CDM production magnets. Therefore, the BCE does not reflect any new data or projection of production costs. Although it is likely that another year or two of experience will be required before a significantly better estimate can be prepared, bottoms-up cost estimates should be reviewed on at least an annual basis.

As of May 23, 1993, the CDM cost report shows cumulative expenditures of $\$ 72.302$ million and an overrun of $\$ 19.193$ million. This figure includes all activities of WBS 321.211X, yet it does not clearly show the more dramatic overrun in the GD contract. The GD cost report shows an overrun through April of $\$ 24.907$ million. This overrun increased through the month of May to $\$ 32.744$ million, thereby resulting in a 
53 percent cost variance. The GD overruns occur in most of the WBS elements, but the largest is in the tooling and equipment category. It is attributed to underestimates and to an increase in scope (see discussion under CDM status). The other categories of overrun include the engineering/design effort, indicating underestimates and difficulties in solidifying designs. The negotiations between the SSCL and GD in arriving at their contract may have resulted in cost targets for magnet development that were too aggressive. Further overruns of the contract budget are likely to continue, but the total should remain within the original cost estimate for development according to the Cost Account Manager (CAM).

In June, GD projected a higher material cost for the development phase of $\$ 50$ million, based on the procurement for the first prototype units. SSCL questioned the GD projections and assigned a team to resolve this issue expeditiously. A member of the subcommittee attended SSC/GD mec 'ings at Hammond on July 21, where the progress of an intensive study conducted by combined SSC/GD teams was discussed. These teams are examining designs, specifications, materials, and methods of procuring materials in an energetic and substantive manner. Results are dramatic in terms of potential reductions of cost.

The subcommittee is also concerned about GD's labor estimates. While the labor costs for the coils that have been wound seem reasonable, the labor hours for cryostat assembly are very low based on the subcommittee's own industrial experience. Thus GD will be starting its labor learning curve from a much higher base than it anticipates and will have to work hard to reach its goals.

\section{Future Changes}

Numerous changes to the scope and cost of the contracts with GD and WEC are in various stages of evaluation and implementation. These include several items relating to the beam tube, assumption of responsibility by MSD for the interconnects, heater energy level changes, changes in the requirements for the primary fiducials, and variations to the magnet support system. 


\section{CDM Schedule}

The program was behind schedule before the recent budget-driven perturbations. SSC's evaluation of the overall schedule shows that, as of the end of May, the first article building schedule is delayed by 5 months. We believe that this is an optimistic projection. Additional delays of 2 to 4 months are likely (total of 7 to 9 months).

\section{General Observations}

The collider dipole program is just now entering its most critical phase, the planned construction of first 12 , then 35 , and eventually a group of 251 full-length magnets by both the leader and follower supplier. There are two objectives for this development phase: (1) to veriiy by production and test that all technical difficulties have been resolved, anc' (2) to provide an adequate experience base for the two manufacturers to compete on a fixed price basis for the majority of the required magnets. Adequate time and resources must be allotted to ensure successful completion of this phase.

The leverage of the magnets to be built and tested in this period is truly enormous. At present there is some cost overrun and schedule slippage in this area. It appears that budget pressures will build and may lead to a general reduction of effort, an inability to keep the follower (WEC) current with the leader (GD), and a temptation to "soften" some specifications and requirements. Indeed, some requirements have already been changed to goals.

While this was not intended to be a technical review, it is impossible to ignore the technical status of the collider dipoles. This is an advanced technology; many questions are not yet answered, and it is not simple to quantify the progress in terms of percent complete. Today's accomplishment may turn out to be tomorrow's glar ig error. It is the reviewers' opinion that one cannot tightly estimate the final costs at a time when not a single long magnet has emerged from an industrial production line for testing and evaluation. The time allotted and the number (35) of preproduction magnets may well need to be increased to answer unforeseen questions. 


\subsubsection{High Energy Booster (HEB) Dipole Magnets - WBS 311.2111}

The HEB dipoles (HDMs) are 6.7-T superconducting magnets $13 \mathrm{~m}$ in length with 50-mm aperture. There are 512 dipoles in the HEB. They must be capable of operating at $63 \mathrm{~A} / \mathrm{s}$ ramp rates to meet the normal operating cycle time. They sire to be designed to operate for a 25 -year life time $(160,000$ cycles) with the total number of failures not to exceed five. The HDM has an allocated availability of 0.996 , including interconnects. Inter:onnects are now the responsibility of ASD but are being moved to MSD.

Westinghouse (WEC) is the prime subcontractor for the HEB dipole magnets (as well as being the follower on the collider dipoles). Coils have been fabricated at the WEC facility and SSCL has tested two model magnets with generally good resuits (although the ram:-rate problem is still evident). The WEC cryogenic test facility is on order and being fabricated at CVI. WEC plans to change the insulation on its model magnets to an allKapton system, chosen by GD as the baseline for the CDMs, even though problems have been seen with $A C$ losses at $B N L$ and $G D$. If the same proves true at WEC, there will be a switch back to the Kapton-epoxy system used in the ASST magnets and the first WEC models.

SSC magnets fabricated by the national labs and the industrial vendors since 1991 have been subject to a ramp-rate dependence of magnetic field quality and quench current due to eddy currents in the cable. This dependence is critical to the HEB magnets, which must ramp sixteen times as fast as the collider magnets. A similar phenomenon was seen during the Tevatron construction, and the solution adopted there, "zebra-stripe" cable, was beginning to be explored by WEC. They had planned to wind and test six model magnets with three different cable treatments. Testing was scheriuled to be completed during November 1993. Unfortunately, as a result of a recent funding freeze by SSCL management, only the first three of the six models have been wound; none of these were "zebra-stripe." While the funds involved are small, not vigorously pursuing this problem poses a significant schedule risk and the effort by WEC should be resumed immediately. 
The SSCL prepared a HDM acquisition plan dated March 20, 1991. The Statement of Work (SOW) covers:

1. Full-scale development effort

2. Technology transfer

3. Design

4. Development and implementation of manufacturing processes to produce

- 6 Model Magnets

- 6 Prototype Magnets

- 20 Pre-production Magnets

- 50 Low-Rate Initial Production (LRIP) Magnets

- 462 Production Magnets

The contract was awarded on January 7,1992, to WEC through competitive solicitation. The contract amount was $\$ 85,735,015$ (CPFF) with a period of performance from January 1992 to July 1996, through LRIP (Annex 1). The System Design Review (SDR) met the scheduled milestone date of March 16-17, 1993. Based on the result of SDR, WEC was authorized to proceed with design of prototype.

In addition to the ramp-rate problem, there are several design issues that need to be addressed before the next phase of manufacturing development. They don't seem to be show stoppers, but do present high potential for increasing cost and schedule:

- The collar stress level exceeds yield.

- The cable insulation system is still in question.

- The sub-allocation of reliability to components has not been addressed.

- Thermal and structural analyses are incomplete.

These issues also pose a risk for any tooling that is not easily adaptable to variations in design details. 
Action items need to be resolved and implemented quickly to affect fabrication of models or prototype units. A technical plan for iteration was not visible, and the time span between various reviews and fabrication appears to be too short to affect procurements of parts.

HDM Costs

BCE for HDM production under WBS 1.2.2.1 was $\$ 144$ million in the January 1991 Baseline (Green Book). As the result of a change to the new WBS 311.2121 and corresponding crosswalk, the BCE as of March 24, 1993, is $\$ 156$ million. The crosswalk includes all approved CCBs. There are no bottoms-up estimates of remaining activities available. There are several pending change requests for added funds for contract modification. They cover specification revisions, balance of cold test facility, and authority to produce additional model magnets.

The cost report for May 1993 indicates an overrun of $\$ 417,000$, which represents 2 percent of the cost-to-date ( $\$ 21.8$ million). In view of the current status of design, these overruns will most likely grow.

The current accumulated cost appears to match the technical progress. Any delay in timely resolution of design issues and funding allocations for the next phase of the work at WEC will result in a cost growth. The solution to the ramp-rate problem will most likely result in a cost increase (of roughly $\$ 3$ million) for the superconducting cable used for the inner coils. Interconnect costs will also grow.

\section{HDM Schedule}

The May status report indicates about a 3 percent schedule variance. However, this does not account for any delays in funding and implementation of contract modifications. Overall, the schedule is success oriented. The subcommittee's major concern is in the area of time allocated to implement design modifications as a result of data generated by test programs, changes in requirements, and pending scheduled reviews. There may well be cost and schedule increases due to the modification of parts or scraping of components and adding prototype units to the test program. 


\subsubsection{Collider Quadrupole Magnets (CQM) - WBS 321.2221}

B\&W has accepted the role of the leader, with GD as the follower. Siemens is a supplier of major components to B\&W. The status of schedule and cost (in thousands) through May 1993 is:

BCWS:

BCWP:

ACWP:

$$
\$ 32,619
$$$$
\$ 27,691
$$$$
\$ 34,312
$$

Schedule variance

Cost variance
$(\$ 4,927) \quad 15 \%$ $(\$ 6,620) \quad 24 \%$

The overall program seems to be on track technically. The next few months will be key as four long models are expected to be completed in September 1993, and the first prototype is planned to be tested January 1994. This is clearly a success oriented plan with high risk of slippage. B\&W is projecting a 12-week slip for preproduction readiness, but expects to catch up in time for the production units. The SSCL Product Manager's assessment is that delivery of LRIP units to the tunnel will slip by 1 month to December 1 , 1994.

There has been some cost growth at B\&W and Siemens $(\$ 10.34$ million at completion of the present development contract). Actions have been launched to reduce the impact to the current contract. Major cost impacts in the future are related to change requests for ASME code compliance ( $\$ 2.5$ million), Rev B Spec. ( $\$ 4.2$ million), magnetic alignment equipment ( $\$ 4$ million) and the Follower subcontract ( $\$ 2.9$ million), along with undefined impacts of the 50-mm aperture, Rev $\mathrm{C}$ and the six strut stands. Per the Dugan memo of April 19, 1993, the 50-mm change will cause an 8-month delay and cost \$23.1 million (FY 1990 \$); the memo also lists \$32.2 million (FY 1990 \$) in cost avoidances. Changes to six strut stands and those in $\operatorname{Rev} C$ can have a significant value.

\subsubsection{HEB Quadrupole Magnets (HQM) - WBS 311.2121}

CEN/Saclay has a firm fixed-price (FFP) contract for HQM prototype design and build, with future deliverables of build-to-print design packages and tooling. Production is expected to be awarded to a Small Disadvantaged Business (SDB) on a FFP contract with 
all production magnets to be cold tested at the SSCL's Magnet Test Laboratory.(MTL). The status of schedule and cost (in thousands) through May 1993 are:

$\begin{array}{lllll}\text { BCWS: } & \$ 5,044 & \text { Schedule variance } & (\$ 301) & 6 \% \\ \text { BCWP: } & \$ 4,743 & \text { Cost variance } & (\$ 150) & 3 \%\end{array}$

This program seems to be on track to resolve technical issues. Schedule slippage of 9 months has already been experienced with the current issue of cryostat development limiting progress. The SSCL Product Manager is projecting a 4-month slip in the delivery of the first production magnet. Key challenges for the future will lie in the technology transfer from Saclay/SSCL. This activity has just begun with three SDB companies. Careful attention and resources will need to be applied in the future to have a seamless transition.

Overall, costs have not been a major issue. Saclay has a FFP contract as will the SDB. Future CCB action shows growth driven by ASME code ( $\$ 1.4$ million), Hi-Q Lattice (\$6.1 million) and SDB Tech Transfer ( $\$ 0.8$ million). Several pending CCB items include test equipment ( $\$ 3.1$ million), the strut mounts, and quench protection system, all of which require cost and schedule estimates.

The program seems to be well directed and its status consistent with what has been reported in the reviews.

\subsubsection{Superconducting Cable}

The program of developing and acquiring superconducting cable appears to have been very successful. Very favorable pricing was received in the manufacturing qualification program, and the number of participants was expanded to provide more competition for the large production buys. While there has been a slip of approximately 6 months, sufficient quantities of superconductor will be available to meet the baseline magnet production schedule.

\subsubsection{Cryogenics - WBS 311.1110 and 321.1110}

Cryogenic systems include the helium liquefaction and refrigeration at the surface and at the tunnel level and the lines connecting them. The BCE included transfer lines 
within the tunnel in the cryogenics WBS element, but these will be transferred to the installation WBS elements for the HEB and collider as appropriate. The PMB for cryogenics systems in these WBS elements for the HEB plus collider is $\$ 292$ million.

Technical status is excellent. The group is somewhat behind in preparing procurement packages for subsystems, but there should be no impact on the project schedule.

Cost performance is also good. Firm fixed-price bids have been received for the helium plants, accounting for more than half the cryogenic costs, and are within budget. In reviewing the budget during the rebaselining exercise, the Laboratory's cryogenics group discovered significant omissions, which they estimate as: LN2 re-coolers ( $\$ 14$ million), cold compressor accessories ( $\$ 6$ million), and transfer lines to spools ( $\$ 6$ million). Underestimates on the below grade distribution and end boxes totaled $\$ 10$ million. With miscellaneous omissions and errors, the requested increase is $\$ 46$ million (collider plus HEB). The committee recommends this should be examined carefully and the PMB appropriately adjusted.

\subsubsection{Spool Pieces - WBS 311.1100 and 321.1100}

Spool pieces are significant and complicated cryogenic devices that are installed in both the HEB and the Collider. There are 1918 spools in the collider and 347 in the HEB according to the latest Level $3 \mathrm{~B}$ specification. In addition, although most of the spools are of two very similar types, there are about 300 more complicated special spools that are more costly than the standard design. Spools have a history of undefined requirements and constantly changing baseline. Management needs to aggressively finalize these requirements.

The spool piece program at the present time involves design work at the laboratory in support of two competing industrial design and prototype programs, one at Martin Marietta (MM), the other at WEC. Phase one of this program was to result in the delivery of two standard spools from each of the vendors in the summer of 1993. Optional phases would result in more prototype spools, to be used in the cryo-loop test. This program was put on hold in June 1993. In addition, the Laboratory has designed and is assembling a spool test station. 
Before the program was stopped, the schedule/cost reports indicated that the industrial program was slightly ahead of schedule, and about 50 percent over budget. Examination of the MM and WEC monthly reports show that the cost overrun is due to labor costs, particularly in design work. The delivery schedule for the spools had slipped about 6 weeks for the MM effort, and about 3 months for WEC. This is troubling because it does not show up in the COBRA report.

It is extremely important to actively support this program in that the spool pieces have become a very complex design problem and the estimated cost has shown very large growth. Putting the program on hold at this time greatly increases both the cost and schedule risk.

The work at the SSCL is also behind schedule. This is mostly design work, and the schedule variance is due to not having staffed the group early enough in the program. The recent release of temporary employees will further exacerbate the problem.

The spool test stands are designed and two are almost complete. Four more will be added at a later date for production testing. In the meantime, tests were planned to be done at Brookhaven on the R\&D and pre-production spools. These tests have not been done, and in fact, there is not an orderly program of testing the completed spools or their components. This is very risky, because the spools are technically highly complex. A solid program of testing must be initiated now. The lack of a comprehensive and aggressive testing program is very troubling.

\subsubsection{Interconnects}

Between every collider and HEB cryogenic device there is a cryogenic interconnect, roughly 13,000 in total, consisting of various bellows and other parts. These do not have their own separate WBS element, but are found in parts lists for the superconducting magnets and in the installation kits.

\section{Assessment of Present Status}

The program to design a cost-effective interconnect that meets all of the requirements has been rather confused. For historical reasons, this effort resided in the ASD until very recently. It appears that it is now in the MSD where it logically belongs. 
There have been many cost estimates over the past few years, ranging between the BCE of $\$ 2343$ per interconnect to almost $\$ 20,000$.

\section{Comments on Cost Growth}

The BCE cost of $\$ 30.5$ million was primarily based on vendor quotes and actual costs. It seems to have ignored a few items, such as bellows restrainers, but nothing major was omitted. When the SSCL decided that everything attached to the magnets had to satisfy ASME pressure vessel code and be code stamped, the ASD staff did a revised cost estimate based on the price of code quality bellows, showing an increase of about $\$ 50$ million to a total of $\$ 80$ million.

The interconnect part are mostly bellows. ASME code-stamped bellows are very expensive. In most cases there is no reason to use such a stringent code on these bellows, and, in fact, even the intent of the code is not necessary. If the code requirement is removed, the cost of the interconnect parts should retreat back to about $\$ 4,000$ apiece for standard units (typically twice that for special ones) for a total of about $\$ 65$ million.

\subsubsection{Corrector Magnets - WBS 311.1090 and 321.1090}

The collider and the HEB have a large and complicated set of superconducting correction magnets located in the spool pieces. They are made of thin strand superconductor so that they operate at low currents, less than $100 \mathrm{~A}$.

The corrector program for the collider has been in an R\&D phase up to this point. Over $\$ 13$ million has been spent so far, including between $\$ 3$ million to $\$ 4$ million for a laboratory to fabricate and test prototypes. The CAM for this program estimated that he will spend $\$ 3.2$ million more before the $R \& D$ program is complete, but, because the magnets have not yet worked reliably, and because models of the higher order multipoles have not yet been built, it is the opinion of the subcommittee that the remaining R\&D will cost closer to $\$ 6$ million.

It was recognized early in the program that to make such strong correctors fit into the limited space available in the spools, the design would have to be more efficient than the Fermilab type of random-wound correctors by about a factor of two. It was thought that a 
way to do this was to use ordered or quasi-ordered windings, a relatively new technique that needed considerable R\&D and tooling.

Whether ordered winding is necessary is not totally clear, particularly if Collider requirements on the corrector strengths can be relaxed, which seems to be a possibility. Apparently, there has not yet been a serious negotiation between the engineering staff responsible for the design and cost of the correctors and the scientists in PMO responsible for the requirements. This negotiation should have taken place already; it must take place soon.

There is some hope that a directly wound (on the beam tube) corrector can be built and would avoid some of the cost increase. It seems unlikely that the R\&D for this can be completed in a timely manner or within the R\&D cost estimate. Nor does it seem likely that direct winding will save $\$ 14$ million in production, as claimed.

\subsubsection{IR/UR Magnets - WBS 321.22XX}

There are six WBS elements covering the Interaction Region (IR) and Utility Region (UR) magnets (plus an element for the Laboratory's Make Magnets Product Office). These will be discussed as a group. There are a total of 488 magnets (192 dipoles and 296 quadrupoles) with a total length of $4,391 \mathrm{~m}$. Of these, at least 88 are expected to be fabricated at the SSCL. The others will be designed at the SSCL and fabricated on a "build-to-print" basis in industry.

Work has only recently begun on these magnets. It became quickly clear that the cost for producing these magnets was underestimated in the $\mathrm{BCE}$, as discussed in Section 7.2.7.3.

\subsubsection{PMO Superconducting Accelerator Groups - WBS 311.9300 and 321.9300}

These accounts support the HEB and Collider accelerator groups in the Project Management Office. (The WBS tables have a somewhat misleading name for these accounts, "HEB Acceptance" and " Collider Acceptance.") These are mainly level of effort and were not shown in the 1991 baseline since these groups have been formed more recently. 


\subsubsection{Earned Value}

A meeting was held with selected CAMs for the purpose of assessing the earned values for the following MSD cost accounts:

$\begin{array}{ll}\text { MA-112.0200 } & \text { Magnet Systems Division Management } \\ \text { MJ-321.2235 } & \text { Low Beta Quadrupole Magnets } \\ \text { MB-323.2321 } & \text { Superconducting Cable Research and Development } \\ \text { MA-323.2322 } & \text { SSCL Research and Test } \\ \text { MD-721.2411 } & \text { MDL Equipment and Tooling } \\ \text { MC-721.2412 } & \text { MTL Equipment and Tooling }\end{array}$

Some general questions were asked of the MSD Management for the purpose of understanding how work progress and earned value are determined. The basis of the Budgeted Cost of Work Scheduled (BCWS) is the amount contained in the Performance Management Baseline/Base Cost Estimate (PMB/BCE) with approved revisions made through the Change Control Board (CCB) process. The accounts are made up of work packages which are opened, closed or added through an authorization process above the division level. Funds within an account can be reallocated by the Division Head.

Cost performance reporting commenced in FY 1993. For FY 1992 and prior years, for the MSD cost accounts, the BCWS and BCWP were set equal to the ACWP. Thus, essentially no variances are reported for MSD prior to FY 1993.

The method of determining the work package status, and thus the earned value, is based on estimating the progress or, where possible, on quantitative information or milestones. The status of work is determined on a continuous basis, at least weekly, and forwarded monthly for inclusion in the Monthly Progress Report and the COBRA System. Each CAM receives input from the various responsible section or group leaders, and has a cost and scheduling analyst to assist in calculating the earned value.

CAMs use various methods to determine the work progress. The method for calculating earned value is dependent on whether the work package is considered level of effort (LOE), percent complete, milestone or other type of classification determined best for progress tracking. The work is planned on an annual basis according to the current schedule of work to be performed, and a sheet is prepared at a detailed level, some manually and some computerized, to show how progress will be measured. These sheets are then used to det?rmine an overall percentage of completeness resulting from calculating 
the individual work items (activities) progress on a percentage basis. Where the progress is dependent on achieving certain goals, product quantities or milestones, the earned value is based on the predetermined value of the related work. Credit for earned value on material purchases is somewhat inconsistent and is taken either when the material is delivered or when the invoice is paid. The CAM determines which method will be used for the work packages in his accounts. Subcontractor earned value is reported through their approved cost performance reporting systems as monitored by the responsible MSD manager.

The MSD uses Open Plan for cost reporting. Open Plan is linked to the Integrated Project Schedule (IPS) and to COBRA based on the start and finish clates. Within the MSD, there is a one-to-one correspondence between the activities used to calculate earned value and the activities in the IPS.

Because of the numerous work packages in each of the accounts reviewed during this meeting, it was decided to select several of the largest work packages in each account for an in-depth assessment of the documentation available to support the data supplied for the May 1993 CPR. In viewing that data it was evident that a uniform approach was used by each CAM to determine the work status, so that the sampling obtained would be representative of all work packages in the accounts, with only minor variation. A review of each account indicated that a document existed describing the work to be performed and the budgeted costs for those items. These documents also indicated quantities, milestones and other data to be used to determine the status of the work. The information from those overall annual plans was then used to establish the work measurement worksheets used to calculate the completeness of the work for input to the CPR. The work package authorization also contains the budget information against which progress is assessed and indicates the method by which the earned value will be determined.

The following SSCL personnel were interviewed during the earned value assessment.

Account

112.0200

321.2235

323.2321

323.2322

721.2411

721.2421

\section{CAM}

Q. Washington for D. Clowers

R. Malnar

D. Capone

R. Coombes

J. Thorne

J. Tompkins 
Roger Coombes, Deputy Division Head, was present throughout all of the interviews. Also attending the reviews in support of the CAMs were M. Caracciolo, R. Sims, and G. Rideaus.

Based on the interviews with the CAMs, examination of the supporting documents and worksheets, and assessment of the methods and procedures used to develop work progress and earned values for the referenced accounts, it is the opinion of the subcommittee that appropriate, acceptable methods were used to obtain a reasonable evaluation of the earned value.

\subsubsection{Schedules}

The current dipole schedule through LRIP is at serious risk. The present design/development schedule forces GD to use prototype magnets not only to integrate the production systems at the Hammond facility, but also to solve technical issues that could be better solved with short magnets. The $15-\mathrm{m}$ dipole prototype program and readiness of the Hammond facility are roughly 6 months behind schedule and trends for both cost and schedule indicate further slippage is inevitable.

Design issues (beam tube coatings, $80 \mathrm{~K}$ barrier performance) and programmatic issues (cold test plan validation, production materials' cost) should be resolved independently of the concurrent efforts to bring the Hammond facility on line. Simplifying each problem will ease the management strain and may result in a savings in schedule. Further use of shiort model magnets to provide quick and cost effective turnaround on tests of design changes could also help.

The schedule for the spools program (which is also closely linked to the corrector magnet program) involves a number of issues: change in scope in Phase I contracts with Martin Marietta and Westinghouse, duplicate work being performed in-house and at contractors, work shutdowns due to loss ui funding, a moving technical baseline with increased spools scope over that costed in the PMB baseline, and a chronic shortage of inhouse resources. Increased management attention must be given to finalizing the spool designs and settling these issues.

Generally, schedule risk for the systems examined is high because performance analysis and forecasting capability of the IPS system is hampered by the fact that the PMCS 
and IPS are not yet fully integrated. The overall 1999 schedule for the SSCL would have been difficult to meet.

\subsubsection{Documentation}

- $\quad$ Cost Performance Reports for

-. WEC - CDM

-. WEC - HDM

-- GD-CDM

-. B\&W-CQM

- $\quad$ Status of Magnet Programs - 6/15/93 - Binder-T.O.Bush

- December 1992 CPR - Rees to Cipriano

- $\quad$ SSC Project Monthly Progress Reports (January, February, March, April, May 1993)

- GD Dipole Cost Reduction Presentation

- $\quad$ T. O. Bush Presentation to Diebold, Limon, Kravec - 7/27/93

- $\quad$ SSCL - Change Requests

-- $15 \mathrm{~m}$ CDM 4/23/93 - 5/18/93

-- CQM 4/26/93 - 7/9/93

- GD - Preliminary Analysis - 7/8/93

- GD - Tooling Analysis - 1/29/92

- $\quad$ RFP - Spools - SSC-92-A-11711 \& Revisions (Folder)

- $\quad$ CQM Baseline Design - Joe Waynet - 2/27/93

- $\quad$ ASME Vessel Code Decision Memos - 7/9/91, etc.

- $\quad$ S/C Vendor Qualification Program - D. Capone

- $\quad$ Technical Evaluation of Desorption/Liner Issues for SSC, R. Rosenberg, ANL - 7/21/93

- $\quad$ MSD Tasks - T. O. Bush

- $\quad$ IR/UR Magnets - R. Malnar - 7/20/93

- $\quad$ Dugan Report on 50 mm Change - 4/19/93

- $\quad$ Memos and presentation material on interconnects

- $\quad$ Cryogenic Systems for SSC - W. Fietz

- $\quad$ GD Contract - R. Coombes

- $\quad$ SSCL Plan for Spares - 12/3/91

- $\quad$ CCB Log

- $\quad$ CDM - BOM (Bill of Materials)

- $\quad$ Spool Discussion - R. Smellie

- Two memos:

-- Clower to Bush (BCE allocation for CDM development) (3/10/93)

-- Turner et. al. to Dugan (regarding liners) (7/28/93)

- $\quad$ Independent Assessment of Spool Pieces

- HDM - CDRL-23 - 3/29/93

- CDRL-16 - HEB - Westinghouse

- Quench Data - R. Coombes 


\subsubsection{Risk}

There are no technical "show stoppers" in the cold accelerators. There are potential risks to the collider performance if reliability goals are not met. In addition, there are manufacturing (production) risks and resulting schedule risks in many areas, especially magnets. There is a serious concern about the beam vacuum as a result of photodesorption. The SSCL has an R\&D effort in place to provide the information necessary for a decision, but at a slower pace than required. Photodesorption and other technical issues are discussed in more detail in Section 7.2.8.

\subsubsection{Projected Changes}

Numerous projected changes have been presented. Many were discussed in Section 7.2.3. Others will be discussed below. Only changes with large potential impact were reviewed, and in many cases adequate information was not available.

\subsubsection{Cost (EAC)}

Key recommended cost changes are summarized in Table 7.2.1-1 in the Executive Summary at the beginning of this section. Some of the reasons are further discussed here.

\section{Collider Dipole Magnets}

The committee has analyzed the cost of the Collider Dipole Magnets and has come to the conclusion that the cost for production units should be adjusted from the current BCE by about $\$ 20,000$ per unit. This would increase the estimate to complete by $\$ 160$ million over 8,000 units. 
The reasoning for the increase follows:

$\begin{array}{lccc} & \begin{array}{c}\text { BCE } \\ (\text { FY90\$) }\end{array} & \begin{array}{c}\text { Present } \\ \text { LRIP Projections } \\ (\text { FY93\$) }\end{array} & \begin{array}{c}\text { Committee Estimate } \\ \text { for Volume Production } \\ \text { (FY93\$) }\end{array} \\ \text { Material } & 102 \mathrm{~K} & 141 \mathrm{~K} & 98 \mathrm{~K} \\ \text { Labor } & 23 \mathrm{~K} & 25 \mathrm{~K} & 20 \mathrm{~K} \\ \text { G/A \& Fees } & 20 \mathrm{~K} & 52 \mathrm{~K} & 26 \mathrm{~K} \\ \text { Shipping } & 2 \mathrm{~K} & 2 \mathrm{~K} & 2 \mathrm{~K} \\ \text { Conductor } & \text { in material } & 50 \mathrm{~K} & 45 \mathrm{~K} \\ \text { Subtotal } & 147 \mathrm{~K} & 270 \mathrm{~K} & 191 \mathrm{~K} \\ \text { Adjust for Inflation } & 12 \mathrm{~K} & \mathrm{n} / \mathrm{a} & \text { n/a } \\ \text { Interconnects } & 2 \mathrm{~K} & \text { in material } & \text { in material } \\ \text { Effect of changes } & 10 \mathrm{~K} & \text { included } & \text { included } \\ \text { Total Unit Cost } & 171 \mathrm{~K} & 270 \mathrm{~K} & 191 \mathrm{~K}\end{array}$

The $\mathrm{BCE}$ has been adjusted for the impact of interconnects $(\$ 2.3 \mathrm{~K})$, escalated by 8 percent for inflation from 1990 and a projected $\$ 80$ million in contract changes to GD prorated over 8,000 units $(\$ 10,000)$.

The LRIP costs are still far from firm. As of July 21 , the material costs were still higher then the contract value by about $\$ 30,000$ per unit and GD is working hard to bring these costs down. The labor costs will also become better understood over the next year as experience is gained with the new tooling. The costs for superconductor cable for the prototypes are expected to be higher $(\$ 67,000)$ than the LRIP cost and are expected to be fairly constant by the end of LRIP through the volume production levels due to its learning curve being so fast.

The review committee extrapolated from the LRIP projections that the production cost of CDMs will average $\$ 191,000$ each. It is felt that in volume buys, material will drop by about a third as is expected for the cost of superconductor (from prototype to volume production) to $\$ 98,000$, labor will average $\$ 20,000$ achieving benefits of the automated tooling, G/A will average $\$ 26,000$ as the factory becomes more fully utilized and superconductor cost will average $\$ 45,000$. The net result is an increase of $\$ 20,000$ per magnet and $\$ 160$ million increase over 8,000 magnets at completion.

Motivated by discussions with the subcommittee, MSD did its own rough price analysis which it presented to members of the subcommittee on July 29 . Using somewhat different assumptions led to essentially the same increase per magnet $(\$ 20,900)$ as was developed by the subcommittee. They also analyzed other (non-recurring) potential cost 
increases, as well as possible cost savings, and suggested that the savings may allow them to make up the cost increases (both per magnet and non-recurring).

\section{Collider Quadrupole Magnets}

In 1990, when the current baseline was defined, the difficulties in designing and operating a machine with a mix of magnets with $40-\mathrm{mm}$ and $50-\mathrm{mm}$ apertures was not fully appreciated. Recent analysis indicates that staying with 40-mm quadrupoles would demand changes that cost one third more than changing the quadrupoles themselves. The SSCL recommends, and the reviewers support, increasing the quadrupole aperture.

\section{Special (IR/UR) Magnets}

These magnets were not well defined in the SCDR and were underestimated. The SSCL has now made a new estimate, increasing the cost $\$ 50$ million, which they believe is worst case. The committee made a reality check on the new estimated production costs by comparing to the CQM preproduction run cost estimate, as most of the IR/UR magnets are quadrupoles and the production quantities are similar. The preproduction CQMs are estimated to cost $\$ 17,000$ per meter while the IR/UR magnets are now estimated at $\$ 27,000$ per meter. This difference is much more reasonable, but may be excessive. It was described as an upper bound by the SSCL. Table 7.2.1-1 shows an estimated change of $\$ 30$ to $\$ 65$ million. Given that there are many varieties of magnets and that conceptual design has begun on only one, contingency is recommended at 35 percent. Costs should be minimized by taking advantage of existing designs and experience wherever possible.

\section{Empty Cryostats}

It was not realized in 1990 that all the pipes in the empty cryostats (needed to fill certain spaces between superconducting magnets) would have to be located at the same radial and angular location, and with the same precision, as those in the magnets themselves. As a result, the estimate was low, and an additional $\$ 15$ to $\$ 30$ million will probably be required. The costs for these devices is spread across several WBS Level 7 elements. 


\section{Cryogenics}

Several items were omitted from the baseline, totaling an additional $\$ 42$ million in the worst case. On the other hand, half of the estimate to complete is covered by firm fixed-price bids in hand. With some additional budget ( $\$ 15$ to 30 million) to cover the omitted items, a contingency of 16 percent on the estimate to complete seems ample.

\section{Interconnects}

Accelerator Systems Division has prepared a change request to transfer the task and the funds in the BCE to the MSD. Informal work done in PMO, indicates that an increase in EAC of $\$ 35$ million, to $\$ 65$ million, will be required.

\section{Spools}

The complexity of the spools program was badly underestimated, as described Section 7.2.3.7. SSCL staff have provided estimates of the new cost ranging from a factor of two to a factor of three higher than the BCE. After reviewing the material, the committee chose the low end as reasonable and left contingency high because definition of the special spools, ore third the cost, is still in the conceptual stage.

The baseline and a recent cost estimate fur the collider spools are compared below:

\section{Item}

Spool production (standard) (1540)

Spool production (other and special) (410)

Mid-half-cell spools (1542)

Tooling

Preproduction prototypes

Engineering \& design

QA

IR lattice change (approved)

Escalation since $1990(2.45 \% / \mathrm{yr})$

Total BCE

R\&D (Collider and ASST)

Totals

Cost growth (not including R\&D)

\begin{tabular}{|c|c|}
\hline $\mathrm{BCE}(\mathrm{KS})$ & New EAC $(\mathrm{K} \$)$ \\
\hline$\$ 79,470$ & $\$ 107,800$ \\
\hline 14,148 & 58,610 \\
\hline 2,953 & 0 \\
\hline 2,900 & 3,000 \\
\hline * & 20,050 \\
\hline $10,348 * *$ & 30,050 \\
\hline$\cdots$ & 17,090 \\
\hline 3,354 & -- \\
\hline 8,539 & $\cdots$ \\
\hline $\begin{array}{r}121,712 \\
22,000\end{array}$ & $\begin{array}{c}236,600 \\
--\end{array}$ \\
\hline$\$ 143,712$ & $\overline{\$ 236,600}$ \\
\hline
\end{tabular}

$\$ 115,000$

* Pre-production prototypes are included in R\&D in the BCE.

** QA is included in EDI in the BCE. 
In the cost comparisons, the $R \& D$ prototypes have already been built, and the number ( $\$ 20.050$ million) in the new EAC includes additional preproduction prototypes.

The BCE was based on a different development model, in which the Laboratory designed and prototyped the items, and they were built to print on the outside. In addition, since there was not a detailed design of the machine, the numbers and types of spool pieces were based on a simplified model of ten identical arc sectors, without specific IR regions.

The EAC is based on the detailed Level 3B specifications for the machine and comprises many different types of spools with more stringent requirements. In addition, two competing contractors are involved in parallel development of the spools and construction of up to six preproduction prototype each.

Some cost reductions are possible, such as going from two to one vendor at an earlier stage in the preproduction phase. This might save up to $\$ 12$ million. A more cost conscious design effort might also save money. The new EAC is not a bottoms-up estimate from the vendors, but is a target, although an informed target that the vendors rave been asked to design to. The other and special spools are not even as well based as the standard spools, and the uncertainty in their costs is greater.

Because of the lack of a comprehe 1 sive testing program up to now, and the recent large changes in the cost and design of the spools, it is very likely that there will be unexpected increases in the cost of spools to cover technical problems dissovered late in the development program. The contingency should not be less than 30 percent of the EAC, at this time.

\section{Correction Magnets}

The BCE was based on a model that used the Texas Accelerator Center (TAC) corrector design with a $35-\mathrm{mm}$ aperture. The new estimates are based on an ordered wound coil with a 50-mm aperture aild field strength defined by the Level 3B specification. The main causes of the cost increase are the higher field strength requirements that not only require more superconductor, but have forced a change to an ordered wound design, which is more expensive than random winding. Other cost drivers include the change to $50-\mathrm{mm}$ aperture and a much larger margin, so the magnets are required not to train to reach 
operating current. The present acquisition plan is to build to print on at least two FFP contracts.

In the plan, the low rate production of 25 each of dipoles, quadrupoles and sextupoles are to be complete by July 1994. Considering the amount of R\&D left to do, that date will be hard to meet. Also, it was noted by the committee that octupole and decapoles are not included (explicitly) in the new EAC, so we included twice the amount that was in the BCE for these high-order elements.

The subcommittee believes that some of the field-strength requirements can be relaxed and Table 7.2.1-1 shows an estimated budget increase of $\$ 20$ to 40 million may be required for the magnets.

The baseline and a recent cost estimate are compared below:

\section{Item}

321.1090 Collider Correctors

313.1090 HEB Correctors

Total

Added (by committee):

Octupole, decapole, and other correctors

Cost growth (not including R\&D)

R\&D spent (Collider and HEB)

$R \& D$ remaining
$\mathrm{BCE}(\mathrm{K} \$)$ NewEAC (K\$)

$\$ 38,658$

9,752

$\$ 77,100$

11,200

$\overline{48,410}$

$\overline{88,310}$

2,000

$\overline{\$ 48,410}$

$\overline{\$ 90,310}$

$\$ 41,900$

$13,000 *$

$3,000 * *$

* Already spent. An insignificant amount of Collider or HEB construction money has been spent on correctors.

** CAMs estimate of remaining R\&D effort. Our estimate is $\$ 6,000 \mathrm{~K}$.

The R\&D on this program has been expensive and is, in fact, not yet complete. No bottoms-up estimate by contractors has been included in the cost estimate. The contingency should not be less than 30 percent. 
Power Supplies, Vacuum Systems, Controls/Instrumentation, and Miscellaneous

The small increases are due to better estimates. The sum of the increase in the estimate and the decrease in contingency is close to zero for the four areas.

RF Systems

The SSCL has decided to move the RF power sources to the surface to reduce the amount of excavation and to ease maintenance. The cost increase of $\$ 18$ million for the collider RF technical systems also includes the expected change to a superconducting system. This increases the cost of the technical components but the decrease in operations and civil construction costs will offset this increase.

\section{Installation}

The amount shown was provided by the review group looking at installation, and reflects a major change in scope.

\section{Preoperations}

Manpower allocation to preoperations was determined to be inadequate by the operations subcommittee and the estimate was increased at their recommendation.

\section{PMO Superconducting Accelerator Groups}

Only relatively small amounts are presently shown in the PMB and these accounts must be augmented. In the case of the Collider group, plans (under the assumption of project completion at the end of FY 1999) show a total of 161 man-years over the period FY 1993 through FY 1999. Support from this account would peak at 34 FTEs in FY 1997, and then fall off as preoperations funds would be increasingly used. Taking an effective rate of $\$ 105$ thousand per man-year results in an EAC for the Collider group of $\$ 18$ million, an increase of nearly $\$ 16$ million over the PMB account. This can be compared to the increase of \$15-20 million suggested by the July 19,1993 memo from G. Dugan to G. Haas. 
The subcommittee did not have time to obtain the corresponding plans for the HEB group. In developing its EAC, the subcommittee assumed an increase of nearly $\$ 10$ million (compared to a range of $\$ 10-12$ million shown in the Dugan memo).

\subsubsection{Contingency}

As has been described above, several of the key technical components of the cold accelerators are still in a state of uncertain definition. The spools and corrector magnets are in the early prototype stage. Many of the special (IR/UR) magnets are just entering the conceptual design phase. The magnet industrialization program is somewhat behind schedule and it is too early to have a good estimate for high rate production costs. Depending on initial experience, the cold testing program for various components, including magnets, may need to be expanded. Resolution of the photodesorption/vacuum problem may require a tube liner (see also below) in the collider, at a net cost of up to about $\$ 70$ million. It has been recommended to use superconducting RF for the collider, and this entails some added risk. As a result of all these factors, described in much more detail elsewhere, the subcommittee allocated contingency in the 16-35 percent range on these components. Net contingency on the estimate to complete for the cold accelerators is then $\$ 797$ million in FY 1993 dollars (approximately 19 percent of the "to go" costs).

\subsubsection{Spares}

The subcommittee reviewed the current plans for providing spares for the technical components of the cold accelerators. In reviewing the $\mathrm{BCE}$ and $\mathrm{PMB}$, it was apparent that no provision has been made in the current cost estimate for initial and recurring spares costs. This evaluation was confirmed several times through interviews with the senior management of the MSD. The current intent is to utilize a strategy of Spares Acquisition Integrated with Production (SAIP).

Utilizing the current specifications for the CDM, only 80 failures are anticipated over the 25-year useful life. This equates to less than one percent failures. For the CQMs, only six failures are anticipated over a similar useful life. Prior history for superconducting magnets for existing accelerators suggest that approximately two percent spares are adequate. Prior detailed analysis by the SSCL indicated that a total spares budget of approximately 1.5 percent is sufficient for the superconducting magnets (all types). These 
anticipated spares requirements are highly dependent on the vendor's ability to meet the specified reliability requirements for the CDM and CQM.

This leads to a spares budget of approximately $\$ 25$ million for tus superconducting magnets. WBS elements 31 and 32 include costs for other technical components in the amounts of approximately $\$ 100$ million and $\$ 300$ million respectively. It is anticipated that the spares budget for other technical components within WBS 31 and 32 would be somewhat higher due to lower quantities and somewhat lower reliability. If five percent is used for a spares budget for these components, an additional amount of $\$ 20$ million is generated.

The subcommittee recommends that $\$ 25$ million be added for superconducting magnet spares, and an additional $\$ 20$ million be added for other component spares within the cold accelerators. Thus, a total of $\$ 45$ million should be added to the PMB as a provision for spares for the cold accelerators.

\subsubsection{Open Technical Issues}

As outlined elsewhere in this section, there are several technical issues which remain open. These will now be discussed in more detail.

\subsubsection{Beam-Tube Liner}

Synchrotron radiation from the $20-\mathrm{TeV}$ proton beam is a major part of the $4 \mathrm{~K}$ heat load of the collider and may desorb sufficient gas (mostly hydrogen) from the walls of the beam tuhe to drastically decrease the beam lifetime, and even cause magnet quenching due to heat from beam gas interactions. These effects were recognized as technical challenges from the very first discussions of the SSC, and R\&D programs were started early to understand these issues.

Experiments have been done, and are continuing, to measure the photon-induced desorption coefficient of hydrogen from beam tubes. It was noticed that during a long exposure of the beam tube to photons the base pressure inside the beam tube continued to rise. This was thought to be the result of the desorbed hydrogen sticking weakly to the walls until a significant thickness was deposited, crusing the pressure to rise dramatically. By warming the tube to $20 \mathrm{~K}$ or $40 \mathrm{~K}$, the deposited hydrogen could be pumped out and the 
pressure would decrease. Furthermore, the desorption coefficient would then be somewhat less than it was before, so it would take longer to deposit enough hydrogen to cause trouble.

One solution would be to perform a number of these exposure and clean up cycles until the tube was very clean. Depending on the photodesorption coefficient, this might not be a very satisfactory solution because warming the machine is difficult, pump out is uncertain, and the frequency of warm-up could be high. Further, if collider components had to be replaced, the clean-up process would have to begin anew. Another solution would be to put a perforated liner inside the beam tube, which allows the hydrogen to hide from the beam where it will not get redesorbed. In order to avoid pressure rise as the hydrogen builds up, the temperature of the outer beam tube must be low enough so that the vapor pressure of the hydrogen remains low, or some sort of high surface area adsorber must be included in the beam tube.

A liner of this sort has some nice features and some bad ones. If the liner is cooled at $20 \mathrm{~K}$ or $80 \mathrm{~K}$, the synchrotron power does not get absorbed at $4 \mathrm{~K}$, and so the refrigeration load is much less dependent on the beam current. This would allow one to increase more easily the beam current if necessary to meet machine or experimental goals. This might be necessary to meet the luminosity specification, for example, if the emittance of the beam were not as small as hoped. On the other hand, an actively cooled liner makes the interconnection region and the beam monitoring devices more complex and puts helium gas inside cooling tubes that are inside the beam tube, raising the possibility of catastrophic leaks.

Recent measurements in Russia that were sponsored by the SSCL show a strong dependence of the desorption coefficient on temperature and that desorption at $4 \mathrm{~K}$ (and even $80 \mathrm{~K}$ ) is much less than at room temperature. This contradicts earlier results obtained and published by Bintinger et. al, and also contradicts electron desorption results obtained at SSCL, both of which indicate that room temperature and $4 \mathrm{~K}$ desorption are nearly equal. If the new results are verified, and if one could find the proper combination of material and treatment for the beam tube, one could build a machine with no liner, perhaps with some highly adsorptive material present inside the beam tube. A fall-back position would be a liner that is at the same temperature as the beam pipe, providing a place to hide adsorptive material from the beam. These options are much less costly and less complicated than an actively cooled liner at a higher temperature. 
If the desorption coefficient is not small at $4 \mathrm{~K}$, the machine will not work as presently designed. Even if the desorption coefficient is small, so that the vacuum issue is not a problem, if the energy of the synchrotron radiation is absorbed at $4 \mathrm{~K}$, the machine will be restricted to beam currents less than about $100 \mathrm{~mA}$, unless rather large refrigerators are added to the intermediate service areas, a very expensive solution, both in capital and operating cost.

There is some hope to be able to pre-treat the beam tubes, for example, by scrubbing the surface with an electron beam, and then maintaining them under vacuum at all times, so as to decrease the desorption to acceptable levels.

In any case, a high priority should be placed on quickly obtaining the data necessary to make a decision so that the design of the many affected systems can be finalized. Several members of the subcommittee believe that the solution to the vacuum problem will require a liner.

\subsubsection{Cold Test Requirements}

The subcommittee found that considerable uncertainty currently exists regarding the fraction of the CDMs which will have to be tested to ensure that the magnets will meet the specified reliability requirements. Current plans are to cold test a minimum of ten percent of the high-volume production $15 \mathrm{~m} \mathrm{CDMs}$ at the two magnet vendors (General Dynamics and Westinghouse). In addition, 100 percent of the pre-production and LRIP magnets will be cold tested at the vendor facilities. A large fraction (currently unspecified, but approaching 100 percent) of the CQMs will be cold tested.

The SSCL plans to study the CDM warm measurements to develop an algorithm which can be utilized to predict magnet performance under cryogenic conditions, thereby minimizing the cold testing requirements for the CDMs. For previously constructed superconducting accelerators, standard practice was to cold test 100 percent of the magnets. It should be noted that all magnets will be cold tested in the tunnel following installation in any case. One of the trade-offs that will be considered is the cost of cold testing single magnets at test facilities versus the cost of diagnosing and replacing faulty magnets in the tunnel. 
The planned testing capability is 11 test stands at the MTL (one of which is dedicated to accelerated life cycle testing), four stands at GD, and an additional two stands at WEC. A cold testing facility is planned for the CQM vendor (Babcock \& Wilcox). No capability is planned for the HQM vendor, and the HQMs will be tested at the MTL.

The subcommittee reviewed the current plans for cold testing the four major magnet types (CDM, CQM, HDN, HQM) and compared those plans to the scope contained in the $\mathrm{BCE}$ and the PMB. The following discrepancy was noted:

- The BCE significantly understated the cryogenic facility costs required to support magnet cold testing.

Approximate recurring costs were estimated using the Cost Performance Reports (CPRs) for the magnet vendors. These costs were estimated at approximately $\$ 4,200$ for the CDMs, and $\$ 3,200$ for the other cold magnets. These unit recurring costs, when multiplied by the respective quantities of $8,460(15 \mathrm{~m}$ and $13 \mathrm{~m})$ and 2,374 yield an amount of $\$ 43$ million of additional costs not reflected in the BCE or PMB, which might be required if 100 percent cold testing turned out to be required.

The actual costs incurred for cryogenic facilities and cold test stands to support the MTL exceed the BCE by approximately $\$ 14$ million. These increases are attributable to the addition of six distribution boxes ( $\$ 4$ million) and cost increases for the 10 planned cold test stands at the MTL ( $\$ 10$ million).

If 100 percent cold test is required for the CDMs, it appears that at least 20 additional test stands will be required. While the cost in the BCE is $\$ 300,000$ per test stand, the actual cost per stand including all associated vacuum systems and instrumentation is approximately $\$ 1.5$ million. Thus, an additional cost of $\$ 30$ million would be anticipated. In addition, the cryogenic capability and the MTL facility would have to be expanded dramatically. Rough order of magnitude estimates for these facility costs are approximately $\$ 30-40$ million. This could be reduced to less than $\$ 10$ million for facilities by locating the additional test stands at other ring cryogenic plants, which will be functional but idle at this time. 
In summary, if 100 percent cold testing is imposed, the following cost increases are anticipated:

$\begin{array}{cc}\text { Increased Cost on Existing } & \\ \text { Cryogenic/Test Facilities } & \$ 14 \text { million } \\ \text { Recurring Costs } & \$ 43 \text { million } \\ \text { Additional Test Stands } & \$ 30 \text { million } \\ \text { Expanded MTL/Cryo Fac. } & \$ 10 \text { million } \\ \text { Total } & \$ 97 \text { million }\end{array}$

In addition, it is likely that the 100 percent test requirement would lead to a schedule delay. This delay would be attributable to both the procurement and construction of the expanded MTL/cryogenics facilities and the additional lag required to cold test the individual magnets.

If the curren: 15 percent testing requirement for the high-rate-production CDMs is found to be sufficient, the additional costs for the existing cryogenic facilities ( $\$ 14$ million) inust still be added to the PMB.

\subsubsection{Wire Coating in Collider}

As discussed for the HEB dipsle magnets, the model magnets being built in industry exhibit quench currents dependent on energization rate, commonly called ramprate dependence. This dependence is due to eddy currents which circulate in loops among strands in the superconducting cable. These eddy currents also cause field errors.

The magnitude of the problem appears to be very dependent on the temperature and pressure at which the adhesive system in the dipole magnets is cured. The ASST magnets and the first WEC model magnets were made with an epoxy system which can be cured at $140^{\circ} \mathrm{C}$, while two $15 \mathrm{~m}$ magnets (at BNL) and three models (at GD) were made with a Kapton system requiring $220^{\circ} \mathrm{C}$ cure. The latter have much higher eddy currents and therefore significant degradation of quench current as a function of energization rate. The BNL magnets appear to be acceptable for use in the collider, while the GD models are not. It is assumed that GD will be able to reproduce the BNL process in its factory and produce acceptable magnets for the collider. There is a small question about this, however, because of the differences in their curing presses and heating methods. Fur'her, the adverse effect on field quality, and, in turn, the operational effects on beam emittance and stability, even at the low ramp-rate of the collider, must be fully understood. 
WEC is using the Kapton system in their next model magnets, and may see the same degradation in performance compared to the epoxy system. This must be accepted under the leader-follower concept, as GD is responsible for the magnet design.

An estimate of \$35 million was made for the possibility of using "zebra-stripe" cable (discusser in the HEB section for the collider) in the event the eddy currents cannot be adequately controlled by proper cable insulation and curing. This figure would suffice to make the cable for the inner coil in the collider magnets zebra-stripe.

\subsubsection{ASME Boiler and Pressure Vessel Code}

During the 18th and 19th centuries, many boilers and pressure vessels exploded as a result of the inexperience of their designers. As a result of these failures, guidelines for design evolved and were codified in the U.S.A. in the ASME Boiler and Pressure Vessel Code. This code has continued to evolve; an ultra low temperature sectioni was added about three decades ago as the liquefied natural gas industry developed. It is also applied now to all cryogenic liquefaction and refrigeration plants. Coding a pressure vessel requires that all design calculations be reviewed by an ASME Authorized Inspector (AI) and that each weld in the system be inspected three times, at setup, root pass, and final pass.

The Magnetic Resonance Imaging (MRI) market is the first commercial application of superconducting magnets, and the first having large public contact with cryogenic systems. During the early years of this market, magnets were designed "to the intent" of the ASME code: guidelines in the code as to allowable stress on materials were followed whenever possible, but vessels were not actually coded. Although it was recognized that there would be little or no advantage in safety, for perception reasons, it was later decided to fully comply with the code.

In January 1990, at an SSCL Magnet Systems Integration Meeting (MSIM), the question of coding the SSCL magnets was raised. The DOE invited the SSCL to devise a policy, suggesting one used by the MRI market in the early 1980's: ("to the intent"), and in July 1991, J. Cipriano, Associate Director for the SSC, Office of Energy Research, DOE, wrote E. Siskin, Laboratory General Manager, instructing that such a poiicy be instituted. Mr. Siskin decided instead to implement the full ASME code to all procurements. While 
simpler than defining a more detailed SSCL policy, the cost of this is estimated at roughly $\$ 50$ million.

This is a policy and management issue, not a safety issue. If the magnets and other technical components have been designed with the safety factors in the code, buying commercial grade material versus coded material and using certified welders without three AI inspections will result in negligible incremental risk to personnel safety.

\subsubsection{Conclusions/Recommendations}

The Executive Summary (Section 7.2.1) provides an overview of the cold components and their associated issues. Some specific conclusions and recommendations follow.

The superconducting magnets remain on or near the critical path and are high risk cost driver items. Their manufacturing development should have the SSCL's highest priority in order to reduce this risk to the project as much and as fast as possible. However, several key development programs for the cold accelerators have recently been slowed or halted altogether.

Care must be taken to ensure the necessary integration and communication between those setting the technical requirements and those executing the various systems, in order to allow technical and cost optimization as the engineering and manufacturing designs evolve. This also requires strong and knowledgeable management to strike the proper balance between the flexibility needed to solve problems as they arise and the discipline to implement a design that is "good enough" rather than make continual improvements.

\subsubsection{Recommendations}

1. Resuming vigorous magnet and spool development, including a renewed short model magnet program with more intimate interaction between the vendors and the SSCL, must be given high priority.

2. The SSCL should do its best to ensure that GD and WEC minimize the material which would otherwise be at risk due to schedule variance. 
3. Westinghouse should continue to be developed as a viable competitor on the CDM program.

4. The Laboratory should decide as soon as possible whether or not to install a liner. Outside reviewers should be asked for input to this decision.

5. Work at WEC on the dependence of eddy currents on ramp rate should be resumed immediately.

6. Changes should not be approved without funding. The GD and WEC contracts have been modified to reflect change orders which are pending before the SSCL change review board.

7. Availability and reliability requirements on the CDM and HDM magnets have been changed from requirements to goals on at least some of the early production run. If these requirements are not enforced, the Level 0 specification of 80 percent availability might not be met.

8. The "teaming" arrangement among the several magnet contractors seems not to have eliminated duplication of R\&D as it was intended to do. Duplication should be reduced where appropriate.

9. A firm technical baseline must be established for the spools and the prototype program must be given high priority. Further, a comprehensive and aggressive spool test program must be defined and implemented.

10. The correction magnets require detailed negotiations and trade-offs between PMO and ASD; this should begin as soon as possible.

11. The dipole design development effort should be closely integrated with the GD and WEC facility production floor integration programs.

12. SSCL should continue to closely monitor the magnet manufacturers in areas of cost reduction, design, performance, and schedule. 
13. The applicability of the ASME pressure vessel code should be reviewed in the near future. A cost optimized design of the interconnects (and other systems) should then be pursued vigorously based on appropriate engineering standards.

14. The collider quadrupole aperture should be officially changed to $50 \mathrm{~mm}$ and the corresponding changes made to the quadrupole development program as soon as possible.

15. Trade off studies should be made, including a careful examination of requirements (e.g., field quality, correction magnet strengths, and spool specifications) that might be relaxed without jeopardizing the high-level specifications of the project. 


\subsection{Resistive Accelerators}

\subsubsection{Executive Summary}

The Warm Accelerator subcommittee found that the warm accelerators are progressing well, but have fallen a year behind the baseline schedule. Although no major technical problems were uncovered, there are concerns about the LEB Radio Frequency (RF) Acceleration System and the control system. The LEB RF Acceleration System prototype cavity failed to reach its design voltage during test, which indicates that more cavities will be needed to meet machine acceleration requirements. A concern exists that the current control system will not meet operational requirements. A top level controls requirement document, along with a clear development plan, is essential to mitigate this concern. The subcommittee found that $\$ 68.6$ million additional dollars will be needed to complete the warm accelerators. This increase is based on better engineering estimates and experience to date.

The Warm Accelerator subcommittee's charter was to determine the status of the warm accelerators [Linear Accelerator (Linac), Low Energy Booster (LEB), and Mediun Energy Booster (MEB)], Test Beams and Global Systems. Initial review showed a cross cut correlation across the warm and cold accelerators among the controls, instrumentation, power systems, safety, vacuum, warm magnets and RF systems. This simmary repuri is hased on teswiked remons prepared by subcommittee members and SSCPO staff, which

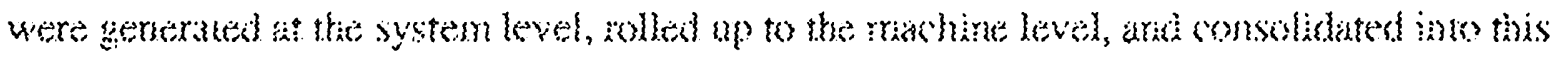
sism:mary. A strong interdisciplinary team of accelerator physicists and engineers from the Department of Energy (DOE), Fermilab, Brookhaven National Laboratory (BNL), Argonne National Laboratory (ANL), Stanford Linear Accelerator Center (SLAC), and the Continuous Electron Beam Accelerator Facility (CEBAF) interviewed members of the Superconducting Super Collider Laboratory (SSCL) staff and wrote detailed reports giving their findings. The subcommittee obtained sufficient information to confidently determine the status of the sections of the SSC project within each Warm Machine Leader's and Cost Account Manager's (CAM) area of responsibility.

\subsubsection{Scope of Work}

The scope of work was reviewed with the Machine Leaders and the CAMs. Both the Machine Leaders and the CAMs were found to be knowledgeable and in agreement with 
the scope of work assigned to his/her area of responsibility. The exception was Global Systems; although some broad areas of responsibility are sketched, much needed detail is missing. The Global Systems WBS descriptions need refinement.

\subsubsection{Assessment of Project Status}

\subsubsection{Technical}

WBS Item Status

$21 \quad$ Linac

The upstream end of the Linac, from the $\mathrm{H}^{-}$source through the Radio Frequency Quadrupole, is being tested with beam. (The $\mathrm{H}^{-}$source now being used will be replaced.) Orders for all of the major components have been placed. No significant problems have surfaced. None are expected.

22

LEB

Progress is good in general. One problem has been identified. The prototype RF cavity does not meet the design specification for gap voltage.

$23 \quad$ MEB

In the design phase. So far, no significant technical problems.

31.xxxx HEB-warm See cross-cut data.

32.xxxx Collider-warm See cross-cut data.

Global Systems Barely started. This part of the project is not well defined. Major items are covered in cross-cut data below.

56

Test Beams No problems so far.

Cross Cut Data: This is a summary assessment of systems that were used on multiple machines (hence the name cross-cut) and includes cold machines to the extent identified.

X.1060 Power Systems In design. The quality of the design and specification work was found to be high. A reliability analysis is currently being planned to identify reliability concerns in the Quench Protection System. 
X.1070 Dipoles

X.1080 Quadrupoles

X.1090 Correctors

$\mathbf{X} .1120$

RF System

LEB RF

MEB RF

HEB RF
The engineering portion of the task is about half complete. Commitments have been made for 60 percent of the procurements. No significant problems should be encountered. These magnets do not require new techniques. Potential savings may be reduced due to U.S. Customs Department duties imposed by having the magnets built through foreign collaboration. Magnets being built abroad through interiaboratory agreements have the potential for delayed delivery.

The engineering portion of the task is about half complete. Commitments have been made for 60 percent of the procurements. Potential savings may be reduced due to U.S. Customs Department duties imposed by having the magnets built through foreign collaboration. Magnets being built abroad through interlaboratory agreements have the potential for delayed delivery.

This task is well along. Some redesign was deemed necessary and has been accomplished. Three-quarters of the engineering is complete and half of the hardware has been ordered. These magnets do not push the state-of-the-a. and few problems should be encountered with them. Potential savings may be reduced due to U.S. Customs Department duties imposed by having the magnets built through foreign collaboration. Magnets being built abroad through interlaboratory agreements have the potential for delayed delivery.

The overall design looks good. However, the cavity RF tuner experiences arcing inside the tuner at 63 percent of design voltage. If this problem cannot be solved, more $R F$ stations will possibly be required in order to meet the RF system accelerating-voltage specification.

The design and prototype work are almost complete and no significant problems have been encountered. None should be. The design is straight-forward. The number of RF stations has dropped from 12 to 10 cavities.

Little work has been done to date. This RF system is the simplest one in the rings. It will use much of the technology developed for the LEB and MEB. No significant problems are anticipated. 
Collider RF Several flaws with the baseline design have been uncovered. They are: 1) the Collider RF system as presently designed has no redundancy. A single failure will disable the Collider, 2) the klystron gallery will be inaccessible when the HEB is operating due to radiation; and 3) there is insufficient higher-order mode damping with the present cavity configuration. In order to rectify these problems, a recommendation to use superconducting cavities, with their klystrons located in a surface building, has been forwarded to the Change Control Board. This solution should fix all three problems.

X.1140 Vacuum

There are no major problems. The design criteria are understood. The designs for the various machines and transport lines are fairly well in hand. The failure of one supplier to deliver ceramic beam tubes for the LEB is annoying, but should not cause any real schedule slippage.

X.1180 Instrumentation The original assumption that many of the Fermilab designs could be used at the SSC turned out to be invalid. This task, therefore, is much larger than originally envisioned. Effort has been expended in developing an instrument facility and organization. This has largely been accomplished. While this activity has been going on, progress on design, development, and procurement of the required instrumentation has been slowed.

X.1190 Controls There has been good progress on the controls for the Accelerator Systems String Test (ASST) and the Linac. Very little progress has been made on the controls for the other machines. The are serious doubts that the current design will meet operational requirements.

X.1200 Safety Systems There is a Safety System operating at the ASST. As far as the complete system is concerned, the perceived scope of work has changed from the baseline due to the incorporation of additional monitoring functions. No reason was found to be concerned about the adequacy and safety of the system.

\subsubsection{Cost to Date}

$\begin{array}{rlrr}\text { WBS } & \text { Item } & \frac{\text { ACWP }}{(\$ M)} & \frac{B C W P}{(\$ M)} \\ 21 & \text { Linac } & 45.9 & 41.7 \\ 22 & \text { LEB } & 23.6 & 23.7 \\ 23 & \text { MEB } & 10.2 & 9.6 \\ 41 & \text { Global Systems } & 19.2 & 18.4 \\ 56 & \text { Test Beams } & 1.4 & 1.7\end{array}$

Note: ACWP - Actual Cost of Work Performed; BCWP - Budgeted Cost of Work Performed 


\subsubsection{Schedule (Actual Percentage Complete)}

$\begin{array}{llll}\text { WBS } & \text { Item } & \text { Status } & \text { Comments } \\ 21 & \text { Linac } & 35 \% \text { complete } & \text { Engineering estimate } \\ 22 & \text { LEB } & 25 \% \text { complete } & \text { Engineering estimate } \\ 23 & \text { MEB } & 5 \% \text { complete } & \text { R\&D more than } 60 \% \text { complete } \\ 31 . x x x x & \text { HEB-warm } & 5-7 \% \text { complete } & \text { See cross-cut data } \\ 32 . x x x x & \text { Collider-warm } & 15 \% \text { complete } & \text { See cross-cut data } \\ 41 & \text { Global Systems } & 10 \% \text { complete } & \text { Not well defined } \\ 56 & \text { Test Beams } & 5 \% \text { complete } & \end{array}$

Cross-Cut Data: This is a summary assessment of systems that were used on multiple machines (hence the name cross-cut) and includes cold machines to the extent identified.

$\begin{array}{llll}\text { X.1060 } & \text { Power Systems } & \text { In design } & \text { Design is 65\% complete } \\ \text { X.1070 } & \text { Dipoles } & \begin{array}{l}\text { Engineering is } \\ 50 \% \text { complete }\end{array} & \text { LEB magnets in prototype test } \\ \text { X.1080 } & \text { Quadrupoles } & \begin{array}{l}\text { Engineering is } \\ 50 \% \text { complete }\end{array} & \text { LEB magnets in prototype test } \\ \text { X.1090 } & \text { Correctors } & \begin{array}{l}\text { Engineering is } \\ 75 \% \text { complete }\end{array} & \end{array}$

X.1120 RF System

$\begin{array}{lll}\text { LEB RF } & \begin{array}{l}\text { Construction 10\%; } \\ \text { R\&D 80\% }\end{array} & \begin{array}{l}\text { Significant additional R\&D may } \\ \text { be required }\end{array} \\ \text { MEB RF } & \begin{array}{l}\text { R\&D 60\%; } \\ \text { construction 3\% }\end{array} & \text { Prototype almost complete } \\ \text { HEB RF } & \text { R\&D 10\% } & \end{array}$

Collider RF -
X.1140
Vacuum
$4 \%$ complete
X.1180 Instrumentation $15 \%$ complete
X.1190 Controls
X.1200
Safety Systems
Linac and LEB in prototype; others no work
Controls operating the ASST;
Linac is $50 \%$ complete; $0 \%$ for all other machines
Linac is $40 \%$ complete; other systems average $4 \%$ complete 


\subsubsection{Changes}

There are two approved changes not reflected in the baseline. The Low Conductivity Water (LCW) change for the resistive accelerators has been approved. The use of contingency funds for this change have been approved by the Project Director. The second approval action is a design change in the Global Systems area.

\subsubsection{Plan to Complete}

\section{WBS Item Plan to Complete}

$21 \quad$ Linac

This assessment estimates that the Linac will be operating by October 1995, a year behind schedule. Most of the major subsystems not now on hand will be acquired as Build-toSpecification items. A few will be acquired as Build-to-Print items. The cavities for the Drift Tube Linac (DTL) are being built by a U.S. company. The modules for the Coupled Cavity Linac (CCL) are being built under an inter-laboratory agreement with China.

(2)

This assessment estimates commissioning to start by October 1995. Most major subsystems will be acquired as Build-toPrint or Build-to-Specification items. These items include the dipole and quadrupole magnets that will be built in Russia through an inter-laboratory agreement.

3 MEB

This assessment estimates commissioning to begin by June 1996. Most major subsystems will be acquired as Build-toPrint or Build-to-Specification items. These items include the dipole and quadrupole magnets that will be built in Russia through an inter-laboratory agreement, as well as the correctors which are being built in China. The Russians are also building the RF cavities.

The planning is incomplete in this area. The scope of work needs to be defined before detailed planning can begin.

Test Beams

This assessment calls for the Test Beams to be completed by January 1, 1997. Most major subsystems will be acquired as Build-to-Print or Build-to-Specification items. The exception is the electrostatic septum, which is part of the MEB extraction system. This specialized device will be built in-house. 


\subsubsection{Interfaces}

The various machine interfaces are well understood. There are some undefined interfaces between subsystems. For specific interface information refer to detailed machine reports prepared by subcommittee members and SSCPO staff.

\subsubsection{Documentation Reviewed, Contacts Interviewed}

\subsubsection{Documentation Reviewed}

Common Documents Used by All Subcommittee Subgroups

1. $\quad$ SSC Project Monthly Progress Report (CPR), May 1993.

2. SSC Work Breakdown Structure (WBS) Detail Dictionary, with LINAC Additions (Rev 2--August 5, 92), DOE 1332.1A.

3. CAM WBS RAM - May 3.0A.

4. WBS EC RAM - May 3.0A.

5. Subcommittee 3 Summary Notebook: Reports, Interview Notes, and Cost Information.

Linac Systems

6. Specification Trees for the SSC, E10-000051 Rev B, February 15, 93.

7. SSCL Change Cost Schedule Request, LCW System Changes for the Linac, LEB, MEB, and Test Beams, 11/6/92, E12-0000120.

8. Status of the SSC, D.E. Johnson, May 93, SSCL Pre-print 343.

9. Interview Notes, Machine Leader: Warren Funk, 7/14/93.

10. Interview Notes, Machine Leader: Warren Funk, 7/22/93.

11. WBS Growth Spreadsheets, Warren Funk, 7/22/93.

\section{Low Energy Booster}

6. CPR Sort, Functional Categories

7. SSCL Change Cost Schedule Request, LCW System Changes for the Linac, LEB, MEB, and Test Beams, 11/6/92, E12-0000120.

8. Current Status Evaluation Plan, Subcommittee 3, 7/13/93.

9. Generic Questions, Subcommittee 3.

10. Interview Notes, Machine Leader: Uli Wienands, Systems Engineer: Tom Webster.

Medium Energy Booster

6. Specification Trees for the SSC, E10-000051 Rev B, February 15, 93.

7. SSCL Change Cost Schedule Request, LCW System Changes for the Linac, LEB, MEB, and Test Beams, 11/6/92, E12-0000120.

8. Rational for Changes, WBS No.231.1190AB.

9. Rational for Changes, WBS No.231.1130.

10. Interview Notes, Machine Leader: Rod Gerig. 
High Energy Booster

6. Specification Trees for the SSC, E10-000051 Rev B, February 15, 93.

7. Computer Aided Performance Analysis System (CAPAS), 1.0 Run, 07/05/93.

8. Interview Notes, Machine Leader: Victor Yarba.

\section{Collider}

6. Specification Trees for the SSC, E10-000051 Rev B, February 15, 93.

7. Computer Aided Performance Analysis System (CAPAS), 1.0 Run, 07/05/93.

8. Interview Notes, Machine Leader: Rainer Meinke.

\section{Global Systems}

6. SSCL Site-Specific Conceptual Design, SSCL-SR-1056, July 1990.

7. Memorandum, Formation of a Global Controls Machine Group, June 14, 93, Tom Dombeck.

8. Interview Notes.

\section{Test Beams}

6. Status of the SSC, D.E. Johnson, May 93, SSCL Pre-print 343.

7. SSCL Change Cost Schedule Request, LCW System Changes for the Linac, LEB, MEB, and Test Beams, 11/6/92, E12-0000120.

8. Interview Notes, Machine Leader, J.McGill, 7/16/93.

\section{Power Systems}

6. Acquisition Plan for SSCL Ring Magnet Power Systems (RMPS), R.A. Winje, $5 / 29 / 92$.

7. Project Leaders Meeting - Procurement Plans for the Ring Magnet Power Systems, R.A. Winje, 3/17/92

8. Preliminary Design Requirements Review (PDRR) for LEB RMPS Supervisory Control System (SCS), E13-000129, April 30, 92.

9. RMPS Advance Acquisition Plan, AEB-8060014, 6/30/92.

10. Ring Magnet Power System Level 5 Specifications.

AEB-8060023, 1/26/93

AEB-8060002, Rev 3, 3/19/93

AEB-3060003, 9/23/91

AEB-8060003, Rev A, 1/10/92

AEB-8060004, Rev A, 5/12/92

AEB-3060059, Rev A, 9/23/92

AEB-8060024, Rev A, 2/12/93

11. RMPS Preliminary Design Review LEB Synchrotron Package, 4/92.

12. Specification Trees for the SSC, E10-000051 Rev B, February 15, 93.

13. Work Packages Work Authorization for WBS 231.1060, MEB Power System, R.A. Winje, 5/23/93.

14. Electrical Engineering Organization Chart, OBS:AEYY, 7/15/93.

15. MEB DC Power Circuit Design Work Package, AC 2311060 10BP AEB DC.

16. Analysis of Design Packages, May 28, 93.

17. Accelerator Systems Division, Electrical Engineering, Technical Reviews, Status as of July 21, 1993.

18. Memorandum, RMPS Work Packages, 3/31/93, R.A. Winje to RMPS Work Package Managers. 
19. Level IV Specification for the Quench Protection System for the Collider, AEC6060227, DRAFT, March 22, 93.

20. Interview Notes.

Warm Magnets: Dipoles, Quadrupoles, Correctors

6. Interview Notes.

\section{RF Systems}

6. Interview Notes, Jim Ferrell, Jim Curbow, and Jimmy Rogers, 7/20/93.

Vacuum

6. Design status of LINAC Vacuum Subsystems/Comiponents.

7. Drawing Tree, LEB Vacuum Chamber Assembly, WBS 221.1140.

8. Interview Notes, Frank Spinos, 7/20/93.

\section{Instrumentation}

6. Beam Instrumentation Department Organizational Chart, revised 7/. 2/93, Webber.

7. Beam Instrumentation Department Head Count, Jan 91 - Apr 93.

8. ASD Beam Instrumentation Department Cost Accounts, Webber, 07/20/93.

9. Memorandum, Request for Estimate for One Time 'Start-up Costs', with attached Cost Accounts Summary, July 22, 93.

10. SSCL Site-Specific Conceptual Design, SSCL-SR-1056, July 1990.

11. Interview Notes.

\section{Controls}

6. Memorandum, Formation of a Global Controls Machine Group, June 14, 93, Tom Dombeck.

7. Reasons (Excuses) for Growth in Costs for Controls WBS Elements, 7/22/93, Dave Gurd.

9. Cost and Schedule Department Contact List, 7/7/93.

10. Memorandum, Letter identifying SSC Laboratory contacts, with attached Points of Contact list, July 7, 93, Roy Schwitters.

11. Global Accelerator Controls Preliminary Design Requirements Review (PDRR), September 10, 92 .

13. SSCL Site-Specific Conceptual Design, SSCL-SR-1056, July 1990.

14. Interview Notes.

Safety Systems

6. Level 4 Specification for the LINAC Safety Systems of the SSCL, WBS No. 211A130, AQA-2200605, 11/23/92.

7. Cost and Schedule Summary Information for Safety Systems, Robert Landis, July 20, 1993.

8. SSCL Site-Specific Conceptual Design, SSCL-SR-1056, July 1990.

9. Interview Notes. 


\subsubsection{Interviewee List}

Linac Systems: Warren Funk, Gordon Leifeste

LEB: $\quad$ Uli Wienands, Tom Webster

MEB: $\quad$ Rod Gerig

HEB: Victor Yarba, Pete Kocur

Collider: Rainer Meinke, Fred Hekking, Bill Baer

Global: $\quad$ Tom Dombeck, Tom Ellioff

Test Beam: John McGill

Power Systems: Russ Winje, Frank Spinos, Bruce Kling, Bobby Abel

Magnets: Wamer Heilbrunn Schulze

RF Systems: Jimmy Rogers, Jim Farrell, Jim Curbow

Vacuum: $\quad$ Frank Spinos, William Turner

Instrumentation: Bob Webber

Controls: Jay Heefner, Dave Gurd, Rolf Bork, Steve Hunt, Surajit Sarkar, Rainer Meinke, Victor Yarba, Rod Gerig, Uli Wienands, Warren Funk

Safety Systems: Robert Landis

\subsubsection{Assessment of Plan to Complete}

\subsubsection{Risk}

This section is summarized from the individual machine and subsystem reports.

WBS Item Technical Risk

21 Linac None

22 LEB The gap-voltage specification for the RF cavity may not be met

23 MEB None

41 Global Systems Definition of the control system is insufficient.

56 Test Beams None 
X.1600 Power Systems None

X.1070 Dipoles None

X.1080 Quadrupoles None

X.1090 Correctors None

X.1120 RF System

$\begin{array}{ll}\text { LEB RF } & \text { Cavitie } \\ \text { MEB RF } & \text { None } \\ \text { HEB RF } & \text { None }\end{array}$

Collider RF May have to change to fully-damped, single cell copper cavities or superconducting cavities

X.1140 Vacuum None

X.1180 Instrumentation None

X.1190 Controls Definition of the control system is insufficient

X.1200 Safety Systems None

\subsubsection{Projected Changes}

Additional RF stations in the LEB. Reduced number of RF stations in the MEB. Additions, such as site-wide environmental monitoring and radiation material handling, are expected in the Global Systems area. Risk mitigation is expected to be handled with change orders.

\subsubsection{Cost (EAC)}

(Dollars in Millions)

\begin{tabular}{|c|l|c|c|c|c|c|}
\hline WBS & \multicolumn{1}{|c|}{ Item } & BAC & $\begin{array}{c}\text { Cost To } \\
\text { Date }\end{array}$ & $\begin{array}{c}\text { Estimate To } \\
\text { Complete }\end{array}$ & EAC & Contingency \\
\hline 21 & Linac & 76.4 & 45.9 & 51.6 & 97.5 & 5.4 \\
\hline 22 & LEB & 76.1 & 23.6 & 71.5 & 95.2 & 7.1 \\
\hline 23 & MEB & 184.7 & 10.2 & 203.0 & 213.2 & 17.5 \\
\hline 41 & Global Systems & 121.2 & 19.2 & 212.7 & 231.9 & 53.7 \\
\hline 56 & Test Beams & 38.1 & 1.4 & 36.9 & 38.3 & 5.0 \\
\hline
\end{tabular}


The following is a summary of the major cost growth drivers:

WBS 2 Resistive Accelerators - Total Projected Growth $=\$ 68.6$ million

- Reason for Growth:

- Controls \& controls integration - task is now better scoped, but there has been limited progress. $\left(^{*}\right)$

- Instrumentation - designs from other laboratories are not applicable, as was originally assumed. $\left(^{*}\right)$

$\left.{ }^{*}\right)$ Total cost impact for controls plus instrumentation $=\$ 15.5 \mathrm{M}$

- Installation - this item is addressed in another section of this report. (\$8.1M)

- RF - problem with original design, mainly LEB. ( $\$ 3.5 \mathrm{M})$

- Power systems - change in installation requirements. (\$3.0M)

- Engineering Design, Inspection, Acceptance (EDIA) - better estimate of time and manpower required. $(\$ 3.7 \mathrm{M})$

- Magnets. (\$4.8M)

- Utilities/Vacuum (mainly LCW). ( $\$ 4.0 \mathrm{M}$ )

- Other - changes are spread out in small amounts in all of the lower level WBS elements. $(\$ 27.0 \mathrm{M})$

WBS 41 Global - Total Projected Growth $=\$ 110.6 \mathrm{M}$

- Reason for Growth:

- Clarification of the requirements for a global controls system $(\$ 41.5 \mathrm{M})$

- No provision in the original budget for applications software (\$12M)

- Site-wide environmental monitoring systems were not included in the original estimate. ( $\$ 6.3 \mathrm{M})$

- No provision for the handling of radioactive material was made in the original estimate. $(\$ 10 \mathrm{M})$

- The remaining increase is in installation and is addressed in another section of this report. 


\subsubsection{Schedule Slip}

$\begin{array}{llccl}\text { WBS } & \text { Item } & \frac{\text { Slip from Baseline }}{\text { (Months) }} & \frac{\text { Worst Case Slip }}{\text { (Months) }} & \text { Comment } \\ 21 & \text { Linac } & 12 & 12 & \\ 22 & \text { LEB } & 6 & 12 & \begin{array}{l}\text { Due to RF } \\ \text { Instrumentation is } \\ \text { the driver. }\end{array} \\ 41 & \text { MEB } & 6 & 12 & \begin{array}{l}\text { Tied to the machine } \\ \text { schedules. }\end{array} \\ 56 & \text { Global Systems } & -- & -- & \end{array}$

\subsubsection{Conclusions/Recommendations}

The assessment in this report is based on 1 week's work by this subcommittee. A coordinated management review should improve the focus and accuracy of the numbers in this report. In most cases the increase inintified was recommended by the CAMs and accepted by the review team. Strong management focus is needed to bring the final project in at the accepted budgets.

The subcommittee's assessment is that the work performed to date correlates well with the money spent and is of high quality. The technical risks are small (i.e., no project impacting issues were uncovered). The LEB RF System poses a technical risk, and therefore warrants a focused attack.

The warm machines and their associated systems are about 1 year behind the baseline schedule. The subcommittee has determined that this schedule slip is real and should be reflected in the project plans.

- A substantial cascaded schedule slip, with the completion dates for the HEB and the Collider delayed by one or more years from the completion of the MEB, would allow prototyping of systems, such as the control system and power systems, to be evaluated before committing extensive resources. An assessment of this scheduling approach should be made.

The EAC for the warm accelerators and Global Systems exceeds the current budget. The subcommittee has identified increases of approximately $\$ 180$ million across all WBS elements reviewed. 
Much of the budget growth can be attributed to Global Systems, Instrumentation, and Controls.

- The growth in the budget for instrumentation is a result of a recognition that the original assumptions used in the baseline were flawed.

- Controls is an area that merits special attention. The original definition of the controls scope of work was insufficient for the task as presently understood. The controls identified in many subsystems need to be integrated into the lab wide controls philosophy and a systems assessment established. Also industry experience needs to be applied to the controls solution.

- Global Systems has become a "catchall" for efforts not considered elsewhere in the SSC project. It is imperative that the scope of work be well established and a clear cost basis be determined.

One of the areas that should be included in Global Systems is the development of a maintenance program, including a spares program. We found limited spares funding in the present planning. We found no planning for maintenance and spares support for the ongoing program. No cost for spares are included in this report. It is strongly recommended that a spares program be initiated. 


\subsection{Detectors}

\subsubsection{Executive Summary}

The dominant features of the SSC scientific facilities are two large detectors: GEM (\$551 million in FY 1993 \$), proposed by the Gammas, Electrons, and Muons Collaboration, and SDC ( $\$ 625$ million), proposed by the Solenoidal Detector Collaboration. Both detectors have progressed well technically and managerially, although their construction would benefit from a 1- to 2-year stretchout beyond the 1999 completion date. The 1991 Baseline Cost Estimate assumed that significant foreign contributions would fill the gap between the \$594 million PMB allowance in WBS 52 and the total cost of these detectors. Foreign contributions now appear unlikely to be able to cover the full difference. Consideration of various proposals for smaller experiments is being planned for late 1994; $\$ 79$ million (WBS 523) is allocated for their support, but is vulnerable to possible cost transfers to other elements, such as project coordination (WBS 57). Efforts that support the detectors, such as Detector Off-Line Computing (WBS 53), Detector Engineering Support (WBS 55), and Physics Research Division Coordination (WBS 57), are by and large in good order, although WBS 57 has experienced a difference between funds requested from the DOE Division of High Energy Physics and funds actually provided. Experimental facilities (WBS 54) are discussed in the section on conventional facilities (Section 7.6).

\subsubsection{Introduction}

The primary mission of the SSC is to produce, detect, record, and analyze protonproton collisions with a center-of-mass energy of $40 \mathrm{TeV}$ in order to test the predictions of the Standard Model in this new, unexplored domain of spacetime and, more important, to seek new and unexpected physics phenomena beyond the Standard Model. The instruments (detectors) that record the collisions, and the associated facilities that are needed for the study of the collision products, are essential for the SSC. They are included in Experimental Systems, WBS elements 51-57. These elements include the following: 


\begin{tabular}{llccc} 
Element & \multicolumn{1}{c}{ Description } & $\begin{array}{c}\text { PMB } \\
\text { (FY93 \$M) }\end{array}$ & $\begin{array}{c}\text { \% Complete } \\
\text { Based on PMB }\end{array}$ & $\begin{array}{r}\text { Committee } \\
\text { (FY93 \$M }\end{array}$ \\
\hline WBS 51 & Detector R\&D & 41.3 & 90 & 41.3 \\
WBS 52 & Detectors & 676.3 & 10 & $1239.0^{*}$ \\
WBS 53 & Det. Off-Line Computing & 80.0 & 15 & 80.0 \\
WBS 54 & Det. Halls and Facilities & 154.5 & 4 & 168.4 \\
WBS 55 & Det. Engineering Support & 74.9 & 20 & 74.9 \\
WBS 56 & Test Beams & 38.1 & 5 & 38.3 \\
WBS 57 & Phys. Research Div. Coord. & 9.3 & 100 & 26.3
\end{tabular}

* Note that the $\$ 1239$ million subcommittee estimate covers the full cost of the detectors, based on U.S. cost estimating rules, independent of the actual source of funding. The PMB cost, based on the 1991 Baseline, shows only the U.S. costs and does not include foreign contributions.

The SSC's $20 \mathrm{TeV} / \mathrm{beam}$ and luminosity of $10^{33} \mathrm{~cm}^{-2} \mathrm{sec}^{-1}$ were carefully chosen as the minimum requirements needed to maximize the SSC's potential for discovery of new physics phenomena. The 1990 HEPAP Subpanel Report on SSC irysics carefully examined the scientific feasibility of a less-costly, lower-energy collider and concluded:

"The very spirit of physics is to explore the unknown. This makes it impossible for us to predict precisely what we will discover in the future. Based on our present knowledge, however, we are confident that the SSC will explore a region in which major new discoveries will be made. The SSC specifications were established with this goal in mind, and experience gained since 1983 has strengthened our conviction of the importance of constructing a proton-proton collider with the beam energy of $20 \mathrm{TeV}$ and luminosity of $1033 \mathrm{~cm}^{-2} \mathrm{sec}^{-1}$, as originally proposed."

The Laboratory has made excellent progress in establishing a scientific program appropriate to prepare for and then exploit the SSC's discovery potential. The dominant features of the SSCL scientific program are the large detectors that have been proposed by the Gammas, Electrons, and Muons (GEM) Collaboration and the Solenoidal Detector Collaboration (SDC). The SSCL. Program Advisory Committee (PAC) has consistently recommended that two such large detectors are needed to fully exploit the new physics opportunities that will be provided by the collider. The SSC without its full complement of scientific instrumentation can be compared to an exquisite clock mechanism with no hands. 
The GEM and SDC projects have progressed well. Each has aitracted large numbers of excellent scientists from the international high energy physics community, organized them well into effective collaborations, completed most of the R\&D needed to finalize their detector's conceptual design, and completed a detailed Technical Design Report (TDR). They are now building and testing various subsystem preproduction modules. They have developed detailed plans and schedules for the completion of the detectors. Although their schedules show completion in time for a 1999 beam turn-on, they are extremely optimistic. The detectors would benefit from a 1-to 2-year stretchout.

The estimated cost of the SDC detector is \$609 million (FY 1992 \$) and that of the GEM detector is $\$ 551$ million (FY $1993 \$$ ). Of the total WBS 52 allocation of $\$ 625$ million (FY $1990 \$$ ), the SSCL has set aside \$550 million (FY 1990 ) for these two detectors. The SSCL initially assumed that significant foreign contributions would fully cover the difference between the baseline cost estimate (BCE) detector allowance and the total detector cost. These contributions now appear unlikely to cover the full difference. The Japanese contributions to SDC are particularly critical in this regard. The SSCL is now developing plans for addressing this critical problem. It should be noted that while no contingency costs were included in the detector allowance in the $\mathrm{BCE}$, the cost estimates shown above do include a contingency or management reserve of about 25 percent of the direct costs.

The remaining $\$ 75$ million (FY $1990 \$$ ) of WBS 52 was allocated as the U.S. cost for other experiments (WBS 523). The Laboratory has received over 10 Expressions of Interest for smaller, more specialized experiments, ranging in estimated cost from $\$ 1$ million to $\$ 300$ million. Proposals for such experiments are expected to be reviewed in late 1994. The Plan is to select experiments that will fit into this allotment of U.S. costs. The adequacy of WBS 523 cannot be judged, however, until these experiments are selected. A proposed $\$ 17$ million transfer from WBS 523 to WBS 57 may further restrict the initial scope of the smaller experiments.

An extensive and successful detector R\&D program (WBS 51) has been supported by the SSCL to develop the needed subsystem technologies for the large detectors. About $\$ 37$ million has been expended to date and the SSCL plans to use the remaining \$4 million during FY 1994-1996 to complete this R\&D program. 
The SSCL experiments will need extensive computing facilities for data analysis and simulations. WBS 53 provides for the cost of these facilities. The SSCL has made an excellent start with the establishment of its Physics and Detector Simulation Facility (PDSF), which is currently providing the computing power of 3000 VAX equivalents. A recent PDSF review states, "The Physics and Detector Simulation Facility is a success. The implementation of the PDSF by the Physics Research Division (PRD) computing staff in general meets the goals and specifications laid out by the Computer Planning Committee..."

This effort, as presently scoped, should be achievable within the SSCL-budgeted EAC of $\$ 80$ million. However, additional tasks are being considered for the Computing Group that would require an additional $\$ 8$ million.

SSCL-based physics research groups are essential to the success of the SSCL's scientific program. The PRD has so far recruited over 60 first-rate physicists. They have made important contributions to the ongoing SSC physics research and detector development. The cost of these efforts have been covered by both WBS 57 (project coordination and liason activities) and by funds from the DOE Division of High Energy Physics (DHEP) (physics research activities).

Coordination activities were not explicitly accounted for in the 1991 Baseline and funds for these activities have been transferred from the oth:r (smaller) detector allocation (WBS 523). The total for these activities will reach about $\$ 26$ million by the end of FY 1993. In succeeding years, the Laboratory plans to fund these activities out of the Laboratory Operations budget (see Section 7.10), although this may be difficult in FY 1994.

\subsubsection{WBS 51 - SSC Detector R\&D}

\subsubsection{Overview}

The progress, current status, and the future plans of the SSCL Detector R\&D projects were discussed with Dr. Harvey Lynch of the PRD on July 14, 1993, at the SSCL. These projects were begun in 1989 and proceeded in two phases. The first phase, Generic Detector R\&D, was initiated to develop particle detection elements having the 
very demanding speed of response, radiation robustnes:s, and resolution needed for SSC applications. The second phase, Detector Subsystem R\&D, was directed at the challenging task of incorporating and integrating typically hundreds of thousands of these elements into workable SSC detector subsystems.

The steps followed by the SSC to accomplish these R\&D objectives were as follows:

1. Annual calls for proposals were made.

2. The submitted proposals were evaluated by the SSCL R\&D Committee, composed of internationally recognized detector experts. The Committee made scope and funding-level recommendations to the Laboratory Director for those proposals it deemed worthy of pursuing.

3. Based on the these recommendations, the Laboratory established Memoranda of Understanding (MOUs) with the proposers. The MOUs contained technical goals and milestones, names of the participating institutions, names and the level of effort of the participating technical individuals, funding allocations, and reporting requirements.

4. The funding was distributed to the participating National Laboratories by DOE financial plan transfers, as well as Memorandum Purchase Orders (MPO) directly issued by the SSCL. University funding was distributed by using the DOE research contract/grant award mechanism and was administered by the Washington-based staff of the Office of SSC (OSSC).

The progress and accomplishments of the Detector $R \& D$ projects have been and continue to be monitored by the SSCL PRD staff, the R\&D Committee (by means of proposals and progress reports), the OSSC staff, and the DOE DHEP staff. The DHEP staff is involved because many of the national laboratory and university physicists involved are concurrently performing SSC-related and ongoing high energy research. It has been a joint SSCL/OSSC/DHEP policy guideline that SSC project funds should not be used to support the high energy physicists' salaries at national laboratories and universities. 
These projects have been very successful in developing the technological base for the SSC detector projects, developing a large and talented community of physicists interested and dedicated to the technical challenges of the SSC experimental program, and advancing the knowledge of particle detectors that will certainly find uses in other fields. The projects' outcomes were: (1) many detector related techniques were explored and developed; (2) a diverse number of prototype devices were built and tested; (3) many of the techniques developed were incorporated in the SDC and GEM designs; and (4) the results were reported at conferences and in journal publications.

\subsubsection{Scope of Work Associated With WBS 51}

WBS 511 includes Generic R\&D on high energy physics detectors an $\mathbb{A}$ detector systems not directly related to a specific detector or experiment.

WBS 512 includes R\&D related to SSCL detectors and detector subsystems, such as tracking, muon detection, calorimetry, and triggering.

\subsubsection{Assessment of Project Status}

WBS 511

The Generic Detector R\&D projects have been completed and the technical objective was fulfilled. The cost expended was $\$ 6.435$ million.

\section{WBS 512}

Technical: The Subsystem Detector R\&D projects rel:ted to the large detectors have essentially been completed and the original technical objectives have been fulfilled. Many of the subsystem technologies now incorporated in the SDC and GEM detectors were developed in this effort. Detector $R \& D$ is being continued at a much lower funding level to advance the development of pixel detectors and techniques for the smaller SSC experiments.

Cost Expended/Committed to Date: Within the budgeted baseline of $\$ 34.841$ million, $\$ 29.174$ million has been expended or committed. 
Scheduled Progress Against Current Baseline: Project objectives have been reached on schedule and this effort is 90 percent complete.

Approved Changes: There are no changes.

\subsubsection{Plans to Complete}

The Laboratory plans to expend about \$4 million during FY 1994-1996 to complete the development of pixel detectors and complete R\&D for the smaller experiments. These projects will complete all the efforts within the scope of this WBS.

\subsubsection{Interfaces}

The WBS 51 projects are directly related to the WBS 52 projects and they interface via the high energy physics research community. The physicists involved in the R\&D efforts (WBS 51) are also usually involved in the detectors ( $\mathrm{W}^{\prime} \mathrm{BS} 52$ ).

\subsubsection{Documentation Available and Reviewed}

The available documentation for these projects includes MOUs between the SSCL and project participants (about 10 to 15 MOUs per year for the last 3 fiscal years.)

Many of the MOUs have been either seen or reviewed by the subcommittee chairman as part of his work as an OSSC and DHEP program officer.

\subsubsection{Assessment of Plan to Complete}

Risk: No contingency is needed for WBS 51, as any future expenditures will be adjusted to match the remaining funds.

Projected Changes: Most of the remaining costs of WBS 512 are connected to the smaller experiments of WBS 523. If decisions are taken in the next year or so to curtail or delay these experiments, an adjustment in the remaining WBS 512 costs may be needed.

Cost (EAC): The SSCL PMB budget of $\$ 41.276$ million is adequate to complete WBS 51. Further development activities required for the detectors are included in 
WBS 52. The cost variance shown in the May 1993 CPR is primarily due to delayed billing/costing.

Schedule: SSCL's planned schedule is satisfactory.

\subsubsection{Conclusions/Recommendations}

The R\&D projects included in WBS 51 were and are well managed and are adequately costed to meet SSCL's overall scientific objectives.

\subsubsection{WBS 52 - SSC Detectors}

\subsubsection{Overview}

The progress, current status, and the future plans of the SSCL Detector projects were discussed with Drs. Kirk (WBS 521), Sanders (WBS 522), and Luth (WBS 523) on July $14-15,1993$, at the SSCL. WBS 521 covers the large detector proposed by the Solenoidal Detector Collaboration (SDC); WBS 522 covers the large detector proposed by the Gammas, Electrons, and Muons (GEM) Collaboration; and WBS 523 covers other smaller detectors. The GEM and SDC projects have been selected by SSCL for the initial scientific program. The selection of the smaller experiments is planned for late 1994.

The major steps followed in the procedure for selecting experiments are as follows.

1. Expression of Interest (EOIs) for experiments/detectors were submitted in May 1990.

2. The SSCL Program Advisory Committee (PAC) in July 1990 reviewed the EOIs and selected four EOIs whose authors were requested to prepare Letters of Intent (LOIs) for large detectors. Also, it recommended that SSCL's initial program consist of two large detectors plus one or more smaller experiments.

3. The PAC recommended in December 1990 that the SDC proceed with the preparation of a Technical Design Report (TDR).

4. A SDC cost review was held in February 1991. 
5. The GEM EOI was presented to the PAC in July 1991.

6. The PAC recommended in December 1991 that GEM proceed with the preparation of a TDR.

7. A review of the SDC TDR by the PAC and a panel of experts was held in May 1992.

8. A GEM cost and schedule review was held in June 1992.

9. A DOE/ER baseline review of the SDC was held October 1992.

10. Review of the GEM TDR by the PAC and a panel of experts was held in May 1993.

The outcome of the SSCL selection procedure was a scientific and technical success. GEM and SDC each comprise a large collaboration of over 1000 scientists from hundreds of institutions from all over the world. They have gone through a vigorous R\&D stage to select most of their final subsystem technologies, formed effective collaboration management systems, and produced detailed design and cost reports. Their progress to date demonstrates that management by scientists of these large projects is not only feasible, but probably critical to their success.

The original BCE did not include the full estimated cost of the detectors. Instead, a "detector allowance" of $\$ 760$ million (FY $1990 \$$ ) was included with the expectation that the remaining costs would be covered by non-U.S. sources. This policy was endorsed by the DOE in the January 1991 "Report on the Superconducting Super Collider Cost and Schedule Baseline." The report states, "... this allowance of $\$ 910$ million (asspent) Federal funds is adequate, along with expected significant foreign detector contributions, to provide two large, general purpose detectors of appropriate scope for the initial SSC physics program as well as two or more smaller experiments." This $\$ 910$ million was to have covered the U.S. portion of the costs for WBS 51,WBS 52, and WBS 53. 
In following this policy, SSCI, has:

1. Reserved $\$ 550$ million (FY $1990 \$$ ) of project funds for SDC and GEM. The SDC detector total estimated cost is $\$ 609$ million (FY $1992 \$$ ) and that of the GEM detector is $\$ 499$ million (FY $1990 \$$ ).

2. Established a review process for arriving at a technical, cost, and schedule baseline for SDC. First, the Laboratory, with the help of its Program Advisory Committee and other outside experts, reviewed in detail the collaboration's TDR and associated documents. The Laboratory and Collaboration then agreed upon a baseline to be presented to a two-stage DOE review. Stage I consisted of a DOE technical, cost and schedule review. Stage II is to be an examination of the detailed funding plan and funding profile, including international and domestic funding sources outside the SSC project. The outcome of this process would be a concise Baseline Report and a detailed financial plan and funding profile (including both international and domestic sources) that were agreed upon by both the SSC and DOE. These would then form the SDC baseline.

Due to uncertainties in the project, as well as the time needed, neither GEM or SDC has been able to obtain the necessary outside commitments, which together with SSCL project funds would fully cover the estimated costs of these detectors.

The work for GEM and S.DC supported by project funds is being carried out by the collaborating U.S. institutions. The project managers annually establish addendums to MOUs with the collaborating institutions for the year's funding. The addenda contain technical goals and milestones; names and the level of effort of the participating technical individuals; funding allocations; and reporting requirements. Monthly progress reports from the collaborators are required. For the work of the U.S. groups not at the SSCL, funding is distributed in the manner described for detector research and development (Section 7.4.2).

\subsubsection{Scope of Work Associated With WBS 52}

WBS 521 includes labor and materials for the R\&D, design, fabrication, assembly, testing, iniegration, ES\& $\mathrm{H}$, and QA for the SDC project. 
WBS 522 includes labor and materials for the R\&D, design, fabrication, assembly, testing, integration, ES\&H, and QA for the GEM project.

WBS 523 includes labor and materials for the R\&D, design, fabrication, assembly, testing, integration, ES\&H, and QA for the other selected experiments.

\subsubsection{Assessment of Project Status}

WBS $521-S D C$

Technical Status: The SDC technical progress is adequately depicted in the CPR. Except for the forward calorimeter, technologies have been selected for all subsystems. Preproduction prototypes have been or are being constructed for the vertex, tracking, calorimeter, and muon systems. Beam tests of these are planned for 1994-1995. Progress on SDC magnet, electronics and software is being made and is on schedule.

\section{Cost Expended/Committed to Date: \$37.401 million}

Scheduled Progress Against Current Baseline: Until this June, the SDC was essentially on schedule. This schedule was very tight for the 1999 turn-on date, with the detector and its experimental hall being on the critical path. However, the SSCL has curtailed and/or suspended some planned FY 1993 expenditures for its scientific program. This may delay the SDC schedule by about 6 months.

\section{WBS $52:-G E M$}

Technical Status: The GEM Collaboration's technical progress is adequately depicted in the CPR. Except for the forward calorimeter, technologies have been selected for all subsystems. Preproduction prototypes are being constructed for the vertex, tracking, calorimeter, and muon systems. Beam tests of these are planned for 1994-i995. Progress on GEM electronics and software is being made and is on schedule. The bids for GEM magnet construction are being evaluated.

Cost Expended/Committed to Date: $\$ 32.827$ million 
Scheduled Progress Against Current Baseline: Until recently GEM was essentially on schedule, taking into account its late start. However, the SSCL has curtailed and/or suspended some planned FY 1993 expenditures for its scientific program. This may delay the GEM schedule by about 6 months. There has also been about a 6-month slippage in the schedule for the GEM underground halls.

\section{WBS 523 - Other Experiments}

Technical Status: Over 10 EOIs have been submitted for smaller, more specialized experiments. They cover topics such as elastic scattering, B-meson physics, and neutrino physics. The experiments described in the original EOIs range in costs from $\$ 1$ million to more than $\$ 300$ million. Proposals for such experiments are expected to be considered in late 1994.

Cost Expended/Committed to Date: $\$ 3$ million was spent for LOI preparations.

Scheduled Progress Against Current Baseline: SSCL is following its plans for developing the other experiments. Being smaller in size, these detectors can be built more quickly and there are scientific and technical reasons to delay their definition as long is possible and still meet the turn-on date.

WBS 521 (SDC), 522 (GEM), and 523 (Other Experiments)

Approved Changes: None for WBS 521 and WBS 522. As described below, some WBS 523 funds have been transferred to WBS 571 ( $\$ 8$ million), as well as being used for LOI preparations, leaving $\$ 79$ million still available in the PMB.

\subsubsection{Plans to Complete}

The SDC and GEM have detailed plans to proceed as outlined in their TDRs. Collaborating institutions are supplying the detector subsystems. The SSCL plans to receive and evaluate proposals for WBS 523 until late 1994. Thus there are now no detailed plans for completion of this program. 


\subsubsection{Interfaces}

The GEM and SDC personnel at SSCL actively interface with personnel associated with: WBS 53 - Detector Off-line Computing; WBS 54 - Detector Halls and Facilities; WBS 55 - Detector Engineering Support; and WBS 56 - Test Beams. No interface problems were evident.

\subsubsection{Documentation Available and Reviewed}

The available documentation for these projects includes:

1. GEM and SDC TDRs submitted to the SSCL.

2. GEM and SDC Cost and Schedule Summaries.

3. Report of the PAC review of the GEM and SDC TDRs.

4. Report of the DOE Office of Energy Research Review Committee on the Solenoidal Detector Collaboration of the Superconducting Super Collider.

5. September 24, 1992 letter from R. Schwitters (SSCL) to J. Cipriano (OSSC) describing the phased approach for DOE review of the SDC project.

6. January 7, 1993 letter from J. Cipriano (OSSC) to R. Schwitters (SSCL) on the plans for establishing the baseline for SDC.

7. May 18,1993 letters from R. Schwitters to the SDC and GEM spokesmen concerning the funding for GEM and SDC.

8. MOUs between the SSCL and collaboration participants.

Except for item 7, none of these documents were specifically examined or audited for this review. However, many the important reports and proposals have been examined by the subcommittee chairman as part of his work as an OSSC and DHEP program officer.

\subsubsection{Assessment of Plan to Complete}

Risk: The technical risks for GEM and SDC are adequately addressed in their TDRs. Their cost estimates contain adequate contingency or management reserve (about 25 percent of the direct costs). As the smaller experiments will be selected in late 1994, no assessment of their risk can be made now. 
Cost (EAC): The total cost to build two large detectors ( $\$ 1178$ million) plus other small detectors ( $\$ 61$ million) is $\$ 1239$ million (FY $1993 \$$ ). (Note that the small detectors are highly uncertain: these experiments and their costs have yet to be proposed, and the amount of foreign contributions to these experiments is also unknown.) The difference between $\$ 1239$ million and $\$ 659$ million in the TPC represents a cost outside the scope of the $\$ 8.249$ billion Baseline Cost Estimate. This is because the 1991 baseline TPC only included the U.S. part of the detector construction costs, and did not include the contributions of subsystems by foreign groups. These additional costs for the detectors must be provided primarily from Federal or foreign funding (some small additional contributions are expected from universities and from the research program supported by the State of Texas).

The SSCL Budgeted EAC for SDC of $\$ 300.789$ million and for GEM $\$ 293.517$ million are consistent with the SSCL budgeted detector allowance. The variances shown in the May 1993 CPR are primarily due to delayed biling/costing. It is beyond the scope of this review to ascertain how much of the remaining costs will be provided to GEM and SDC by outside funding sources.

Schedule: Both the GEM and SDC schedules are extremely optimistic. They contain little or no float for technical delays. A 1-year schedule extension for SDC and a 2-year extension for GEM should be considered. The schedule for other experiments will be established in 1994. However, one major schedule concern for the smaller experiments is the definition, planning, and construction of appropriate halls.

\subsubsection{Conclusions/Recommendations}

The technical progress of GEM and SDC is properly described in the CPR. They both could profit from an extended schedule. Their major problem is the uncertainty in funding outside the TPC.

\subsubsection{WBS 53 - Detector Off-line Computing}

\subsubsection{Overview}

The progress, current status, and the future plans of the SSCL detector off-line computing were discussed on July 14-15, 1993, at the SSCL with Dr. Laird Cormell, the head of the PRD Computing Group. The group has the responsibility, working with the 
SSC detector collaborations, to define, procure, install, and operate the off-line computing systems. This group's effort includes software development, computer hardware systems, and network systems. The group works with the detector collaborations and seeks to find commonalty in their computing requirements and to promote common solutions.

Off-line computing is required for detector modeling and simulation studies, as well as for analyzing data recorded by the detectors. Both of these tasks will eventually involve extremely large and complex data sets requiring mass storage capacities in excess of 1 petabyte ( $10^{15}$ bytes), CPU power corresponding to nearly a million VAX 11/780s, and data transmission rates in excess of $1 \mathrm{~GB} / \mathrm{s}\left(10^{9}\right.$ bytes/sec). The need for these computing resources will grow as the detector projects evolve through their design, test, fabrication, installation, and operational phases. Initially, simulation studies are required to study how well proposed detector designs will work. WBS 53 includes funds for the Physics and Detector Simulation Facility (PDSF), which currently is operating at 3000 VAX equivalents.

The total scope of work performed by the Computing Group is not completely covered by the SSCL BCE. The cost of operating the computer facilities for physics research is not included in the BCE. Funds for this purpose have been provided by the DOE DHEP.

The Laboratory has sought user input in the formulation of its off-line computing plans and strategy by using committees of outside experts and joint working groups composed of users and the Computer Group staff.

\subsubsection{Scope of Work Associated With WBS 53}

WBS 531 includes experimental systems computing equipment and administration related to the detectors' off-line computing systems and their integration with the on-line computing systems.

WBS 532 includes the development of off-line computer simulation systems, data storage and retrieval services, and data analysis systems for support of the experimental physics projects. 
WBS 533 includes the integration of on-line systems developed by the detector collaborations with the off-line systems provided by the PRD Computing Group.

\subsubsection{Assessment of Project Status:}

Technical: The PDSF has provided the needed computing resources for the design stage of the SDC and GEM detectors. It serves both SSCL-based users and high energy physicists at major universities and laboratories around the world. The system averages 60-80 users every 24 hours, 7 days a week. Until its recent upgrade to 3000 VAX equivalents, it was running at full capacity.

Cost Expended/Committed to Date: $\$ 11.3$ million (15 percent of the budget) had been expended as of May 1993.

Scheduled Progress Against Current Baseline: The Computer Group has, to date, managed to meet the requirements of the SDC and GEM Collaborations on schedule.

Approved Changes: There are no changes to date.

\subsubsection{Plans to Complete}

The PRD Computer Group's plan to establish off-line computing facilities to meet the needs of the SSCL experimental program are outlined in the "Experimental Systems Computing White Paper" and the "Experimental Systems Computing Project Management Plan." The key elernents of the plans are to: (1) stage acquisition to take advantage of the year-by-year improvement rate of computers and storage systems; (2) use a distributed computing environment; (3) employ a more structured approach to hardware and software developments; and (4) be responsive to user needs (i.e., SDC, GEM, and other experiments) by the use of joint PRD/user teams to work on specific tasks. The Computer Group's plans are now being reviewed by the SSCL's current Long Range Computer Planning Committee and a draft report has been written.

\subsubsection{Interfaces}

The WBS 53 projects are directly related to the WBS 52 projects and they interface with the detector collaborations via direct contact and joint working groups. WBS 53 also uses SSCL Information Services personnel for maintenance of the PDSF. 


\subsubsection{Documentation Available and Reviewed}

The available documentation for these projects include:

1. SSCL Long Range Computer Planning Committee Reports.

2. Experimental Systems Computing White Paper.

3. Experimental Systems Computing Project Management Plan.

Except for item 2, none of these documents were examined or audited for this review. They were identified in the discussions for this review held with Dr. Cormell on July 14-15, 1993.

\subsubsection{Assessment of Plan to Complete}

Risk: There is low technical risk, owing to the constantly improving performance of computing systems.

Projected Changes: There are two factors that may result in an increase in the EAC cost. First, the off-line computing resources needed by SDC and GEM for their test-beam work at other laboratories are currently being evaluated and may increase costs. Second, the cost for off-line computing for smaller experiments is presently unknown because, according to present plans, they will not be selected until late in 1994.

Cost (EAC): The SSCL budgeted EAC of $\$ 82.014$ million is sufficient to complete WBS 53 with its present scope. The variance shown in the May 1993 CPR is primarily due to delayed billing/costing. An $\$ 8$ million increase in the budgeted EAC is estimated for the possible increased scope as discussed above.

Schedule: The SSCL plan to stage computer acquisitions is sound. There is sufficient time to provide adequate off-line facilities for the experimental program. The development of these systems should be staged and this should not delay detector commissioning or initial operations. 


\subsubsection{Conclusions/Recommendations}

The technical, cost, schedule, and management performance of the Computer Group is properly described in the CPR. The group has shown that it is capable of providing the required computing support to the SSCL experimental program. However, there are major uncertainties in the future scope and costs related to the SDC and GEM detectors, which are now being defined by the Laboratory, and the group's role in the smaller experiments should be clear late in 1994.

\subsubsection{WBS 55 - Detector Engineering Support}

\subsubsection{Overview}

Status and plans of the Experimental Facilities Department of SSCL PRD were discussed with Robert Richardson, director of the department, and Stephan McNiel, group leader for Program Controls, on July 23, 1993, at the SSCL.

\subsubsection{Scope of Work Associated with WBS 55}

WBS 55 covers Experimental Systems Support, which includes development of detector facility requirements, as well as supplying cryogenics, "clean" and standard electrical power, and other "conventional" systems for the detectors, allowing members of the detector collaborations to focus on design of the detectors rather than on utilities supplying the detectors.

\subsubsection{Assessment of Project Status}

Because of budget constraints, the Experimental Facilities Department has been making do with less manpower than planned, but has nonetheless achieved its major milestones on time and has in fact recovered from an earlier 6-month schedule slippage (related to design of facilities for the two large detector halls) that existed when the department was organized into its present form.

Technical: Much of the Experimental Facilities Department's work currently involves conducting Preliminary Design Requirements Reviews. 
Major milestones achieved to date include completion of several Preliminary Design Requirements Reviews for cryogenics, low conductivity water systems, mixed chilled water systems, liquid helium systems, electrical systems and communications cable trays, and technical grounding systems. Written requirements for Interaction Region 8 have been completed and Notice to Proceed has been released.

Cost Expended/Committed to Date: A total of $\$ 14.5$ million had been expended as of May 1993. This total included $\$ 3.2$ million for administration/engineering resources, $\$ 6.9$ million for engineering support, $\$ 0.5$ million for test-beam instrumentation support, $\$ 1.9$ million for SDC support, and $\$ 1.9$ million for GEM support. No money has been committed or spent yet for support of other detectors.

Schedule Progress Against Current Baseline: Work is approximately 20 percent complete.

Approved Changes: There have been no approved changes for WBS 55 other than one to Project Management Office in October 1992 (integrated cost/schedule system).

\subsubsection{Plans to Complete}

The Experimental Facilities Department has recently conducted many of its Preliminary Requirements Design Reviews for the systems for which it is responsible. Later stage reviews of designs and acceptance-test plans are to be completed as work on these systems progresses. Title III design drawings of surface buildings for Interaction Region 5 (north and south assembly buildings) are being completed.

\subsubsection{Interfaces}

The Experimental Facilities Department works with Conventional Construction Division and with the detector collaborations. 


\subsubsection{Documentation Available}

1. Experimental Facilities Department Project Management Plan (document R20-000523).

2. Experimental Systems Support Status Report, June 1993.

3. Cost Account Manager's Handbook for PRD Experimental Facilities Department. None of these were examined in detail for this review.

\subsubsection{Assessment of Plan to Complete}

Risk: The risk is relatively low, provided that SSC funding proceeds according to the baseline. Staffing for the Experimental Facilities Department is lower than the baseline calls for at this time (about 80 full-time equivalents as compared to the 101 planned), but the present staff can be shifted to meet the schedule. However, serious schedule slippage is much more likely if understaffing is continued for the next year or so.

Projected Changes: The Experimental Facilities Department is being asked to support additional projects not considered in the Performance Measurement Baseline it submitted in October 1992. Increased staffing will be needed to complete these projects.

Cost (EAC): The budgeted cost is $\$ 74.931$ million. If no further tasks are given to the Experimental Facilities Department beyond those in the current baseline, the baseline funding profile and schedule should be sufficient for completing WBS 55 . However, if some of the $\$ 26$ million requested from contingency funds for detector hall work [see discussion of WBS 54] is to be supplied from the PRD's budget instead, the Experimental Facilities Department might require an additional few million dollars more for its own budget for sufficient staff to complete their part in the work.

\subsubsection{Assessment of Business Management Systems}

The business management systems appear satisfactory for this WBS element.

\subsubsection{Conclusions/Recommendations}

The current budget and schedule appear sufficient to complete the work for WBS 55 . 


\subsubsection{WBS 57 - Physics Research Division Coordination}

\subsubsection{Overview}

The progress, current status, and the future plans of the SSCL PRD Project Coordination effort were discussed on July 14-15, 1993, at the SSCL with PRD Director, Dr. Fred Gilman. This effort consists of the PRD Electronics Group, iiie GEM Physics Group (Group B), and the SDC Physics Group (Group A). The Electronics Group designs, fabricates, and tests electronics systems needed by PRD experimental groups. Groups A and B comprise the SSCL physics staff and support personnel involved with detector design, development, testing, fabrication, integration, and coordination. The costs of these activities are split between WBS 57 (project integration and coordination) and physics research (part of the Laboratory Operations budget and thus outside the scope of the $\mathrm{BCE}$ ).

\subsubsection{Scope of Work Associated With WBS 57}

WBS 57 includes physics liaison, engineering coordination, technical support, and other project coordination activities required to plan, develop, and manage the construction of experimental detectors and detector facilities.

\subsubsection{Assessment of Project Status}

Technical: The technical progress made by the SSCL Electronics Group, Group $A$, and Group B is properly depicted in the CPR. They have made significant contributions to the SSCL experimental program and have important roles in the GEM and SDC Collaborations.

Cost Expended/Committed to Date: $\$ 20.8$ million had been expended as of May 1993.

Scheduled Progress Against Current Baseline: This WBS element has no baseline schedule, but extends over the entire program duration.

Approved Changes: This WBS element or its associated cost was not covered in the original $\mathrm{BCE}$; they were instituted by $\mathrm{CCB}$ request $\mathrm{E} 12-000118$. This change 
resulted in establishing about $\$ 8$ million for WBS 57 . The funds were obtained from WBS 523 - Other (smaller) Detectors.

\subsubsection{Plans to Complete}

PRD has made detailed plans for this effort, and they have been described in its proposals to DHEP. These plans call for a tripling of staff by FY 1999.

\subsubsection{Interfaces}

The WBS 57 personnel are directly involved in the WBS 52 projects and they interface via the SSCL GEM and SDC project managers and Group A and Group B heads.

\subsubsection{Documentation Available and Reviewed}

The available documentation related to this WBS include:

1. Report on the Superconducting Super Collider Cost and Schedule Baseline, January 1991.

2. Proposal from the SSC Laboratory Physics Research Division to the Department of Energy Division of High Energy Physics, April 1992.

3. Proposal from the SSC Laboratory Physics Research Division to the Department of Energy Division of High Energy Physics, May 1993.

None of these documents were specifically examined or audited for this review. However, they have been reviewed by the subcommittee chairman as part of his work as an OSSC and DHEP program officer.

\subsubsection{Assessment of Plan to Complete}

Risk: The continued transfer of funds from WBS 523 to WBS 57 may result in the initial scientific program having few or no experiments smaller than SDC or GEM. However, without adequate staffing of Groups A and B, the SDC and GEM projects cannot be carried out successfully. Appropriate levels of Laboratory Operations funding are required (see Section 7.10). This may be difficult in FY 1994.

Projected Changes: A transfer of an additional $\$ 17,000,018$ to WBS 57 from WBS 523 has been requested (E12-000157) to cover FY 1993 costs. 
Cost (EAC): Including the change request to cover the $\$ 17$ million of FY 1993 costs, will bring the total for WBS 57 to about $\$ 26.3$ million. The Laboratory plans to support these coordination activities in future years out of the Laboratory Operations budget (see Section 7.10).

Schedule: To support the presently planned experimental program will require yearly increases in PRD physics groups. The PRD estimate of tripling the present staff may not be appropriate or possible, depending on the future scope of the program and the level of funding.

\subsubsection{Conclusions/Recommendations}

The progress made in establishing the PRD experimental physics group has been excellent. They have recruited first-rate staff and have made important contributions to GEM and SDC. 


\subsection{Startup and Commissioning}

\subsubsection{Executive Summary}

The SSCL pre-operations plans-for the sequential startup and comm' ssioning of the series of individual accelerators, their beam transfer lines, and other tech.ical facilities comprising the SSC--were examined. The subcommittee finds the overall proposed plan for the pre-operations activities reasonable. Many factors will influence the overall schedule and require adjustment of the detail of the pre-operations dates, but the overall anticipated durations and budgeted costs for most of the pre-operations activities are reasonable at this time. The staff levels assumed for pre-operations cover only those personnel necessary for commissioning and pre-operations tasks; pre-operations funds are not intended to pick up and carry additional design and construction staff and technicians after the construction phase is complete, and JSC management will need to continually make appropriate and timely adjustments in both the staff levels and the mix of staffing disciplines as the project moves through the design, construction, installation, testing, commissioning, and operations phases.

The subcommittee recommends approximately $\$ 10$ million be added to the baseline cost for collider-sector commissioning to cover additional staff that we expect to be required. The subcommittee, therefore, recommends increasing the overall baseline budget from $\$ 137.239$ million to $\$ 147.25$ million for pre-operations.

\subsection{2 ¿cope of Work Associated with Pre-operations WBS}

The subcommittee reviewed SSCL plans for the sequential startup and commissioning of the series of individual accelerators, their beam transfer lines, test beams, and experimental facilities comprising the SSC. The SSC requires a series of individual accelerators and beam transfer lines of increasing energy in the injector chain. These are the Linac, Low Energy Booster (LEB), Medium Energy Booster (MEB), and High Energy Booster (HEB); each individual accelerator will undergo individual phased startup and commissioning as it becomes sequentially available. Each injector accelerator system must be completed in sequence in order to be able to provide beam to the next higher-energy accelerator. The collider itself is comprised of ten separate sectors, and each sector will undergo individual startup and commissioning as the installation and checkout work is completed; these collider-sector commissioning activities span a period of nearly 
3 years in the baseline schedule. The completion of all injectors and all ten collider sectors is required before stored beams can circulate in preparation for colliding beam operation.

The committee reviewed the SSCL plan for the pre-operutions scope of work. The series of sequential activities addressing system testing, staff training, commissioning, and pre-operations are included within the WBS for each of the major injector accelerators and collider sectiors and are covered by TPC funds.

Construction completion for each major facility is defined as the time at which all major systems of the facility are in place and ready to operate together to meet the basic objective of that facility. In the case of an injector accelerator, it is expected that each technical component (e.g., magnets, power supplies, rf system, etc.) will have been individually tested during the construction phase to insure that performance requirements have been met.

Pre-operations provides for the build-up and training of the technical staff who will help to commission and subsequently operate the facility. The commissioning follows construction completion. During commissioning all systems are tested and operated together to ensure that the basic technical objectives are achieved; in the case of an accelerator system, this basic objective is accelerated beam. This commissioning activity includes tuning, timing, debugging, and perhaps minor modifications of individual components to optimize performance as well as reliability.

Operations allows use of each facility following the successful commissioning. In the case of injector accelerators, this period would include operations for continued improvements, operations for test beams and physics experiments, and service to other accelerators that are not part of commissioning. In addition to its own commissioning period, when an injector accelerator is used in the commissioning program for one of the higher-energy accelerators or the collider, the cost of its operation is charged to preoperations. For example, during the commissioning period of the MEB, the Linac and LEB (each having already been commissioned and therefore subsequently operated with funds outside the WBS/TPC) are charged half-time to pre-operations and half-time to operations.

The Pre-operations budgets contain costs for staff, materials and supplies, power, and cryogenics required during the staff training and commissioning phase. These 
elements are addressed in WBS categories for each of the main accelerator systems, transport lines, and experimental facilities; a portion of the pre-operations expenses common to all of the accelerator systems is addressed in a WBS category for global systems. Not all of the design, construction, installation, and testing staff that were required for the construction phase are assumed to be involved in the commissioning and pre-operations activities; the pre-operations plans assume that many will be shifted over to other necessary construction activities, where they will not be supported by pre-operations budgets (e.g., a large number of LEB engineers, designers, technicians, etc., will shift over to HEB or collider construction activities when LEB construction is complete, and thereafter will not be supported by the LEB pre-operations funds). When examined together, the sum of all the pre-operations costs collected throughout the TPC WBS categories represents $\$ 137.239$ million in FY 1993 dollars.

\subsubsection{Assessment of Project Status}

There have been essentially no costs to date for Pre-operations activities. Since the original cost baseline was established the SSCL has reviewed and updated plans for both the Pre-Operation and Operation phases (e.g., SSCL Commissioning and Operations; Report SSCL-SR-1210; March 31, 1992). The SSCL has also developed detailed staffing and operations projections for the year FY2000 and beyond to provide planning information during the transition from construction activities to full laboratory operations (e.g., SSC Laboratory Operations Program Plan FY 2000 to FY 2005; Report SSCL-SR-1216, November 1992). The subcommittee reviewed both of these recent documents. In general terms, the plans are still consistent with funding requirements and assignments within the baseline cost estimates for the injector accelerator systerns. However, the subcommittee feels that some additional staff for collider sector preoperations should be added.

Since no money has been spent to date and no schedule milestones have yet occurred (or slipped) for pre-operations elements, the current project status is assessed as adequate.

\subsubsection{Plan to Complete}

The plan to complete is essentially as presented in the Commissioning and Operations planning document SSCL-SR-1210 described above. No immediate changes 
are under current consideration. In general terms, the plan developed in that report is still consistent with funding requirements and assignments within the baseline cost estimates for the injector accelerator systems. Some discussions with Collider staff and further comparisons with the general Operations Program Plan cited above give some indication that the projected staffing level for collider sector commissioning should be increased somewhat. This has not yet resulted in a proposed change action by the Laboratory, but the subcommittee recommends $\$ 10$ million be added to the $\$ 75$ million collider baseline cost to cover this additional staffing requirement.

\subsubsection{Interfaces}

Detailed definition and clear understanding of the interfaces with the elements for pre-operations are critical. The agreed-upon interfaces are described in general terms in the above documents. Detailed definitions are included within the WBS Dictionary task descriptions. For the Pre-operations activities specifically, the WBS elements are designated by xxx.9200 in each appropriate facility, and the technical description states in each case, for example,: "Verify all LEB related operator training and certification programs, participate in equipment pre-operational tests, prepare and manage the LEB commissioning program, analyze and report on test and commissioning results, and support procurement of the necessary operating supplies."

Before the commissioning activities begin, the interface point with other subsystems requires each technical component (e.g., magnets, power supplies, rf system, controls, etc.) to have been individually tested during the construction phase. The installation contractor carries out the installation, hook-ups, and rough adjustments for components. After the physical installation, each technical sub-system checkout and performance verification is assured by SSCL staff before the commissioning activities (and costing to the pre-operations WBS categories) begin. Each technical component WBS Dictionary element includes in the statement of work and the cost element statement "EDI/QA, procurement, fabrication, testing...". In addition, each systems engineering WBS element (i.e., xxx.1010) includes additional subsystem/acceptance testing.

At the conclusion of the pre-operations and commissioning activities, the interface with "Operation" must also be clearly defined. For each subsystem the start of operations is signaled when the basic objective is achieved, i.e., the facility can supply adequate beam for start-up and commissioning of the next, higher-energy accelerator. Operations includes 
running for continued improvements, operations for test beams and physics experiments, and service to other accelerators that are not a part of commissioning.

\subsubsection{Documentation Available and Reviewed}

The following documents were reviewed by the subcommittee:

SSC Project Monthly Progress Report, May 1993

WBS Detail Dictionary

BCE old WBS/New WBS Crosswalk Handbook

SSCL Commissioning and Operations; SSCL-SR-1210

SSCL Operations Program Plan FY 2000 to FY 2005; SSCL-SR-1216

\subsubsection{Assessment of Plan to Complete}

The subcommittee considers that the interfaces have been described adequately, and the proposed staffing model and anticipated commissioning schedule have been developed in a reasonable manner. The activity durations are considered acceptable by the subcommittee. The subcommittee considers the current SSCL plan for Pre-operations activities to be adequate for the injector accelerator systems. The subcommittee feels that some additional staff for collider sector pre-operations will be required and recommends that approximately $\$ 10$ million be added to WBS 3.2.1.9200 increasing the cost from $\$ 74.990$ million to $\$ 85.000$ million.

\subsubsection{Risk}

The potential risks associated with successfully carrying out the pre-operations plans must be recognized and addressed. The technical and schedule risks, of course, must be considered together. It is not possible to predict the exact time that each accelerator will operate at its maximum capability, particularly with regard to emittance and intensity. It is expected that after the commissioning period, each accelerator will readily have the capability to commission the next, higher-energy machine. This means that the beam ejection system and beam transfer lines to the next accelerator must be operational. In addition, the commissioning tests must provide evidence that the machine has the capability to reach maximum design performance and that the methods of achieving full design 
performance are understood. (Operations covers the period of time during which performance improvements, and ultimate design goals, might be demonstrated).

However, if problems are encountered in the individual testing or system acceptance tests for critical elements, or if component reliability becomes a problem and breakdowns, component unavailability, etc. occur during the commissioning period, the commissioning period will have to be extended, which will have a direct bearing on both the cost and schedule of subsequent activities. Similarly, the assumptions about staffing levels and staff costs have a direct effect on the pre-operations cost. Although reasonable assumptions are being made in the current plans, the methods of budgeting the necessary support staff may have a future effect on the total cost (e.g., Laboratory overhead rates may fluctuate, Safety, QA and documentation requirements may change, etc.). A critical assumption of the pre-operations plan is that a large number of design, construction, installation, and testing staff that were required for the construction phase are not involved in the commissioning and pre-operations activities; it is assumed that most will be shifted over to other necessary construction activities and not be supported by pre-operations budgets. If, contrary to the plans outlined above, many construction staff are carried on pre-operations funds when construction work is complete, the pre-operations costs may grow considerably.

\subsubsection{Projected Changes}

The subcommittee recommends that approximately $\$ 10$ million be added to WBS 3.2.1.9200, increasing the cost from $\$ 74.990$ million to $\$ 85.000$ million. The total for all pre-operations increases, therefore, from $\$ 137.239$ million to $\$ 147.250$ million.

\subsubsection{Cost (EAC)}

The SSCL current baseline cost for EAC is $\$ 137.239$ million. The subcommittee recommends increasing the $\mathrm{EAC}$ to $\$ 147.250$ million.

\subsubsection{Schedule}

The subcommittee considers the schedule durations for the pre-operations activities reasonable. However, the overall pre-operations schedule is largely driven by the availability of other systems, and any adjustment to critical subsystem schedules will have a 
direct affect on the pre-operations schedule. It is critical to have the Integrated Project Schedule include detailed requirements for interfaces with the start-up group and all other associated subsystems and contractors. This was not evident in the project schedule reviewed. This function is on the critical data memo KD\#4 - Start Operations.

\subsubsection{Conclusions/Recommendations}

The subcommittee finds the proposed plan for the pre-operations reasonable. Many factors will influence the overall schedule to adjust the detailed pre-operations dates, but the overall anticipated durations and budgeted costs for the pre-operations activities are generally reasonable at this time.

The subcommittee recommends that for the collider sector commissioning approximately $\$ 10$ million be added to the baseline to cover additional staff. The subcommittee also recommends that detailed planning schedules for commissioning be developed at an appropriate time, with measurable milestones and checkpoints indicated to allow commissioning progress and performance measurements to be demonstrated. 


\subsection{Conventional Facilities}

\subsubsection{Executive Summary}

Documentation and management-system deficiencies-such as lack of a Work Breakdown Structure detailed dictionary (and other Configuration Control Board shortcomings), an approved Master Site Development Plan, and an integrated, task-loaded, master schedule encompassing the whole project-make it extremely difficult for an independent outside team to accurately assess the overall status of construction budgets and schedules simply by referring to management-system reports. However, further investigation reveals that, except for certain early contracts associated with magnet testing, the status of conventional construction is very close to what was published in the May 1993 Project Status Report.

\subsubsection{Introduction}

The subgroup was charged with reviewing the May 1993 SSC Project Monthly Progress Report and assessing whether the status was accurately reflected in that document and the Estimate at Completion (EAC) adequately reported the amount of work remaining. The original budget which the May 1993 status report uses is based on a cost and schedule baseline developed and reported in a document titled "Report on the Superconducting Super Collider Cost and Schedule Baseline," dated January 1991. That report gave the current Total Project Cost estimate of $\$ 8.249$ billion. Since the January 1991 report, a new WBS numbering format has been adopted and a crosswalk between the old and new formats was provided to the subgroup. The subgroup accepts the baseline estimate provided in the January 1991 report as reference.

The current budget reflected in the May 1993 Progress Report still uses the $\$ 8.249$ billion budget. The subgroup agreed that for conventional facilities, the crosswalk between January 1991 and May 1993 reports should be equal to the budget cross walk done in October 1992 (which was used to transfer the budget to the new WBS structure) plus any subsequent $\mathrm{CCB}$ actions that would modify the budget of a WBS element or would transfer or change the work scope of a particular WBS. With the exception of Configuration Control Board (CCB) actions that have yet to be incorporated into the Project Management Baseline (PMB), the sampling of CCB incorporations indicate the Laboratory had changed the affected WBS budget accounts appropriately. 


\subsubsection{Conventional Facilities Cost Drivers}

The projected and approved changes identified in the detailed section (7.6.8) of the subgroup report either add to or reduce the current Project Management Baseline, as contained in the May 1993 Project Status Report.

The changes are broken down into three categories:

- Approved changes as of May 1993 but not incorporated.

- Approved and pending changes since May 1993 report.

- Potential future changes.

These changes total $\$ 192.6^{1}$ million

A summary description of each of the major cost driver changes is given in Table 7.6.2-1, below. A more detailed description is also contained in the Section 7.6.8, organized by individual Work Breakdown Structure elements.

Table 7.6.2-1. Conventional Construction Additional Major Cost Drivers

WBS

114-CCD Management

314-HEB Conv Construction

324-Collider Conv Construction

543-IR-8

544-IR-5

700-Infrastructure

Various WBS

\begin{tabular}{cc} 
Cost. & $\mathbf{M}$ \\
\hline 25 & $\mathbf{S}$ \\
10 & $\mathrm{M}$ \\
-4 & $\mathrm{M}$
\end{tabular}

$7 \mathrm{M}$

$10 \mathrm{M}$

$11 \mathrm{M}$

$7 \mathrm{M}$

$24 \quad \mathrm{M}$

$71.2 \mathrm{M}$

\section{Description}

Management

Tunnel Cooling

$\$ 20 \mathrm{M}$-Concrete Invert

(\$24M deduct)-69V

Distribution

HVAC and Electrical

HVAC and Electrical

Communications

Spoils

Electrical

CCD Rebaseline Adjustment

The subgroup found the Laboratory has established target costs with its architectengineering/construction manager (PB/MK). The finalization of the target costs between SSCL and PB/MK are contained in Contract Mod. 42 to the SSCL and PB/MK contract. Some adjustments to the current project management baseline will be necessary to reflect

\footnotetext{
$1 \$ 192.6$ million includes $\mathrm{CCB}$ Action 254 , which adds $\$ 71.2$ million that had not been distributed to the WBS as of the May 1993 report.
} 
the corresponding CCB action 254. The target cost will be used to determine the incentive fee at the completion of the conventional construction, thereby adding considerable impetus for $\mathrm{PB} / \mathrm{MK}$ to manage construction work in a manner that minimizes cost. Some confusion may exist in trying to ascertain the status of the project and whether adequate budget is available to complete the project until CCB action change 254 is incorporated into the Froject Management Baseline, since various WBS budgets may need adjustment. There is no updated Work Breakdown Structure dictionary, no approved master site development plan, and no integrated master schedule. These issues are further addressed below. Finally, the Laboratory has not completed the development of an integrated database. Therefore, it is very difficult to get information that crosses Divisional lines. The above items increase the risk of the project and were included in our estimates of required contingency to complete the project.

\subsubsection{Potential Risks}

Under the potential risk factors, the subgroup has found some items that add to the perception of risk. Although it is difficult to quantify the risk associated with each of the items listed below, they have contributed to the subgroup's overall assessment of contingency. Therefore each is discussed with respect to subgroup concerns.

\section{Work Breakdown Structure (WBS) Detailed Dictionary. During the} Conventional Facilities Subgroup review of the WBS detailed dictionary, it was noted that certain $\mathrm{CCB}$ changes that affected the scope of a WBS element were not reflected in the current dictionary. It is the committee's assessment that a certain amount of risk is added when the WBS dictionary is not updated to be consistent with CCB actions. The method used to communicate changes in definition of scope in a particular WBS item to other organizations-including outside reviewers-should be the WBS detailed dictionary.

2. Approved Master Site Development Plan. The subgroup is concerned about the status of the Master Site Development Plan. Without an approved final plan, it is difficult to determine if the infrastructure budget is appropriate. The location of roads, utilities and potentially buildings can be impacted by using either best guesses or unofficial copies of draft site development plans. The subgroup recognizes that a Level 2 Specification has been generated by the DOE SSC Project Office, which provides a listing of all conventional facilities. However, 
it is our understanding that the Laboratory has not accepted this specification as of our review. It is the subgroup's recommendation that both the Master Site Development Plan and the Level 2 Specification be finalized and approved as soon as possible to eliminate the risk associated with not having either.

If not all facilities are accounted for, there is some probability of improperly siting facilities which will increase cost and impact schedules.

3. Integrated Master Schedule. The subgroup was unable to find an integrated, resource-loaded master schedule that depicts the project's critical path and is being utilized by the Cost Account Managers (CAMs). Obviously, this adds to the schedule risk. It is very important that the Laboratory develop such a schedule and obtain agreements from the CAMs. Without a critical path, the urgency of starting an action, or the impact of not completing an action, will be ineffectively communicated. The subgroup also found that SSCL utilized schedules that did not integrate with the master schedule, and that the master schedule is not an iterative system.

The risk is that schedule impacts will not be identified in a timely manner.

\subsubsection{Conclusions}

Even with the lack of maturity of the Project Management Systems, the conventional construction status appears to be very close to the values reported in the May 1993 Project Status Report. Contracts for conventional construction have been consistently within the PMB estimate, with the exception of some early contracts for certain facilities that supported the magnet development program. This is due in part to a favorable bidding market.

Based on size of the project and its level of maturity, the business management systems appear to be functional but not timely in responding to approved CCB changes impacting on Latest Revised Estimates, for the conventional construction. Without project critical path based on a total-project, resource-loaded integrated schedule, and without the timely incorporation of $\mathrm{CCB}$ actions into the project management baseline, it is extremely difficult to ascertain cost and schedule status from the performance report data. 


\subsubsection{Recommendations}

1. The WBS Detailed Dictionary should be updated to reflect the current CCB status.

2. The site development plan should be approved by the Laboratory and put under configuration management.

3. All conventional construction should be accounted for by the Conventional Construction Division (CCD) (e.g., the N-15 Warehouse being constructed by LTS, etc.) for efficiency and consistency.

4. It is mandatory that a resource-loaded, integrated project schedule showing the critical path be developed, and that reports be generated monthly.

5. The Laboratory needs to improve the method for accurately reflecting the Latest Revised Estimates of WBS accounts.

6. The Laboratory must incorporate CCB-approved actions into the Project Management Baseline in a timely manner.

7. The acquisition strategy for the West Campus needs to be identified.

The following report contains an analysis of the conventional facilities and infrastructure, validating the project progress/status as identified in the May 1993 Cost Performance Report; projects an estimate-at-completion range based on current trends/projected changes; and provides an assessment of the usefulness of the business management systems to determine project status based on experience from the review. In summary, the subgroup has no reason to question the actual cost of work performed shown in the May 1993 Project Status Report. The subgroup made a site tour to review the status of construction and did not find any major variation from the project status as reported in the Niay 1993 Project Status Report. 


\subsubsection{Scope of Work Associated with WBS Assessed}

There are five major categories of conventional facilities construction: (1) site and infrastructure, (2) campus and industrial support, (3) injector, (4) collider ring, and (5) experimental facilities.

This scope of work covers all conventional construction for the SSC. Included are the facilities to support the Linac Accelerator (Linac), the Low Energy Booster (LEB), the Medium Energy Booster (ME:F), the Collider Tunnels, all supporting surface facilities and various administrative and technical support facilities. All roads and utilities are also included in conventional construction.

The original acquisition strategy was to have all conventional facilities construction provided by an Architect Engineering/Construction Management (AE/CM) firm with oversight by the Laboratory's CCD. The West Campus facilities have been removed from the scope of the AE/CM firm's contract. Additional conventional construction activities were identified that are outside of the $\mathrm{AE} / \mathrm{CM}$ firm's scope and are not subject to oversight by the CCD. This concerns the subgroup in regards to a uniform method of handling construction, including acceptance of completed work, implementation of appropriate laws arid regulations, etc.

\subsubsection{Assessment of Project Status}

WBS No. 114 - Conventional Construction Division Management

Technical: This account covers the SSCL CCD management and administration personnel, as well as project insurance, temporary power (non-PB/MK), and the West Campus.

Cost Expended/Committed to Date: The $\$ 32.636$ million CCD management and administration cost are only budgeted through FY 1994. Only 37 percent of the cost in WBS 114 is for CCD management and administration.

Schedule Progress Against Current Baseline (Percent Complete): 36 percent complete and on schedule. 
WBS No. $117-P B / M K$ Project Management and Administration

Technical: This account covers $\mathrm{PB} / \mathrm{MK}$ project management and administration, pre-title 1 services, geotechnical exploration, survey and mapping, master plan, and $\mathrm{PB} / \mathrm{MK}$ fee.

Cost Expended/Committed to Date: $\$ 78.150$ million.

Schedule Progress Against Current Baseline (PercentComplete): PB/MK efforts are 50 percent complete and essentially on schedule; master draft plan has been completed.

WBS No. 214 - Linac Conventional Construction

Technical: Design complete.

Cost Expended to Date: $\$ 5.5$ million; cost for actual work performed is slightly below budgeted cost of work performed.

Schedule Progress Against Current Baseline (Percent Complete): Design100 percent; construction-75 percent; work is on schedule.

WBS No. 224 - LEB Conventional Construction

Technical: Design complete.

Cost Expended to Date: $\$ 2.3$ million.

Schedule Progress Against Current Baseline (Percent Complete): Slightly behind baseline schedule.

WBS No. 234-MEB Conventional Construction

Technical: Design complete.

Cost Expended to Date: $\$ 2.5$ million on design. 
Schedule Progress Against Current Baseline (Percent Complete): Design complete; construction contract awarded behind original baseline (slightly).

WBS No. 314.3110 - High Energy Booster/Conventional Construction

Technical: Design Requirements Document (DRD) Draft (4/30/93) issued internally for comment and to PB/MK for beginning of Title I design, 5/3/93.

Cost Expended/Committed to Date: $\$ 25,000 \mathrm{~PB} / \mathrm{MK}$ costs for attendance at meetings to develop DRD and HEB share of survcy monuments placed in the field.

Schedule rogress Against Current Baseline (Percent Complete): Essentially 0 per-ent complete; design (Title I) initiated 5/3/93.

WBS No. 324 - Collider Conventional Construction

Technical: Includes Basic Tunnel Construction, Shaft Construction, Tunnel Finish Contracts, niches that were omitted from firc 3 tunnel contracts.

Cost Expended/Committed to Date: $\$ 66.646$ million - design and construction of tunnels (10 miles complete) and shafts (15 complete).

Schedule Progress Against Current Baseline (Percent Complete): 13.7 percent.

WBS No. 325.311 - ASST Conventional Construct. Machine and Experimental Facilities

Technical: Conventional construction completed.

Cost Expended/Committed to Date: $\$ 7.173$ million, May CPR.

Schedule Progress Against Current Baseline (Percent Complete): 100 percent complete. 
WBS No. 541 - IR-1 Conventional Construction

Technical: Design requirements not established.

Cost Expended/to Date: $\$ .4$ million spent on old initial studies (lost effort).

Schedule Progress Against Current Baseline (Percerit Complete): On schedule; design requirements are not scheduled for completion for approximately 1 year.

WBS No. $542-I R-4$ Conventional Construction

Technical: Design requirements not established.

Cost Expended/Committed to Date: $\$ 260 \mathrm{~K}$ expended on early studies (lost effort).

Schedule Progress Against Current Baseline (Percent Complete): On schedule; design scheduled to begin late 1996.

WBS No. $543-I R-8$ Conventional Construction

Technical: Design essentially complete.

Cost Expended/Committed to Date: $\$ 1,509 \mathrm{~K}$ spent on design.

Schedule Progress Against Current Baseline (Percent Complete): On schedule, but underground work contract has been placed on hold due to lack of funding.

WBS No. 544 -IR - 5 Conventional Construction

Technical: Design essentially complete.

Cost Expended to Date: $\$ 1,505 \mathrm{~K}$ spent on design.

Schedule Progress Against Current Baseline (Percent Complete): On schedule, but underground construction contract on hold due to lack of funäing. 
WBS No. 545 - Support Facilities Conventional Construction

Technical: WBS 100 percent complete.

Cost Expended/Committed to Date: $\$ 3,333 \mathrm{~K}$, which is $\$ 47 \mathrm{~K}$ over budget.

Schedule Progress Against Current Baseline (Percent Complete): Completed on schedule.

WBS No. 565 - Test Beams Conventional Construction

Technical: Design complete.

Cost Expended/Committed to Date: $\$ 1$ million on design; $\$ 3.5$ million committed as a part of the MEB construction contract; major tunneling included in MEB tunneling contract.

Schedule Progress Against Current Baseline (Percent Complete): Slightly behind baseline schedule.

WBS No. 711 - West Campus Surface Facilities

Technical: A conceptual plan has been presented; design requirement documents are being developed.

Cost Expended/Committed to Date: $\$ 318 \mathrm{~K}(\$ 10 \mathrm{~K})$ variance.

Schedule Progress Against Current Baseline (Percent Complete): 0 percent.

WBS No. 712 - West Complex Common Infrastructure

Technical: This WBS includes infrastructure items associated with other conventional construction activities, utilities, spoils, paving and environmental work that are normally part of larger construction packages. Infrastructure is basically standard conventional construction. With the conventional construction design program around 65 percent complete, most requirements are now known. 
Cost Expended/Committed to Date: $\$ 3,987 \mathrm{~K}$ ( $\$ 579 \mathrm{~K})$ variance.

Schedule Progress Against Current Baseline (Percent Complete):

$\begin{array}{lc}\text { BCWP } & 3,408 \mathrm{~K} \\ \text { Budgeted } & 61,177 \mathrm{~K}=5.6 \text { percent } \\ \text { Variance } & 141 \mathrm{~K}\end{array}$

WBS No. 713 - West Complex Injector Infrastructure

Technical: This WBS includes infrastructure items associated with other conventional construction activities, utilities, spoils, paving and environmental work that are normally part of larger construction packages. Infrastructure is basically standard conventional construction. With the conventional construction program around 65 percent design complete, most requirements are now known.

Cost Expended/Committed to Date: $\$ 2,668 \mathrm{~K}$ variance ( $\$ 264 \mathrm{~K}$ ).

Schedule Progress Against Current Baseline (Percent Complete):

$\begin{array}{lc}\text { BCWP } & 2,404 \mathrm{~K} \\ \text { Budgeted } & 21,543 \mathrm{~K}=11.2 \text { percent } \\ \text { Variance } & (1,885 \mathrm{~K})\end{array}$

WBS No. 714 - West Complex Experimental North Infrastructure

Technical: This WBS includes infrastructure items associated with other conventional construction activities, utilities, spoils, paving and environmental work they are normally part of larger construction packages. Infrastructure is basically standard conventional construction. With the conventional construction design program around 65 percent complete, most requirements are now known.

Cost Expended/Committed to Date: $\$ 196 \mathrm{~K}$ variance $(\$ 23 \mathrm{~K})$ 
Schedule Progress Against Current Baseline (Percent Complete):

BCWP

Budgeted

Variance
$173 \mathrm{~K}$

$4,690 \mathrm{~K}=3.7$ percent (638K)

WBS No. 715 - West Complex Experimental South Infrastructure

Technical: This WBS includes infrastructure items associated with other conventional construction activities, utilities, spoils, paving and environmental work they are normally part of larger construction packages. Infrastructure is basically standard conventional construction. With the conventional construction design program around 65 percent complete, most requirements are now known.

Cost Expended/Committed to Date: $\$ 310 \mathrm{~K}$ variance $(\$ 29 \mathrm{~K})$.

Schedule Progress Against Current Baseline (Percent Complete):

$\begin{array}{lc}\text { BCWP } & 281 \mathrm{~K} \\ \text { Budgeted } & 7,469 \mathrm{~K}=3.8 \text { percent } \\ \text { Variance } & (72 \mathrm{~K})\end{array}$

WBS No. $721-E-1$ Campus Surface Buildings

Technical: Project complete (conventional construction); equipment portion of WBS in construction.

Cost Expended/Committed to Date: $\$ 52,707 \mathrm{~K}$.

Schedule Progress Against Current Baseline (Percent Complete): 77.9 percent complete.

WBS No. 722 - El Area Infrastructure

Technical: Infrastructure to serve existing building is essentially complete; infrastructure to serve the N15 Warehouse has not yet started design.

Cost Expended/Committed to Date: $\$ 16,930 \mathrm{~K}$. 
Schedule Progress Against Current Baseline (Percent Complete):

$\begin{array}{ll}\text { BCWP } & 19,212 \mathrm{~K} \\ \text { Budgeted } & 19,704 \mathrm{~K}=97.5 \text { percent }\end{array}$

\section{WBS No. 732 - East Complex Experimental North}

Technical: This WBS includes infrastructure items associated with other conventional construction activities, utilities, spoils, paving and environmental work that are normally part of larger construction packages. Infrastructure is basically standard conventional construction. With the conventional construction design program around 65 percent design complete, most requirements are now known.

Cost Expended/Committed to Date: $\$ 1,078 \mathrm{~K}$ variance ( $\$ 224 \mathrm{~K})$.

Schedule Progress Against Current Baseline (Percent Complete):

BCWP

Budgeted

Variance
$854 \mathrm{~K}$

$11,418 \mathrm{~K}=7.5$ percent

$(1,178 \mathrm{~K})$

\section{WBS No. 733 - East Complex Experimental South}

Technical: This WBS includes infrastructure items associated with other conventional construction activities, utilities, spoils, paving and environmental work that are normally part of larger construction packages. Infrastructure is basically standard conventional construction. With the conventional construction design program around 65 percent complete, most requirements are now known.

Cost Expended/Committed to Date: $\$ 2,698 \mathrm{~K}$ variance $(\$ 1,587 \mathrm{~K})$.

Schedule Progress Against Current Baseline (Percent Complete):

$\begin{array}{lc}\text { BCWP } & 1,111 \mathrm{~K} \\ \text { Budgeted } & 10,289 \mathrm{~K}=10.8 \text { percent } \\ \text { Variance } & (267 \mathrm{~K})\end{array}$


WBS No. 741 - Collider Infrastructure

Technical: This WBS includes infrastructure items associated with other conventional construction activities, utilities, spoils, paving and environmental work that are normally part of larger construction packages. Infrastructure is basically standard conventional construction. With the conventional construction design program around 65 percent complete, most requirements are now known.

Cost Expended/Committed to Date: $\$ 3,381 \mathrm{~K}$ variance $(\$ 1,396 \mathrm{~K})$.

\section{Schedule Progress Against Current Baseline (Percent Complete):}

BCWP
Budgeted
Variance
$\$ 4,777 \mathrm{~K}$

$\$ 26,647 \mathrm{~K}=17.9$ percent $(\$ 1,937 \mathrm{~K})$

WBS No. 751 - Off-Site Facilities and Infrastructure

Technical: The work on the Central Facility is proceeding on schedule.

Cost Expended/Committee to Date: $\$ 30,390$.

Schedule Progress Against Current Baseline (Percent Complete): 88 percent complete.

\subsubsection{Plan to Complete}

The subgroup evaluated the May 1993 SSC Project Status Report as the Laboratory's plan to complete. The evaluation by the subgroup is contained under the heading assessment of Plan to Complete elsewhere in this report.

\subsubsection{Interfaces}

Except for the campus and infrastructure, the conventional construction scopes of work are within the various machine Work Breakdown Structures (WBSs). The design requirements as well as the completed designs require the machine leaders' approval. 
The interface between the conventional-construction CAMs and the machine leaders appears to be adequate. It should be noted that a major portion of the conventionalconstruction design and the construction itself is required to be completed before the design of the special research facilities has been fully completed. Experience from past construction projects, and from certain fast-tracked conventional facilities on this project, indicates that this will lead to costly changes or major retrofits in order to accommodate changes to the machine designs or needs of the projects. Outfitting of buildings is not done by the CCD, but rather by Laboratory Technical Services. It is not always clear what WBS is charged for changes. The potential for duplication of staff exists between the CCD and Laboratory Technical Services.

There is a lack of data integration (both cost and schedule) across WBS categories. This masks the total potential impact to cost and schedule changes caused by individuals and collectives.

\subsubsection{Documentation Available and Reviewed}

Conventional Construction Document Listing reviewed in addition to documents provided to all committees is shown below.

Number

1. CCN 093-0896

2. CCN 093-0896

3. SSC Laboratory

4.

5.

6. $\mathrm{CCN} 093-0891$

7. $\mathrm{CCN}$ 093-0896

8. SSC Laboratory

9.

10. SSCL Chg. Rqst

11. SSCL Chg. Rqst.

12. None

13. None

14. None

15. SSCL Doc. No. Y15-00018

Rev. AOO

16. None
Title

PB/MK Monthly Cost Schedule Process Report

FY 93 Annual Work Plan Status Report-May 1993

Project Contingency Plan

Conventional Construction FY 931 yr. Roller FY93

Conventional Construction 10 yr. PMB

FY93 Annual Work Plan Status Report-Man 1993

Monthly Cost/Schedule Progress Report Definitive Subcontract SSC-90B-0946

Project Contingency Plan

Conventional Construction $\mathrm{K} \$ \mathrm{X}$-Walk-Old to

New WBS

E20-000519/E12-000174

G12-000120

HEB Work Scope prepared by R. Molenaar

Working Papers WBS 314 (M.J. Bebon)

Handout from R. Molenaar SSCL CAM for WBS 314 None

Excerpt from Draft Design Requirement Doc for HEB 4/30/93

Cindy Howe (SSCL) memo of 7/7/93, Subject

Responsibility Assignment Matrix
Date of

Document

$6 / 22 / 93$

$6 / 21 / 93$

$8 / 1 / 93$

$6 / 2 / 93$

$6 / 2 / 93$

$6 / 21 / 93$

$6 / 22 / 93$

$8 / 1 / 93$

$10 / 1 / 92$

$12 / 4 / 92$

$11 / 6 / 92$

$7 / 20 / 93$

$7 / 23 / 93$ 
17. None

18. None

19. None

20. None

21. PAO-000031

Rev C

22. E12-000187

23. E12-000114C

24. E12-0000120

25. None

26. E12-000254

27. E12-000170

28. E-12-000171

29. E12-000211

30. E12-000225

31. E12-000225

32. E12-000227

33. E12-000261

34. E22-000018

35. E22-000020

36. None

37. E12-000227

38. E12-000261

39. E22-000018

40. E22-000020

41. E22-000020

42. E20-000151C

43. E10-000057

44. E10-000056
J. Ives (SSCL) memo of 6/24/93, Subj. Infrastructure Cost Estimate

Project Management Control System Compliance

$6 / 24 / 93$

$7 / 93$

Earned Value for the May CPR

Working Paper-William O'Connor-WBS 324

$7 / 93$

Configuration Management System

$3 / 3 / 93$

CCD Baseline Adjustment with Back-up

$2 / 3 / 93$

BCE Update to Correct WBS Allocation

Low System Changes for Linac, LEB, MEB

$6 / 2 / 93$ and Test Beam

CCB Log Report as of July 8, 1993

EEC Scope/Subcontract Adjustment SSCPO Ltr $\quad 5 / 11 / 92$ of July 8, 1993

HEB and Collider Service Areas

(Date approved by Schwitters)

Test Beam Budget Redistribution

$12 / 16 / 93$

LEB, MEB, MEB Power Systems

$5 / 6 / 93$

IR5 and IR8 Experimental Facilities (Schedule Chg.) 5/19/93

Collider Stub-out Tunnel Dimensions Increase $\quad 5 / 19 / 93$ Increase at IR5 and IR8

525 and 540 Tunnel Drive Redirection 5/3/93

Collider Tunnel Concrete Lining Additions $6 / 18 / 93$

Linac Conventional Construction-Construct 6/20/93 Crane Foundation

Exploratory Shaft Instrumentation and Monitoring $\quad 6 / 18 / 93$

Convuntional Construction Budget and Changes 7/22/93 by Carney

S25 to S40 Tunnel Drive Redirection 5/3/93

Collider Tunnel Concrete Lining Additions $\quad 6 / 18 / 93$

LINAC Conventional (Construction-Construct Crane Foundation) 5/20/93

Exploratory Shaft Instrumentation and Monitoring $\quad 5 / 18 / 93$

Conventional (Construction Budget Changes by Carney) 7/22/93

General Warehousing 3/11/92

Level 2 System Spect. on Buildings of the Superconducting Super Collider 3/31/93

Level 2 System Spec. for SSC Infrastructure 3/26/93

\subsubsection{Assessment of Plan to Complete}

WBS No. 114 - Conventional Construction Division Management

A. Assessment of Projected Configuration Control Board Changes

1. Approved Changes Since May 1993 Monthly Progress Report: None

2. Pending Changes: None

3. Projected Future Changes: $\$ 25$ million for CCD management and administrative costs for FY 1995 through FY 1999 
B. Assessment of Risk

1. Technical: Low; CCD studies and PB/MK design are more than 60 percent complete and SSCL has a good basis for remaining technical work

2. Schedule: Low; key activities are on schedule

3. Cost (Contingency): Low; assuming the additional $\$ 25$ million is funded

4. Overall Assessment: Low; there appears to be a low overall risk to this WBS element

C. Assessment of Cost at Completion

Given a low overall risk, a 5 percent contingency allowance is recommended.

Current May 1993 Estimated Cost at Completion

Additional Budget for FY 1995 - FY 1999 Staffing

Estimate at Completion

$101,798 \mathrm{~K}$

$\frac{25,000 \mathrm{~K}}{126,798 \mathrm{~K}}$

Contingency Allocation (5 percent)

WBS No. 214 - Linac Conventional Construction

A. Assessment of Projected Configuration Control Board Changes

1. Approved Changes Since May 1993 Monthly Progress Report:

E12-000120-LCW System Changes-\$129K

2. Pending Changes: None

3. Projected Future Changes: Design errors and omissions $\$ 476 \mathrm{~K}$

B. Assessment of Risk

1. Technical: Low; design 100 percent; no new technology; 5 percent contingency

2. Schedule: Low; baseline completion August 1993

3. Cost (Contingency): Low; design 100 percent; construction 75 percent

4. Overall Assessment: Low

C. Assessment of Cost at Completion

$\mathrm{CM}$

Title I \& II

$554 \mathrm{~K}$

Title III

Contract value

LCW System Changes

Design Errors \& Omissions

EAC

* Current PMB is $\$ 6,825 \mathrm{~K}$. The EAC of $\$ 6,497 \mathrm{~K}$ reflects the actual construction contract award.

Recommended Contingency: 5 percent 
A. Assessment of Projected Configuration Control Board Changes

1. Approved Changes Since May 1993 Monthly Progress Report:

E12-000120-LCW Changes- $\$ 178 \mathrm{~K}$

2. Pending Changes: None

3. Projected Future Changes: Design errors and omissions $\$ 300 \mathrm{~K}$

B. Assessment of Risk

1. Technical: Design 100 percent; no new technology; risk low

2. Schedule: Low

3. Cost (Contingency): Contract awarded, but less than 50 percent complete; 15 percent contingency

4. Overall Assessment: Low risk

C. Assessment of Cost at Completion

\section{$\mathrm{CM}$}

Title I \& II

Title III

Const. Contract

LCW System Changes

Design errors and omissions

EAC

$$
\begin{gathered}
360 \mathrm{~K} \\
1,127 \\
200 \\
5,536 \\
178 \\
300 \\
\hline 7,701 \mathrm{~K}^{*}
\end{gathered}
$$

* Current PMB is $\$ 795 \% \mathrm{~K}$. The EAC of $\$ 77(01 \mathrm{~K}$ reflects the actual construction contract award.

Recommended Contingency: 15 percent

WBS No. $234-M E B$ Conventional Construction

A. Assessment of Projected Configuration Control Board Changes

1. Approved Changes Since May 1993 Monthly Progress Report: E12-000120-LCW Changes-\$123K

2. Pending Changes: None

3. Projected Future Changes: Change E12-000168 is in current contract 
B. Assessment of Risk

1. Technical: Design complete; no new technology; risk low

2. Schedule: Risk low

3. Cost (Contingency): Contract awarded, but 0 percent complete 15 percent contingency

4. Overall Assessment: Low risk

C. Assessment of Cost at Completion

$\mathrm{CM}$

Construction Contract Value

Title I \& II

Known Additions

Title III

EAC
$114 \mathrm{~K}$

33,983

1,823

123

$\frac{41}{36,084 \mathrm{~K}}$

Recommended Contingency: 15 percent

WBS No. 314.3110: - HEB Conventional Construction

A. Assessment of Projected Configuration Control Board Changes

1. Approved Changes Since May 1993 Monthly Progress Report: None

2. Pending Changes: None

3. Projected Future Changes:

Impact on

HEB EAC

3.1 Project TEC Impacts

Tunnel Cooling System

- not in design requirements document scope

$\$ 7 \mathrm{M} \quad \$ 7 \mathrm{M}$

- chilled water/air handling units to maintain niche temperature at approximately $85^{\circ} \mathrm{F}$

- cooling pond and cooling towers

Industrial Cooling Water System $\quad \$ 2.8 \mathrm{M}$

$\$ 2.8 \mathrm{M}$

- not in design requirements document scope

- provide heat rejection from low conductivity water (LCW) (closed-loop) system

- pumps and associated piping from LCW heat exchanger to cooling-pond and cooling towers

H-30 and $\mathrm{H}-70$ Shafts

Impact on

HEB EAC

- eliminate
$(\$ 0.5 \mathrm{M})$

Impact on

Project EAC

$(\$ 0.5 \mathrm{M})$ 


\subsection{Internal Scrope/Cost Realignment}

\section{MEB - HEB Transfer Tunnels}

$$
\$ 0 \mathrm{M}^{1}
$$

$\$ 0 \mathrm{M}$

- move 200 LF of clockwise tunnel to HEB

- move $1200 \mathrm{LF}$ of counterclockwise tunnel to HEB

HEB - Collider Transfer Tunnels

$(\$ 4.1 \mathrm{M})$

$\$ 0 \mathrm{M}$

- move both transfer tunnels to W. Utility Straight (324.315)

- move HEB tunnel section into W. Utility Straight (324.315)

H-10 North Shaft

- move to W. Utility Straight (324.315)

$\$ 0 \mathrm{M}$

- redesignate $\mathrm{N} 135$

Magnet Delivery Shaft Headhouse $\quad(\$ 0.5 \mathrm{M})^{2} \quad \$ 0 \mathrm{M}$

- transfer responsibility for Magnet Delivery Shaft from HEB/CCD to ASD (411.1210)

$$
\text { TOTAL } \$ 2.4 \mathrm{M}
$$

$\$ 9.3 \mathrm{M}$

Notes:

1 BCE for HEB included 50 percent of MEB to HEB tunnels

2 WBS 411.1210 estimate for the Magnet Delivery Headhouse being transferred in is $\$ 1.26$ million vs. the $\$ 536 \mathrm{~K}$ being transferred from WBS 314 .

B. Assessment of Risk:

1. Technical: Low

- There is significant and local experience with tunneling conditions and shaft construction from construction activities associated with the collider.

- Remainder of WBS is standard conventional construction.

- Minor concern over feasibility of design assumption that no potable water/sanitary service is required for surface facilities.

2. Schedule: Low

- Design Requirements Document complete and well-scoped.

- Design and Construction schedule appears adequate.

- No significant technical issues exist which could impact design and construction schedule.

Note: Current plan is for a single construction contract package for this entire WBS; this makes schedule adherence highly dependent on Budget Authority (BA) 
3. Cost (Contingency): Low

- There is considerable cost data available on tunneling from collider contracts.

- Borings indicate virtually all of HEB and shafts will be in Austin Chalk, the most favorable geologic condition.

- The HEB tunnel does not cross under significant surface water

4. Overall Assessment: With the exception of the decision to package the entire WBS into a single construction contract. There appears to be a low overall risk to project completion, on-time/within budget, with the exception of the currently identified changes for tunnel cooling and industrial cooling water systems.

\section{Assessment of Cost at Completion}

The scope of this review was to evaluate changes from the 1/91 DOE baseline ("Green Book") and assess estimate at completion based on progress to date $(5 / 93)$ projected changes, and related issues.

- High Energy Booster-Cost Baseline

(\$K)

1/91 Green Book

CCB Actions through 10/1/92

E 12 - 18 Decrease circumference

E 12 - 65 Chg. Collider elev.

10/1/92 Baseline

$(2,124)$

Escalation added

71,903

E 12 - 187 CC.D Baseline Adj.

5/93 Current Baseline

Add: Approved CCB Changes (E 12 - 170)

5,723

(5,814)

71,815

Add: Future Baseline Changes:

PB/MK Charges

Tunnel Cooling System

Industrial Cooling Water System

Delete H-30 and H-70 Shafts

Adjust as appropriate

Subtotal

5/93 Projected Estimate at Completion

Less: Future Transfers to other

Proiect WBS Elements

HEB to Collider Tunnels to 324.315

H-10 North Shaft to 324.315

81,312

Magnet Delivery Headhouse to ASD

Revised Estimate At Completion 
- High Energy Booster Conventional Construction - Contingency

The predominant portion ( $~ 90$ percent) of the HEB conventional construction scope is the tunnel, shafts, and related services. The tunnel is basically the same as the Collider and should be all in Austin chalk, the most favorable geologic material. The SSCL and area contractors have gained appreciable cost and technical experience on tunneling. As a result, at this point in the project schedule, a 10 percent contingency on the current baseline is recommended.

The future baseline changes are not well scoped at this time and should, therefurc, carry a higher contingency; 25 percent is recommended.

Contingency Required (K\$)

$\begin{array}{lrr}\text { Current Baseline } & (\$ 71,815) \times 0.10= & 7,182 \\ \text { Approved CCB Changes }(172 \times 0.10)= & 17 \\ \text { Future Baseline Changes }(\$ 9,325) \times 0.25= & 2.331 \\ \text { Total Contingency } & 9,530\end{array}$

- HEB Conventional Construction Cost Summary

5/93 Current Baseline

Contingency

Approved CCB Change w/Contingency

71,815

7,182

Future Baseline Changes

Reductions

9,325

Contingency

Estimate at Completion Including Contingency

Contingency $\%$ Overall $=\$ 9,530 / 73,592=12.9 \%$ 
WBS No. 324 - Collider Conventinnal Construction

\section{A. Assessment of Projected Configuration Control Board Changes}

1. Approved Changes Since May 1993 Monthly Progress Report:

Inc. Collider and HEB Cold Box Area Bldg.

Collider Tunnel Conc Liner Plate Additions N20-N225

Tunne: Above Size Adjustment

Subtotal

2. Pending Changes:

Add S10 Shaft

3. Projected Future Changes:

Concrete Increase Tunnel Finish

West Utility Straight-Include N10 Shaft

Subtotal

3.408

Collision Optics Shafts/Galleries

3,408

Electrical $69 \mathrm{KV}$ distrib/10 substations and collider ring feed

Note: High risk item HEB to Collider Tunnels

H-10 North Shaft

Subtotal

TOTAL $=20,371 \mathrm{~K}$

20,000

5,440

6,528

$(24,100)$

4,145

2,258

14,271

\section{B. Assessment of Risk}

1. Technical: Low

- 6 of 10 tunnel sections under contract

- 29 of 36 shafts under contract (15 completed)

- Remaining work under design

2. Schedule: Low

Work generally progressing well. Some concern as there is no Integrated Master Schedule. Thus, is not possible to see how a delay in one of WBS 324 items affects project completion.

3. Cost (Contingency): Low

Only complicated work in WBS is tunneling. As 5 of 6 awarded tunnels are under construction, costs are well know. With reasonably good ground and little water, risk is low. Some concern as there is no Integrated Construction Management Information System that tracks all the costs to a bottom line number.

4. Overall Assessment

Tunnel construction is planned and executed well. Is obvious that SSC has able and experienced personnel running this portion of the work. So far, they appear to have done all the right things, and looking ahead, there appears to be no potential problems. 
C. Assessment of Cost at Completion

$\begin{array}{llc}\text { WBS 324-BAC } & = & 477,913 \mathrm{~K} \\ \text { Projected CCB's } & = & 20,371 \\ \text { Estimate of Completion } & = & 498,284 \\ \text { Actual Cost of Work Performed } & = & 66,646 \\ \text { Work Remaining } & = & 431,638 \\ \text { Contingency @ 10\% } & = & 43,164 \mathrm{~K}\end{array}$

WBS No. 325.311 - ASST Conventional Construction

A. Assessment of Proiected Configuration Control Board Changes

1. Approved Changes Since May 1993 Monthly Progress Report: None

2. Pending Changes: None

3. Projected Future Changes: None

B. Assessment of Risk

1. Technical: Low

2. Scheulule: N/A

3. Cost (Contingency): N/A

4. Overall Assessment: N/A

C. Assessment of Cost at Completion Same $\$ 7.173$

WBS No. 541 - WN IR-1 Conventional Construction

A. Assessment of Projected Cc.nfiguration Control Board Changes

1. Approved Changes Since May 1993 Monthly Progress Report: None

2. Pending Changes: None

3. Projected Future Changes: None

B. Assessment of Risk

1. Technical: Medium; design requirements not defined-no new technolozy

2. Schedule: Low; scheduled design start 1995

3. Cost (Contingency): Medium; design requirements undefined; 20 percent cost contingency recommended

4. Overall Assessment: Medium 
C. Assessment of Cost at Completion

$\$ 20,458$ estimate is a budget number based on excavation required to accommodate very preliminary experiment equipment. Final experiment equipment may result in significant pluses or minuses to this estimate.

We support the $\$ 20,458 \mathrm{PMB}$, but recommend a 20 percent contingency.

$\$ 391 \mathrm{~K}$ spent to date on early studies is a lost effort.

$$
\text { EAC } \quad \frac{20,458 \mathrm{~K}}{20,849 \mathrm{~K}}
$$

Recommended Contingency: 20 percent

WBS No. 542 - WS IR-4 Conventional Construction

\section{A. Assessment of Projected Configuration Control Board Changes}

1. Approved Changes Since May 1993 Monthly Progress Report:

2. Pending Changes: None

3. Projected Future Changes: None

B. Assessment of Risk

1. Technical: Medium; design requirements not established; 20 percent contingency

2. Schedule: Low

3. Cost (Contingency): Medium; design requirements not established

4. Overall Assessment: Medium risk

C. Assessment of Cost at Completion

$\$ 1,774 \mathrm{~K}$ based on slight widening of tunnel to accommodate experiment equipment; \$260K spent to date on lost efforts.

$$
\mathrm{EAC}=\$ 2,034 \mathrm{~K}
$$

Recommended Contingency: 20 percent 
WBS No. 543 - EN IR-8 Conventional Construction

A. Assessment of Projected Configuration Control Board Changes

1. Approved Changes Since May 1993 Monthly Progress Report: None

2. Pending Changes: E20-000519 HVAC and electrical scope omitted; $\$ 6.8$ million

3. Projected Future Changes: None

B. Assessment of Risk

1. Technical: Low; design complete; no new technology

2. Schedule: Low

3. Cost (Contingency): Low; underground work contract and assembly building contract awarded; 20 percent contingency

4. Overall Assessment: Low risk

C. Assessment of Cost at Completion

$\mathrm{CM}$

Title I \& II

Title III

Fin. Sys Const (est)

Assy Build Contract Value

Other Constr. (est)

$\mathrm{U} / \mathrm{C}$ Const.

Contract Value

Pending Add.

EAC
$4,031 \mathrm{~K}$

1,894

540

8,034

7,820

9,890

25,757

$\frac{6,800}{64,766 \mathrm{~K}}$

Recommended Contingency: 20 percent

WBS No. 544 - ES IR-5 Conventional Construction

A. Assessment of Projecter Configuration Control Board Changes

1. Approved Changes Since May 1993 Monthly Progress Report: None

2. Pending Changes: E20-000519 Additional HVAC and Electrical Scope $9,900 \mathrm{~K}$

3. Projected Future Changes: None 


\section{B. Assessment of Risk}

1. Technical: Low; design complete; no new technology

2. Schedule: Low; on schedule

3. Cost (Contingency): Low; underground construction contract awarded; 20 percent contingency

4. Overall Assessment: Low

C. Assessment of Cost at Completion

$\begin{array}{lc}\text { CM } & 4,027 \mathrm{~K} \\ \text { Title I \& II } & 2,094 \\ \text { Title III } & 409 \\ \text { U/G Const. Contract Value } & 29,732 \\ \text { Fin. Syst (est) } & 7,387 \\ \text { Assy Buildings (est) } & 17,830 \\ \text { Other Const (est) } & 6,034 \\ \text { Pending Add } & 9,900 \\ \text { EAC } & 77,413 \mathrm{~K}\end{array}$

Recommend Contingency: 20 percent

WBS No. 545 - Support Facilities

A. Assessment of Projected Configuration Control Board Changes

1. Approved Changes Since May 1993 Monthly Progress Report: None

2. Pending Changes: None

3. Projected Future Changes: None

B. Assessment of Risk

1. Technical: No risk

2. Schedule: No risk

3. Cost (Contingency): No risk

4. Overall Assessment: WBS complete; no risk

C. Assessment of Cost at Completion Actual Cost of Work Performed-\$3,333K 
WBS No. 565 - Test Beams Conventional Construction

A. Assessment of Projected Configuration Control Board Changes

1. Approved Changes Since May 1993 Monthly Progress Report:

E12-000120 LCW System Changes; $\$ 156 \mathrm{~K}$

2. Pending Changes: None

3. Projected Future Changes: None

B. Assessment of Risk

1. Technical: Low; design complete; no new technology

2. Schedule: Low

3. Cost (Contingency): Medium; design complete, but contract not awarded

4. Overall Assessment: Low

C. Assessment of Cost at Completion

$\begin{array}{ll}\text { PMB } & 20,326 \mathrm{~K} \\ \text { LCW Changes } & \frac{156}{20,482 \mathrm{~K}}\end{array}$

Recommended Contingency: 15 percent (contract not awarded)

WBS No. 711 - West Campus Facilities, Conventional Construction

A. Assessment of Projected Configuration Control Board Changes

1. Approved Changes Since May 1993 Monthly Progress Report: None

2. Pending Changes: None

3. Projected Future Changes:

- Title I Redesign. [Additional \$300K]

- Title I design previously completed, but is now obsolete due to siting change of West Campus Surface Buildings

- Title I will be redesigned from scratch 


\section{B. Assessment of Risk}

1. Technical: Medium

- The design requirements are not complete

- The requirements are being driven by baseline cost

- Siting of campus is not approved

- Decision needs to be made if Central Facility is permanent place for exchange of campus

2. Schedule: Low

- There should be no urgency for construction

- Should not be affected by technical changes

3. Cost (Contingency): Low

- Basic office and admin type construction

4. Overall Assessment: Low overall risk

C. Assessment of Cost at Completion

Baseline EAC

Changes

Committee EAC
$39,838 \mathrm{~K}$

300

$\overline{40,138 \mathrm{~K}}$

Contingency: 10 percent of remaining work

WBS No. 712 - West Campus Common Infrastructure, Conventional Construction

A. Assessment of Projected Configuration Control Board Changes

1. Approved Changes Since May 1993 Monthly Progress Report: None

2. Pending Changes:

- Industrial Road-\{additional $\$ 2,100 \mathrm{~K}\}$

3. Projected Future Changes:

- Radioactive material, hazardous waste storage and handling facilities [additional \$3,100k]-unforeseen Requirement

- Infrastructure, Electrical [additional $\$ 11,700 \mathrm{~K}$ ]

- Gas Utility Savings [savings of $\$ 200 \mathrm{~K}$ ]

\section{B. Assessment of Risk}

1. Technical: Low

- All requirements have been developed

- Standard conventional construction

- Siting information allows adequate time for design activities 
2. Schedule: Low

- This WBS is basically only a part of a larger construction package

- Schedule appears adequate for both design and construction

3. Cost (Contingency): Low

- All construction in the WBS is standard conventional construction and contractors should bid with minimum contingency

- Siting information is known and should result in minimal changes during construction

4. Overall Assessment: Low

- This appears to be a low overall risk to completing the project on-time and within budget

C. Assessment of Cost at Completion

Baseline EAC

Changes

$61,177 \mathrm{~K}$

Committee EAC

16.700

$77,877 \mathrm{~K}$

Recommended Contingency: 10 percent of remaining work

WBS No. 713 - West Campus Injector Infrastructure, Conventional Construction

\section{A. Assessment of Projected Configuration Control Board Changes}

1. Approved Changes Since May 1993 Monthly Progress Report:

- LCW systems changes for LINAC, LEB, MEB [savings of \$2,364K]

- CCD Fund Transfer

2. Pending Changes:

- Injector cooling pond spillway [additional \$300K]

3. Projected Future Changes:

- Communication ducts for injectors [additional $\$ 6,200 \mathrm{~K}$ ]

- understated baseline cost estimate

- Water utility savings [additional $\$ 100 \mathrm{~K}$ ]

- Gas utility savings [savings of $\$ 1,000 \mathrm{~K}$ ]

- Sewer utility savings [savings of $\$ 400 \mathrm{~K}$ ]

B. Assessment of Risk

1. Technical: Low

- All requirements have been developed

- Standard conventional construction

- Siting information allows adequate time for design activities 
2. Schedule: Low

- This WBS is basically only a part of a larger construction package

- Schedule appears adequate for both design and construction

3. Cost (Contingency): Low

- All construction in the WBS is standard conventional construction and contractors should bid with minimum contingency

- siting information is known and should result in minimal changes during construction

4. Overall Assessment: Low

- this appears to be a low overall risk to completing the project on-time and within budget

C. Assessment of Cost at Completion

Baseline EAC

Changes

Committee EAC
$21,543 \mathrm{~K}$

2.836

$24,379 \mathrm{~K}$

WBS No. 714 - West Campus Experimental North Infrastructure, Conventional Construction

A. Assessment of Projected Configuration Control Board Changes

1. Approved Changes Since May 1993 Monthly Progress Report: None

2. Pending Changes: None

3. Projected Future Changes: None

B. Assessment of Risk

1. Technical: Low

- All requirements have been developed

- Standard conventional construction

- Siting information allows adequate time for 'esign activities

2. Schedule: Low

- This WBS is basically only a part of a larger construction package

- Schedule appears adequate for both design and construction 
3. Cost (Contingency): Low

- All construction in the WBS is standard conventional construction and contractors should bid with minimum contingency

- Siting information is known and should result in minimal changes during construction

4. Overall Assessment: Low

- This appears to be a low overall risk to completing the project on-time and within budget

C. Assessment of Cost at Completion

Baseline EAC

Changes

Committee EAC

$$
\begin{gathered}
4,690 \mathrm{~K} \\
\frac{0}{4,690 \mathrm{~K}}
\end{gathered}
$$

Recommended Contingency: 10 percent of remaining work

WBS No. 715 - West Campus Experimental South Infrastructure, Conventional Construction

A. Assessment of Projected Configuration Control Board Changes

1. Approved Changes Since May 1993 Monthly Progress Report: None

2. Pending Changes: None

3. Projected Future Changes:

- South loop connector road (additional $\$ 3,000 \mathrm{~K}$ )

- siting change

- West IR cooling pond (additional $\$ 2,000 \mathrm{~K}$ )

- unforeseen environmental regulations

- IRs $1,4,5$, and 8 communication ducts (additional $\$ 1,700 \mathrm{~K}$ )

- understated baseline cost estimate

B. Assessment of Risk

1. Technical: Low

- All requirements have been developed

- Standard conventional construction

- Siting information is known

- The schedule allows adequate time for design activities 
2. Schedule: Low

- This WBS is basically only a part of a days construction planning

- Schedule appears adequate for both design and construction

3. Cost (Contingency): Low

- All construction in the WBS is standard conventional construction and contractors should bid with minimum contingency

- Siting information is known and should result in minimum changes during construction

4. Overall Assessment:

- There appears to be a low overall risk to completing project on time and within budget

C. Assessment of Cost at Completion

Baseline EAC

Changes

Committee EAC
$2,469 \mathrm{~K}$

$\frac{6,700}{14,169 \mathrm{~K}}$

Contingency: 10 percent of remaining work

WBS No. 721 - E1 Campus Facilities Conventional Construction

A. Assessment of Projected Configuration Control Board Changes

1. Approved Changes Since May 1993 Monthly Progress Report: None

2. Pending Changes: None

3. Projected Future Changes: None

B. Assessment of Risk

Conventional construction 90 percent complete-only warehouse facilities remain to be constructed; minimum risk

1. Technical: Low

2. Schedule: Low

3. Cost (Contingency): Low

4. Overall Assessment: Low 
C. Assessment of Cost at Completion

Baseline EAC $\$ 62,742 \mathrm{~K}$

Changes

Committee EAC $\$ 62,742 \mathrm{~K}$

Contingency: 10 percent of remaining work

WBS No. 722 - E1 Campus Infrastructure Conventional Construction

A. Assessment of Projected Configuration Control Board Changes

1. Approved Changes Since May 1993 Monthly Progress Report:

- N15 warehouse [additional $\$ 1,100 \mathrm{~K}$ ]

2. Pending Changes: None

3. Projected Future Changes:

- Infrastructure; electrical [additional $\$ 600 \mathrm{~K}$ ]

- understated baseline cost estimate

\section{B. Assessment of Risk}

1. Technical: Low

- All requirements have been developed

- Standard conventional construction

- Siting information allows adequate time for design activities

2. Schedule: Low

- This WBS is basically only a part of a larger construction package

- Schedule appears adequate for both design and construction

3. Cost (Contingency): Low

- All construction in the WBS is standard conventional construction and contractors should bid with minimum contingency

- Siting information is known and shcuid result in minimal changes during construction

4. Overall Assessment: Low

- This appears to be a low overall risk to completing the project ontime and within budget 


\section{Assessment of Cost at Completion}

Baseline EAC

Changes

Committee EAC
$19,704 \mathrm{~K}$

$\frac{1,700}{21,404}$

Contingency: 10 percent of remaining work

WBS No. 732 - East Campus Experimental North Infrastructure Conventional Construction

A. Assessment of Projected Configuration Control Board Changes

1. Approved Changes Since May 1993 Monthly Progress Report:

- IR5 and IR8 Site Grading [additional \$900K]

- CCB \# E12-000123

2. Pending Changes: None

3. Projected Future Changes:

- IR5 and IR8 cooling ponds [additional $\$ 1,500 \mathrm{~K}$ ]

- CCB\# E12-000219

- IRs $1,4,5$, and 8 communication ducts [additional $\$ 1,700 \mathrm{~K}$ ]

- understated baseline cost estimate

- Infrastructure; electrical [additional $\$ 10,800 \mathrm{~K}$ ]

- understated baseline cost estimate

B. Assessment of Risk

1. Technical: Low

- All requirements have been developed

- Standard conventional construction

- Siting information allows adequate time for design activities

2. Schedule: Low

- This WBS is basically only a part of a larger construction package

- Schedule appears adequate for both design and construction

3. Cost (Contingency): Low

- All construction in the WBS is standard conventional construction and contractors should bid with minimum contingency

- Siting information is known and should result in minimal changes during construction 
4. Overall Assessment: Low

- This appears to be a low overall risk to completing the project on-time and within budget

C. Assessment of Costat Completion

$\begin{array}{ll}\text { Baseline EAC } & 11,410 \mathrm{~K} \\ \text { Changes } & \frac{14,900}{26,310 \mathrm{~K}} \\ \text { Committee EAC } & \end{array}$

Contingency: 10 percent of remaining work

\section{WBS No. 733 - East Campus Experimental South Infrastructure Conventional} Construction

A. Assessment of Projected Configuration Control Board Changes

1. Approved Changes Since May 1993 Monthly Progress Report:

- IR5 and IR8 site grading [additional \$900K]

$$
\text { - CCB \# E12-000123 }
$$

2. Pending Changes:

- East Complex Connector Road [additional $\$ 3,000 \mathrm{~K}$ ]

- Wetland Mitigation E/W Complex [additional \$200K]

3. Projected Future Changes:

- IR5 and IR8 cooling pools [additional $\$ 2,000 \mathrm{~K}$ ]

- CCB\# E12-000219

- IRs $1,4,5$, and 8 communication ducts [additional $\$ 1,900 \mathrm{~K}$ ]

- understated baseline cost estimate

- Infrastructure; electrical [additional $\$ 1,000 \mathrm{~K}$ ]

- understated baseline cost estimate

\section{B. Assessment of Risk}

1. Technicai: Low

- All requirements have been developed

- Standard conventional construction

- Siting information allows adequate time for design activities

2. Schedule: Low

- This WBS is basically only a part of a larger construction package

- Schedule appears adequate for both design and construction 
3. Cost (Contingency): Low

- All construction in the WBS is standard conventional construction and contractors should bid with minimum contirgency

- Siting information is known and should result in minimal changes during construction

4. Overall Assessment: Low

- This appears to be a low overall risk to completing the project on-time and within budget

C. Assessment of Cost at Completion

Baseline EAC

Changes

Committee EAC
$10,289 \mathrm{~K}$

$$
9,000
$$$$
\frac{9,000}{19,289} \mathrm{~K}
$$

Contingency: 10 percent of remaining work

WBS No. 741 - Collider Infrastructure Conventional Construction

A. Assessment of Projected Configuration Control Board Changes

1. Approved Changes Since May 1993 Monthly Progress Report: None

2. Pending Changes:

- Collider remote site roads [additional $\$ 3,500 \mathrm{~K}$ ]

- CCB \#12-000079

3. Projected Future Changes: None

B. Assessment of Risk

1. Technical: Low

- All requirements have been developed

- Standard conventional construction

- Siting information allows adequate time for design activities

2. Schedule: Low

- This WBS is basically only a part of a larger construction package

- Schedule appears adequate for both design and construction 
3. Cost (Contingency): Low

- All construction in the WBS is standard conventional construction and contractors should bid with minimum contingency

- Siting information is known and should result in minimal changes during consiruction

4. Overall Assessment: Low

- This appears to be a low overall risk to completing the project on-time and within budget

C. Assessment of Cost at Completion

$\begin{array}{ll}\text { Baseline EAC } & 26,647 \mathrm{~K} \\ \text { Changes } & \frac{3,500}{30,147 \mathrm{~K}} \\ \text { Committee EAC } & \end{array}$

Coutingency: 10 percent of remaining work

WBS No. 751 - Off-Site Facilities and Infrastructure Conventional Construction

\section{A. Assessment of Projected Configuration Control Board Changes}

1. Approved Changes Since May 1993 Monthly Progress Report: None

2. Pending Changes: None

3. Projected Future Changes: None

B. Assessment of Risk

1. Technical: None

2. Schedule: None

3. Cost (Contingency): None; will complete on budget

4. Overall Assessment: Satisfactory

\subsubsection{Assessment of Business Management System}

\subsubsection{CCD Baseline Adjustment}

The subgroup attempted to evaluate the CCD Baseline as contained in the Business Management Systems used to prepare the May 1993 Monthly Status Report. One problem encountered by the subgroup was our confusion in determining the exact budget, by WBS, of the conventional construction portion of the project. An outside reviewer with little 
knowledge of the project would come to the conclusion, based on the maturity of the project, that there are potentially some serious problems with the business management system.

On February 3, 1993, the SSCL Configuration Control Board approved CCSR E12-000187, CCD Baseline Adjustment, dated February 3, 1993. CCB change 187 request reallocates the $\mathrm{CCD}$ baseline to reflect the $\mathrm{AE} / \mathrm{CM}$ contract negotiations and the expected construction contract bids. The change was a level two change. Accordingly, the change was submitted to DOE for approval, because the change to the baseline exceeded the Laboratory's threshold.

The actual effect of CCB change 187 was a negative $\$ 3,775,000$ based on escalation to then-year dollars. The change adjusted the construction budget down based on the trend in construction contracts awarded and increased the accounts for design, construction management and AE/CM support upward, again in then-year dollars, to reflect known overruns and shortfalls in budgets. The negative result of CCB 187 is as a result of spending more dollars sooner based on the reallocation of budget to earlier accounts thereby saving inflation. It should be noted that budgets for CCD salaries, insurance, medical, and temporary power, are not $\mathrm{PB} / \mathrm{MK}$ activities, but were included in the CCD/WBS 114. The West Campus facilities are also not PB/MK activities, but remain in WBS 711.

$\mathrm{CCB}$ change 187 was then reversed and a new change $\mathrm{CCB}$, change 254 , was approved, although neither change 187 has been deleted or change 254 added to the May 1993 Monthly Progress Reports Project Management Baseline (PMB). CCB change 254 reflects the amount of work remaining in the conventional construction program excluding work which is assigned to the Laboratory Technical Support Division. CCB change 254 recognizes a savings in actual bids received prior to October 1992 of $\$ 30,925,000$. The total impact of CCB change 254 is a positive $\$ 71.2$ million.

$\mathrm{CCB}$ change 254 will adjust the $\mathrm{PB} / \mathrm{MK}$ baseline to increase the budgets for the design, construction management, and the AE/CM support to conform to agreements reached during the negotiation of Modification 42 to the PB/MK contract. The Laboratory has also estimated that $\$ 22,694,000$ has been recognized in bid savings since October 1992. Therefore, there is some money which can be added to SSCL management reserve if the savings in fact are realized. 
However, as noted in the details contained in this report, the $\mathrm{CCD}$ budget for salaries is short by at least $\$ 25$ million since the account for salaries goes to zero after FY 1994. It is clear that CCD staff is required after FY 1994 to monitor the construction activities and design changes required.

It is the subgroup's conclusion that it is extremely difficult for an outside, independent team to determine the collective effect of CCB actions on the overall project status, given the lack of integration of CCBs across the WBS.

\subsubsection{Latest Revised Estimate (LRE)}

The subgroup found that the reporting of LRE in the May 1993 Project Status Report was totally inaccurate for the conventional construction WBS. The CAMs indicated this was the first attempt at reporting LRE and it was based on a computer formula. However, it is not clear that the formula reflects needed input from the CAM. An example is WBS 114, CCD Management and Administrative costs. The May 1993 Project Status Report indicated an LRE of $\$ 90,309 \mathrm{~K}$ with an original budget of $\$ 101,798 \mathrm{~K}$. WBS 114 contains such items as temporary power, insurance, etc., along with the administrative costs. Based on our discussions with various CAMs and staff of the project management office, it was clear that WBS 114 was already recognized to be short at least $\$ 25$ million. In looking at the salary budget for $\mathrm{CCD}$, only enotigh budget was available for one more year. The additional $\$ 25$ million would carry CCD through construction completion. Another WBS, WBS 751 indicated a projected cost overrun of $\$ 360 \mathrm{~K}$. The CAM for that account indicated that there would be no overrun and that the calculation was erroneous.

It was noted that approved Change Control Board Actions which were incorporated into the May 1993 Project Status Report were not reflected in the LRE. It would seem prudent that if the CCB was approved, whether budget had been allocated or not at the present time, that the LRE should be updated to reflect a growth in projected costs. The CAMs were also aware of pending CCB's as well as other changes which are not reflected in the LRE.

The LRE calculations did not give this subgroup a "warm" feeling that meaningful data was being provided. In fact we have a great deal of concern regarding how the LRE will be calculated in the future. 


\subsubsection{Work Breakdown Structure Detailed Dictionary}

In reviewing the detailed work breakdown structure (WBS) with several cost account managers, it was clear that scope which had either been reduced, transferred, or increased by Configuration Control Board actions were not reflected in the WBS detailed dictionary given to the DOE team by the SSCL. We are concerned that the WBS detailed dictionary is not being updated as CCB actions modify WBS elements. It seems to the subgroup that the detailed WBS dictionary communicates to the SSCL staff what the scope of the SSC project is, how it is broken-down, and who is responsible.

The subgroup found that the WBS detailed dictionary for WBS 117 did not indicate that certain scope of work for providing support to $\mathrm{PB} / \mathrm{MK}$ had been transferred to WBS 114. The Laboratory needs to take seriously the implications of not maintaining this very important management tool in defining how changes impact the overall project scope. Each CCB which impacts the detailed WBS dictionary should contain a revised dictionary package(s) which reflects the proposed changes. These changed pages could then be issued upon approval of the CCB action to communicate the changes to the Laboratory staff. This would also assist outside reviewers in examining and understanding the changes in project requirements between the original WBS and a given review date. Also, this would assure that scopes of work is not lost during transfers.

\subsubsection{Conclusions/Recommendations}

\subsubsection{Conclusions}

Even with the lack of maturity of the Project Management Systems, the overall conventional construction status has been determined by the Committee to be very close to the reported values in the May 1993 Project Status Report. Although some early contracts for certain facilities exceeded the Laboratory's estimate, more recent contracts have been awarded below the Laboratory estimates. The project is benefitting from a favorable bidding market.

Based on the size of the project and its level of maturity, the business management systems appear to be functional but not timely in responding to approved $\mathrm{CCB}$ changes impacting on the LRE for the conventional construction. There is no critical path based on a total-project-resource loaded integrated schedule. With numerous CCB actions not 
incorporated into the project management baseline in a timely manner, it is extremely difficult to ascertain cost and schedule status from the performance reports.

\subsubsection{Recommendations}

1. The WBS Detailed Dictionary should be updated to reflect the current CCB actions.

2. The site development plan should be approved by the Laboratory and put under configuration management.

3. All conventional construction should be managed by the CCD (e.g., N15 Warehouse being constructed by LTS, etc.) for efficiency and consistency.

4. It is mandatory that a resource loaded integrated project schedule showing the critical path be developed and reported on, on a monthly basis.

5. The Laboratory needs to improve the method for accurately reflecting the Latest Revised Estimate (LRE).

6. The Laboratory must incorporate CCB approved actions into the Project Management Baseline in a timely manner.

7. The acquisition strategy for the West Campus needs to be identified. 


\subsection{Environmental, Safety and Health}

\subsubsection{Executive Summary}

Although the Environmental, Safety and Health (ES\&H) Department within the Superconducting Super Collider Laboratory (SSCL) has not been specifically identified and funded in the present WBS, it has performed its function very successfully. The documentation required of this organization has been prepared and processed, and the necessary approvals have been obtained, in a timely manner. The ES\&H Department has rcsently issued a "5-year plan" and identified the necessary funds to implement it. The plan arid the identified additional funds (not now included in the EAC and estimated to be approximately $\$ 75.7$ million for FY 1993 through FY 1999) will be adequate to achieve their required tasks.

\subsubsection{Scope of Work Associated with WBS Assessed}

The ES\&H Department is responsible for developing, administering, and coordinating the SSCL's ES\&H program. The responsibility and authority for implementing the SSCL ES\&H program lies with line management.

\subsubsection{Assessment of Project Status}

Funding was never established for an independent ES\&H Department in the SSCL baseline. Consequently, each SSCL division hired personnel and initiated its own environmentai, safety, and health compliance effort. The ES\&H Department performed a support and overview role. This work was performed without any WBS identification and appears to have been accomplished with funds obtained from the Project Management and line organizations' budgets (an estimate of the costs incurred to date is $\$ 16$ million). The work has included support in the preparation and overview of Safety Analysis Reports (SARs), environmental permitting, environmental monitoring, medical, industrial safety and hygiene and radiological control. The subcommittee's assessment of this work indicates that it has been performed very successfuliy. The required documentation for NEPA compliance, environmental permitting, and safety has been prepared and processed, and the necessary approvals have been obtained, in a timely and effective manner. 


\subsubsection{Plan to Complete}

On February 24, 1993, a "Superconducting Super Collider Laboratory Environmental, Safety, and Health 5-Year Plan" was submitted to the U.S. Department of Energy. This Plan estimated the environmental, safety, and health operating expenses for Fiscal Years 1993-1999. A Change Control Board Request (CR\#E20-000608) dated February 12, 1993, which identifies the necessary funds for an independent ES\&H Department in the SSCL Baseline, is pending. The CR identifies 17 existing funded FTEs and a request for an additional 30 FTEs in FY 1993, peaking at an additional 79 FTEs in FY 1997. Requests for new labor dollars and new non-labor dollars range from $\$ 7.776$ million in FY 1993 to a maximum of $\$ 10.575$ million in FY 1996. The total requested funds in this CCB are $\$ 67.066$ million. Separate CCB Requests for the Medical Emergency Support Group, and for the Environmental Monitoring Programs (estimated together at $\$ 15$ million) are being prepared. Estimated funding requirements for all of the change requests are approximately $\$ 82$ million.

System Safety Program Plans defining the hazards analyses and the SAR process have been prepared for most of the major SSC systems. The safety analyses for the detectors are being planned and prepared by the Physics Research Division (PRD). The PRD ES\&H program plan and the planning for the safety analysis for the PRD are consistent with the ES\&H Department program planning.

\subsubsection{Interfaces}

Interfaces with the ES\&H Department will be site-wide. All activities will require close interface with this department. Additional funding for the ES\&H Department to support ES\&H activities that directly support the line organizations (Radiological Control and Preparation of SARs) are included but not specifically identified in the line-organization budgets. The line-organization budgets do include funding for direct-report staff within the line organization. It is planned to include ES\&H Department support as a specific item in the WBS for each line organization beginning in FY 1994. 
7.7.6 Documentation and Staff Available and Reviewed

\subsubsection{Documentation}

1. Final Supplemental Environmental Impact Statement for the Superconducting Super Collider, DOE/EIS-0138S (December 1990).

2. Mitigation Action Plan for the Superconducting Super Collider (March 1991).

3. Project Management Plan for the Superconducting Super Collider (March 1993).

4. Superconducting Super Collider Site Environmental Report for Calendar Year 1991, Pre-Operational.

5. Superconducting Super Collider Laboratory Environmental, Safety, and Health 5-Year Plan (February 24, 1993).

6. Change Request CR\#E20-000608 (Draft), February 12, 1993: Change Control Board Request for the Superconducting Super Collider Laboratories Environmental, Safety, and Health Department.

7. SSC Laboratory Environmental, Safety, and Health Manual (control document \#D10-000001), Rev. 2 (February 1992).

8. Report of Permitting Activities for the Superconducting Super Collider, 1992 Fiscal Year.

\subsubsection{Staff Interviews}

SSCL Staff

1. Dr. Phillip E Shelley, Ph.D., Department Head, Environmental Safety and Health Dept.

2. Ben Rietz, Manager, Safety Office, Environmental Safety and Health Dept.

3. Richard Wiebe, Manager, Environmental Affairs Office, Environmental Safety and Health Dept.

4. Barry Hendrix, Manager, System Safety Group, Environmental Safety and Health Dept.

5. Edward R. Verminski, Manager, Environmental Safety and Health Physics, Research Division. 
DOE SSC Project Office (SSCPO)

1. Nat Brown, Director, Compliance Division.

2. Tony Robledo, Environmental Engineer, Environmental Safety and Health Division.

3. George Whitlock, Manager, Safety and Occupational Health Division.

\subsubsection{Assessment of Plan to Complete}

The SSCL ES\&H 5-Year Plan, along with the approval of the CCB Requests, will create the funding to establish an ES\&H Department within the SSCL baseline. The funding requests are judged to be consistent with the staffing requirements to fulfill the established scope of work ior site-wide activities. It is anticipated that the additional funding identified but not approved for FY 1993 will be required in subsequent years as well.

The close working relationship and interface established between the project and regulatory agencies are critical to the continued success of the project. Funding must be provided to continue environmental permitting, monitoring, and mitigation of environmental impacts. Evolving legislation with subsequent changes in regulatory requirements could impose a considerable risk to the project schedule and costs.

Preparation and DOE approval of PSARs is not planned prior to the procurement or construction of individual systems. This imposes risks if safety issues identified during the safety analysis require design modifications for adequate mitigation of potential hazards. This risk is minimized but not eliminated by performing hazards analyses in the early design stages. The SARs are planned to be complete 6 months prior to commissioning, which should allow adequate time for DOE approval. PSARs are planned for the Collider that will allow potential safety issues to be identified and addressed during the design and construction phases.

\subsubsection{Conclusion/Recommendations}

The ES\&H Department activities have not been funded as a separate function, but the required activities have so far been completed in a timely manner. This has been accomplished by the identification of required ES\&H needs and obtaining required 
funding. Implementation of the ES\&H Plan and inclusion of specific WBS items for ES\&H Department support is recommended to assure that the necessary activ:iies are appropriately funded and tracked. This includes funding the function by $\$ 75.7$ million.

There is no cost and schedule performance tracking of the ES\&H activities since they are not specifically identified in the WBS structure. This poses potential risks to the cost and schedule for completing the design and operation of the SSC, and this function must be picked up in the Project Control System tracking. 


\subsection{Schedule}

\subsubsection{Executive Summary}

In the opinion of the Committee, numerous deficiencies in project cost and schedule controls are apparent. The Integrated Project Schedule (IPS) has been established and maintained in a cumbersome fashion, and many of the items in it have questionable logical relationships to eacii other. The scheduling staff does not appear to routinely generate and use the analytical reports that are more or ksss standard throughout industry (e.g., total float-early start report, constraint list, duration changes). These problen's are exacerbated by the lack of user-friendliness of the software with which the IPS is managed. As a result, the IPS and any critical-path analysis drawn from it are suspect.

The relationship between the IPS and the cost system is also difficult to track as are figures related to cost performance. In fact, the monthly CPR and many key performance indicators such as BCWS, BCWP, ACWP, and LRE appear 'o have been derived manually and/or subjectively. Compounding hese shortcomings is the lack of central authority and coordination; each mack.ine staî does things in its own way, with a lack of philosophical or procedural uniformity across the entire SSC.

If these problems are not resolved, it will become more and more difficult to adhere to the intent of DOE Order 4700.5 and, in general, to determine where the project is today and where it will be going tomorrow.

\subsubsection{Integrated Project Schedule Review}

In conjunction with the overall objective of establishing the current status of the project, a detailed review of the information housed in the IFS was conducted as it relates to real project data in the May 1993 Project Progress Report. The most current issuance of the IPS was utilized, dated July 20,1993, with a schedule date of May 23, 1993. The following are the findings of that review.

While participating in the project review committee meetings, certain generalized conditions became apparent. While there may be a certain amount of credibility at the detailed level relative to intra-machine schedules, the interface points between machines 
are defined by the SSCL as the commissioning milestones. This committee believes that all interface points between machines are not adequately identified. For example, the interface points from the machines to the instrumentation and controls systems and power systems are not fully developed in the IPS. This shortcoming makes it unclear what impact a slippage in one machine would logically have on another machine or support system. The lack of credible logic in the above areas makes the IPS questionable and any critical path analysis drawn from it suspect.

1. Of the approximately 18,000 activities in the IPS, 5,500 are milestone activities with a duration of zero on them, and 2,500 are "hammock" activities (summaries of lower-level detail); see Figure 7.8.2-1. This leaves only about 10,000 "real" activities. Many of the activity durations in the IPS are too large to ascertain the specific steps necessary to complete a given task within the required time frame. The given pieces are too large to monitor accurately on a monthly basis and can only give rise to subjective assessments of physical percentage complete. Currently 47 percent of the activities housed in the IPS have durations greater than 60 working days, and 28 percent have durations greater than 120 working days, as shown in Figure 7.8.2-2. In order for the IPS to become useful to the project, the larger, more summary-type activities must be broken down into more-measurable parts.

2. Thirty-four percent of the remaining activities in the IPS are in the critical path or are within 3 months of becoming critical. To date, of the number of activities required to be completed by May 23, 1993, 81 percent have met their requirements. With this in mind, it would appear that the ability to achieve a reasonable completion date for the project is slowly eroding. Current forecast completion versus current required completion (total float) is shown in Figure 7.8.2-3. It should be noted that the updating process for the IPS is inconsistent with standard updating procedures. Out-of-sequence progress is not addressed, violated logic relationships are not fixed on a consistent basis, nor is the schedule maintained in an "as built" condition. 
Figure 7.8.2.-1 Number of Activities
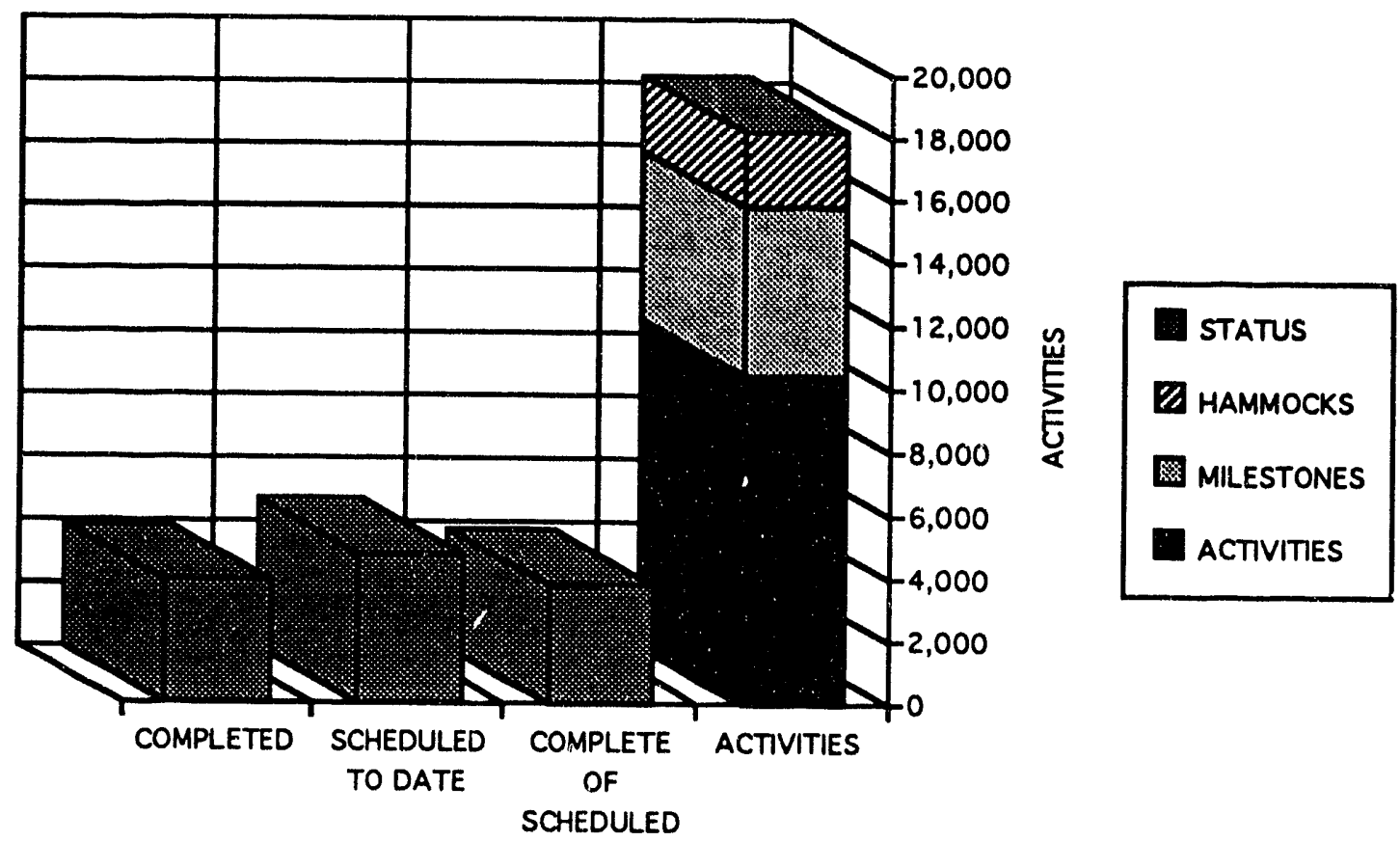

Figure 7.8.2-2 Activity Duration

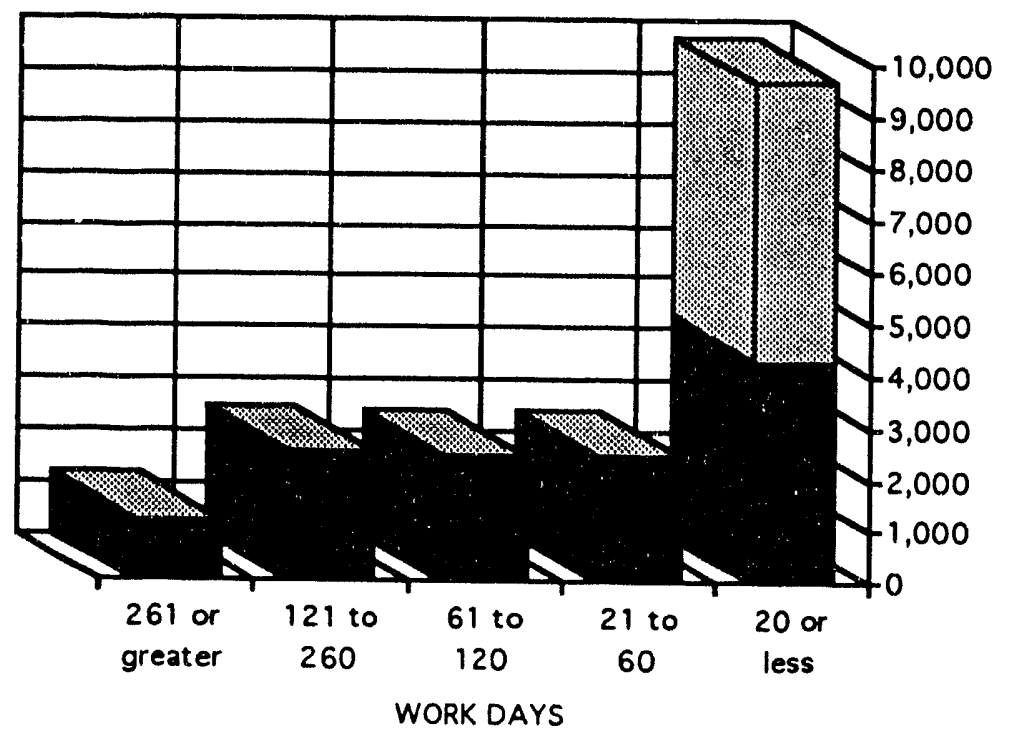

MILESTONES

ACTIVITIES

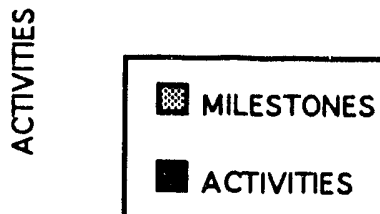




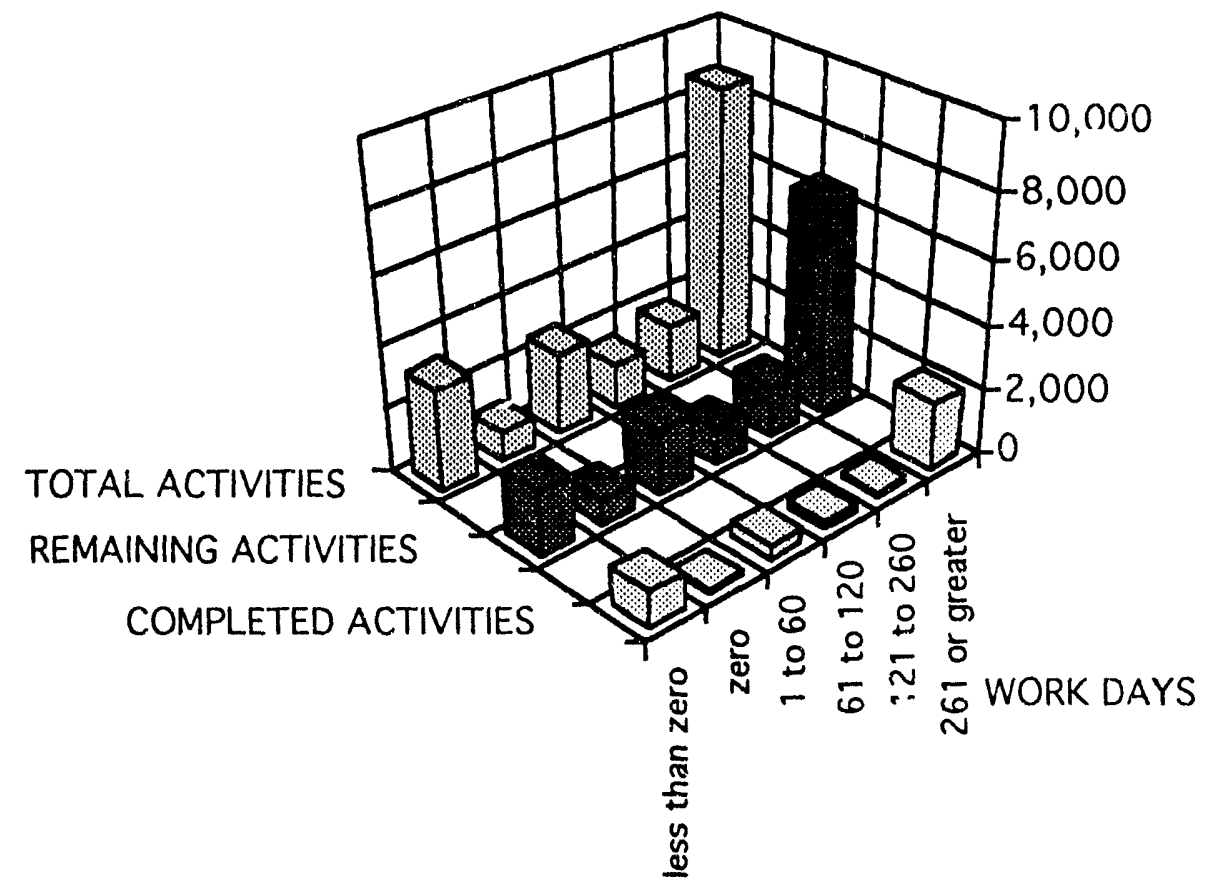

3. There are more than 5,000 milestone activities in the IPS amounting to almost 30 percent of its entire content. In addition to the quantity issue, there appears to be many milestones that are not tied into the logic trails of the IPS. These "hanging" milestones have no relationships to existing logic, nor can one ascertain what would drive their requirements (i.e., activity 240H_2020, HEB Accelerator Preliminary Design Review, and activity 240H_3030, HEB Transfer/Abort Final Design Review). In other cases, milestones have predecessor or successor relationships, but it is unclear what the real requirements for these activities are. It is extremely-hard to analyze the ability to achieve a given milestone without being able to ascertain if the prerequisites for it have been met. The milestones should be reviewed based on their need and should be tied logically into the network. The remaining questionable milestones should then be purged from the system. 
4. A related problem arises from 3,400 'imposed' dates in the IPS. These constraints artificially force start or completion date requirements for a given task, irrespective of its logical interface with other tasks. The problem is not necessarily that of imposed dates, but a matter of trying to analyze critical paths when the dates are not supported by logical relationships between tasks. In several cases the constraints should be removed and the requisite logic should then be developed and substituted for the constraint. Consideration should be given to only housing the Level I milestones and constraints in the IPS and providing logic for all other required milestones.

5. In an effort to analyze the logic within the IPS, several "industry standard" analytical documents were requested (e.g., activity report and others as stated previously). As it took quite a long time and several iterations to get these tools, it became quite clear that what was being asked for was not considered standard, nor readily available. This fact leads one to question what is being used by the scheduling staff, on a normal basis, to check the IPS data for accuracy and to ferret out problems in the data. The reports that were asked for were not unusual by any means and are standard tools employed in the industry. It would appear that the scheduling system currently being employed to run the project is not as user-friendly as originally stated. In an effort to brtter serve the project, some consideration should be given to a more comprehensive use of existing systems and report formats.

6. In reviewing the IPS against its baseline data, it was noted that a significant number of the activity and schedule requirements are diverging to the point where the baseline data are becoming irrelevant (Figures 7.8.2-4 and -5). It was also noted, when comparing the two data sources above, that almost as many durations have increased as decreased. In several areas where tasks were denoted as critical in the current schedule, the baseline schedule was not available to verify this fact. This would lead one to assume that the baseline requirements were, in fact, too late to meet the overall project requirements from the beginning. 
Figure 7.8.2-4

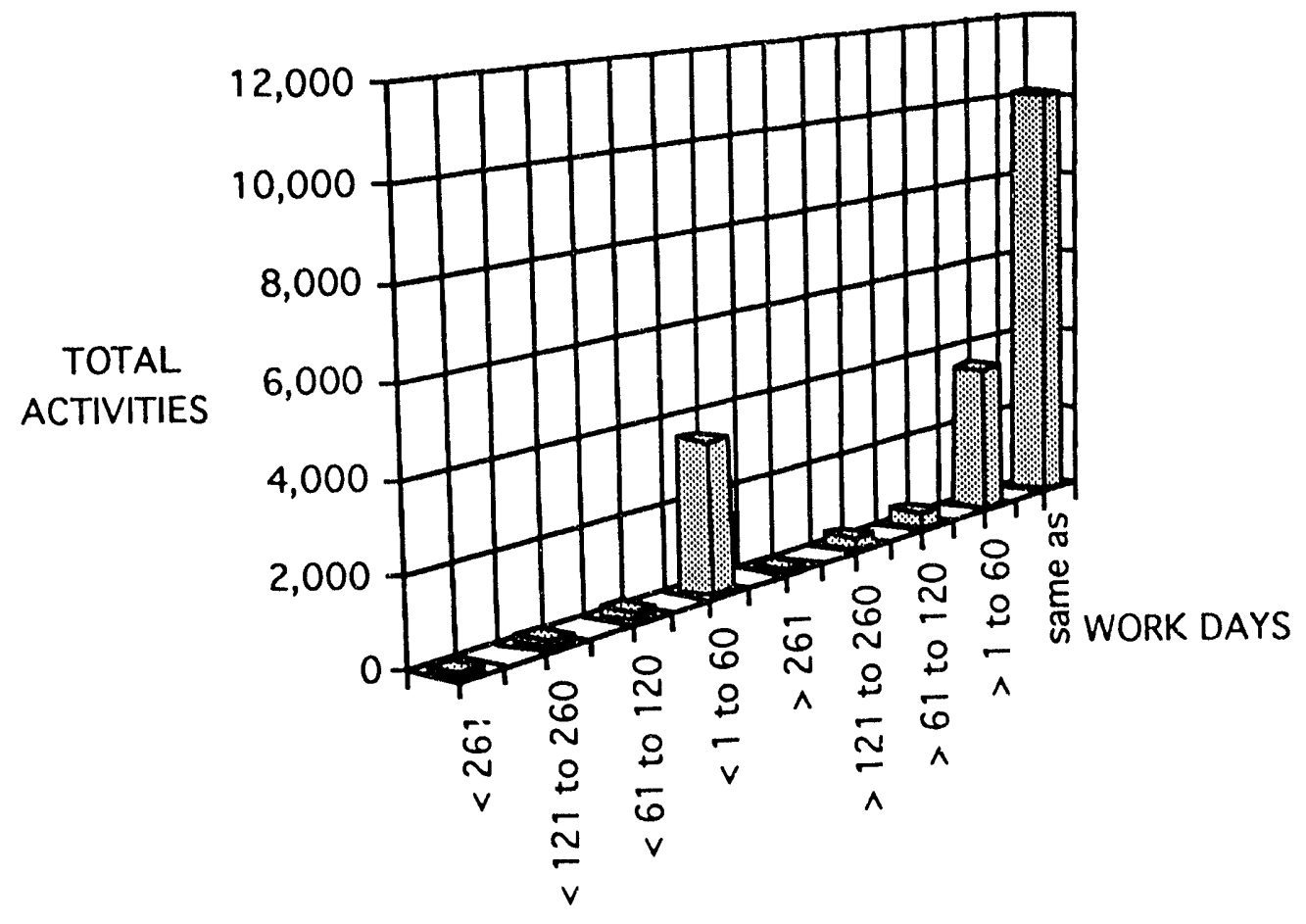




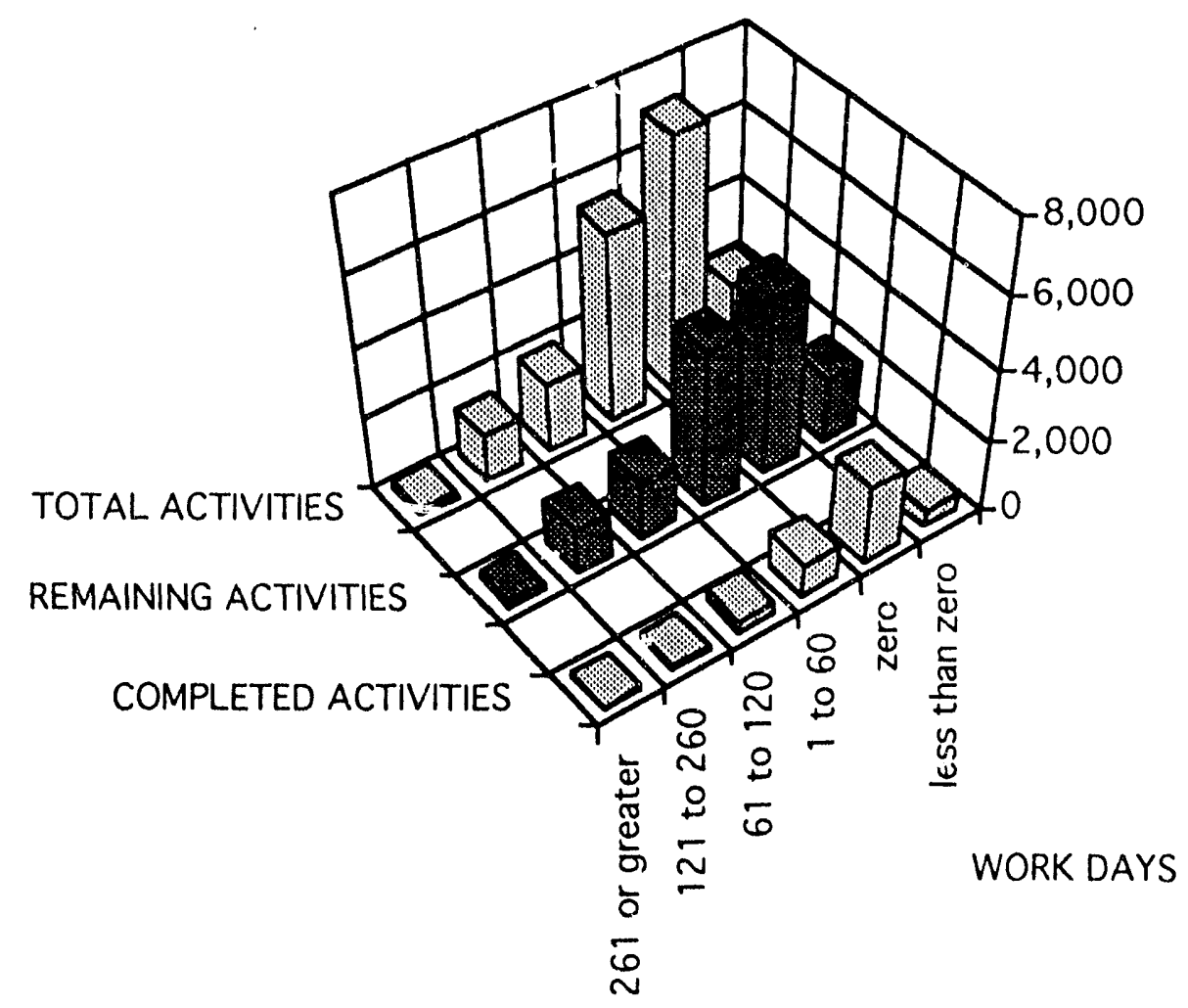

It should also be pointed out that a "real" target schedule does not exist for this project. What is considered to be the baseline is essentially original forecast (early) dates housed in a field in the Open Plan processor. It is extremely difficult to establish a viable project direction unless the target has been verified to be achievable when originally planned. The baseline of the project must be reevaluated against existing project status, scope changes, funding profiles, etc., to ensure the overall goals of the project can be met by the required end date. 
In an effort to understand the relationship between the IPS and the cost system a review of existing methods of cost and performance was conducted. The following are the findings of that review.

1. It was determined that only 30 percent of the activities in the IPS are interfaced with the COBRA cost system. This fact leads to questioning the budgeted cost of work scheduled (BCWS figure), as well as the performance measurement calculation, (i.e., earned value). It is essential that the cost and schedule systems be fully integrated. Without this integration, figures relative to cost performance are often subjective. The data in the monthly Cost Performance Report (CPR) appear to have been manually calculated and are not a function of a totally automated and verified set of calculations.

2. In conjunction with the above, it was established that the BCWS is determined by the cost account managers (CAMs). The budgeted cost of work performed (BCWP) is also determined by the CAMs. The manner in which BCWS and BCWP are calculated is sometimes subjective, and it would appear that even the method for doing so varies from CAM to CAM. To amplify this condition further, during the interview on the MEB, the question of percent complete was posed. The answer was 5 to 7 percent complete. The next question was "how was that derived?"; the answer was they had spent 5 to 7 percent of their budgeted dollars. This subjective assessment must be made more quantitative.

3. In reviewing the data in the monthly CPR, some anomalies appear. It would appear that the Latest Revised Estimate (LRE) in some cases has little to do with current performance. Under normal industry practices the LRE is a calculation based on a performance or efficiency ratio measured by how one did against the BCWS, the BCWP, and the actual cost of work performed (ACWP). In one case in the May CPR, the latest revised estimate was the same as expenditure spent to date, while the current-period data reflected $\$ 651$ thousand spent with zero dollars earned and zero dollars scheduled. In addition, the cost curves provided in the monthly report lack an essential piece of data, the estimate to complete (ETC). 
To illustrate the projection of final costs using efficiency ratios, the overall increase to the project budget would be $\$ 655$ million (see Figure 7.8.3-1). Ultimately, the system or how it calculates performance should not be a primary concern. The main concern should be putting the correct data in the system so that the output of an appropriate calculation would accurately reflect the current project condition.

\section{Figure 7.8.3-1 Budget Efficiency Analysis}

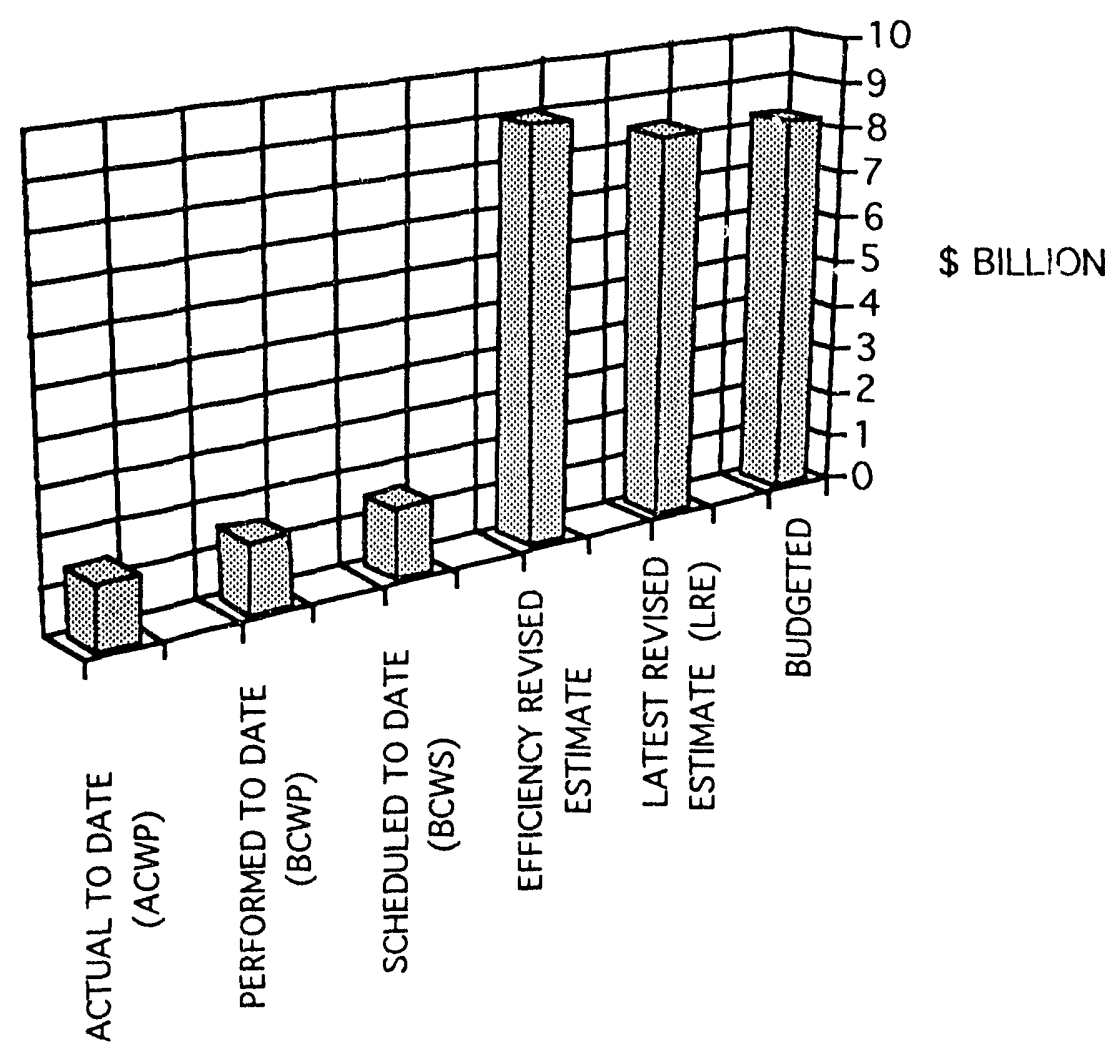




\subsubsection{Cost and Schedule Organization Review}

During the interview process, several weaknesses related to the cost/schedule organization were noted. The following is an assessment of that structure.

The Cost and Scheduling Organization is fragmented. The central cost and scheduling group has little or no control of the cost and scheduling personnel assigned to the various Divisions, who function at the direction of the CAMs. Due to this fact, there does not appear to be one uniform project control philosophy, and it is unclear if a specific project controls procedure exists, or if so, how it is implemented and enforced. This condition can only lead to a lack of unity. It is essential that all cost and scheduling personnel be responsible to one organization, and that group must report to the highest project authority. It will become more difficult to manage this project as time progresses without having the proper tools or an organizational philosophy that encourages good project-control practices. 


\subsection{Installation}

\subsubsection{Executive Summary}

Since the 1991 "Green Book," Baseline Cost Estimate (BCE), there has been a major change in the strategy for installing accelerator systems: installation by one of three already pre-qualified bidders under a single cost-plus-incentive-fee contract, as opposed to installation performed by SSCL and various subcontractors (which was the basis of the $\mathrm{BCE}$ ). The Installation Contract subcommittee notes areas of risk, including chan, res in the scope of work, cost, and schedule, and the make up of the SSCL team managing the effort. The subcommittee believes that the awarding of the contract and subsequent performance by the subcontractor are on the critical path and determined that all planning for this contract is directed toward a FY 2001 "stretch out" completion date for the SSC. The SSCL stated that the installation planning supports the 1999 completion if the subcontract for installation is awarded in June 1994 and components are delivered as required by the installation subcontractor. The cost of this contract is deleted for business sensitive reasons relating to a pending procurement action. The installation effort should be a primary subject of immediate SSCL, focus.

\subsubsection{Scope of Work}

The 1991 Baseline Cost Estimate (BCE) included installation costs for the SSC with the assumption that the installation tasks would be accomplished by the SSCL. The present plan, however, is to issue a single contract for installation tasks, including accelerator-systems installation for the Collider Ring, High Energy Booster (HEB), Medium Energy Booster (MEB), Low Energy Booster (LEB), Abort Lines, Test Beams, and a separate subcontract for installation of Linac systems/components. The planned contract includes management of installation, the logistics of transporting components, installation of the components at their respective positions, and some testing. The SSCL will provide management oversight of the installation subcontractors to ensure that the subcontractor meets the technical, cost, and schedule baselines for each of the technical systems. The installation manager and staff will be co-located with the subcontractor to ensure close cooperation and oversight. Table 7.9.2-1 shows the relationships of the system/components to be installed for each machine. 
Table 7.9.2-1 System Component Matrix

\begin{tabular}{|l|l|l|l|l|l|l|l|}
\hline \multicolumn{1}{|c|}{ MACHINE } & & & & \multicolumn{3}{|c|}{ COLLIDER } & \\
\hline System/Component & Linac & LEB & MEB & HEB & ARCS & STRAIGHTS & NOTES \\
\hline & & & & & & & \\
\hline MAGNETS & & $\mathrm{X}$ & $\mathrm{X}$ & $\mathrm{X}$ & $\mathrm{X}$ & $\mathrm{X}$ & \\
\hline SPOOLS & & & & $\mathrm{X}$ & $\mathrm{X}$ & $\mathrm{X}$ & \\
\hline POWER SYS & $\mathrm{X}$ & $\mathrm{X}$ & $\mathrm{X}$ & $\mathrm{X}$ & $\mathrm{X}$ & $\mathrm{X}$ & \\
\hline VACUUM & $\mathrm{X}$ & $\mathrm{X}$ & $\mathrm{X}$ & $\mathrm{X}$ & $\mathrm{X}$ & $\mathrm{X}$ & \\
\hline CABLE/TRAYS & $\mathrm{X}$ & $\mathrm{X}$ & $\mathrm{X}$ & $\mathrm{X}$ & $\mathrm{X}$ & $\mathrm{X}$ & \\
\hline STANDS & $\mathrm{X}$ & $\mathrm{X}$ & $\mathrm{X}$ & $\mathrm{X}$ & $\mathrm{X}$ & $\mathrm{X}$ & \\
\hline BEAM INST SYS & $\mathrm{X}$ & $\mathrm{X}$ & $\mathrm{X}$ & $\mathrm{X}$ & $\mathrm{X}$ & $\mathrm{X}$ & \\
\hline CONTROLS & $\mathrm{X}$ & $\mathrm{X}$ & $\mathrm{X}$ & $\mathrm{X}$ & $\mathrm{X}$ & $\mathrm{X}$ & \\
\hline RF & $\mathrm{X}$ & $\mathrm{X}$ & $\mathrm{X}$ & $\mathrm{X}$ & $\mathrm{X}$ & $\mathrm{X}$ & \\
\hline CRYOGENICS & & & & $\mathrm{X}$ & $\mathrm{X}$ & $\mathrm{X}$ & NOTE 1 \\
\hline UTILITIES & $\mathrm{X}$ & $\mathrm{X}$ & $\mathrm{X}$ & $\mathrm{X}$ & $\mathrm{X}$ & $\mathrm{X}$ & \\
\hline ABORT SYS & $\mathrm{X}$ & $\mathrm{X}$ & $\mathrm{X}$ & $\mathrm{X}$ & & $\mathrm{X}$ & \\
\hline TEST BEAMS & & & $\mathrm{X}$ & & & & \\
\hline SAFETY SYS & $\mathrm{X}$ & $\mathrm{X}$ & $\mathrm{X}$ & $\mathrm{X}$ & $\mathrm{X}$ & $\mathrm{X}$ & \\
\hline COMM SYS & & $\mathrm{X}$ & $\mathrm{X}$ & $\mathrm{X}$ & $\mathrm{X}$ & $\mathrm{X}$ & \\
\hline & & & & & & & \\
\hline
\end{tabular}

NOTE 1: The cryogenic installation includes the transfer lines from the refrigerator plants to the tunnel shaft, the below-ground piping, and the recovery system. It does not include the refrigerator plants.

A general description of the tasks associated with the installation scope are:

1. Communications - design, procure system and install

2. Low Conductivity Water (LCW) Systems - procure and install

3. Cable Tray - procure and install

4. Cable - procure and install

5. Power Supplies - install

6. Niche Cooling - procure and install

7. Six-point magnet stands - procure and install

8. Cryo warm return line piping from plant to cold machines - procure ard install

9. Transporter Systems - design and procure

10. Head Houses - design, procure and construct

11. Elevator Systems - design, procure and install

12. Magnets - install

13. Spool pieces - install

14. Absorbers - install

15. Provide testing of all systems up to but not including energization

16. Instrumentation - install 


\subsubsection{Assessment of Project Status}

Technical:

1. Installation design and planning has progressed through concept definition and a Phase I installation study of the collider arcs. The Phase I installation study was performed by three industrial teams: Bechtel National Inc., Brown \& Root, Inc., and Martin Marietta Corporation. Primary objectives of Phase I studies were: 1) to move technology from the Laboratory to industry, 2) to involve industry in the cost estimating process, 3 ) to develop industrial tooling and methods for installation, and 4 ) provide innovative means to reduce cost and schedule. At least one solution to each recognized problem has been identified. Phase I installation studies have now been completed.

2. Phase II of the accelerator installation activity involves selecting a subcontractor to provide design, procurement, installation, and construction services for the accelerator components and other nontechnical components. A draft Request For Proposal (RFP) has been prepared by the SSCL for this scope of work and submitted to the DOE SSCPO for review and comment. The proposed subcontract includes the scope of work described in 7.9.2 scope of work. The schedule for the solicitation and award of this subcontract as presented by the SSCL, is shown below.

\section{SUBCONTRACT MILESTONE SCHEDULE \\ Event \\ Date}

RFP to DOE

RFP Issued

Proposals Received

Source Selection Complete

Subcontract Award (Letter contract)
August 1, 1993
Octoher 1993
45 day's after RFP issuance
60 days after receipt of proposals
90 days after submission to DOE

Because of the anticipated review time for DOE approval of the overall installation subcontract and the pressing need to initiate the LEB installation work, SSCL will request interim approval to award the LEB critical tasks to the winning subcontractor. SSCL expects to award a letter contract for the LEB work no later than June 1994. 
3. Installation of technical components has not begun in the Linac; this is scheduled to commence in August 1993. This subcontract is on hold in the award process. The tunnel survey monuments have been installed.

A full cell of 10 collider dipoles and two quadrupoles have been installed in the Accelerator Systems String Test (ASST) facility. This was completed in July 1993.

\section{Cost Expended/Committed to Date:}

1. The costs expended to date associated with the installation program have been for installation engineering and design functions, and the Phase I installation study conducted by three separate subcontractors. The total expended to date, according to information furnished by SSCL, is $\$ 3.131$ million. The earned value for the costs incurred is accepted because of the relatively small value. The cost expended also represents only 2 percent of the budget forecast, which appears to represent a fair approximation for the current status.

\section{Schedule Progress Against Current Baseline:}

The schedule progress against the current baseline, installation planning, and establishment of design requirements, appears to be on track. The delay in the award of the Linac installation subcontract will impact the completion of the Linac. Foreseeable delays in the Phase II accelerator system installation subcontract award could also have an impact on the ability to complete the installation in 1999. The SSCL stated that if work on the LEB installation was initiated via a letter contract no later than June 1994 then the installation work would support the 1999 completion date.

\section{Approved Changes:}

1. To date there are only three changes associated with the installation program that have been approved by the change control board as follows: 
- Change E12-0000120 involved changing the LCW piping from fiberglass to steel for a total increase of $\$ 4,330,000$ of which only a portion is attributable to the installation program.

- Change E12-000074 \& E12-000104 Rev 4, changed to the Linac installation BCE, by $\$ 204,000$, and resulted in a realignment of charges within the various groups in the Accelerator Systems Division.

- Change E22-00015 resulted in a single transfer of $\$ 18,500$ from the Accelerator Systems Division to the Conventional Construction Division to install sight pipes that enabled the ASD geodesy group to install the tunnel monuments.

\subsubsection{Plan to Complete}

\subsubsection{Introduction}

The Installation Program by ASD is being managed ty T. Kozman, Associate Director, through the Mechanical Engineering Department, J. French, Department Head, and F. Spinos, Group Leader. Mir. Spinos has under his direction four engineers and seven technicians. Their plan to complete the Installation Program for all machines except the Linac is described in the RFP Document No. AMA-4120016, Rev. O, dated June 23, 1993, entitled "The Assembly, Design, Material Procurement and Installation of Components and Electrical Power Connections."

\subsubsection{Installation Program}

The plan for compieting the installation program has shifted somewhat from the original concept of primarily instailing the major magnet components to a program that now includes the entire machine component assemblies and connections included in the LEB, MEB, HEB, and Collider, as well as the technical components in the Linac.

Through scope development or expansion, work has been shifted from the various machine groups to the installation group. The new scopes of work have been included in the aforementioned RFP, which is planned to be awarded to a single contractor from 
among the three pre-qualified bidders: Bechtel National Corp., Martin Marietta Corp., and Brown and Root, Inc.

Presently the plan is to issue the RFP in October 1993, and to award and mobilize a contractor by June 1994. Work is to commence with headhouse design and construction, continue through utility installation and transport system design, procurement and installation, and culminate with installation of the spool pieces, magnets and electrical connections for all machines.

The plan presented to the Committee for installation does not maintain the 1999 target completion for installation, and is extended to 2002. The period of performance for each of the installation tasks is shown below:

\begin{tabular}{|l|c|c|}
\hline \multicolumn{1}{|c|}{ MACHINE/TASK } & $\begin{array}{c}\text { INSTALLATION } \\
\text { Start }\end{array}$ & $\begin{array}{c}\text { INSTALLATION } \\
\text { Complete }\end{array}$ \\
\hline Program Management & FY 1994 & FY 2002 \\
\hline LEB & FY 1995 & FY 1997 \\
\hline MEB & FY 1996 & FY 1999 \\
\hline HEB & FY 1996 & FY 1999 \\
\hline COLLIDER ARCS & FY 1995 & FY 2002 \\
\hline CRYOLOOP & FY 1994 & FY 1996 \\
\hline Comm System & FY 1994 & FY 2002 \\
\hline Test Beams & FY 1996 & FY 1999 \\
\hline & & FY 2002 \\
\hline Collider Systems & FY 1997 & \\
\hline
\end{tabular}

However, SSCL plans and schedules that support a 1999 completion have two stipulations:

1. Letter Contract must be awarded no later than June 1994.

2. Components must be delivered to the installation subcontractor as required by installation planning.

\subsubsection{Interfaces}

The installation program interfaces with all machine component assemblies and connections included in the LEB, MEB, HEB, and Collider systems and facilities test beams, and conventional construction. 


\subsubsection{Documentation Available and Reviewed}

1. Advance Acquisition Plan, Accelerator Systems Installation, Rev 3, dated July 7, 1993, Document No. AØA-1010098

2. Draft Request for Proposal, Document No. AMA-4120016, the assembly design, material procurement and installation of components and electrical power connections

3. Installation Program for Symposium by F. Spinos

4. Discussions with Mr. Frank Spinos

5. SSC Project Monthly Cost Report April 1993

6. SSC Project Monthly Cost Report May 1993

7. URA Cost Detail Report for Installation from F Spinos

8. Installation Schedule from F Spinos

9. Discussions of Cost for Installation with F Spinos and Bruce Kling

10. Cost estimate for installation portion collider arcs and HEB--Details from F. Spinos

11. BCE old WBS from Bruce Kling

12. BCE old WBS vs. new WBS Crosswalk from Bruce Kling

13. Change Request E12-0000120 from Brian Edwards

14. ASD cost details associated with E12-0000120 from Brian Edwards

15. Conference with Brian Edwards

16. BCE -Installation cost detail level 3 from Bruce Kling

17. Project Insurance Manual from Sarah Kassahun

18. Bechtel National, Inc. Proposal to perform Collider Installation from Sarah Kassahun

19. Martin Marietta Proposal to perform Collider Installation from Sarah Kassahun

20. Brown and Root Proposal to perform Collider Installation from Sarah Kassahun

21. SSC Beam Absorber Change Estimate Option List, dated February 2, 1992, from Brian Edwards

\subsubsection{Assessment of Plan to Complete}

\subsubsection{Risks}

There are two significant risks associated with this installation subcontract:

1. The award of this subcontract is on the project critical path, and any delay in the award would put project completion at risk. Every month of schedule slippage would increase the installation costs by more than $\$ 3$ million (at a minimum, the drivers will include continuing overhead and economic escalation).

2. Cost estimates are not tied to activity manloaded schedules and have inconsistent labor applied to hours. 


\subsubsection{Proposed Changes}

The SSC Laboratory has revised the scope and budget associated with the Installation contract. Table 7.9.7.2-1 is a list of the Laboratory's changes to support the revised installation concept.

It was determined that many of these anticipated revisions to the contract have no presen $\mathfrak{i}$ funding identified, and that detailed, definitive estimates are not available. A Government cost estimate for bid evaluation has not yet been prepared. Consequently, it is the review subcommittee's determination that there is a significant risk that the true scope of this installation program will stay in flux for some time, and that the definitive cost estimate may continue to vary. This will put any contract cost in question if it does not reflect a true risk analysis and if the appropriate risk factors and appropriate contingency are not assigned.

Table 7.9.7.2-1. Projected Revisions to the Installation Estimate

(\$ FY 1993 Millions)

WBS

321.1110

321.1210

321.1210

321.1210

321.1210

321.1210

321.1210

311.1110

311.1210

231.1210

232.1210

221.1210

222.1210

322.1210

322.1210

322.1210

322.1210

322.1210

322.1210

322.1210

322.1210

322.1210

322.1210
Description

Cyro Header

Dipole Stands

Quad Stands

Spool Stands

Place Magnets

Connections

Empty Cryostats

Cryo Header

Place Magnets

Place Stands

Place Stands

Place Stands

Stands

Place Magnets

Abort Stands

Steel Shielding

Concrete Shielding

Special Stands

Tunnel Transport

Tunnel Niche Ventilation

Tunnel Communications

Head Houses

Installation Databases

TOTAL
Est. Revisions

to 1991 Installation BCE

24.758

7.662

10.869

.680

$-27.973$

$-.724$

.559

8.161

.481

.527

.204

.009

.005

New Increased

Scope Estimate

14.967

3.517

15.544

.928

16.317

43.052

3.098

3.534

$84.953 \quad 20.634$ 


\subsubsection{Cost Estimate at Completion (EAC)}

Assessing the EAC for the Installation Program cost was an evolutionary process which began with the 1991 "Green Book" Baseline Cost Estimate (BCE) for installation included in machine WBS elements XXX-1210, a total estimate of $\$ 133.2$ million. These estimates are included in Table 7.9.7.3-1 as the "1991 BCE". By adding the SSCL approved Change Control Board changes and other SSCL estimated changes, the SSCL Revised BCE of $\$ 158.8$ million was verified. As indicated in Section 7.9.2, "Scope of Work", the concept of installation has changed significantly since the $1991 \mathrm{BCE}$. Therefore many WBS elements in the BCE have installation costs in them. These are included in Table 7.9.7.3-2 as "Slide-Over" funding, a total of \$140.3 million.

The subcommittee used the following general analysis to arrive at its Estimate-atCompletion:

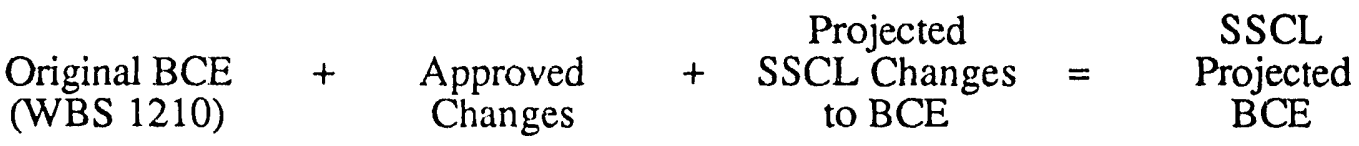

\begin{tabular}{|c|c|c|c|c|c|c|c|c|c|c|c|}
\hline $\begin{array}{c}\text { SSCL } \\
\text { Projected } \\
\text { BCE }\end{array}$ & + & $\begin{array}{l}\text { "Slic } \\
\text { (Oth }\end{array}$ & $\begin{array}{l}-O \\
\text { Wpe } \\
\text { W }\end{array}$ & $\begin{array}{l}\text { er" } \\
\text { Ss) }\end{array}$ & + & $\begin{array}{r}\mathrm{Ad} \\
\text { to } \mathrm{Sl}\end{array}$ & $\begin{array}{l}\text { tions } \\
\text { e Over }\end{array}$ & + & $\begin{array}{l}\text { New } \\
\text { Scope }\end{array}$ & $=$ & $\begin{array}{l}\text { SSCL Estim } \\
\text { Contract Pr }\end{array}$ \\
\hline $\begin{array}{l}\text { SSCL } \\
\text { Cont }\end{array}$ & $c t$ & $\begin{array}{l}\text { ted } \\
\text { ce }\end{array}$ & + & $\begin{array}{r}\mathrm{L} \\
\mathrm{Oth}\end{array}$ & $\begin{array}{l}\text { ab } \\
\text { her }\end{array}$ & $\begin{array}{l}\text { ad } \\
\text { ders }\end{array}$ & + & Con & tingency & $=$ & $\begin{array}{c}\text { Committee } \\
\text { Total }\end{array}$ \\
\hline
\end{tabular}

Since 1991, there has been considerable effort expended in defining more precisely the installation project scope and cost. This effort, including the Phase I Installation Study described in Section 7.9.3, "Assessment of Project Status", resulted in the identification of proposed changes to the WBS elements containing "Slide-Over" tasks and funding and other installation project scope increases. The cost estimates for these changes along with a new SSCL Installation Cost Estimate of $\$ 439.3$ million (including $\$ 34.7$ million contingency) is included in Table 7.9.7.3-2 This latest SSCL BCE was vased on 1990 labor rates. 
Table 7.9.7.3-1. SSCL Revised BCE (M\$)

\begin{tabular}{|l|c|c|c|c|}
\hline & 1991 BCE & $\begin{array}{c}\text { CCB Approved } \\
\text { Changes }\end{array}$ & $\begin{array}{c}\text { Est. Changes to } \\
\text { BCE }\end{array}$ & $\begin{array}{c}\text { Projected } \\
\text { BCE }\end{array}$ \\
\hline Linac & 2.662 & .204 & 0.0 & 2.866 \\
LEB & 1.948 & & .746 & 2.694 \\
MEB & 3.254 & & 2.643 & 5.897 \\
HEB & 10.310 & & 6.559 & 16.869 \\
Collider & 95.245 & & 15.272 & 110.517 \\
Global & 19.563 & & 0.0 & 19.563 \\
Test Beams & .188 & -.019 & 0.261 & .430 \\
\hline Totals & 133.169 & .185 & 25.481 & 158.835 \\
\hline
\end{tabular}

Table 7.9.7.3-2. SSCL 1993 Baseline Estimate Including Changes

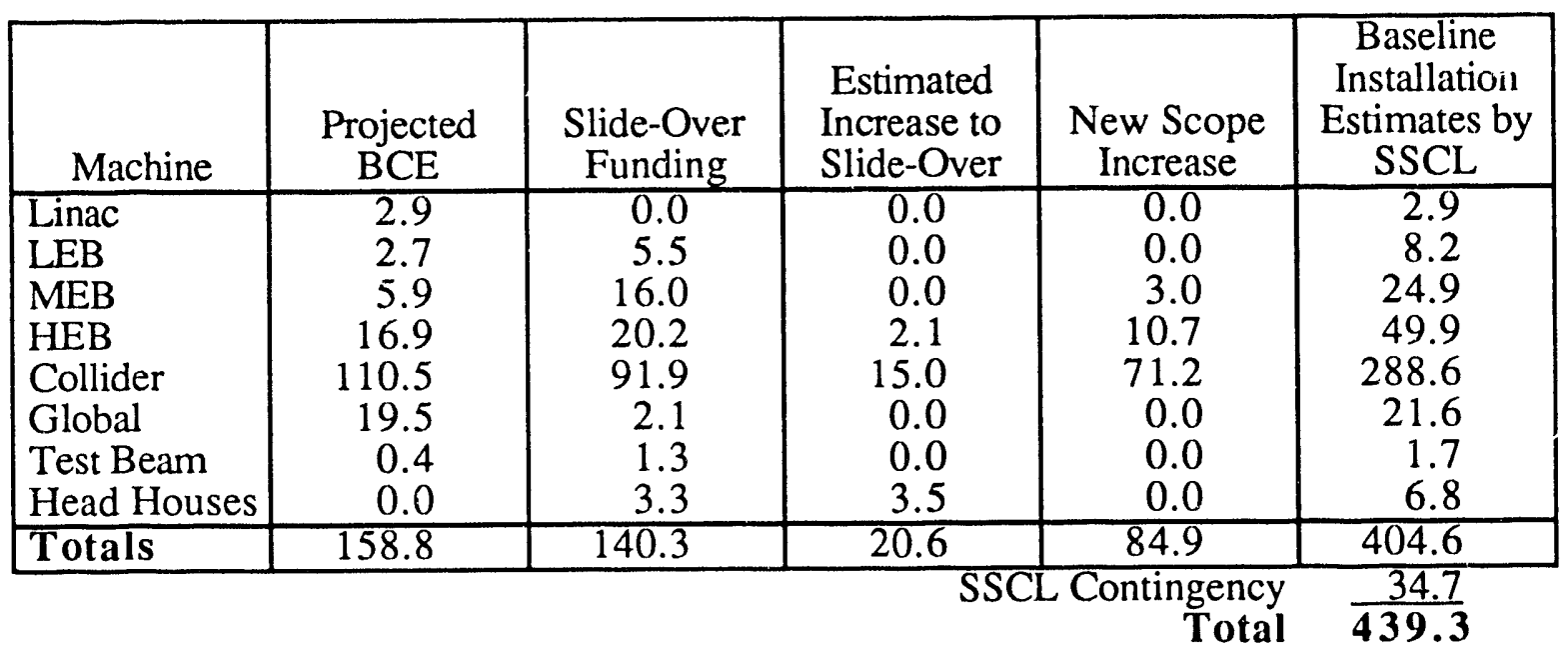

To provide a realistic assessment of the Installation Project EAC the subcommittee estimated, for each machine, increases in labor costs (1993 versus 1990) and contingency. In addition, costs which could not be assigned to a specific machine; i.e., contractor fees for material costs, LCW piping change, and beam absorber steel, were estimated and added. This cost is deleted because it is business sensitive, relating to a pending procurement action. The subcommittee's best estimate of installation project cost has been removed from Table 7.9.7.3-3. 
Table 7.9.7.3-3. Subcommittee Best Estimate Installation Cost

\begin{tabular}{|c|c|c|c|c|c|}
\hline \multirow[b]{2}{*}{ Machine } & \multirow{2}{*}{$\begin{array}{c}\text { SSCL New } \\
\text { Baseline Est. } \\
\text { for Install. }\end{array}$} & \multirow{2}{*}{$\begin{array}{c}\text { Subcommittee } \\
\text { Labor } \\
\text { and Other } \\
\text { Adds. }\end{array}$} & \multirow[b]{2}{*}{$\begin{array}{c}\text { Subcom. } \\
\text { Cost }\end{array}$} & & \multirow[b]{2}{*}{$\begin{array}{l}\text { Subcommittee } \\
\text { Cost \& } \\
\text { Contingency }\end{array}$} \\
\hline & & & & \begin{tabular}{c|c}
\multicolumn{2}{c}{ Contingency } \\
$\%$ & $\$$
\end{tabular} & \\
\hline $\begin{array}{l}\text { Linac } \\
\text { LEB } \\
\text { MEB } \\
\text { HEB } \\
\text { Collider } \\
\text { Global } \\
\text { Test Beam } \\
\text { Head House }\end{array}$ & & & & & \\
\hline & & & & & \\
\hline
\end{tabular}

Dollar amounts have been removed from this table because they are business sensitive relating to a pending procurement action.

\subsubsection{Schedule}

A reviev of the schedule presented by SSCL indicates that it has insufficient detail and integration definition to evaluate the time allotted for the installation activities. The subcommittee could find no information available that allowed an evaluation of durations based on crew sizes, crew make-up, and crew work plans that would justify the personhours in budgets and relate them to the durations for activities shown on the level one schedule presented. It is anticipated in the proposed installation contract that the subcontractor will be responsible for providing the detail schedule and manloading forecasts to meet the completion schedule presented. As a result of the assessment of the plan to complete, the subcommittee found that a completion during FY 1999 is feasible if the subcontract is awarded in June 1994 and material deliveries are provided in support of the installation schedule. The subcommittee could not determine funding profiles from the data presented.

\subsubsection{Conclusions and Recommendations}

\section{General}

SSCL personnel were very supportive and helpful during the committee's review of their operations. The manager of the Mechanical Systems Installation Group has assembled an experienced and enthusiastic team, and is providing strong leadership based 
on his many years of experience in this area. The present installation manager is a vaivable asset to the ultimate success of the installation operations, and because this contract will presume long-term continuity, depth in his staff is vital.

The installation manager and team appear knowledgeable in applying the necessary cost and schedule control systems. Further, the team has a number of innovative ideas for performing the assembly tasks with greater efficiency and less expense.

\section{Risk Assessment}

The review subcommittee has concluded that the installation operations represent a high-risk area for the following reasons, in spite of the fact that a considerable amount of planning has been accomplished:

- The scope of work is changing due to engineering changes and slide-overs from other WBS accounts.

- The present cost estimate and sciedule have not been integrated.

- There is no evidence of a resource-loaded schedule. It is not clear if construction and component delivery must work to the installation schedule or vice versa.

- The original cost estimate appears to be low-particularly the hourly rate for field craft labor.

- Contingency is low, basically because they have not been applied to the most recent estimates.

- Because there are a large number of repetitive tasks, particularly in the collider assembly operations, a small miscalculation of time or an unanticipated assembly task could have a significant impact on the installation cost and schedule. Thus, the best available baseline cost estimate and schedule must be developed and approved. 


\section{Recommendations}

The review subcommittee recommends that the installation effort be a primary subject of immediate SSCL focus. During this focus period, the following tasks must be accomplished:

- Actions must be taken to expedite contract award including approval of the Advanced Acquisition Plan, issuance of the RFP, and coordination of the procurement effort with DOE Headquarters. Work-around planning must be accomplished in case of any delays in this process to provide for other means of accomplishing critical path procurements, i.e., breaking out the cryo-loop test.

- A finalized scope of work must be developed and baselined. The Scope of Work must be defined by WBS such that tracking of work and associated cost is properly documented. SSCL staffing and funding included in other WBS accounts must be reduced where work is transferred to the installation account.

- Consideration should be given and pros and cons defined for treaking up the larger contract, for example, awarding smaller contracts for each machine.

- Decision should be made as to the applicable ES\&H requirements for the installation subcontract to mitigate costs that have been estimatec to exceed $\$ 40$ million.

- A detailed, resource-loaded schedule defining the agreed-on scope of work must be developed. This schedule must show all integration and interface points and must ensure that construction activity and component delivery are accomplished on schedule to avoid a critical impact on installation costs and schedule.

- The projected SSCL installation staff to manage this effort must be increased over the current staff and must include technical experts from other groups in SSCL to train/certify personnel, oversee work, and provide a resident installation "corporate knowledge" at SSCL.

- A new bottoms-up cost estimate for this effort must be prepared and the contingency must be applied to reflect the latest cost estimates. 


\subsection{Laboratory Operations}

\subsubsection{Executive Summary}

The Laboratory Operations budget addresses certain activities at the SSCL that are not included as part of the construction project TPC, even though they occur during the overall projected construction timeframe. Examples of such activities include the operation of general laboratory facilities and services not specifically related to construction, the operating costs for the individual accelerators in the injector chain once these facilities have been commissioned, and the costs of SSCL physics research groups. The overall proposed plan for these operations activities were reviewed and are considered reasonable. These operating funds are driven by the planned staffing levels and schedules. Many factors will influence the overall schedule to adjust the detailed commissioning sequences and project completion dates, but at this time the overall budgeted costs and current staff plans for operations activities are consistent with project completion at the end of 1999. At the final completion date, it is expected that Key Decision \#4 will be granted, to commence SSCL facility operations and research programs; at that time the ongoing operating budgets will be developed on an annual basis.

The subcommittee considers the approximately $\$ 506$ million (FY $1993 \$$ ) [\$561 million as spent] budget estimate for Laboratory Operations occurring during the overall construction period reasonable.

\subsubsection{Scope of Work Associated with Laboratory Operations Funds}

The SSCL plan for the sequential commissioning and operation of the series of individual accelerators, beam transfer lines, and other technical facilities comprising the SSC was reviewed. A portion of this review addressed the activities at the SSCL that are not included as part of the construction project TPC, even though they occur during the overall projected construction timeframe. Examples of such activities include the operation of general laboratory facilities and services not specifically related to construction, the operating costs for the individual accelerators in the injector chain once these facilities have been commissioned, and the costs of the SSCL physics program. The DOE hus made the following decision with regard to these operations categories for 
the SSCL (Report on the Superconducting Super Collider Cost \& Schedule Baseline, U.S. Department of Energy, DOE-ER-0468P, January 1991, p. 39):

"It is the Department's conclusion that the funding for these operating costs, which are estimated to total approximately $\$ 460$ million (as-spent), should be provided outside the total project cost. These costs will begin at a low level in FY1993, with a slow ramp-up during the remainder of the construction project. This is consistent with the approach used at other laboratories and is a logical decision since the costs are more endemic to operations after construction than to preparations for operations during construction."

The following definitions are used to determine which activities are funded within the TEC and TPC.

Construction completion for each major facility is defined as the time at which all major systems of the facility are in place and ready to operate together to provide the basic objective of that facility. In the case of an injector accelerator it is expected that each technical component (e.g., magnets, power supplies, rf system, etc.) will have been individually tested during the construction phase to ensure that performance requirements have been achieved. These activities are included within the WBS for each of the major injector accelerators and collider and are covered by TEC funds .

Pre-operations provides for the build-up and training of the technical staff who will help to commission and subsequently operate the facility. The commissioning follows construction completion. During commissioning all systems are tested and operated together to test and ensure that the basic technical objectives are achieved; in the case of an accelerator system, this basic objective is accelerated beam. This commissioning activity includes tuning, timing, debugging, and perhaps minor modifications of individual components to optimize performance, as well as reliability. The series of sequential activities addressing system testing, staff training, commissioning, and pre-operations are included within the WBS for each of the major injector accelerators and collider and are covered by TPC funds.

Operations allows utilization of each facility following the successful commissioning. In the case of injector accelerators, this period would include operations 
for continued improvements, operations for test beams and physics experiments, and service to other accelerators that are not part of commissioning. However, in addition to its own commissioning period, when an injector accelerator is used in the commissioning program for one of the higher energy accelerators or the collider, a portion of the costs of its operation is again charged to pre-operations. It is assumed that lower energy accelerators will be utilized half-time in the commissioning of higher energy machines. For example, during the commissioning period of the MEB, the Linac and LEB (each having already been commissioned themselves and, therefore, subsequently operated with operations funds outside the WBS/TPC) are charged half-time to pre-operations and halftime to operations.

The projected Laboratory Operations costs for the following SSC Laboratory facilities and research areas were reviewed:
a) Injector Accelerators
b) Test Beams
c) Experimental Facilities
d) Magnet Research Laboratory
e) Physics Research

The project timeframe considered for operating costs was 1991-1999. There are no Collider operations funds included in this category since Collider commissioning is not complete until the end of 1999; it was assumed Collider operations begin in 2000.

\subsubsection{Assessment of Project Status}

There has been a very low level of cost to date for Laboratory Operations activities. Some small levels of expenses have been covered by operations funds to date (a total of $\$ 7.5$ million for the years 1991-1993) to support the physics research program. The SSCL has reviewed and updated their plans for both the Pre-operation and Operation phases since the original cost baseline was established (e.g., SSCL Commissioning and Operations; Report SSCL-SR-1210; March 31, 1992). The SSCL has also developed detailed staffing and operations projections for FY 2000 and beyond to provide planning information during transition from construction activities to full laboratory operations (e.g., SSC Laboratory Operations Program Plan FY 2000 to FY 2005; Report SSCL- 
SR-1216; November 1992). The subcommittee reviewed both of these recent documents. In general terms, the plans developed in these relatively recent documents are still consistent with funding requirements within the baseline cost estimates for the Laboratory Operations programs.

\subsubsection{Plan to Complete}

The Laboratory's plan to complete is as presented in the Commissioning and Operations planning document SSCL-SR-1210 described above. In general terms, the plan developed in that report is still consistent with funding requirements within the Laboratory.

\subsubsection{Interfaces}

Detailed definition and clear understanding of the interfaces with the elements for pre-operations are very critical. For the accelerator systenıs, the start of operations is signaled when the accelerator's basic objective is achieved (i.e., the facility can supply adequate beam for start-up and commissioning of the next higher-energy accelerator). These definitions are described in Section 7.10.2. The Magnet Development Laboratory (MDL) and Magnet Test Laboratory (MTL) activities will be funded with Laboratory Operations funds when all superconducting magnets for the SSC Collider and HEB have been designed, built, and tested, and both facilities are available for operations support and continued magnet research and development. The physics program operating funds include budgets for operating the experimental facilities after they are commissioned, as well as research and theory activities and detector collaboration and coordination.

\subsubsection{Documentation Available and Reviewed}

The following documents were reviewed by the subcommittee:

Report on the SSC Cost and Schedule Baseline, DOE/ER-0468P, January 1991

SSC Project Monthly Progress Report, May 1993

BCE old WBS/New WBS Crosswalk Handbook

SSCL Commissioning and Operations; SSCL-SR-1210

SSCL Operations Program Plan FY 2000 to FY 2005; SSCL-SR-1216 


\subsubsection{Assessment of Plan to Complete}

The subcommittee considers that the interfaces have been described adequately, and that the proposed staffing model and anticipated commissioning and operations schedule have been developed in a reasonable manner. The overall plan for funding these operations elements is indicated in Table 7.10.7-1.

Table 7.10.7-1

\begin{tabular}{|c|c|c|c|}
\hline Fiscal Year & $\begin{array}{l}\text { SSC Oper. Plan } \\
\text { (FY91M\$) }\end{array}$ & $\begin{array}{c}\text { Lab Operations } \\
\text { (FY93M\$) }\end{array}$ & $\begin{array}{l}\text { Lab Operations } \\
\text { (As Spent M\$) }\end{array}$ \\
\hline 1991 (actual) & 3.2 (plan) & 2.0 & 2.0 \\
\hline 1992 (actual) & 9.4 (plan) & 3.0 & 3.0 \\
\hline 1993 (actual) & 15.7 (plan) & 2.5 & 2.5 \\
\hline 1994 (plan) & 21.4 & 22.9 & 23.5 \\
\hline 1995 (plan) & 30.9 & 33.1 & 34.7 \\
\hline 1996 (plan) & 51.8 & 55.5 & 59.5 \\
\hline 1997 (plan) & 97.0 & 104.0 & 114.1 \\
\hline 1998 (plan) & 118.8 & 127.4 & 142.9 \\
\hline 1999 (plan) & 145.5 & $150 . \overline{0}$ & 178.8 \\
\hline Totals: & 493.7 & 506.4 & 561.0 \\
\hline
\end{tabular}

\subsubsection{Risk}

The potential risks associated with following this Laboratory Operations funding plan must be recognized and addressed. The two major risks are staffing and schedule uncertainties.

Staff Risk: The assumptions in staffing levels and staff costs have a direct effect on the operations cost. Although reasonable assumptions are being made in the current plans, the methods for budgeting the necessary operations staff may have a future effect on the total cost. (e.g., Laboratory overhead rates may fluctuate, safety, QA, and documentation requirements may change, etc.). The operations plan assumes that a large number of the design, construction, installation, and testing staff that were required for the construction phase are not involved in the preoperations and operations activities; it is assumed that the levels and mix of staff categories are adjusted after construction activities are complete and not all will be supported by preoperations and operations budgets. If more construction staff are carried on operations funds when construction work is complete the operations costs may grow considerably. 
Schedule Risk: It is not possible to predict the exact time that each accelerator completes its commissioning phase and when its operation will begin to be charged to operating funds. It is expected that after the commissioning period each accelerator will readily have the capability to commission the next higher energy machine. This means that the beam ejection system and beam transfer lines to the next accelerator are operational. In addition, the commissioning tests must provide evidence that the machine has the capability to reach rnaximum-design performance and that the methods of achieving full-design performance are understood. Operations then covers the period of time during which performance improvements, and ultimate design goals, might be demonstrated. However, if problems are encountered in the individual testing or system acceptance tests for critical elements, or if component reliability becomes a problem and breakdowns, component unavailability, etc., occur during the commissioning period, the duration of the commissioning period will have to te extended and will have a direct bearing on both the cost and schedule of subsequent activities. Although reasonable assumptions are being made now for schedule, any difficulties in this area could have a significant cost effect on the pre-operations and operations budgets. The projected schedule assumes that Laboratory operations funds will be used to support the facility operations through the approval of Key Decision \#4 (KD4). The baseline schedule assumes KD4 approval at the end of 1999 , and at that point, subsequent laboratory operating budgets are to be developed on an annual basis. If the overall completion date of the project slips, or KD4 is not approved in a timely manner, then the projected budget for the Laboratory operations cost category will be seriously affected.

\subsubsection{Cost}

The subcommittee recommends that approximately $\$ 506$ million be recognized as the total budget for the Laboratory Operations category in FY 1993 dollars (including the approximately $\$ 7.5$ million in this category funded for FY1991-1993). For as spent dollars, the present plan escalates to approximately $\$ 561$ million. Adjustment of the project completion date, of course, will have a direct effect on the total cost. 


\subsubsection{Schedule}

The subcommittee considers the schedule for the operations activities reasonable. However, the operations and pre-operations schedules are largely driven by the availability of other systems, and any adjustment to critical subsystem schedules will have a direct affect on the pre-operations and operations schedule and budget.

\subsubsection{Conclusions/Recommendations}

The subcommittee finds the proposed plan for the Laboratory Operations reasonable. 
APPENDIX A 
MEMORANDUM FOR

FROM:
FRANKLIN G. PETERS

OFFICE OF THE ASSOCIATE DEPUTY SECRETARY

FOR EIELD MANAGEMENT.

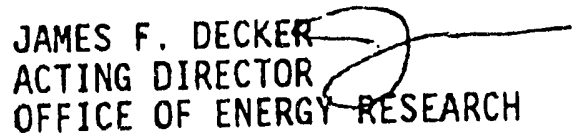

SUBJECT:

STATUS VALIDATION OF CURRENT BASELINE FOR THE SUPERCONDUCTING SUPER COLLIDER

In accordance with the Secretary's testimony of June 29, 1993, before the House Subcommitttee on Oversight and Investigations, the Office of the Superconducting Super collider has initiated a project validation of the current baseline. This review will result in a written report to the Acting Director of the office of Enorgy Research that will validate the project progress and status as identified in the May 1993 Cost Performance Report. The report will also project an estimate-at-completion range based on current trends and projected changes and provide an assessment of the usefulness of the business management systems based on information gathered from the review. This validation w17l be accomplished between July 12 and August 9, 1993. The attached document sets the course of action necessary to accomplish the validation.

I am requesting that $\mathrm{Mr}$. John Scango be made avallable to assemble and chair a review committtee to perform this effort. The Office of the Superconducting Super Collider will provide support to your office and fund the efforts as required. Dr. Robert Diebold will be the Office of the Superconducting Super Collider contact for this review.

This memorandum supersedes my memorandum of May 17, 1993, to $\mathrm{Mr}$. George Haymond requesting a review of the result of the replanning exerctse.

Attachment 
APPENDIX B 


\section{SSC Baseline Validation Committee Chairman: John Scango (DOE/FM) \\ Deputy: Robert Wunderlich (DOE/CH) \\ Vice: William Sylvester (DOE/FM) \\ Energy Research Representative: Dan Lehman (DOE/ER)}

1. Management Subcommittee

$\begin{array}{ll}\text { Yanglia Cho* } & \text { ANL } \\ \text { Alan Goetz* } & \text { DOE/SSCPO } \\ \text { Klaus Berkner } & \text { LBL } \\ \text { Joe Bozik } & \text { DOE/FM } \\ \text { Eugene Desaulniers } & \text { ANL/APS } \\ \text { Steve Flannery } & \text { G/C } \\ \text { Tony McCloskey } & \text { G/C } \\ \text { David Myers } & \text { DOE/SSCPO } \\ \text { Robert Zich } & \text { DOE/ER }\end{array}$

SSCL POC: Cindy Howe, Wanda Mizutowitz

2. Superconducting Accelerators Subcommittee

Jay Benesch*

Robert Diebold*

Vic Karpenko

Thad Konopnicki

Henry Kravec

Peter Limon

Richard Lundy

Charlie Marcincavage

John Reedy
CEBAF

DOE/ER/OSSC

Consultant

DOE/FM

Consultant

FNAL

Consultant

$\mathrm{G} / \mathrm{C}$

$\mathrm{G} / \mathrm{C}$

SSCL POC: Gerry Dugan

3. Resistive Accelerators Subcommittee

Lindsay Coffman*

Rich Orr*

Leigh Harwood

Dave Haught

Danny Punch

Skip Simmers
DOE/SSCPO

Consultant

SURA/CEBAF

DOE/SSCPO

$\mathrm{DOE} / \mathrm{SSCPO}$

$\mathrm{G} / \mathrm{C}$

SSCL POC: Tom Elioff, John McGill

4. Experimental Systems and Detectors Subcommittee

Marvin Gettner*

(Robert Diebold)

William Watson
DOE/ER

DOE/ER/OSSC

DOE/SSCPO

SSCL POC: Fred Gilman, Jon Ives

* Subcommittee Chairman 
5. Startup/Commissioning Subcommittee

Ronald Yourd*
(Peter Limon)
(Thomas Mann)

SSCL POC: Gerry Dugan

Proposed Changes Support

Greg Haas*

Mike Harrison

William Poage
DOE/ER

FNAL

ANL/TAC

SSCL POC: Susan Archer, John Rees

Conventional Facilities (Shared with Subcommittees 3 and 4)

James Carney*
Robert Selby*
Michael Bebon
Barry Benroth
Robert Bray
David Cassady
Dale Christenson
Wendell Mansel
William O'Connor
John Phillips
Wayne Reber
James Risse
Barry Savnik

SSCL POC: Fred Gilman, Jon Ives

Environmental, Safety and Health Support
Nat Brown*

Joseph LaRue* (Env.)

Tony Robledo

Dean imith (Safety)

SSCL POC: Phil Shelley

Schedule Support

Ron Bates

Tom Border
DOE/ER/OSSC

DOE/CH

BNL

DOE/FM

Consultant

Consultant

DOE/SSCPO

DOE/SSCPO

DOE/FM

DOE/SR

DOE/SSCPO

DOE/SSCPO

DOE/SF 
Accelerators Systems Support (Shared with Subcommittee 2)

$\begin{array}{ll}\text { Eugene Colton* } & \text { DOE/SSCPO } \\ \text { Robert Bell } & \text { SLAC } \\ \text { Robert Benson } & \text { DOE/SSCPO } \\ \text { William Brewster } & \text { DOE/SSCPO } \\ \text { Gaylon Cobb } & \text { DOE/SSCPO } \\ \text { Jock Fuggitt } & \text { CEBAF } \\ \text { Terry Jackson } & \text { LBL } \\ \text { Rol Johnson } & \text { CEBAF } \\ \text { Andy McNerney } & \text { BNL/AGS } \\ \text { Harvey Robbers } & \text { G/C } \\ \text { Richard Rosenberg } & \text { ANL/APS } \\ \text { Ralph Sanders } & \text { BNL }\end{array}$

SSCL POC: Tom Elioff, John McGill

Installation Contract Support

Robert Brown*

Terry Williams*

Donald Knutson

(Peter Limon)

Thomas Mann

Robert Scarlett

William Sepples

DOE/RL

DOE/SSCPO

PPPL

FNAL

HARC

DOE/FM

$\mathrm{G} / \mathrm{C}$

SSCL POC: Gerry Dugan

Laboratory Operations

(Peter Limon)

(Ron Yourd)

FNAL

DOE/ER

Editoral Suppert

Joe Chew

Art Robinson LBL

LBL

Administrative Support

Linda Staples DOE/ER/OSSC

Anna Bennington

DOE/ER/OSSC

Brent Baker DOE/ER

Casey Clark DOE/ER/OSSC

Sarah Davenport

Jama Thurman

DOE/ER/OSSC

Heather Whitman

DOE/FM

DOE/FM

* Subcommittee Chairman 
APPENDIX C 
Project Controls Engineer, Santee Cooper, South Carolina Public Service Authority, Cross Generating Station, Unit 1; previously Project Controls Engineer on various domestic and international fossil and nuclear powered electric generating facilities.

\section{Michael.J. Bebon}

BEME, NY Univ. 1972

$$
\text { MBA, Univ. of UT, } 1975
$$

Deputy to the Associate Director for Management and Physical Plant, BNL; previously Division Manager, Plant Engineering Division, BNL.

Member:

American Society of Mechanical Engineers; American Society for Quality Control.

$\begin{array}{ll}\text { Robert A. Bell } & \text { BSME, UC Berkeley, } 1958 \\ \text { MSME, UC Berkeley, } 1960\end{array}$

Chief Engineer, PEP - II, Asymmetric B - Factory, SLAC; previously Chief Engineer, SLD, SLAC; previously Head of Conventional Facilities, SLC, SLAC; previously Head of Mechanical Systems, PEP, SLAC.

Honors:

National Engineering \& Mechanical Engineering Honors Societies.

DOE Committees:

GEM Muon Review; SDC Toroid Review; SDC Baseline Review; SSC Baseline Review; STAR Baseline Review; AGS Booster Review; DO Review.

Jay F, Benesch

BS, Physics, Mass. Inst. Tech.

MS, Engineering Science, Yale

Ph.D., Physics, Univ. of TX (Austin)

Senior Staff Scientist and Cavity Group Leader, CEBAF; previously Magnet Program Manager, Office of Superconducting Super Collider (OSSC); previously Electromagnetics Design Manager and Systems Integration Manager, General Electric Magnet Systems.

DOE Committees:

SSC SCDR Review - Magnet Subcommittee; SSC SDC Review - Chaired Magnet Subcommittee; LBL Program Review - 1993.

DOD Committees:

Technical Consultant to SMES Technical Review Committee (DNA). 
Barron Benroth

BSPE MS State University 1966

MS, Financial Management, 1981

General Engineer, Office of Field Management, DOE/HQ; previously Civil Engineer Corps, Facilities Management, Engineering and Construction, U.S. Navy.

Bob Benson

BS, Physics, Univ. of TX, Arlington, 1972

MA, Physics, Univ. of TX, Arlington, 1977

Staff, Systems Engineering Branch, Superconducting Super Collider Project Office (SSCPO); previously, Project Leader, Information Services, Atlantic Richfield Company; previously, Staff, Scientific Computing, Bell Helicopter Textron.

\section{Klaus Berkner}

Associate Laboratory Director for Operations, Lawrence Berkeley Laboratory.

Responsibilities:

Accelerator construction and operation, engineering, environmental, safety, and health, information and computer sciences, and plant engineering.

Thomas . Border

Physics, Penn State Univ., 1964 - 1966

Metallurgical Eng., Temple Univ., 1969-1971

Business Adm., Albright College, 1978-1980

Supervisor, Project Controls Department, Gilbert/Commonwealth, Inc.; previously Project Controls Manager, Advanced Neutron Source, Oak Ridge, TN; previously Manager, Field Planning \& Scheduling, Westinghouse Nuclear Korea, South Korea.

DOE Committees:

ICE on Savannah River Particulate Control \& Stack Addition.

Bobert E. Bray, P.E. BSCE, AL, 1962

Consultant, Cost Estimating, Civil Geotechnical (ERC); previously Chief, Civil and Geotechnical Engineering, (HNDCE); previously Chief Engineering for Ground Base Laser Facilities; White Sands, NM, (HNDCE); worked 30 years for U.S. Army, Corps of Engineers in civil, geotechnical, and engineering management positions.

\section{William H. Brewster $\quad$ BSEE, Virginia Tech, 1991}

Electrical Engineer, SSCPO.

Honors:

Outstanding Performance Award, 1993; Outstanding Performance Award, 1992;

Special Act/Service Award, 1990; Eta Kappa Nu Electrical Engineering Honor Society; Gamma Beta Phi Honor Society.

Engineer-in-Training. 
Nat Brown

BSEE, Prairie View Univ., 1963

MBA, Univ. of North TX, 1978

Director Compliance Division, SSCPO.

DOE Committees:

Member, DOE Construction Safety Advisory Committee; Member, SSC Environmental Compliance Committee; Chairman, SSC Socioeconomic Monitoring \& Mitigation Group.

Robert Brown $\quad$ BSME, Wichita State, 1972

Director, Tank Waste Remediation System Projects Division, Richland Operations Office, DOE; previously Director, Construction Division, Richland Operations Office, DOE.

James Carney $\quad$ BSCE, Univ. of AR, 1966

MS, Engineering Mgmt., Univ. of MO, 1978

Principal Engineer, Office of Superconducting Super Collider, GTN; previously Chief of Validation Branch, DOE/HQ.

David C.Cassady.Jr. $\quad$ BS, Building Construction, Auburn Univ., 1956

Consultant (Cost Engineer) ERC; previously Chief Cost Engineering Division Huntsville Division, Corps of Engineers.

Yanglai Cho

BS, Seoul National Univ., 1956

MS, Cornell Univ., 1960

Ph.D., Carnegie Tech., 1965

Deputy to Associate Laboratory Director, Argonne National Laboratory; previously Project Director, Advanced Photon Source, Argonne National Laboratory.

DOE Committees:

Office of Energy Research Review Committee.

Dale Christenson $\quad$ BSCE, Univ. of WA, 1983

MSCE, Univ. of MD, 1993

Mechanical Engineer, SSCPO; LT, USNR, NAS Dallas, TX, ONI - 1770.

Honors:

Tau Beta Pi Engineering Honor Society.

Registered Professional Engineer, State of Maryland, 1993. 
Systems Engineer, Department of Energy, SSCPO; previously Communications Engineer, Central Intelligence Agency: RF Communications Department, African Area Engineer, Imagery Systems Department.

\section{Lindsay Coffman BSEE, Virginia Tech, 1963}

Director, Systems Engineering, SSCPO.

DOE Committees:

Member, Source Evaluation Board for SSC Prime Power.

Eugene Colton

BS, UCLA, 1962

MS, Physics, UCLA, 1964

PhD, Physics, UCLA, 1968

Director, Technology Branch, SSCPO; previously Physicist, LBL, ANL, LANL.

DOE Committees: Reviews of SSC, DHEP Programs.

Eugene R. Desaulniers

BS/BA, Boston University, 1956

MBA, Southern IL Univ., 1974

Manager, Advanced Photon Source Procurement, Argonne National Laboratory; previously Director, Materials Management, CEBAF.

Member National Contract Management Association; Certified Professional Contracts Manager, Fellow NCMA.

Honors: Blanche Witte Award Winner NCMA.

Robert E. Diebold $\quad$ BS, Univ. of NM, 1958

MS, Physics, Cal Tech, 1960

PhD, Physics, Cal Tech, 1963

Director, OSSC Program Coordination Division, DOE; previously Senior Physicist, Division Director for High Energy Physics, Argonne National Laboratory.

Honors:

Fellow, American Physical Society (APS); Secretary - Treasurer, Division of Particles and Fields of APS (1980 - 1983); Program Advisory Committee Member - Brookhaven (1972 - 1974), SLAC (1973 - 1975), Fermilab (1973 - 1976), Argonne (1979 -

Chairman), Cornell (1983 - 1985); Fermilab Users Executive Committee (1978 - 1980);

Rappateur for International Conference on High Energy Physics: Meson Resonances

(Chicago - 1972), Hadron - Hadron Reactions, High Multiplicity (Tokyo - 1978);

Leader of design team for POPAE (Proton - Proton Collider at Fermilab - 1975 -

1976); Leader of Accelerator Group on 20-TeV PP Colliders (Snowmass, 1982). 
DOE Committees:

HEPAP Subpanels (1973, 1978, 1979, 1980); HEPAP Member (1975 - 1979); Zero Gradient Synchrotron Review Panel (1976); ESCAR Review Committee (1978);

Review of HEP Programs at LBL, SLAC and BNL (1982); Technical Assessment Committee on University Programs (1982 - 1983); several reviews of various aspects of the SSC (1985 - present).

\section{Stephen A. Flannery}

BSCE, Univ. of MI, 1966

MSCE, Univ. of MI, 1967

Project Manager, Independent Cost Estimating, Gilbert/Commonwealth, Incorporated, Reading, PA.

\section{Jock A. Fugitt}

RF Systems Group Leader, CEBAF; previously Electrical Engineering Department Head, CEBAF; previously RF \& Pulse Power Systems Engineer, ALS, LBL; previously Vice President of Engineering, Mertec; previously Operations Engineer, S-HILAC, LBL; previously Power Conditioning Systems Engineer, SHIVA, LLNL; previously RF Systems Engineer, S-HILAC, LBL.

Honors:

DOE Energy Efficiency Award for individual achievement.

DOE Committees:

SLS DOE Review Committee.

Marvin Gettner

BS, University of Rochester, 1956

$\mathrm{PhD}$, University of PA, 1961

Physicist with the Physics Research Branch/DOE HEP; previously Physicist with the Science and Technology Division/DOE OSSC; previously Physics Professor (High Energy Experimental Physics), Northeastern University, Boston, MA.

Alan Goetz

BA, Industrial Relations, Rockhurst College, 1970 MPA, Labor Relations, Univ. of MO, 1975

IR Speciaiist, SSCPO; previously IR Specialist, DOE/Chicago Operations Office.

Gregory M. Haas

BS, Mathematics, Lamar Univ., 1957

BSEE, Lamar Univ., 1958

MSEE, LA State Univ., 1960

PhD, Physics, LA State Univ., 1963

Chief Scientist, SSCPO; previously Branch Chief Fusion Technologies, Plasma Technologies, MFTF Project Manager, Office of Fusion Energy, Department of Energy. 
Head, Collider, RHIC Project, BNL; previously Deputy Head, Accelerator Division, Fermilab.

Member: American Physical Society.

DOE Committees: Fermilab Main Injector Review, 1992, 1993; SSC Machine Advisory Committee, Biannual - 1990, permanent member; CEBAF, DOE Annual Review 1991.

\section{Leigh Harwood}

BA, Univ. of TN, 1974

MS, Physics, FL State Uriv., 1977

PhD, Physics, FL State Univ., 1978

Head, Arcs Department, Acreelerator Division, CEBAF; previously Head, Technology Services Group Engineering Division, CEBAF; previously faculty and research positions at Michigan State University.

DOE Committees:

SSCL Cold Magnet Measurement Review; MIT/Bates Storage Ring cost/schedule review; SPEAR Injector cost/schedule review.

Dave Haught

Electrical Engineer, SSCPO.

Terry Jackson
BSEE, Univ. of MD, 1982

Department Head, Accelerator E. ectronics, Lawrence Berkeley Laboratory; previously Group Leader, Magnet Power SL:plies, Advanced Light Source; previously Group Leader, Electronics, Magnetic Fusion Energy (MFE); previously Group Leader, Magnet Power Supplies, PEP.

\section{Bolland Paul.Johnson}

BA, Mathematics, U. of CA, Berkeley, 1964

PhD, Physics, U. of CA, Berkeley, 1970

Head of Instrumentation and Controls Department, CEBAF Accelerator Division. Responsible for Control, Beam Instrumentation, and Safety Systems. Program coordinator for machine commissioning.

\section{Victor $N$. Karpenko $\quad$ BSME, U.C. Berkeley, 1948}

Consultant, Technology and Management; previously Division Head, Magnet System SSC, CDG URA; previously Project Manager, Mirror Fusion Test Facility, LLNL; previously Division Head, Nuclear Test Engineering, LLNL; previously Group Leader, Applied Mechanics, LLNL; previously Project Engineer, Nuclear Weapons Design, LLNL; previously Staff Engineer, Nuclear Reactor Design, GE. 
DOE Committees:

Containment Evaluation Panel, Nuclear Tests Fusion Safety.

Donald Knutson

BSE, Trinity College, 1954

MSME, Drexel Univ., 1966

1966 - Present Princeton University, Plasma Physics Laboratory:

a. Mechanic al Engineering

Diagnosti;s, RF Systems, Cooling Systems, Coils

b. Assembly - Resp unsible for PDX machine

c. Assembly - TFTR liaison

d. Deputy Head - Mechanical Engineering Division

e. Principal Engineer - Mechanical Engineering, TPX Project, structural design and assembly.

1954-1966 Westinghouse Electric Corporation:

a. Training Program and Manufacturing School

b. Large Turbine Division - Erection and Test; - Blade and Tool

Thad Konopnicki

BSME, University of VA, 1978

MBA, University of Dallas, 1980

MSEE, Boston University, 1986

Chief, Environmental Restoration \& Waste Management Branch, DOE/FM; previously Cost \& Schedule Engineer, OSSC, DOE/ER; previously Independent Cost Estimating Staff, DOE/MA.

DOE Committees:

ER SSC Conventional Construction Review Committee, July, 1992; ER SSC Review Committee, June, 1990; ER CEBAF Review Committee, 1990; SSC Independent Cost Estimating Committee; 1990.

Henry Kravec

BSME, University of Cincinnati, 1971

PE, Mechanical Engineer

PE, Manufacturing Engineer

Graduate of GE Manufacturing Management Program

Industrial Experience with GE; Managerial Responsibility with GE S/C Magnet Systems - involved in business start-up; managed new product development introductions.

Joseph H. LaRue

BS, Physical Science, CA Poly University, 1972

Principal Engineer, Regulatory Compliance, Westinghouse Hanford;

Previously Senior Engineer, Environmental Compirance, Southern California Edison. 
Director, Division of Construction Management Support, Office of Energy Research, Department of Energy.

DOE Committees:

Chaired: SSC - SDC Detector Review ( $\$ 600 \mathrm{M})$; RHIC, Fermilab Main Injector, APS

Baseline and Semiannual Reviews.

Other project and experimental reviews.

Member:

SSC Reviews: 1984 Reference Design Review; 1986 Conceptual Design Review; 1990 Site Specific Conceptual Design Review; SSC Site Selection Committee.

Baseline and Semiannual Reviews: Energy Saver, FNAL; Tevatron I, FNAL; Tevatron, FNAL; CDF Detector, FNAL; SLC, SLAC; SDC Detector, SLAC; Others.

Peter Limon $\quad$ BS, Physics, Tufts Univ. , 1963

PhD, Physics, Univ. of WI, 1968

Scientist, CDF, Fermi National Accelerator Laboratory; previously Scientist Central Design Group, SSC.

DOE Committees:

SSC Schedule Validation Committee.

Richard A. Lundy

BS, Physics, Univ. of Chicago, 1955

MS, Physics, Univ. of Chicago, 1957

$\mathrm{PhD}$, Physics, Univ. of Chicago, 1962

Retired, part-time private consultant; previously Associate Director for Technology, Fermi National Accelerator Laboratory; previously Head, Technical Support Section, Fermi National Accelerator Laboratory; previously Head, Energy Doubler Magnet Group.

Honors:

The National Medal For Technology, 1989.

Thomas L. Mann. Jr.

BSME, George Inst. of Tech., 1965

Graduate studies, Engineering Science and

Mechanics, Univ. of TN, Knoxville

Systems Integration and Installation Coordinator, Advanced Photon Source, Argonne National Laboratory; previously Deputy Project Manager, Continuous Electron Beam Accelerator Facility/Southeastern Universities Research Association; previously Deputy Division Head, Superconducting Radiofrequency Division, CEBAF; previously Senior Mechanical Engineer, Texas Accelerator Center, Rice University; previously Project Engineer, Fermi National Accelerator Laboratory, General Dynamics/Convair Division; previously Senior Design Engineer, Fermi.

Registered Professional Engineer - Mechanical, GA; American Society of Mechanical Engineers; American Nuclear Society. 
BSME, Kensington Univ., 1982

MSPE, Kensington Univ., 1986

BS, Envir. Sci., Univ. of AL, 1994

Genera//Mechanical Engineer, DOE/SSCPO: Facilities Maintenance Engineering, Energy Conservation, Energy Conservation and Utility Acquisition, CAMP and CAS Coordinator, Energy Efficient Technology Coordinator and In-House Energy Manager, Facilities Acceptance Inspector: DOE/SSCPO - Conventional Division; previously General/QA Engineer: QA Program Manager, Certified Lead Auditor: DOE/SSCPO Compliance Division; Engineering Duty Officer, USNR, LTJG, NAVSEA DET 811, NAS Dallas, TX.

DOE Committees:

Baseline Validation Review - Conventional Construction Subcommittee; Environmental Working Group; QA Design Task Group; NRC Licensing Group.

\section{Charles.J.Marcincavage $\quad$ BSCHE, Penn State Univ., 1949}

Project Cost Engineer, Gilber//Commonwealth, Inc. - process and project engineering, estimating and cost engineering for utility, industrial and government projects.

\section{Anthony.J.McCloskey $\quad$ BS, SDCET, Penn. State Univ., 1991}

Cost Engineer, Gilbert/Commonwealth, Incorporated.

Engineer-in-Training, 1992.

Andrew J. McNerney

BSEE, 1962 Polytechnic Institute of Brooklyn MSEE, 1965 Polytechnic Institute of Brooklyn

Accelerator Division, Deputy Head, AGS Dept. BNL

Senior Member IEEE.

Paul R. Miller $\quad$ BSME, Univ. of MN, 1946

Department of Navy: 1951-1975; Last Position - Director of Quality and Reliability, Naval Sea Systems Command

Department of Interior - Bureau of Reclamation: 1946-1951

\section{David A. Myers $\quad$ BA, Political Science, Austin College}

International Affairs Specialist, International Division, SSCPO; previously Program Analyst, Materials Control \& Accountability Branch, Office of Safeguards and Security, DOE; previously Security Specialist, International Branch, Office of Safeguards and Security, DOE; previously Policy Analyst (Safeguards), Office of International Programs, U.S. Nuclear Regulatory Commission; Management Intern, U.S. NRC. 
Honors:

Monetary Award for Superior Job Performance, May, 1993; Monetary Award for

Superior Job Performance, September, 1992.

DOE Committees:

Management Subcommittee, DOE Central Training Academy, Self Assessment; Defense Programs Intern Program Committee; Founding Member, International Safeguards Committee, Institute for Nuclear Materials Management.

William O'Connor $\quad$ BSCE, IL, 1965

MSCE, Stanford, 1976

MBA, Univ. of HI, 1981

Naval War College, 1991

General Engineer, Program/Project Management Division, DOE/HQ.

Rich Orr BA, University of IA, 1955

PhD, University of WA, 1965

Positions at Fermi National Accelerator Laboratory 1970-1991: Associate Director for Administration; Head of the Accelerator Division; Tevatron Project Manager; Assistant Director; Associate Head of the Research Division.

Honors:

National Medal of Technology, 1989.

DOE Committees:

Lehman/Temple Reviews of SLAC (SLC), CEBAF, BNL; Validation Committee for RHIC Magnets; National Energy Strategy Advisory Committee; Panofsky Panel for SSC.

John R. Phillips

BS, Mathematics, FL State Univ.

MSIE, Univ. of FL

Chief, Nuclear Materials Projects, SROO.

Bill A. Poage

BS, Physics, CSU, 1967

Graduate work-Physics: Univ. of AR 1968 -1969

CA State Univ. 1990

Senior Systems Engineer, SSCPO; previously Division Head, Medium Range Missile Ships, NWSES, DOD; previously Class Engineer, MRMS; previously Branch Head, AEGIS Combat System, NSWSES.

Honors:

AEGIS Excellence Award; Who's Who American Colleges \& Universities;

NDEA Title IV Fellowship; Nominated Outstanding Scientist/Engineer, NSWSES, 1988. 
Mechanical Engineer, SSCPO, DOE; previously Mechanical Engineering Project Manager, Strategic Weapons Programs, NWAC, Measurement Science Directorate; previously Construction/ Maintenance Engineering Project Manager, Terminal Facility/Service Station Construction, Gulf Oil Refining and Marketing; previously Mechanical Design Engineer, Production Tool Development, Tenneco Automotive, Mechanics Division.

DOE Committees:

Class "A" Accident Investigation Team, Mechanical Engineer, Committee Support Member.

Wayne H. Reber

BS, Univ. of IL, 1974

MA, Univ. of IL, 1976

Architect, Conventional Construction Division, SSCPO; previously Project Manager, U.S. Air Force Regional Civil Engineer, Central Region; previously Project Design Manager and Architect, U.S. Army Corps of Engineers;

Registered Architect, State of Illinois, 1978;

National Council of Architectural Registration Boards (NCARB), 1986.

John H. Reedy.Jr. Associate DDT, Penn State Univ., 1958

Senior Estimator, Gilbert/Commonwealth, Inc. - construction cost estimating, budgeting, and contract administration support for multimillion dollar utility, industrial, and environmental projects. Multi-discipline experience, speciaiizing in civil/structural work.

Harvey S. Robbers

BSEE, CA Poly State Univ., 1972 MMP, General Electric, 1975

Engineer, Gilbert/Commonwealth Engineering; previously Principal Engineer, Automation Equipment Controls Inc.; previously Technical Project Engineer, NEBO Control \& Instrumentation, General Electric Corporation.

Richard Rosenberg

BSChE, Northwestern, 1971

MS, Chemistry, Univ. of IL, 1974

$\mathrm{PhD}$, Chemistry, Univ. of CA., 1979

Staff Scientist, Advanced Photon Source, ANL; previously Staff Scientist, Synchrotron Radiation Center, University of Wisconsin; previously Research Scientist, Naval Weapons Center, China Lake, CA.

DOE Committees:

SSC Vacuum Review, May 1991. 
Project Engineer, RF Upgrade Project, BNL; previously, RF Group Leader, Booster Project, BNL; previously, RF Group Leader, AGS, BNL; previously, Project Engineer, Heavy Ion Fusion RF, BNL; previously, Project Engineer, AGS, BNL.

Barry Saynik

BSIE, Univ. of CA, Berkeley, 1976

MBA, CA State Univ., 1983

Assistant Director, Engineering and Facilities Management Division, DOE/SF; previously Chief, Facilities Management Branch, Naval Aviation Depot, Alameda, CA.

Professional Engineer, State of California \#1188.

G.John Scango

BSME, Carnegie Mellon University, 1962

Deputy Director for Program/Project Management Division, Office of Field Management, DOE; previously U.S. Synthetic Fuels Corporation; previously Assistant Manager for Engineering, Strategic Petroleum Reserve Project Office.

Registered Professional Engineer.

\section{B.R. Scarlett}

BS, Univ. of NC, 1953

MBA, George Washington Univ., 1977

Special Assistant to Program/Project Management Division, Office of Field Management, DOE; previously Director, Office of Independent Cost Estimating.

\section{Robert C. Selby $\quad$ BSNE, KS State Univ., 1965}

Director, Programs and Facilities Management Division, Chicago Operations, DOE; previously Head, Reactor Engineering Division, Mare Island Naval Shipyard.

Registered Professional Engineer.

Honors:

DOE Special Service Award (Bronze), 1990.

DOE Committees:

Chairman, Architect Engineer/Reactor Manufacturer Selection Committee for New Production Reactors; Real Estate Committee Member, SSC Site Selection Committee; Chairman, Chicago Management Assessment Committee for Ames Laboratory and Batavia Area Office. 
William F. Sepples

BSEE, Power Systems, Northeastern Univ., 1971 Graduate Studies, Nuclear Engineering, Total Quality Management, 1993

Construction Manager, Gilbert/Commonwealth, Reading, PA; previously Manager of Construction for Dravo Corporation and Vice President of Commerce Electric Company, Incorporated.

\section{Edgar V.Simmers $\quad$ AAS, DeVry Institute, Chicago}

Cost Estimator, Gilbert/Commonwealth; previously Estimator, General Electric; Previously Job Planner/Detailer, General Electric; previously Senior Designer, General Electric.

Dean Smith BSME, University of NE, 1973

Principal Engineer, Systems Safety Analysis, Westinghouse Hanford.

William G. Sylvester $\quad$ BA, Business Management, Univ. of AR, 1973 MA, Human Resources Mgmt., Webster U., 1975 MA, Information Tech., Pepperdine Univ., 1979

Director, Field Liaison, Office of Field Management, DOE Headquarters; previously Director, Information Technology, New Production Reactors, DOE; previously, Director, Nuclear Shipyard Technology Development, Office of Secretary of Navy; previously, Director, Technology Facilities Management, Naval Sea Systems Cmd (07); previously Director, Workload and Technology, Office of the Naval Civilian Personnel Office.

Jama L. Thurman $\quad$ BS, General Engineering, Univ. of IL, 1988

General Engineer, Office of Program/Project Management, Office of Field Management, DOE.

Engineer-in-Training, Illinois.

DOE Committees:

Business Management Review Teams at Oak Ridge and Lawrence Livermore National Laboratory. 
Physicist, DOE, SSCPO.

Member: American Physical Society.

DOE Committees:

Member of DOE Committee to Review the Technical Design Report of the Solenoidal Detector Collaboration, Subcommittee for Electronics, Data Acquisition, and On-line Computing.

Terry D. Williams BSIE, Univ. of AR, 1964

Director, Reliability, Maintainability, and Quality Assurance, OSSC.

Robert Wunderlich BSME, Penn State, 1973

MSNE, Penn State, 1975

Project Manager, Advanced Photon Source Project, DOE; previously Deputy Project Manager, Salt Repository Project, DOE.

DOE Committees:

Deputy for the Baseline Validation Committee.

Ron Yourd

BSME, Univ. of CA, Berkeley, 1964

MSME, Univ. of CA, Davis, 1966

Lawrence Berkeley Laboratory Detailee Assignment, DOE/HQ ER-65; previously Project Manager, ALS Project, LBL; previously SSC Central Design Group, LBL; previously Project Manager, NCAM Project, LBL; previously Project Engineer, HILAC and Bevalac Facility at LBL; previously Staff Engineer, Los Alamos National Laboratory, LBL.

DOE Committees:

SSC Review Committee, June 1990; 1991 - 1993 APS Project Semi-Annual DOE Reviews, ANL.

\section{Robert Zich}

Director, Division of Acquisition and Assistance Management, Office of Energy Research. 
APPENDIX D 
DATE: REPLY TO ATTN OF:

SUBJECT:

TO:
UUL 141993

ER-90, SSCPO

Project Review Committee-Questions of Occupational Conflicts

John Scango, AD/FM

Chairperson, DOE-SSC Validation of Current Baseline Committee

This memorandum is being written to address questions that have been or that may be raised concerning possible conflict of interest or conflicting occupational relationships of team participants as reflected by the composition of the team as described on the Attachment to this memorandum. The participants involved in the baseline validation have been intentionally drawn from a variety of DOE, M\&O, consultant, and other sources including FERMI lab because of the need to strengthen the factfinding ability of the team membership using both internal and external sources including experts and professionals from the FERMI Laboratory.

For purposes of this review, I have determined that the individuals assigned to the review should participate in an official capacity in this review process because of their very specialized knowledge and qualifications. I have determined that no single person's participation in this review will have a direct and predictable effect on the Committee findings upon which the final report be produced by the Committee Chairperson.

I am providing a copy of this inemorandum to each team member for information purposes and request that each member assess his/her previous efforts on this project and voluntarily disqualify himself/herself from participation in any assigned matter to the extent that he or she feels that they cannot act objectively and appropriately in completing their individual committee assignments. Moreover, I request that each member report any potential problem in this regard to my attention or the attention of the Chairperson so that appropriate action is taken to deal with the appearance or actual conflicts that could arise in connection with any other members participation in the review.

Please let me know if you have any queptions.

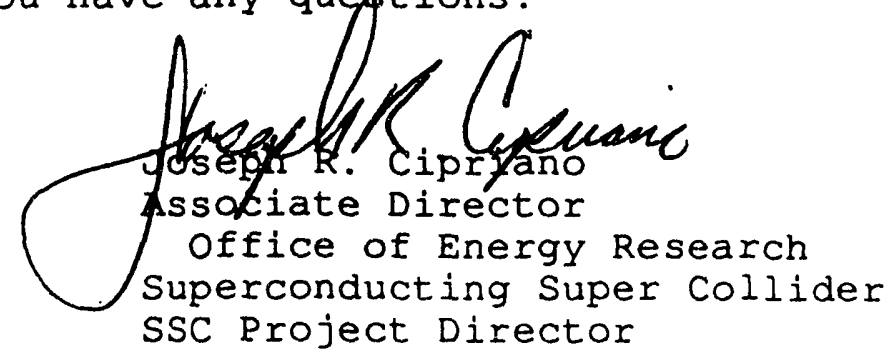

Attachment 
APPENDIX E 

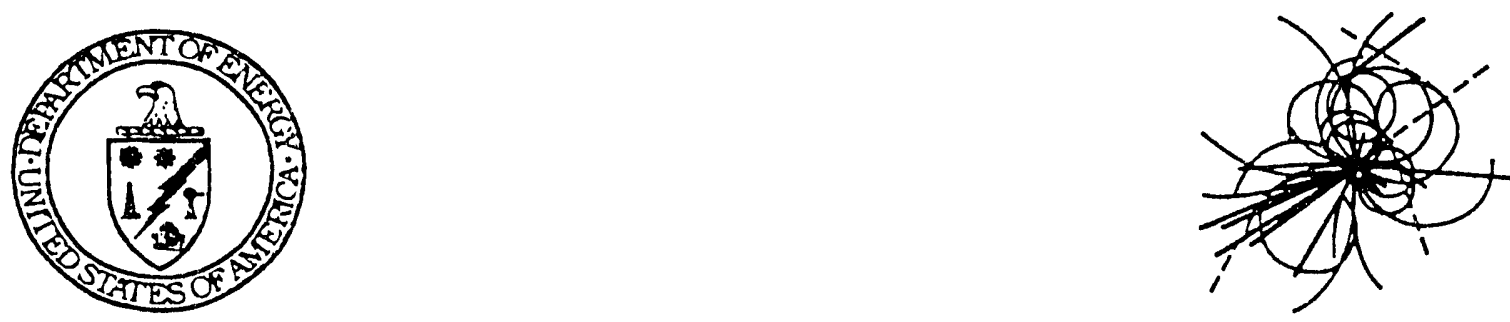

\section{CONFIDENTIALITY AGREEMENT}

\section{SSC Baseline Validation Review}

I hereby acknowledge that certain information and documents associated with the U.S. Department of Energy Baseline Validation Review of the Superconducting super Collider (SSC) will be furnished to me. During the conduct of the baseline validation review, and thereafter, I agree not to disclose any information related to the baseline validation which is privileged, confidential or senitive, directly or indirectly to any person other than a person duly authorized by the Department of Energy.

The information and documents may relate to or contain sensitive budgetary information which is protected from mandatory public disclosure pursuant to 5 U.S.C. 552 (b) (5). In addition, the information and documents may relate to or contain information which is procurement sensitive and is considered Government Commercial Confidential Information (GCCI) by the Department of Energy and is protected from mandatory public disclosure pursuant to 5 U.S.C. 552 (b) (5). It may also contain commercial confidential or trade secret information as contemplated by 18 U.S.C. 1905 and/or. 5 U.S.C. (b) (4). The information shall be afforded confidentiality as contemplated by the Procurement Integrity Act (41 U.S.C. 423) and the Trade Secrets A.ct (18 U.S.C. 1905). Violations of these acts may result in civil and criminal penalties.

In this regard, I hereby agree to hold all information and documents provided to me and which is shared with me confidential and shall not make disclosures of such information to a third party except as such disclosure may be required by a court, Government agency or regulatory agency, or as otherwise required by law. If I am required to make such disclosure, I shall take such further efforts as is necessary to minimize the disclosure.

(name) 
APPENDIX F 


\section{INEORMATION OBTAINED FROM THE SSCL}

1. Specification Trees for the Superconducting Super Collider, E10-000051, Rev B

2. Level 1 Specification

System Specification (Level 1) for the superconducting super Collider

Level 2 Specifications

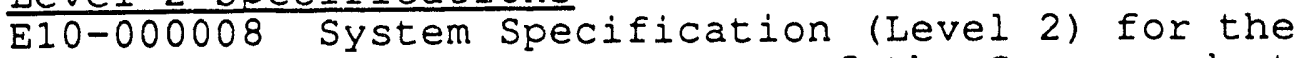

Accelerator system of the superconducting super

Collider

R00-000001 System Specification (Level 2) for the

Experimental systems of the superconducting

Super Collider

Level $3 A$ Specifications

E10-000003 Segment Specification for the IINAC of the Supercondicting super Collider Laboratory (Level 3A), W 5.S. 1.1.2

E10-000004 superconducting Super Collider Laboratory Segment Specification for the Low Energy Booster (Level 3A), W.B.S. 1.1.3

E10-000005 Segment Specification (Level 3A) for the Medium Eneigy Booster of the Superconducting Super Collider, Initial Issue, 20 september 1991, W.B.S. 231

E10-000006 Segment Specification for the HaB System of the Superconducting Super Collider Laboratory (Level 3A) W.B.S. 1.1.5, August 7, 1991

E1 1-000007 Segment Specification for the collider system of the Superconducting super Collider Laboratory, August 2, 1991, W.B.S. 1.1.6

E10-000042 Segment Specification for the Test Beam system of the superconducting super Collider

Laboratory, Level 3A, W.B.S. 56, May 5, 1993

Level 3B specifications
C12-00040
SSC Linear Accelerator - Conventional
Construction, Preliminary Design Requirements, Superconducting Super Collider Laboratory, Eebruary 1991, Revised April 1991
C13-00027
SSC Low Energy Booster: Conventional Construction, Preliminary Design Requirements, Superconducting Super Collider Laboratory, June 1991 (Revised September 1991)
C14-00003 Element Specification (Level 3B) for the Medium Energy Booster Technical Facilities of the Superconducting Super Collider, 20 september 1991, W.B.S. 2.1.4.1
C17-00004 Design Requirements Document, SSC Test Beam Area (Eacilities 3B Spec), Target Hall (WP-8) - Calibration Hall (WP-12), March 31, 1992
E10-J00009 System Requirement Definition for Accelerator Systems String Test (Ehase 1) of the Superconducting Super Collider Laboratory (Level III-B) 
E10-000022 Element Specification (Level 3B) for the Medium Energy Booster Accelerator of the

Superconducting Super Collider, Initial Issue, 2 December 1951, W.B.S. 231

E10-000024 Element Specification for the Medium Energy Booster Beam Transfer and Abort Line of the Superconducting Super Collider Laboratory, Level 3B, W.B.S. 232, June 10, 1992

E10-000025 Element Specification (Level 3B) for the Linear Accelerator of the Superconducting Super Collider Laboratory, July 22, 1991, W.B.S. 1.1 .2 .1

E10-000026 Element Specification for the LINAC Beam Transfer Line of the superconducting Super Collider Laboratory, Level 3B, WBS 212, June 15, 1993

E10-000027 Element Specification (Level 3B) Collider Accelerator Arc Sections, Superconducting Super Collider Laboratory (SSCL), August 1992

E10-000028 Element Specification for the High Energy Booster Beam Transfer and Abort Lines of the Superconducting Super Collider Laboratory, Level 3B, W.B.S. 312, Novemiver 7, 1991

E10-000030 Element Specification (Level 3B) for the Low Energy Booster to Medium Energy Booster (LEBMEB) Beam Transfer Line of the Superconducting Super Collider, W.B.S. 222, Initial Issue, 29 October 1991

Ej0-000039 Element Specification for the Low Energy Booster Accelerator of the Superconducting Super Collider Laboratory (Level 3B), WBS 221

E10-000054 Element Specification for the HEB Accelerator of the Superconducting Super Collider Laboratory, W.B.S. 311

3. a. Work Breakdown Structure Dictionary: Detail b. Work Breakdown Structure Dictionary: Summary.

4. SSCL Site-Specific Conceptual Design, July 1990

5. SSC Laboratory Integrated Project Schedule, Status as of May 23, 1993

6. SSC Baseline Validation Committee List (for SSCL Points of Contact)

7. SSC Laboratory Organizational Charts (7-12-93), with estimated manloading to level two WBS elements

8. SSC Project Monthly Progress Reports for January, February, March, April, May 1993, Superconducting Super Collider Laboratory. December 1992 Cost Performance Report.

9. CCB Log Report As of: July 8, 1993

10. SSC Project: DOE Semi-Annual Review (and viewgraphs)

11. a. Summary of Major Subcontracts - Magnets

b. Subcontract Modification Summary, Collider Dipole

c. FY 93 Annual Work Plan Modification 1, May Monthly Status Report, The PB/MK Team, June 21, 1993

d. Monthly Cost/Schedule Progress Report, Definitive Subcontract SSC-90B-0946 (PB/MK) 
12. Conventional Eacilities Master Plan
a. Site Development Plan, 17 January 1992

b. Main Campus Development Plan

13. SSC Laboratory Organizational Charts, 7/12/93

14. SSCL Human Resources Directory

15. SSC Laboratory, BCE Old WBS/New WBS Crosswalk, BCE/PMB Comparison, PMB/Subcontract Reconciliation, May 1993

16. Report on the Superconducting Super Collider Cost and Schedule Baseline, January 1991 (Green Book)

17. Project Management Plan for Superconducting Super Collider, January 1993, P40-000021 Rev A

18. Responsibility Assignment Matrix 1 (RAM) (PMB WBS RAM - May CPR)

19. Percent Complete for each WBS (SSCI will present necessary data to justify procurement, design, construction, planning, etc.)

20. Estimate at completion (projected): SSCL will present data in the following format:

- Baseline

- Projected Scope Changes Cost

- Baseline Estimate Revisions Based on Schedule Changes Justification of each element of the EAC will be presented

21. Super collider (portfolio) 
APPENDIX G 


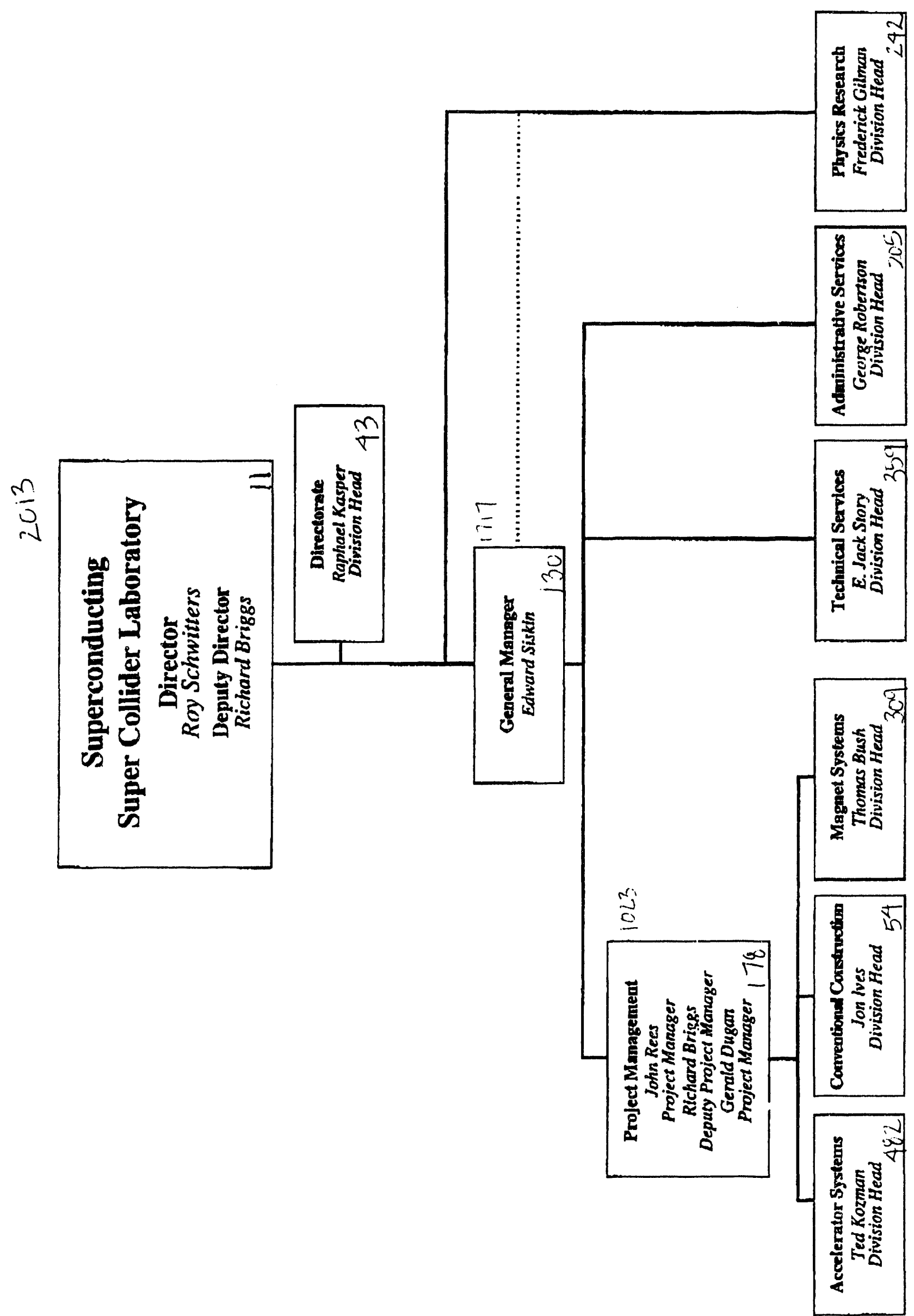




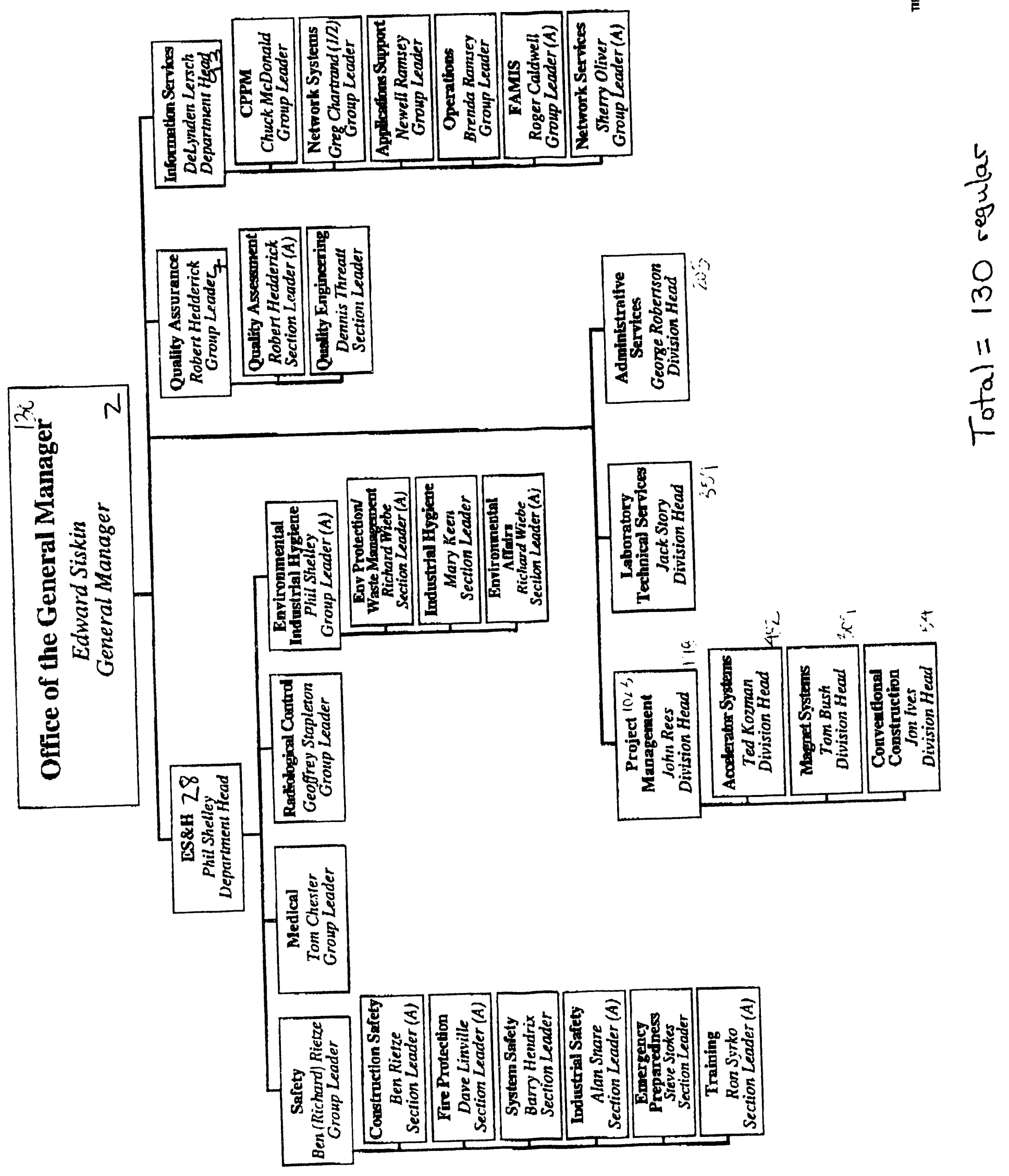




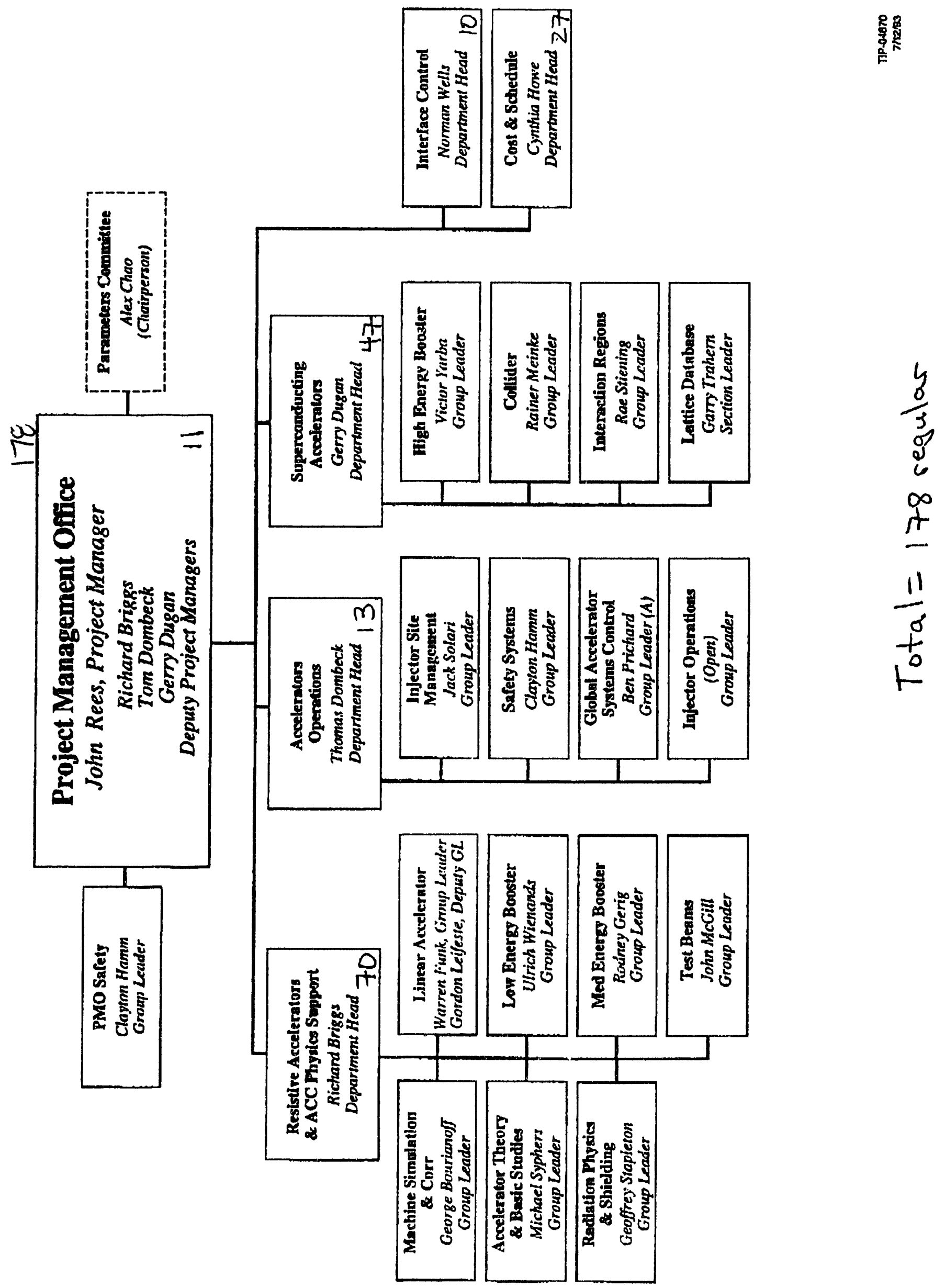




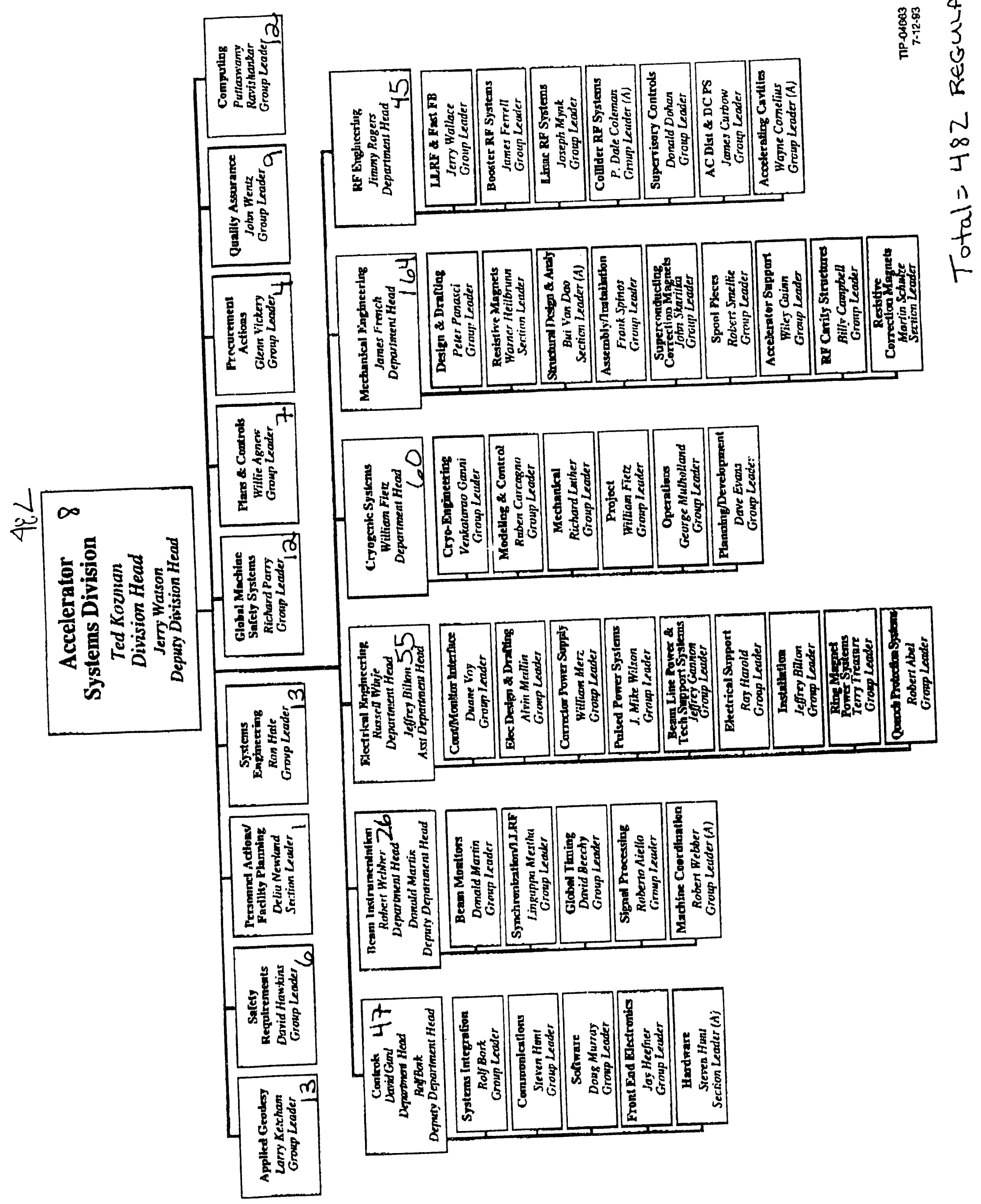




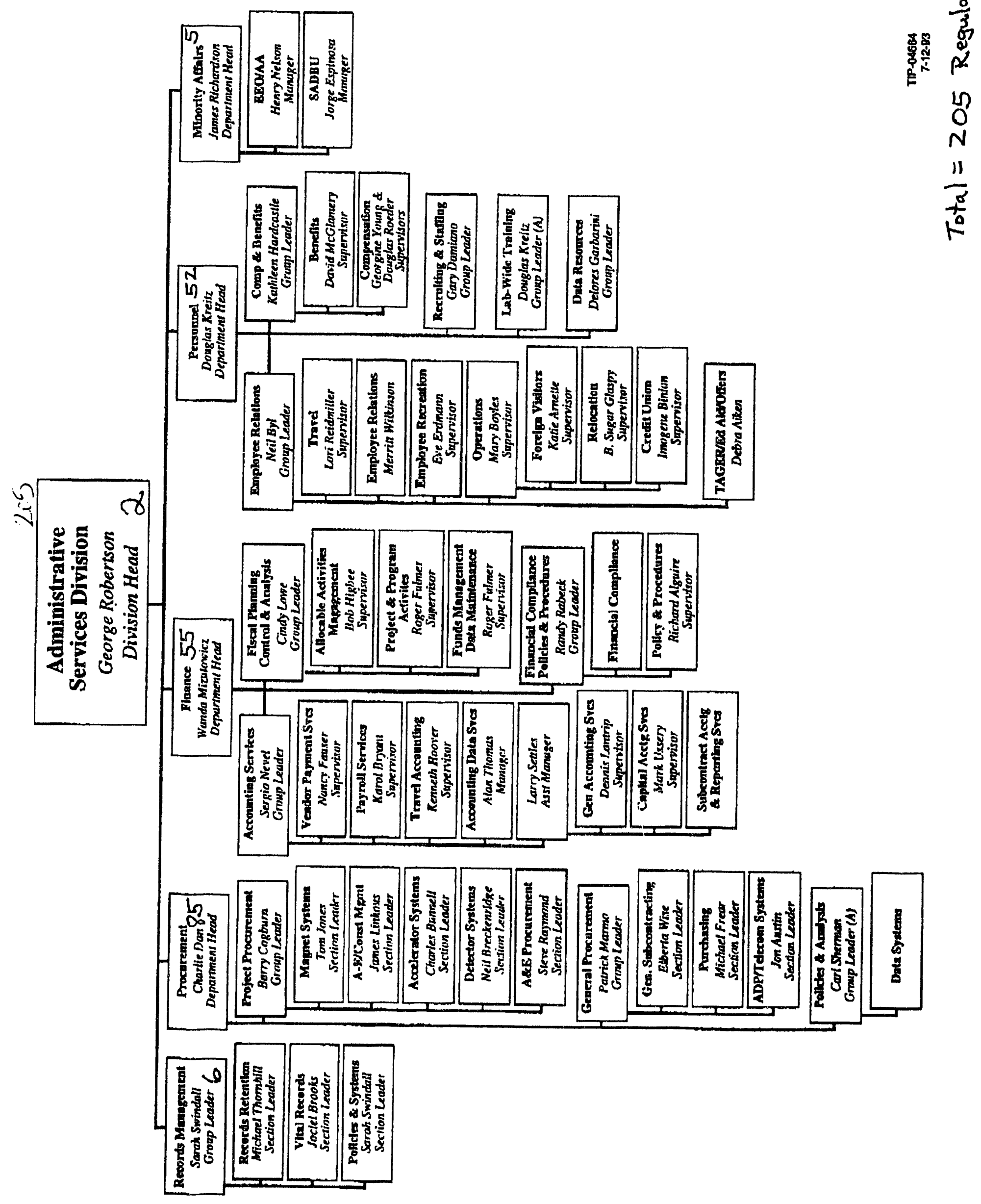




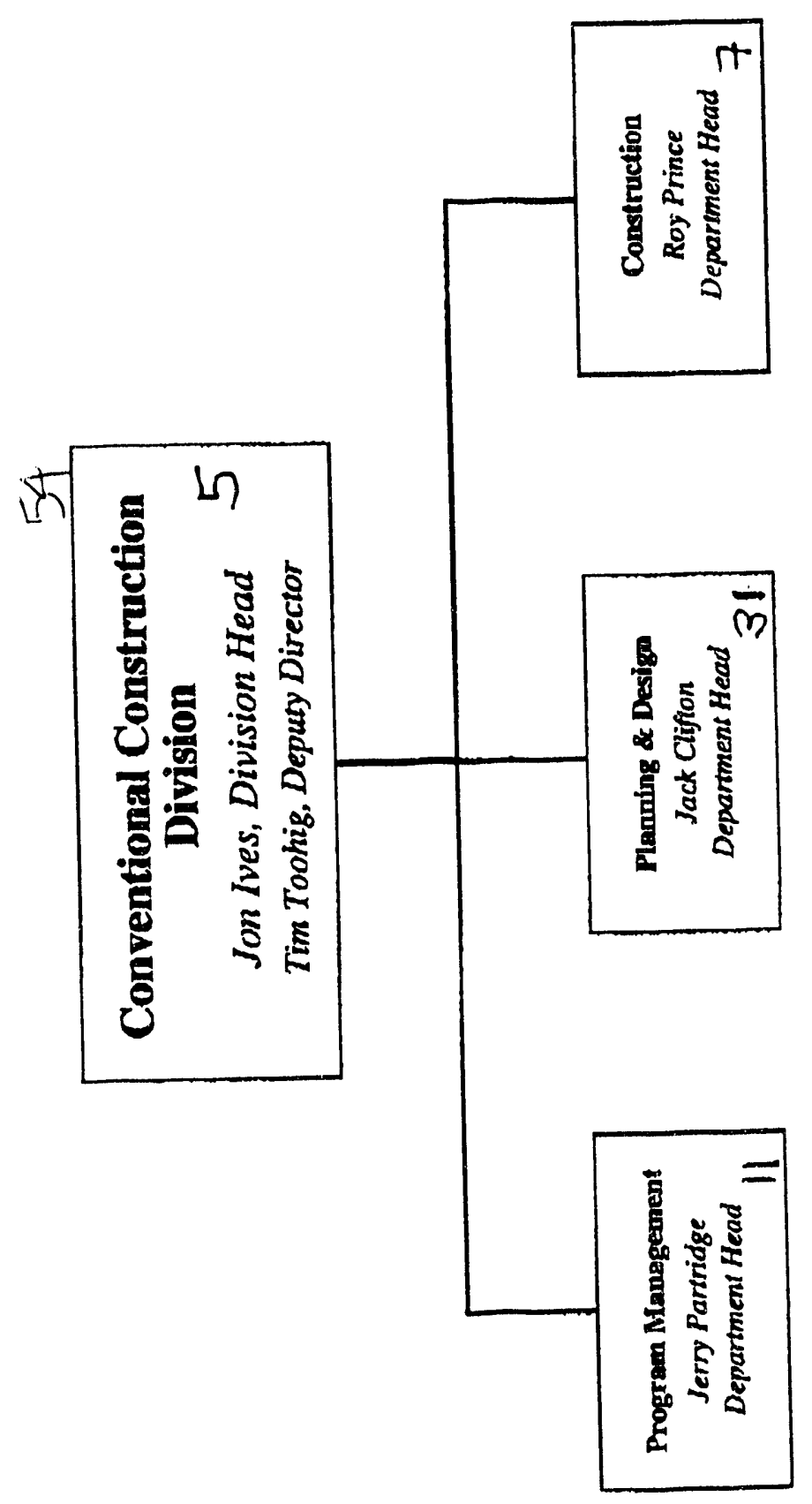




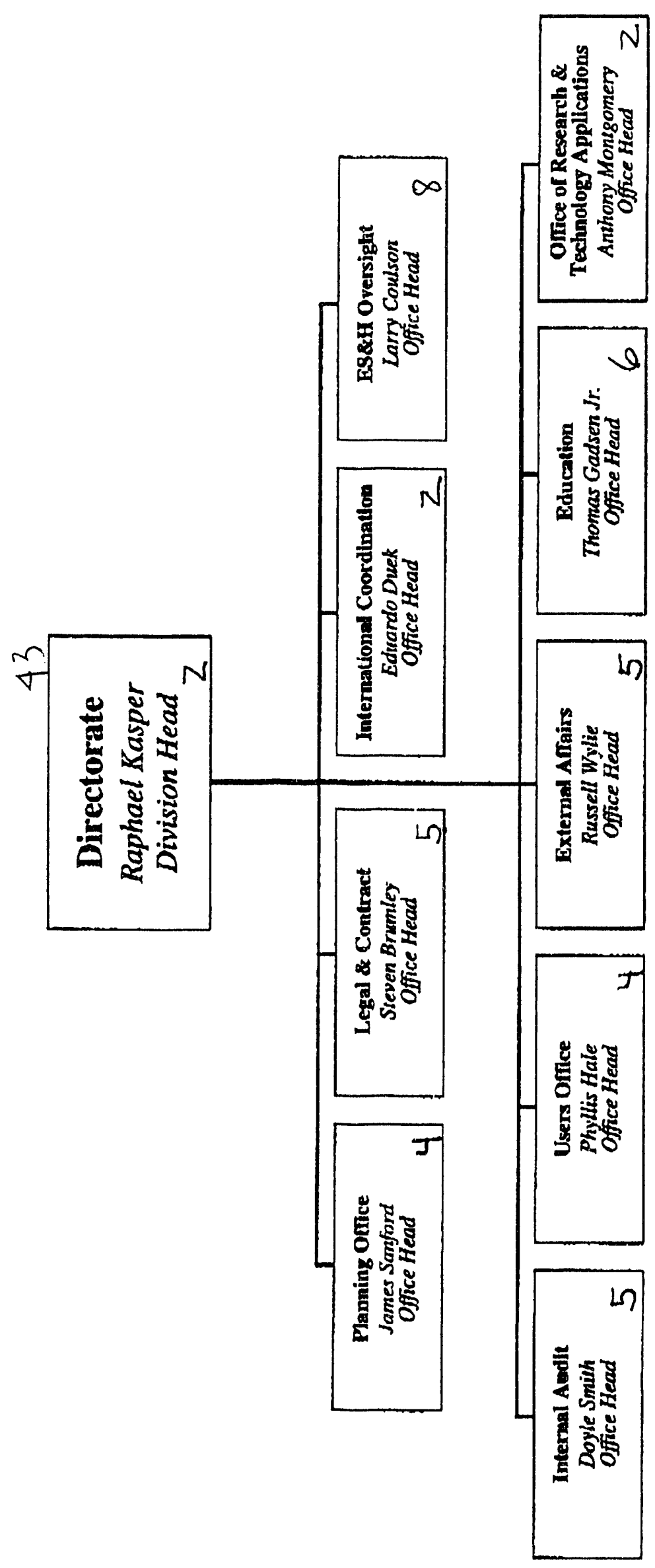




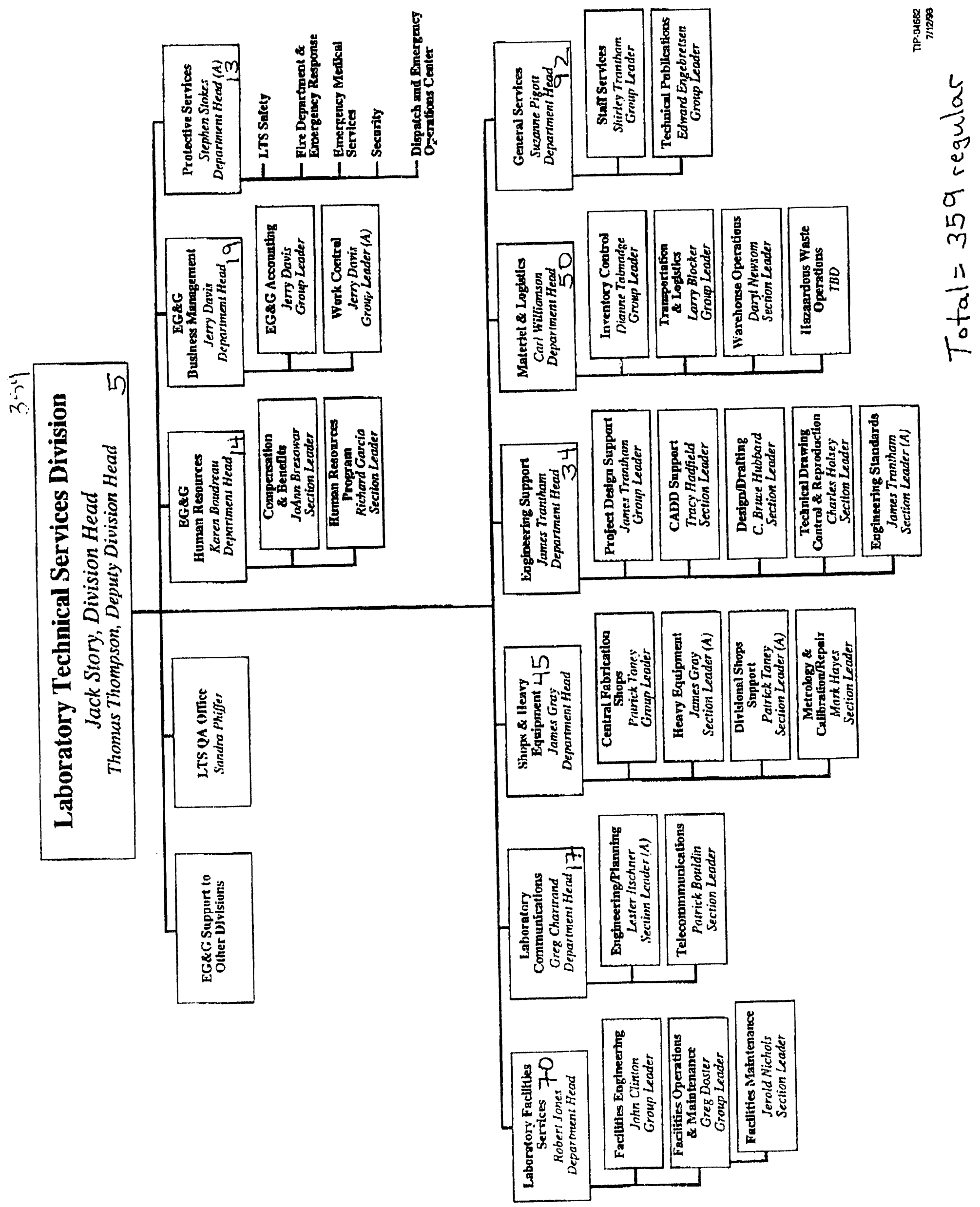




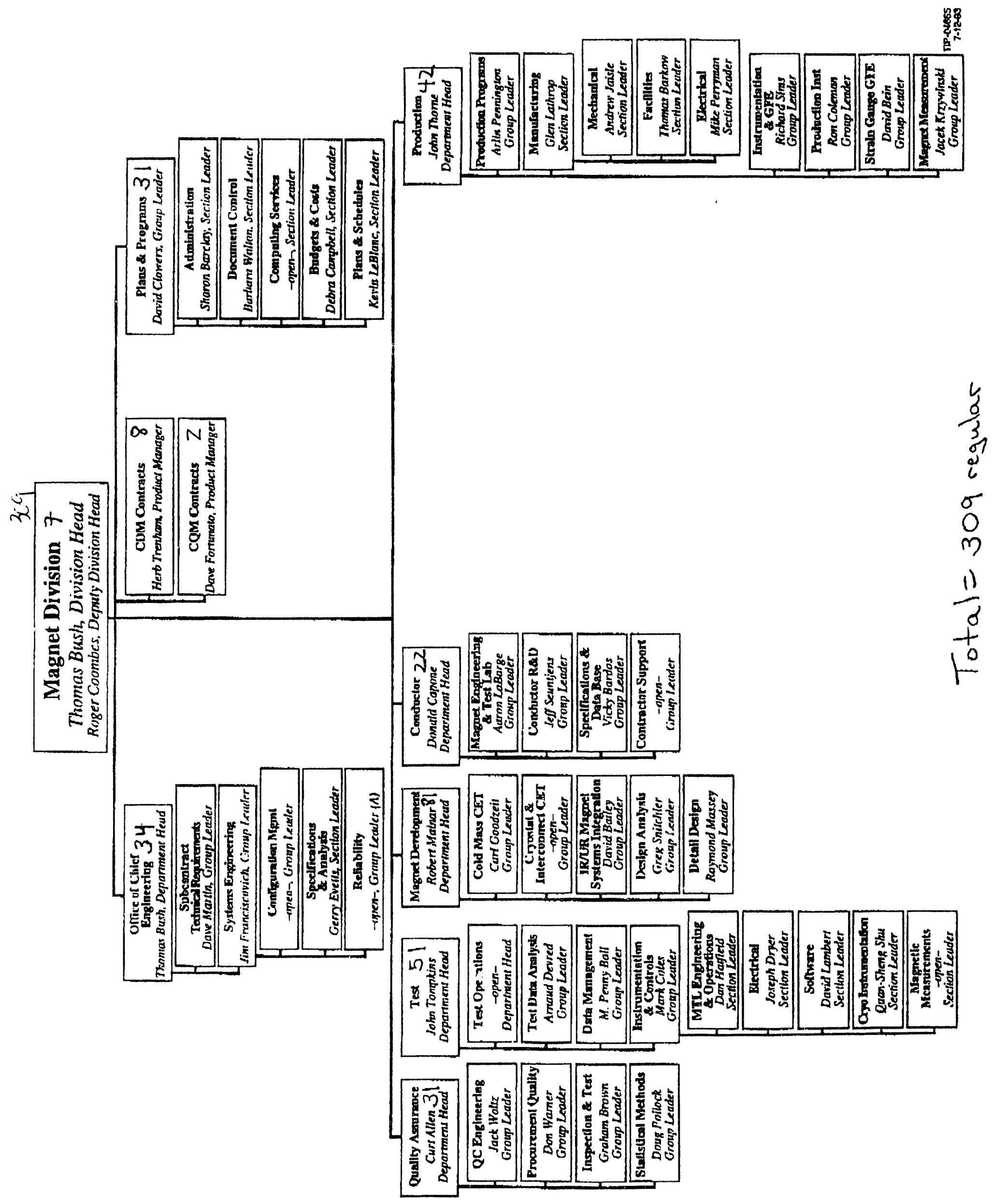




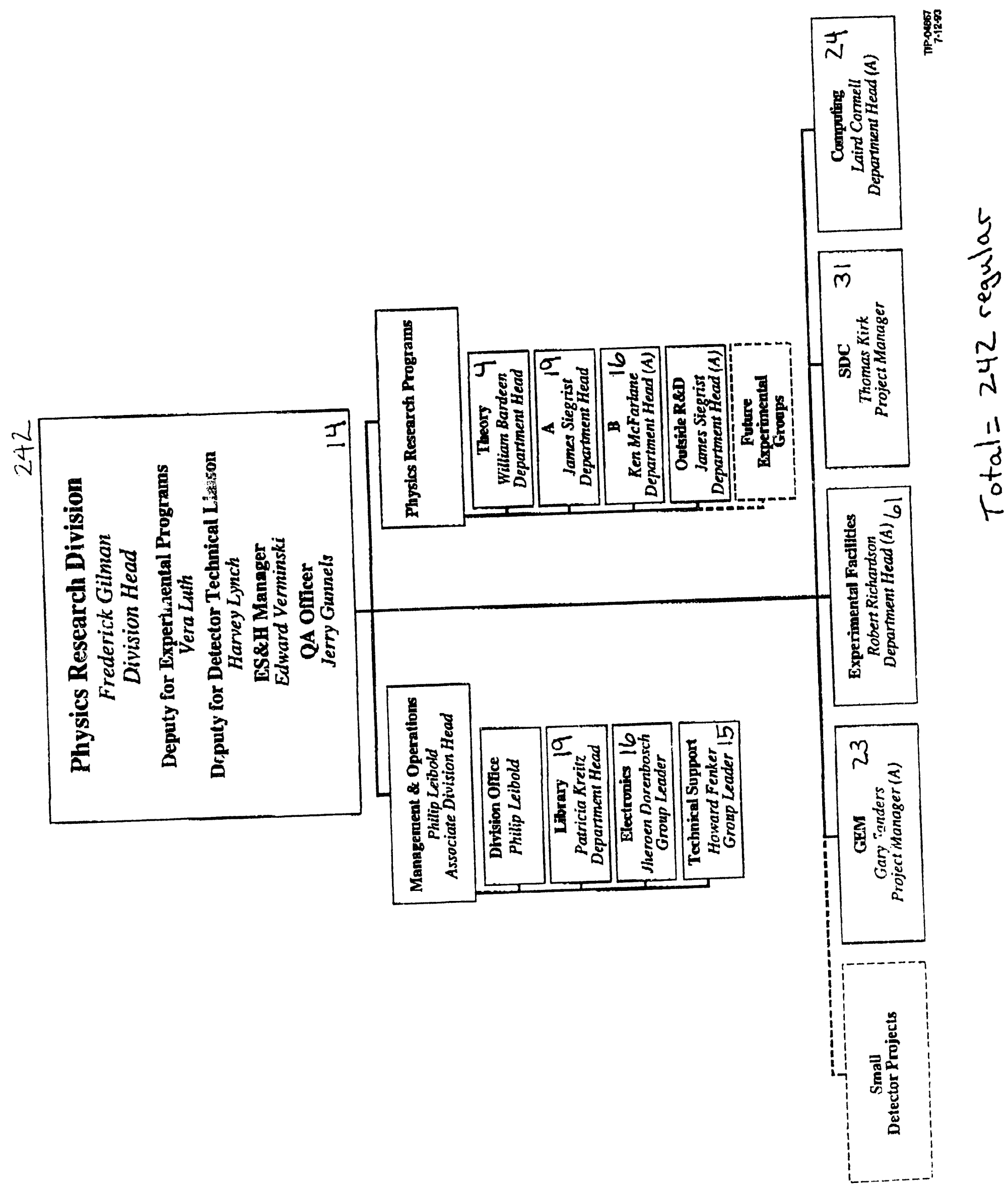






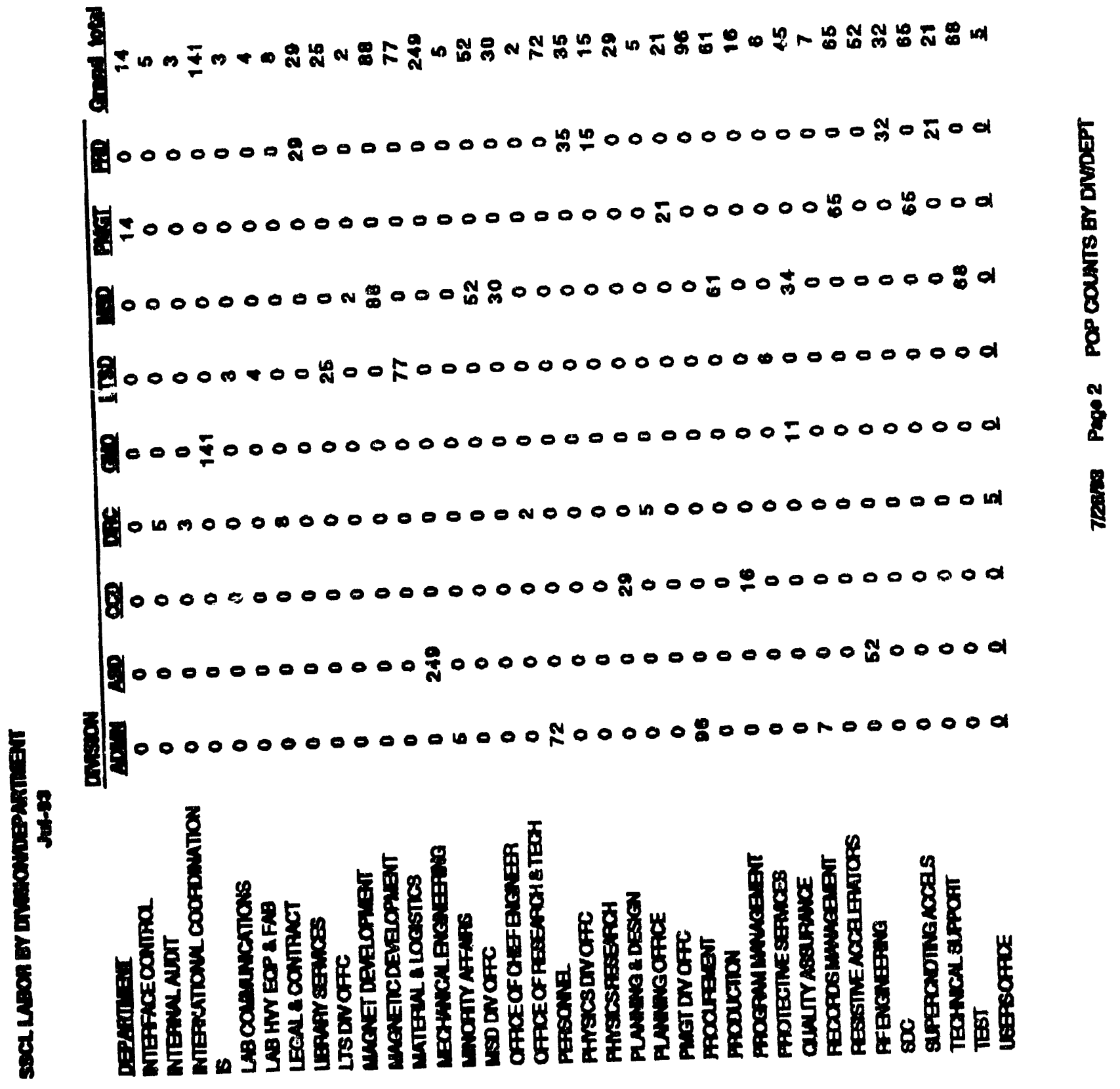




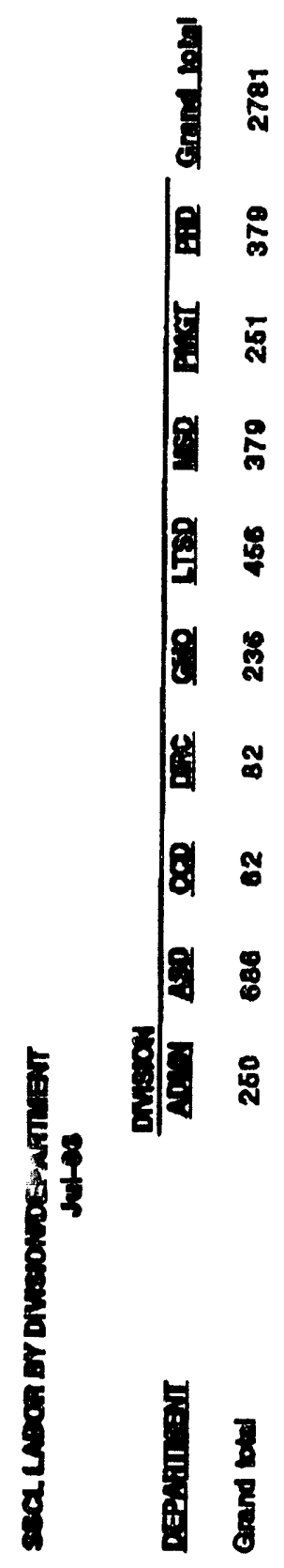

5
5
5
0
$\vdots$
5
5
8
8
8
8
8
8
8
$\frac{8}{5}$ 
APPENDIX H 
PROJECT MANAGEMENT OFFICE

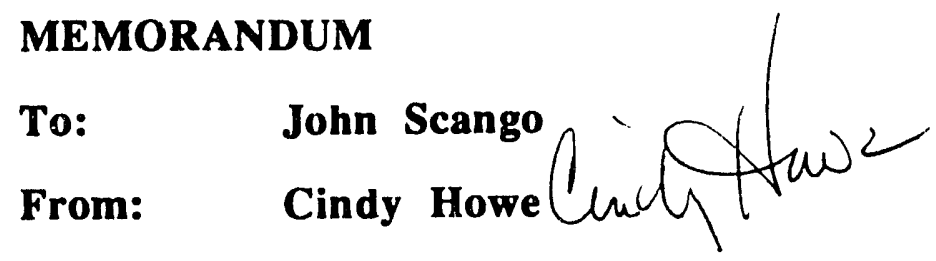

Date: $\quad$ July 21, 1993

Subject: Project Overview - Critical Path

Per your request, we have highlighted the primary and secondary critical paths on the Project Summary Overview, as defined by the May IPS. The primary path is highlighted in pink, and represents the longest path to the Beam to Experiment milestone. The secondary paths are highlighted in yellow, and represent the paths to the final level 1 milestones of each of the machines.

I'm sure that you recognize that this is limited by the summary nature of the graphic representation of the overall project. We have identified the components which comprise the critical path for each of the machines in the left-hand column of the project overview. 


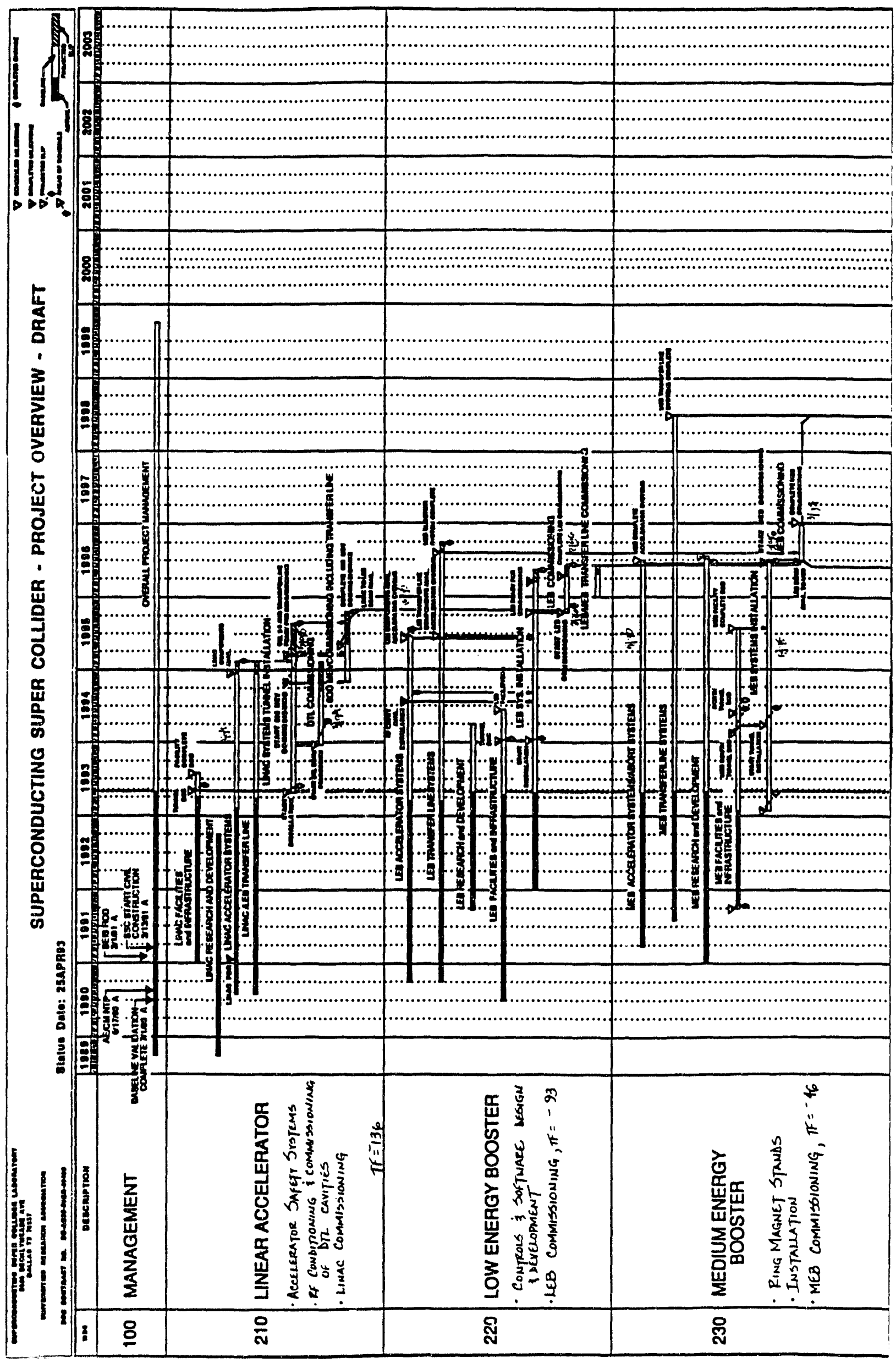




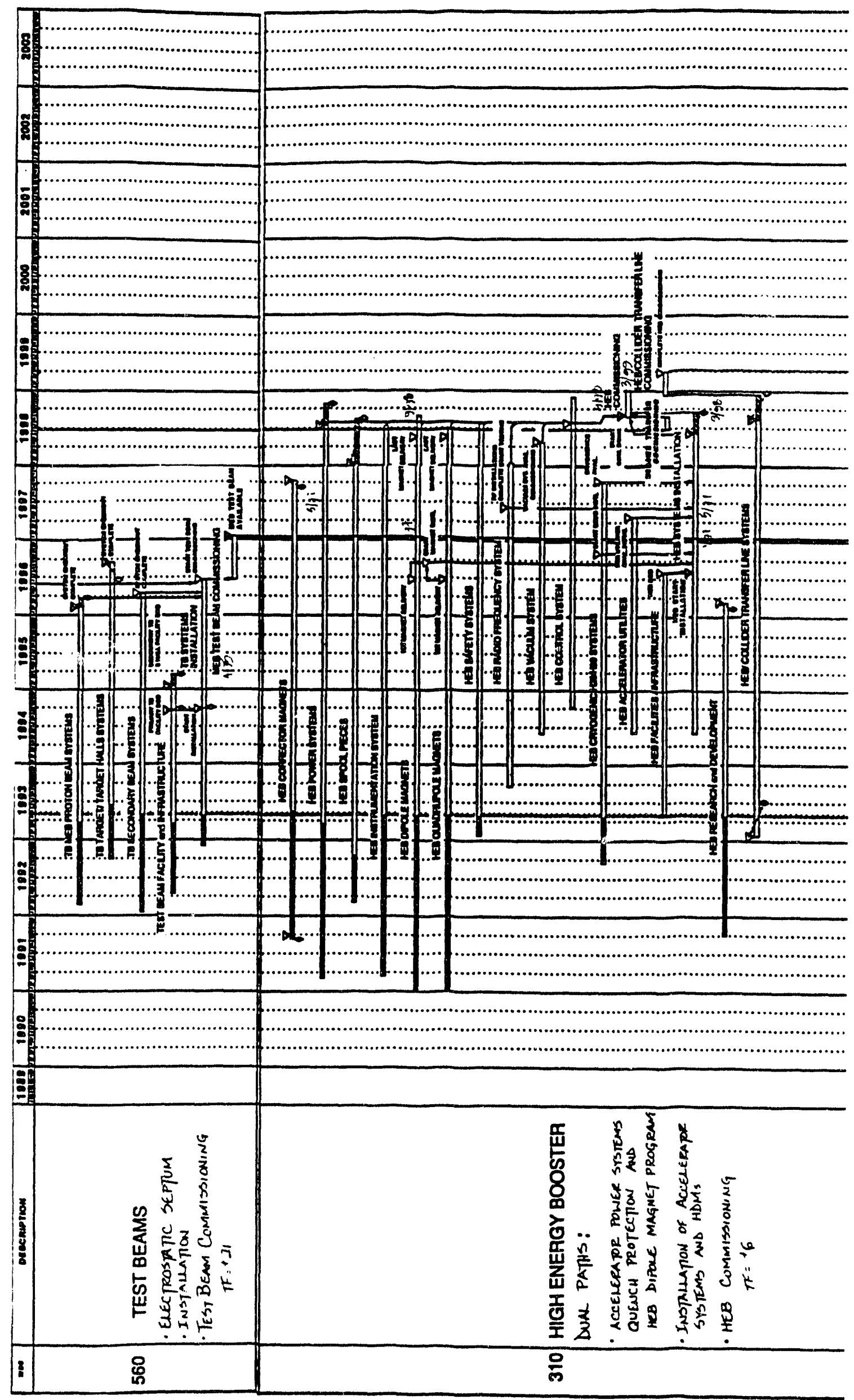




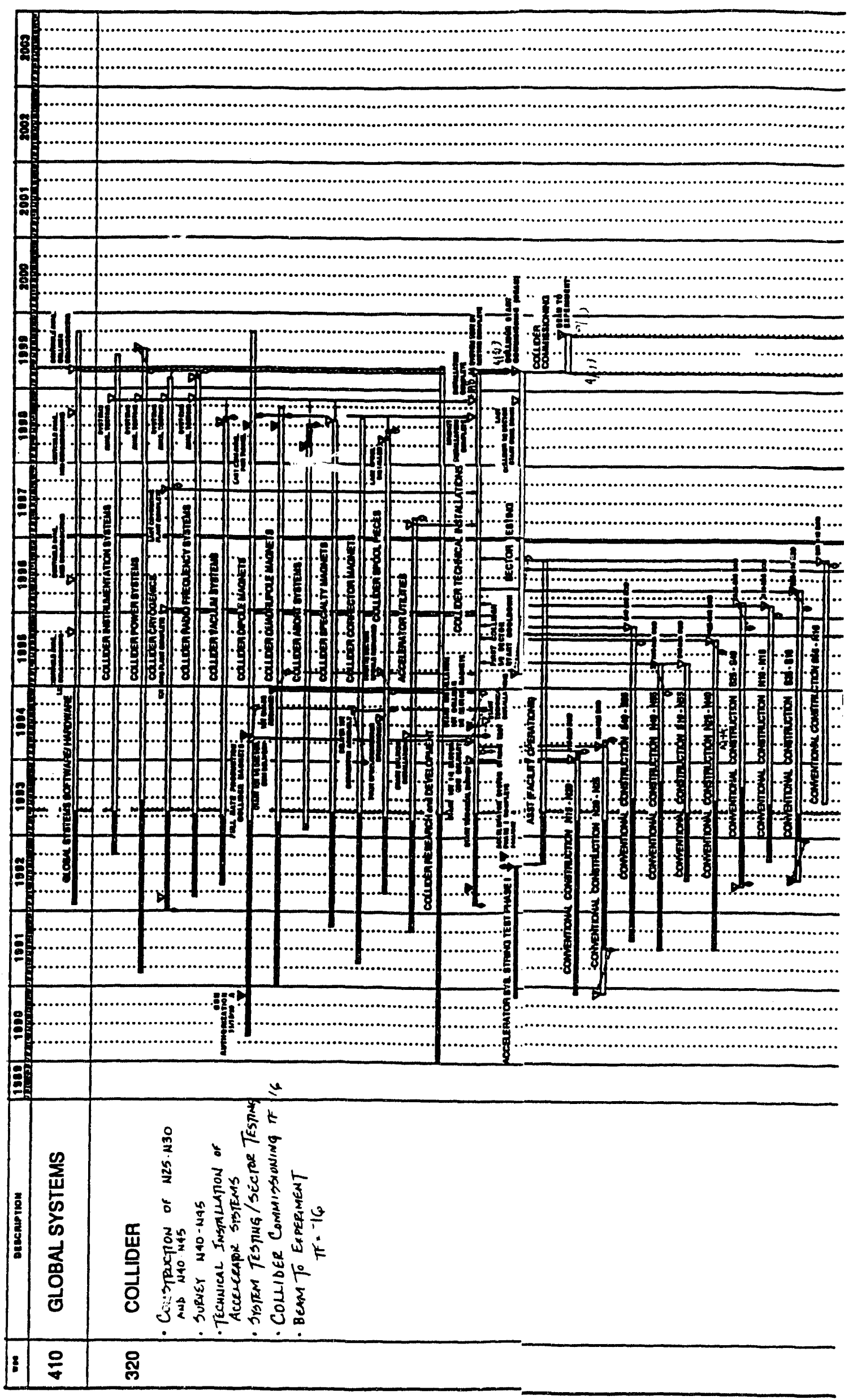




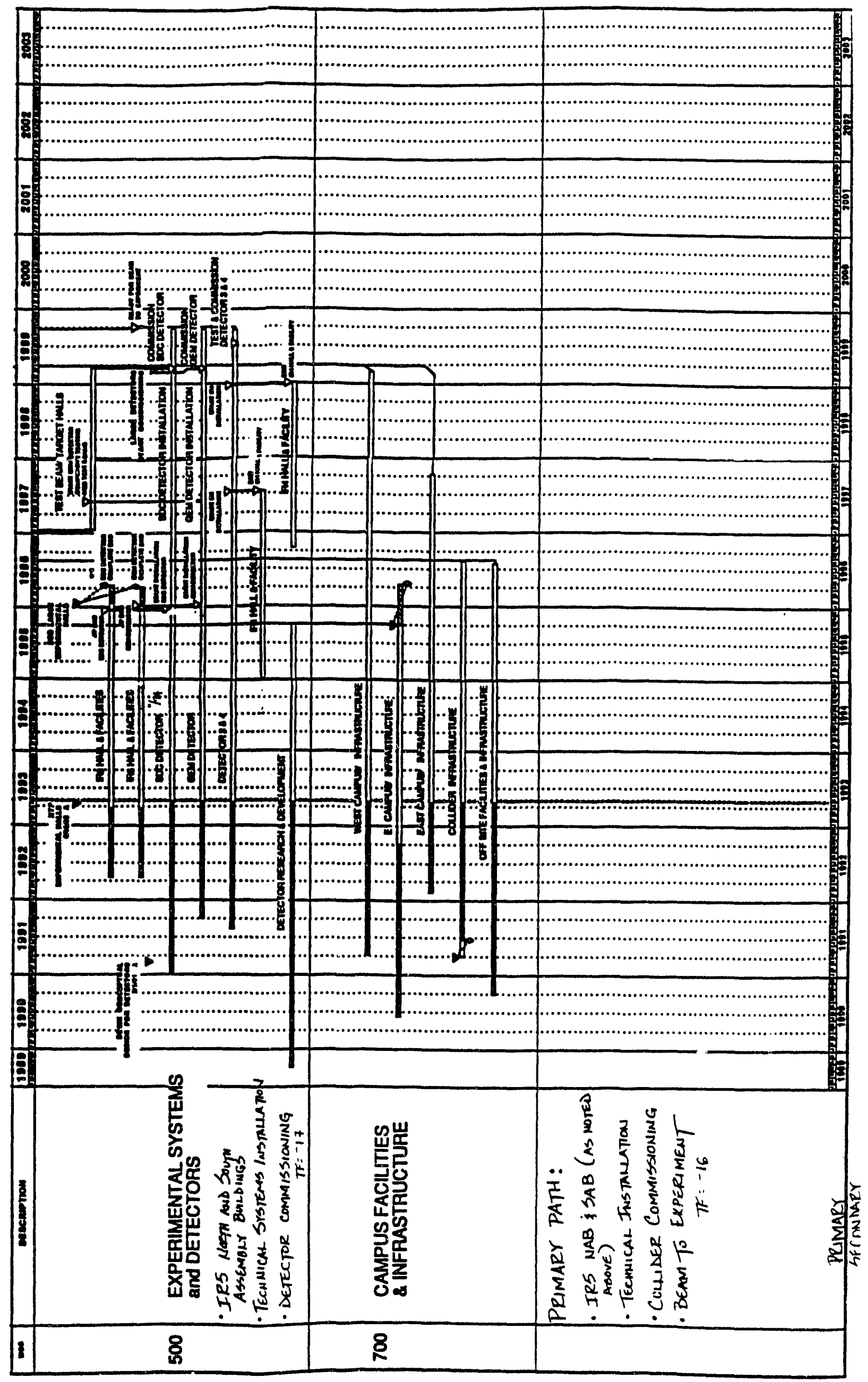



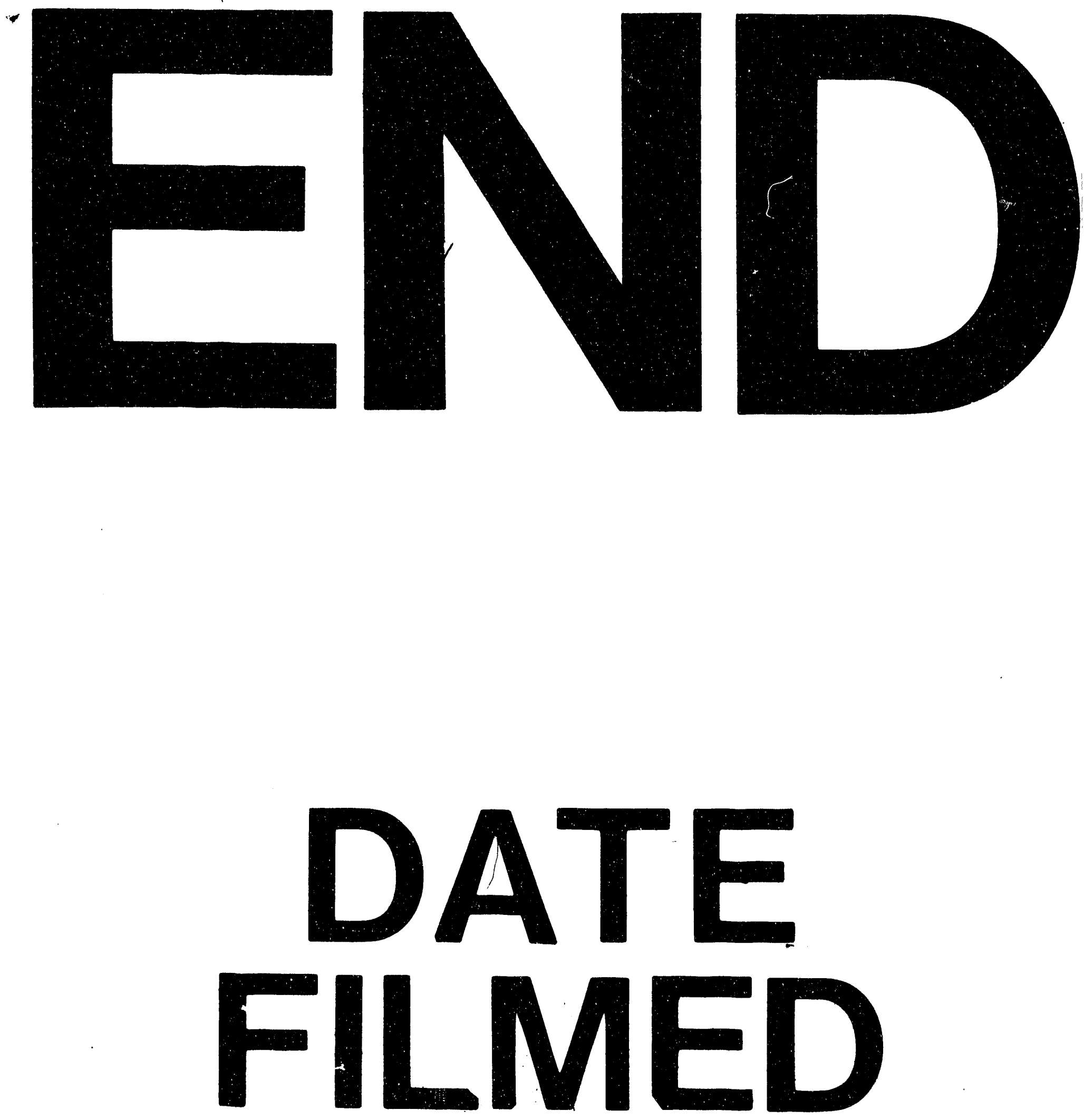

1

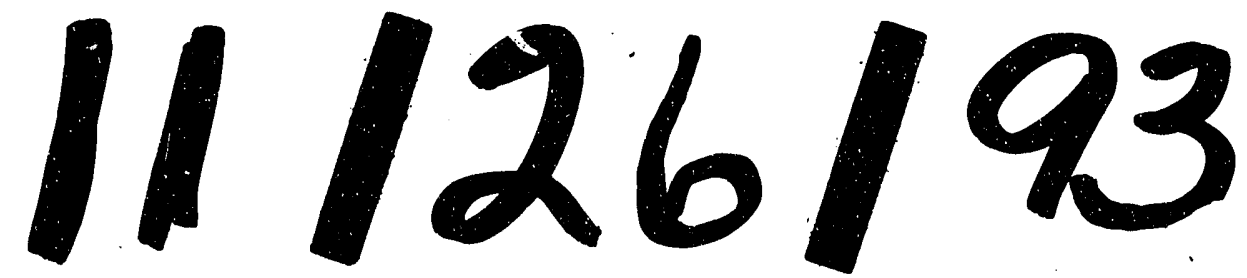


